\title{
'Making a difference': \\ University teachers' narratives of student diversity
}

by

Clare Mariskind

\begin{abstract}
A thesis
submitted to Victoria University of Wellington

in fulfilment of the requirements for the degree of

Doctor of Philosophy

in Education
\end{abstract}

Victoria University of Wellington

2011 


\begin{abstract}
An increasing diversity of students in higher education has prompted much research investigating diverse students' learning needs and experiences; however there is little research investigating teachers' experiences of student diversity. This thesis reports on a study aimed at helping to redress this imbalance. Twenty-two New Zealand university teachers were interviewed and asked what 'diversity' means to them and invited to talk about their experiences of student diversity in small-group teaching contexts.
\end{abstract}

The study had two aims. The first was to examine the meanings study participants make of the notion 'diversity' and of their experiences of teaching diverse students. The second aim was to problematize the notion of 'diversity' by exploring how these teachers position themselves and are positioned within classroom relationships and institutional contexts, and by considering the narrative and discursive resources they draw on to talk about their experiences. The study was underpinned by a relational ontology and used narrative and post-structural methods of data analysis. A review of the literature on diversity in higher education identified ways that diversity is conceptualized. Because teaching diverse students involves relations of power and care, analysis of the meanings of 'power' and 'care' in the literature provided further conceptual tools for data analysis.

Analysis of participants' narratives finds that 'diversity' is not an innocent concept but a powerful way of positioning people within or outside categories of difference, in relation to dominant norms, or in ways that challenge such positioning. Study participants described diversity positively when talking about it as a concept but their narratives of experience often portrayed it as problematic, and they employed various narrative strategies to reconcile the tension between these positions. Participants' narratives often conflicted with the public narratives of their universities, suggesting that the challenges participants face and the practical knowledge they have acquired teaching diverse students are not adequately recognized or valued. This study shows that there are multiple ways to 'speak and do' diversity that are embedded in relations of power and care, and constructed within and from larger social, political and educational narratives. This study challenges those in higher education to think reflexively about diversity, and offers suggestions for constructing alternative narratives of diverse educational relations. 


\section{Acknowledgments}

My sincere thanks go to my supervisors who have supported me on this long and sometimes bumpy doctoral journey, Dr Sue Cornforth and Dr Stephanie Doyle of Victoria University of Wellington, and Dr Lise Claiborne of Waikato University. I appreciate their insightful feedback and suggestions, the encouragement they gave me to explore new and challenging ideas, and the opportunities they facilitated to enable me to share my ideas with postgraduate classes. Thanks especially to Sue for supporting me when I felt stuck and did not think I could finish this thesis.

I wish to acknowledge and thank Victoria University of Wellington for awarding me a doctoral scholarship that enabled me to undertake this research. I also wish to thank Universities New Zealand (formerly the New Zealand Vice-Chancellors' Committee) for awarding me the Tertiary Education Union Crozier Scholarship in 2008 and again in 2009. The financial support from this award contributed greatly to the completion of this project.

Thanks to Sheila Law, Postgraduate Office Manager in the Faculty of Education at Victoria University, who answered all my questions and sorted out any administrative difficulties I encountered over the last four years. Cheers to my fellow $\mathrm{PhD}$ students at Victoria University with whom I enjoyed friendship, great conversations about the highs and lows of research, and delicious potluck lunches. Thanks also to my colleagues in the Department of Arts, Development and Health Education at Massey University who have supported and encouraged me over the last year to complete this thesis. I also wish to thank all my family and friends who have put up with my preoccupation during this research project.

Finally, this research could not have been undertaken without the enthusiastic participation of the twenty-two university teachers who so generously gave their time to participate in this study and who shared with me their experiences of teaching diverse students. I learned so much from them and have been greatly inspired by their stories of the challenges and rewards of university teaching. I offer them all my sincere appreciation and gratitude. 


\section{Table of Contents}

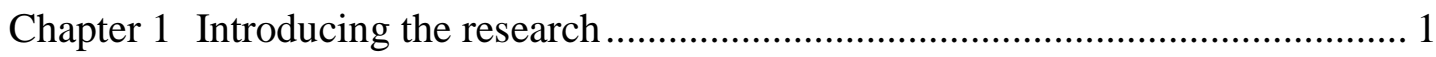

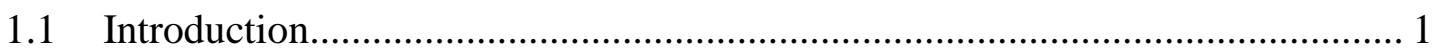

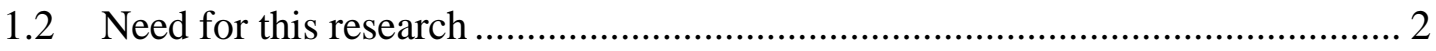

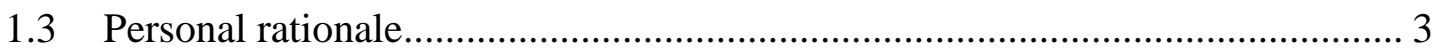

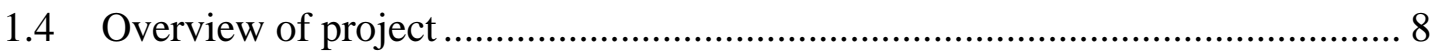

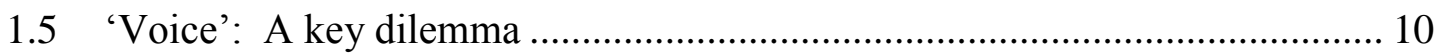

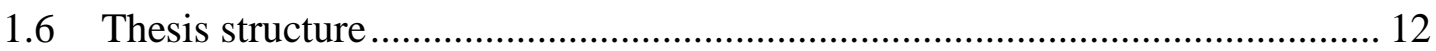

Chapter 2 Background and context: Locating the study ........................................ 14

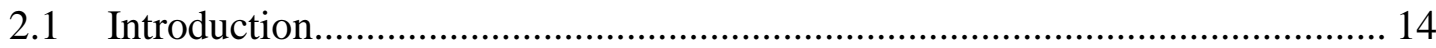

2.2 Student diversity in New Zealand higher education...................................... 14

2.3 Widening participation in higher education ................................................. 17

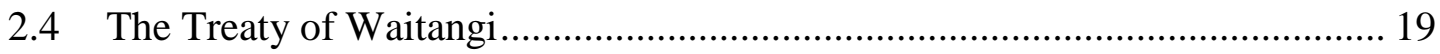

2.5 International students, internationalisation and globalization ........................ 21

2.6 Neoliberalism and the marketization of universities .................................... 24

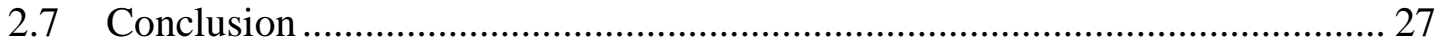

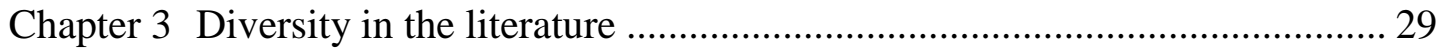

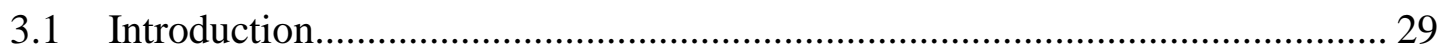

3.2 Research on teachers' experiences of student diversity ................................. 30

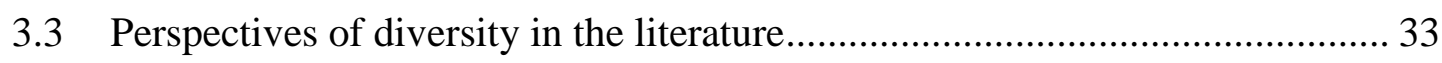

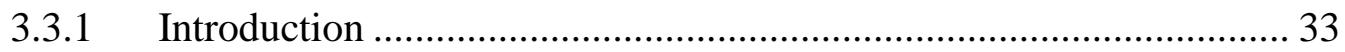

3.3.2 Assimilation perspectives of student diversity …............................ 34

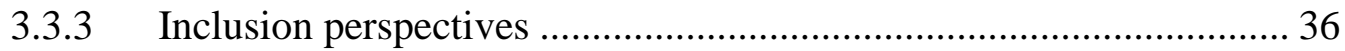

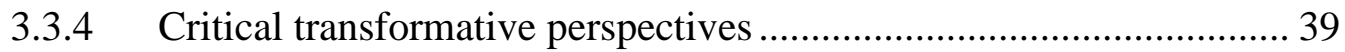

3.3.5 Poststructural perspectives of diversity ......................................... 43

3.3.6 'Managing diversity' perspectives ............................................... 45

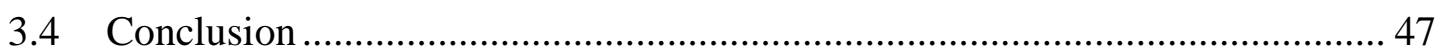

Chapter 4 Concepts of power and care in the literature.......................................... 49

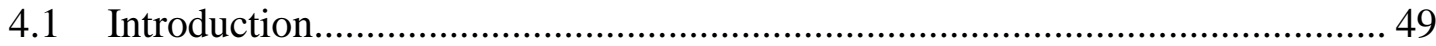




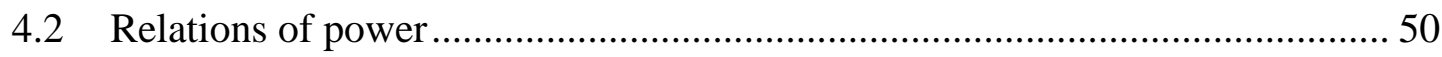

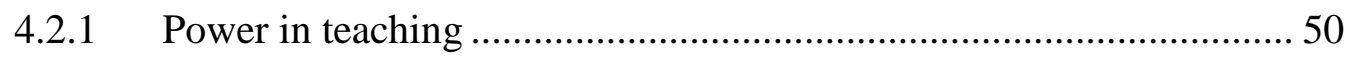

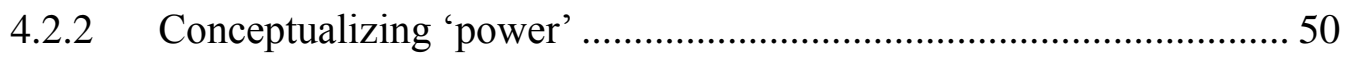

4.2.3 Theoretical perspectives of power in the literature ............................ 55

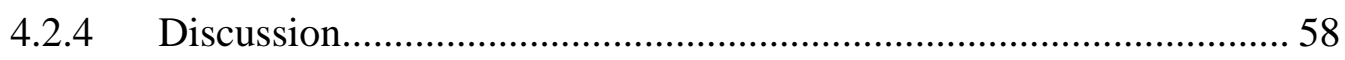

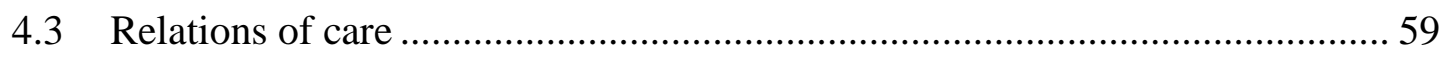

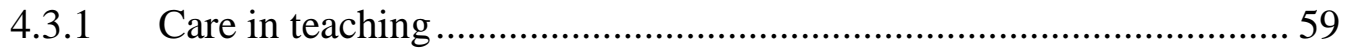

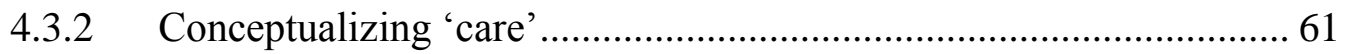

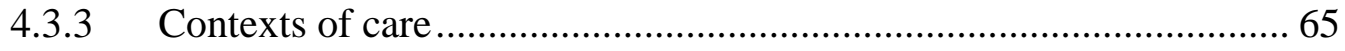

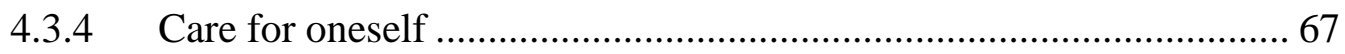

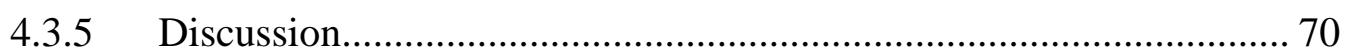

4.4 Theoretical perspectives of care and links to power..................................... 71

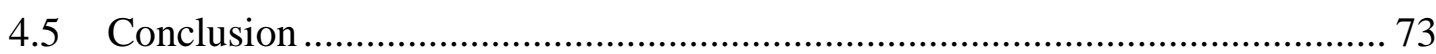

Chapter 5 Constructing the study: Research theory and methods .......................... 75

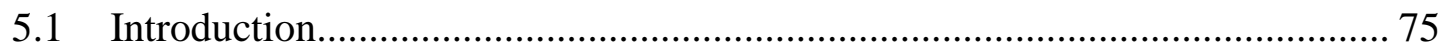

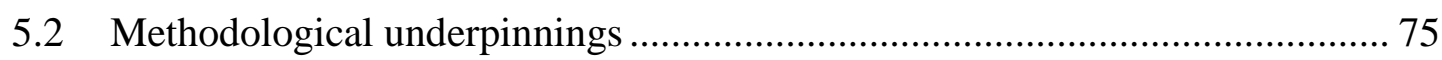

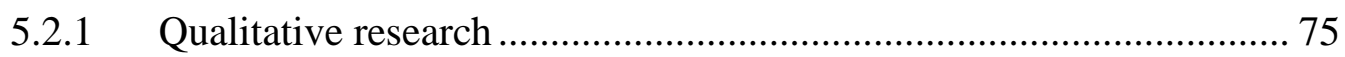

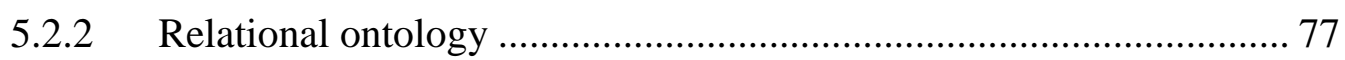

5.2.3 Constructing knowledge relationally .............................................. 79

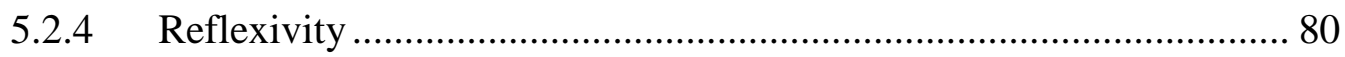

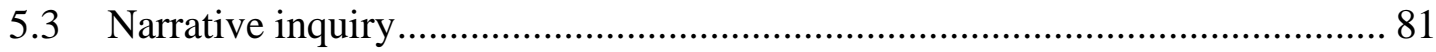

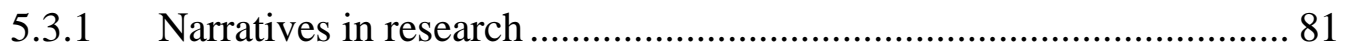

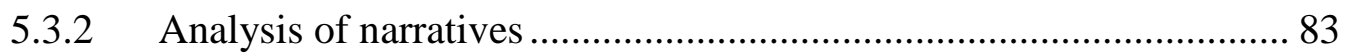

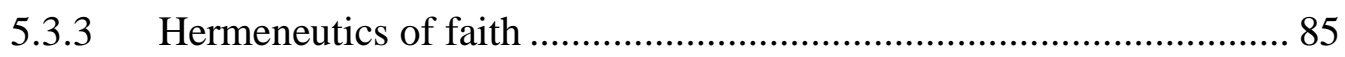

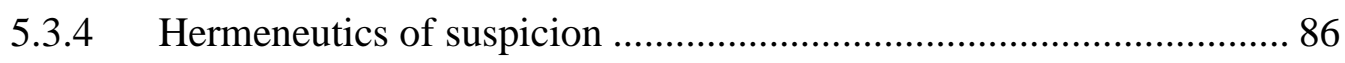

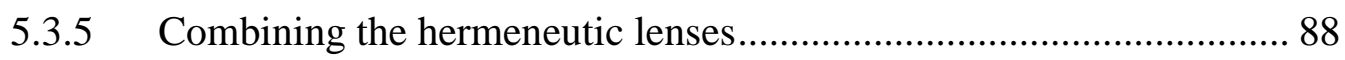

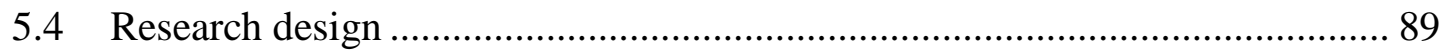

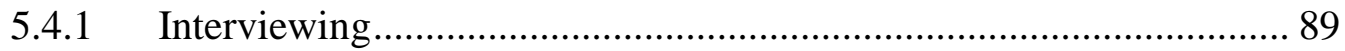

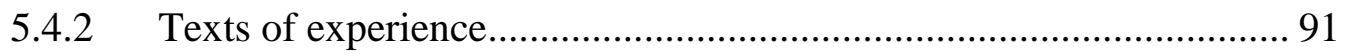

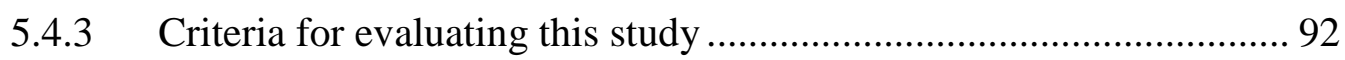

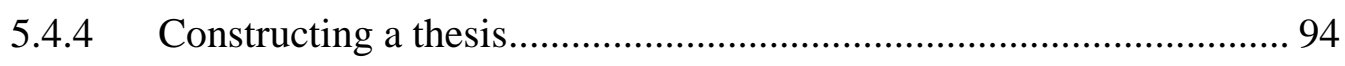

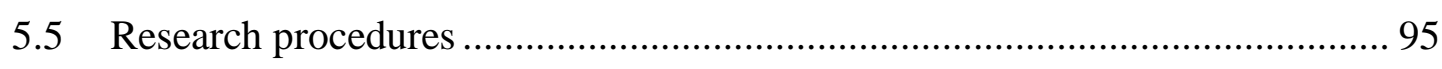

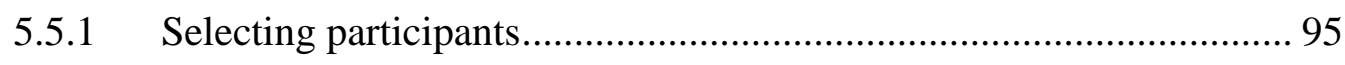




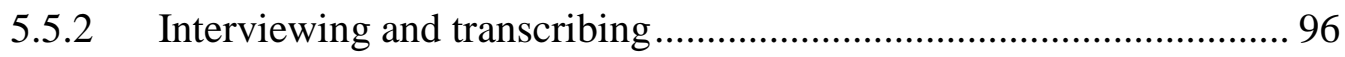

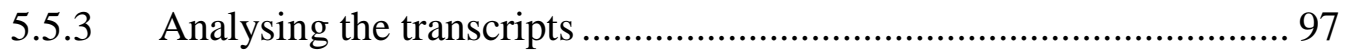

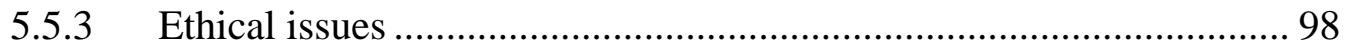

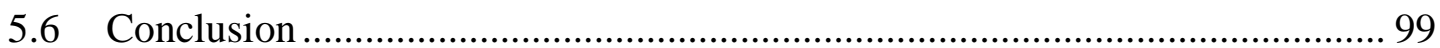

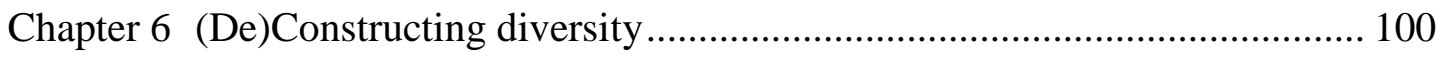

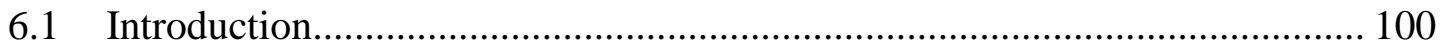

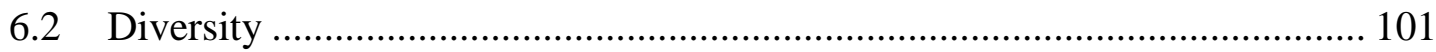

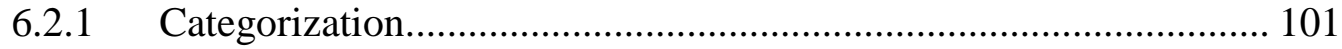

6.2.2 Participants' categories of diversity ................................................ 101

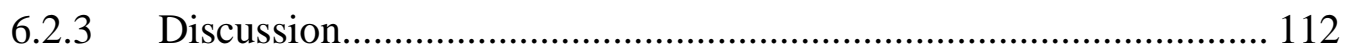

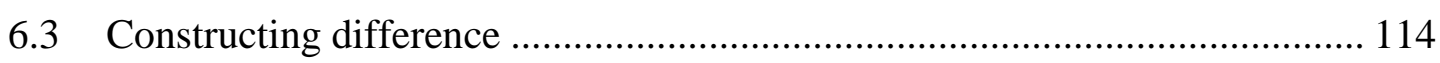

6.3.1 Participants' constructions of difference ...................................... 114

6.3.2 Metaphors of difference ........................................................... 117

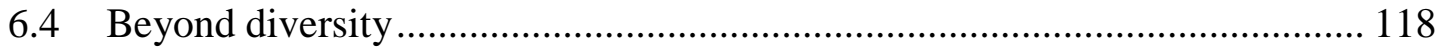

6.4.1 Diversity and social justice........................................................ 118

6.4.2 Beyond limiting notions of difference............................................. 120

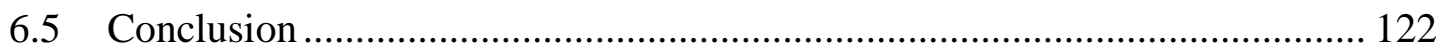

Chapter 7 "What's going on here?" Challenge narratives and the production of

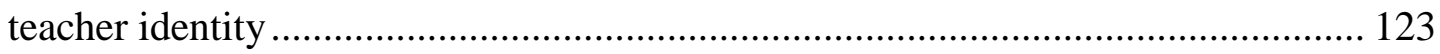

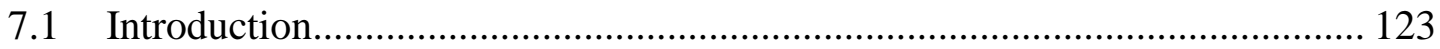

7.2 Participants' challenging experiences of student diversity........................... 124

7.3 The narrative production of teacher identity .............................................. 126

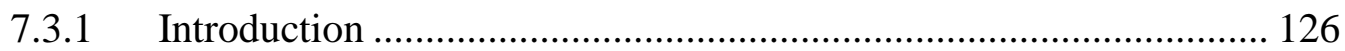

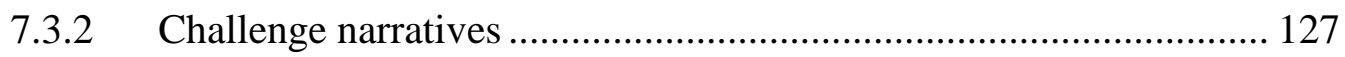

7.3.3 Narratives of overcoming challenges .......................................... 136

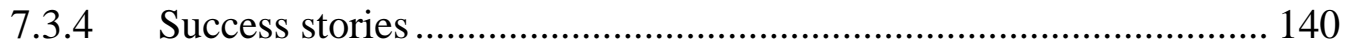

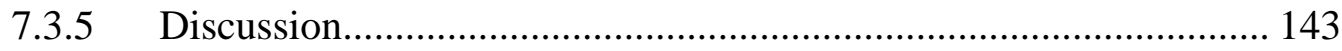

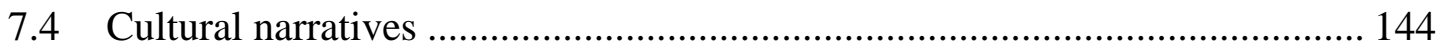

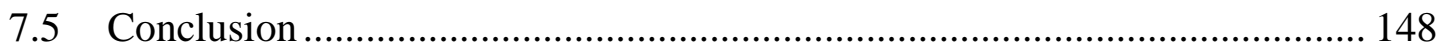

Chapter 8 "As good a teacher as I can be": Learning to teach diverse students..... 150

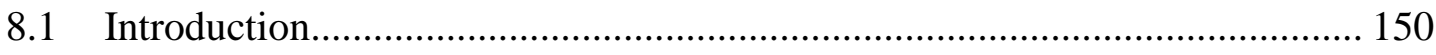


8.2 How participants learn to teach diverse students....................................... 150

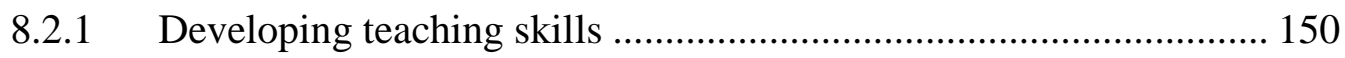

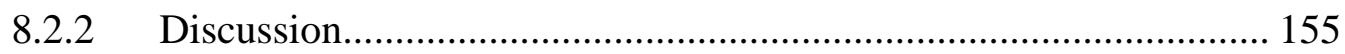

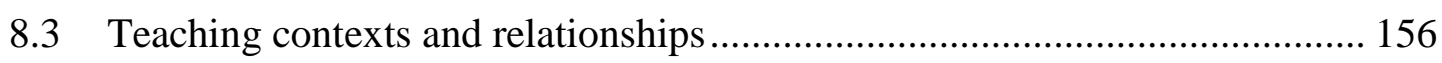

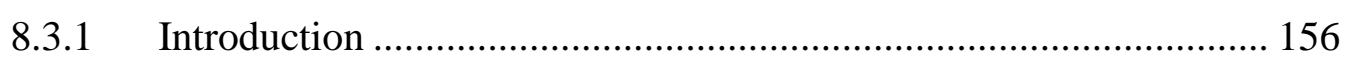

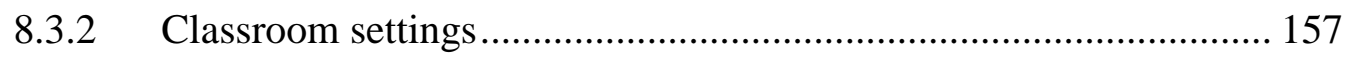

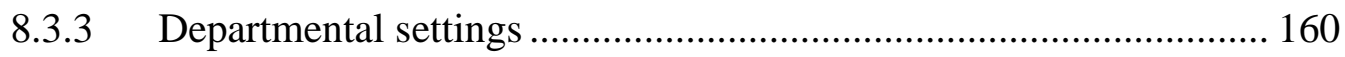

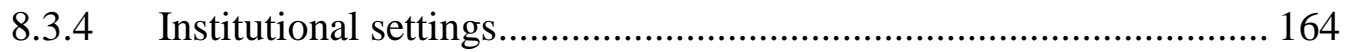

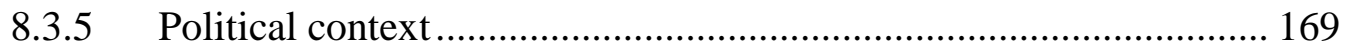

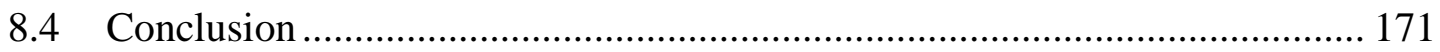

Chapter 9 Inclusive practices: Acts of care or means of discipline? .................... 173

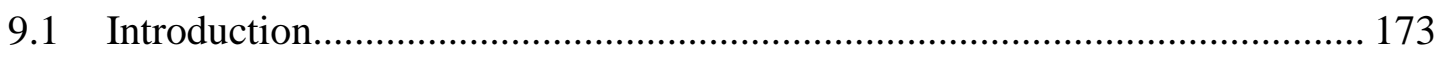

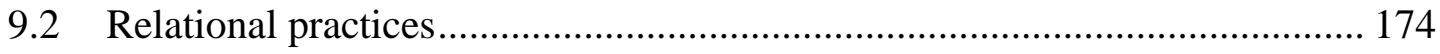

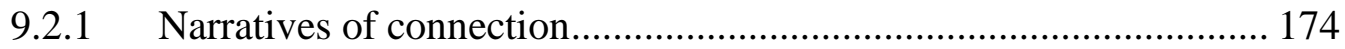

9.2.2 Teachers connecting to students ................................................. 175

9.2.3 Connecting students to each other................................................. 177

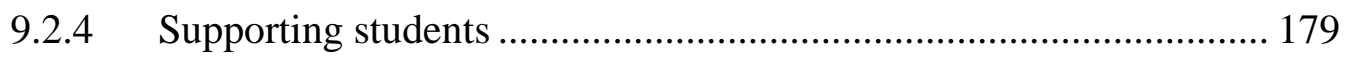

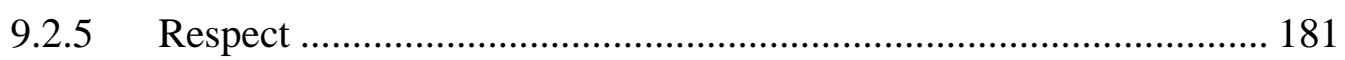

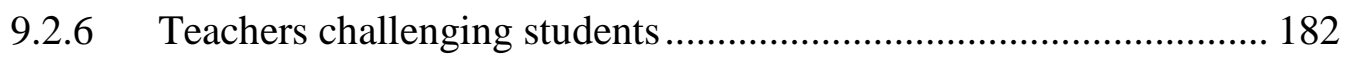

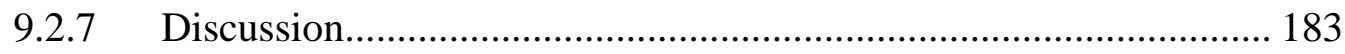

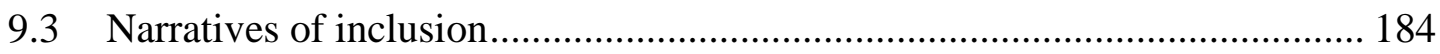

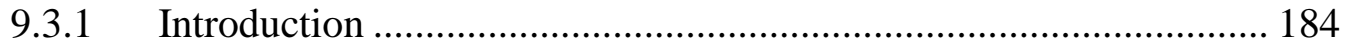

9.3.2 Narratives of participation .......................................................... 185

9.3.3 Narratives of supporting vulnerable students ............................... 191

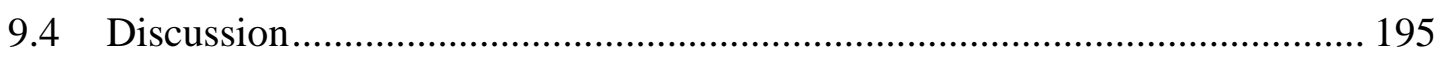

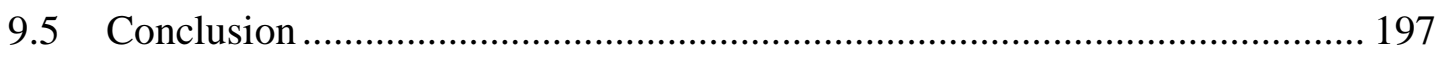

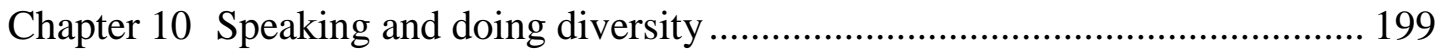

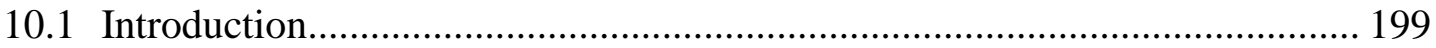

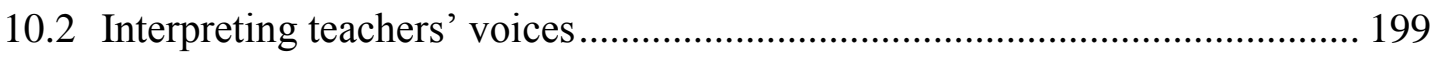

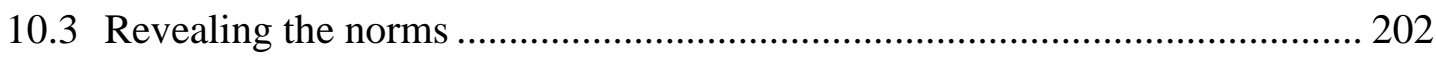

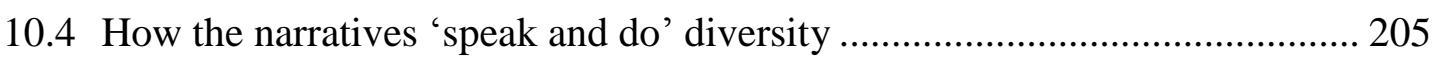

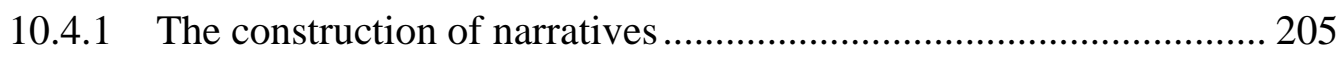




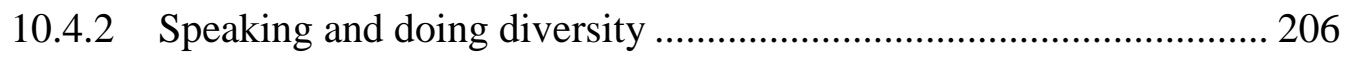

10.4.3 Speaking and doing diversity powerfully …................................... 207

10.4.4 Speaking and doing diversity carefully .......................................... 209

10.5 Speaking and doing diversity differently.................................................. 210

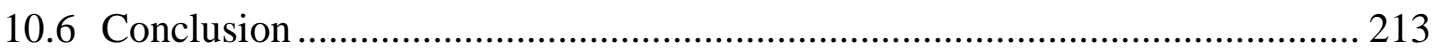

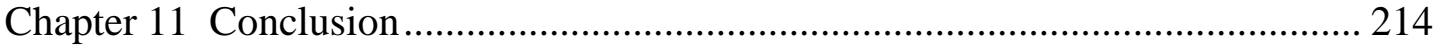

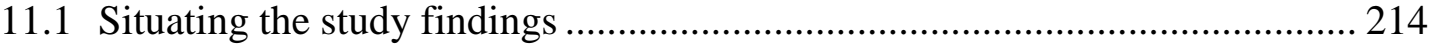

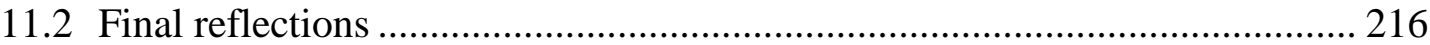

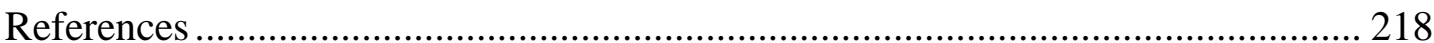

Appendix A

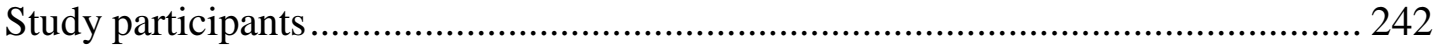

Appendix B

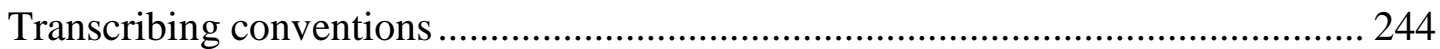

Appendix C

Participant information and consent forms ….................................................. 245 


\section{Chapter 1 \\ Introducing the research}

\subsection{Introduction}

In an increasingly globalized world, higher education institutions are faced with greater student and staff diversity, and the need to teach inclusively. This requires classroom practices, curriculum design, and institutional policies that provide respectful and relevant learning opportunities for all students. My own work in undergraduate university settings involves teaching an increasingly diverse range of students. Challenging incidents in the classroom exposing my lack of knowledge and skills regarding student diversity have led me to reflect on my experiences, discuss inclusive teaching practices with colleagues, and read the literature about diversity. I also began to wonder what experiences other tertiary teachers might have and what 'diversity' might mean to them in relation to the students they teach, prompting this research. In this study, I investigate how university teachers understand and experience student diversity in their teaching. While there has been much attention given to understanding diverse students, their learning needs and effective ways to teach them, few studies have investigated tertiary teachers' own experiences of student diversity and given them a voice in the research literature. This research seeks to redress this imbalance. I interviewed twenty-two teachers in two New Zealand universities, asking what diversity means to them in the context of their teaching and inviting them to talk about their experiences of student diversity in small group teaching contexts.

This thesis looks at how participating teachers narrate their experiences of diversity and the meanings they construct around issues of diversity. It considers how teachers position themselves, and are positioned, within their institutional contexts and the cultural and discursive resources they draw on to talk about their experiences. This thesis also describe the research journey I undertook as I attempted to provide some answers to these questions, as well as the conclusions (tentative and open-ended) that arise from the research findings. I begin this thesis by introducing the research journey. In this chapter, I discuss why this research is needed and the educational context it is located in. I also explain the personal motivation that underpins this study, drawing from my teaching journal and from the writings of other teachers. I then give an overview of the research 
project, identify the research questions, and discuss a key dilemma that arose as I considered the purpose of this research and the outcomes I wanted to achieve. Finally I provide an overview of the thesis structure.

\subsection{Need for this research}

There is little New Zealand research that foregrounds tertiary teachers' experiences of student diversity, a recent exception being a qualitative survey of 137 teachers in seven New Zealand tertiary institutions conducted by Zepke and Leach (2007). Research conducted by government departments such as the Ministry of Education (Education Counts, 2008) and individual tertiary institutions has surveyed student diversity and provided statistics on various student characteristics. Research has also been undertaken in New Zealand to understand diverse students' learning needs and how to teach diverse students effectively, such as Sherrard (2004), Benseman, Coxon, Anderson and Anae (2006), Zepke and Leach (2002). Policies and practices aiming to make tertiary teaching more inclusive in New Zealand need to be based on research that has not only investigated the diversity of students but also considered teachers' experiences of that diversity. Research is therefore needed that gives higher education teachers opportunities to discuss the issues they consider important and/or challenging in their teaching as they interact with students from diverse backgrounds with a variety of learning approaches and needs.

In a global era, increasing geographic mobility leads to an increasing ethnic and cultural diversity as many people study and work in places other than their home countries or cities. New Zealand universities teach domestic and international students from a variety of cultural and ethnic backgrounds, and multicultural classrooms present teachers with additional challenges (Ward, 2006). As well, changes in the structure of employment and careers mean that people face many changes through their working life and beyond, and consequently may need to study at any age or stage of life (McNair, 2001). Students will therefore come from many different backgrounds and with differing needs, and their motivation for tertiary study will vary widely as will their expectations of what university study should provide them with and what outcomes they are seeking (Cushman, 2006; Davey, Neale \& Morris Matthews, 2003; Holmes \& O’Steen, 2008; Stephens \& Higgins, 2003). This will impact on teachers who themselves bring differing motivations, 
expectations and backgrounds to their teaching. Working in higher education environments with such diversity means that teaching is an increasingly complex activity (Cherrington \& Green, 2010), and research that investigates teachers' experiences and perspectives can help understand the changes and challenges teachers are facing.

In my own experience of teaching at universities, I have found that my students bring a range of identities, ways of relating to others, and educational experiences and expectations into the classroom. Likewise, as a teacher, my own background, experiences and expectations influence my teaching practices and relationships with students. I have become aware of power issues arising in the classroom, in collegial relationships, and institutional practices in the educational sites that I have taught in, leading me to also consider how teachers are supported in their work. Keeping a journal of my teaching has stimulated critical reflection about issues of diversity, power and care in teaching and led me to explore these in the literature. Through my involvement in this research study I have also come to understand that the ways diversity is conceptualized and talked about are also diverse, and that these matter. If a concept such as diversity is talked about in certain ways and not others, some people will be advantaged and others, who understand differently, will be disadvantaged. Some educational theorists argue that the way we view our world is "unduly cramped and narrowed by a reliance on a restricted domain of language" (Noddings, 2003, p. 2). In this thesis I attempt to identify and expand the 'restricted domain of language' used to talk about diversity, power and care in tertiary teaching, and to generate new ways of understanding and talking about these concepts that could open up greater possibilities for teaching diverse students within and beyond higher education.

\subsection{Personal rationale}

Research is often informed by a personal interest in a topic (Middleton, 2001) and this thesis is no exception. My own tertiary teaching experiences and the questions they raised brought me to this research. At times I have struggled to make sense of why my teaching did not seem to be effective, to best facilitate the learning of diverse students, and to stay positive about the job when faced with conflicts in the classroom. In the different courses I have taught in university classrooms, I have encountered a diversity of students whose identities, backgrounds, educational experiences, approaches to learning, expectations and 
purposes for study have varied widely. I have sometimes felt overwhelmed by this diversity and my lack of knowledge about how to teach these students effectively and appropriately. Ongoing professional development, the support of colleagues and feedback from students have been of great value, as has reflecting on and trying to learn from my teaching experiences. I have kept a journal of my teaching practice, including reflections on diversity and inclusive teaching and resulting issues of power and care. This has provided ideas to stimulate my thinking on the topic and helped formulate questions posed in interviews with teachers.

One way to learn more about our own teaching is through self-study. Teacher self-study involves a teacher reflecting on a significant experience in his or her teaching practice in order to construct knowledge about teaching and learning that leads to a deeper understanding of educational practices and that uncovers connections between the personal, the pedagogical and the political (Sharkey, 2004). A common motivation and subject for teacher reflection is a 'critical incident'. Critical incidents are highly charged episodes in teaching that offer opportunities for personal change and growth (Sikes, Measor \& Woods, 1985). These incidents are unanticipated, and can challenge teacher identity or show up key difficulties in the teaching role (Woods, 1993). In my own teaching I can identify a number of critical incidents. I recorded some of these in my teaching journal, and one in particular stood out as I began to construct my thesis topic. This incident from my journal (written several years before I began this research) is rewritten in the present tense as the following vignette:

It is near the end of tutorial and I have been discussing with my Stage One education students the different political approaches to education. This is the first time I have tutored on campus and so I am new to teaching at tertiary level. We are in a long narrow classroom, below the main level of the building and somewhere within a warren of corridors. This room feels like a basement cupboard, and with the students spread out across the narrow space, it has been difficult for me to get good group interaction occurring. In this tutorial, one student talks about how Māori ${ }^{1}$ are now doing well and do not need special treatment, and that all students have the same opportunities. I am uncomfortable with her neoliberal position, and though I am aware that this young middle-class

\footnotetext{
${ }^{1}$ New Zealand's indigenous people.
} 
Pakeha ${ }^{2}$ student probably has not known any other political ideologies, in my inexperience I do not know how to challenge her comments or invite other viewpoints. Instead I acknowledge the success of many Māori and refer to a recent news article. Then my only Māori student who usually says very little speaks up and says that it is difficult to learn and achieve when you don't have enough food or warm clothes. I acknowledge what he says but by now it is time to end the tutorial so we finish and the students rush off to the lecture. I am left feeling very uncomfortable, thinking that I have handled the situation badly and have in fact reinforced cultural stereotypes and dominant power relations.

For a long time I did not want to think about this incident and I felt uncomfortable whenever I remembered it. As I learned more about teaching, it raised a number of issues and questions for me to consider. The issue of voice is about who spoke and who did not speak or only spoke occasionally, and whose voices had more authority. Power is important, seen here in the subtle and overt reinforcement of cultural stereotypes, and in the relationships between myself as tutor and my students, among the students based on perceived differences, and between myself as tutor and my university department. The issue of care is raised as I consider what sort of support and teacher education I did or did not receive (especially since this was the first course I had tutored), and how my students felt cared for (or not) by me, each other and the university. Resources are important, and in this case the tutorial room made it difficult to create a space where all students could interact easily. Politics are always present and this incident reinforced that education is a political act that I was ill-prepared for (in spite of the tutorial topic). Diversity existed in the classroom as a group of students and a teacher came together to learn. In this class, as well as cultural differences, I was aware of age, socio-economic and prior educational differences. Other differences I became more aware of over time were related to health and dis/ability, religion, and approaches to learning. I also thought about how I am positioned by my students and the university and how I position myself in the classroom interactions. How did the Pakeha and Māori students in my critical incident view me, as a middle-class, middle-aged, Pakeha, female tutor perhaps? How did they view each other, and how did these positions influence their actions in the classroom? What assumptions did I make about my students? What assumptions did I and the students make about university teaching and learning?

\footnotetext{
${ }^{2}$ A Māori word generally used to signify New Zealanders of European ancestry.
} 
These issues are also reflected on by other teachers. Cochrane-Smith (2000, p. 158) asks "In our everyday lives as teachers and teacher educators, how are we complicitintentionally or otherwise - in maintaining the cycles of oppression that operate daily in our courses, our universities, our schools, and our society?” Answering this question requires that as teachers we acknowledge and make visible the power relations in the classroom. This can mean considering who is encouraged and advised, and who is invited to enter the conversation (Jackson, 1995). It asks us as teachers to be aware of our own subjectivities and to find ways to work with students who also bring diverse values, worldviews and subjectivities into the classroom, teaching with "authority and openness that invites inquiry, discussion, and a critical examination of issues and ideas" (Jackson, 1995, p. 144). Bird (2004) argues for an approach that juxtaposes and intertwines differences such as gender, culture, sexuality and disability, and that enables participants to be grounded in their own places in culture and community while being able to empathize and dialogue with those from different groups. Durie (1996) suggests creating space in the classroom that allows multiple experiences and understandings, acknowledges complex relations of privilege and oppression, and brings the possibility of hearing new voices that expand our understanding and our world.

Creating the kinds of learning communities in classrooms as suggested by Bird (2004) and Durie (1996) is not easy. Vacarr (2001, p. 285) asks "what prepares White teachers to enter the classroom and effectively deal with moments of difference that reveal racial, religious, ethnic, cultural and class variations?" Ward (2006) and hooks (1994) note that teachers are often poorly prepared for teaching culturally diverse students and that it can be difficult for individuals to make changes to teach more inclusively. In my journal I wrote about these issues.

Reflection on my critical incident leads me to ask: Where was the support for me to learn the teaching skills I needed to respectfully include diverse students and their viewpoints in the class 'learning community' and to relate these to the topic under discussion and extend the students' learning? What support is there available to encourage and extend my reflections on my teaching? Universities seem to assume that a good grasp of the subject matter and some initial induction into the teaching role are all that is required for teaching at tertiary level. This implies that it is the responsibility of individual teachers who want to become better teachers and who are student-centred in their teaching to attend to their 
own development. While there are professional development workshops on a variety of topics offered to lecturers and tutors, these are optional and are not always held at a convenient time or location to fit in with teaching and other commitments. Nor do they necessarily address student diversity. How is teaching in universities valued or devalued? What effects do government funding and policies have on universities' attitudes and practices regarding supporting their teaching staff? How do these layers of context that individual teachers work within impact on their beliefs and attitudes about teaching and on the interactions they have with diverse students? I don't have answers for these questions but considering them reminds me that my teaching is situated within political, social and economic contexts.

My journal provides me with opportunity to reflect on my teaching practice and look at ways to improve it. With ongoing teaching experience and professional development I have learned much about teaching diverse students, valuing different perspectives, and encouraging different views to be acknowledged and, when appropriate, critiqued. Yet there are still situations that arise where my knowledge, skills and good intentions are inadequate and I am motivated to further learning about teaching diverse students. These situations and my journal reflections helped inform the development of my research topic and questions.

Reflecting on teaching practice is an informal means of professional development for teachers that is widely practised and written about. In this research, my interviews with teachers acted as opportunities for them to reflect on their teaching practice. Reflective practice is often based on a constructivist perspective of education and involves thinking about experiences and making meaning from them. This knowledge gained through experience allows teachers to "make judgements in complex and murky situations" (Merriam, Cafarella \& Baumgarten, 2007, p. 172), and requires pausing during or after teaching practice to examine beliefs, goals and actions using higher level thinking processes. The aim of reflection is to gain insights that can lead to action. However it is based on an assumption that meaning is made from experiences (rather than considering how experience might be made from meaning), and implies that some kind of 'truth' can be found. I had a naïve approach to 'experience' and 'knowledge' when I started this research, and this was challenged through reading the literature and engaging with theory 
and methodology, leading me from an unquestioned realist epistemology towards an interpretivist stance and the use of post-structural critiques.

Reflecting on my teaching and reading the literature also led to an awareness of how some aspects of human diversity are more visible than others and/or more acceptable to acknowledge or discuss in classroom settings. In a postgraduate course I attended that explored diversity in education, one of the assignments involved students writing a critical $\log$ about an issue of diversity of their choice. None of the students in this class wrote about sexuality as an aspect of diversity in education. Bird (2004) discusses students' attitudes to diversity in education and, along with Johnson and Pihama (1995), notes that some differences count more than others. Questions of power are implicated in discussions of diversity and difference, and thus power became an important topic for me in this research. As I considered how power acts in the ways diversity is understood and experienced, I also pondered the challenges teachers face and their need for support. This led to considerations of care by and for tertiary teachers interacting with diverse students, and I noticed a lack of discussion about this in the literature. Care therefore became another topic I wanted to include in my research on teachers' experiences of student diversity. While the concept of diversity remains central to this research, I also explore and question notions of difference, power and care in relation to teachers' understanding and experience of student diversity.

\subsection{Overview of project}

This study was informed by my desire to include teachers' perspectives in the research on student diversity in higher education. I selected narrative methodology as an appropriate and effective means of studying research participants' understandings and experiences (Connelly \& Clandinin, 1990; Riessman, 1993), and I used interviews as a way to hear and record participants' stories (Kvale, 2007). The small number of participants and the fact that they were self-selected means that I do not have a representative sample, and thus my research does not accurately survey teachers' viewpoints and experiences. Instead it aims to provide an opportunity for some key issues to be identified and explored, and seeks to contribute to ongoing conversations about teaching in higher education. Teaching is an academic and applied discipline, and this thesis aspires to "enable conversation between 
theory and practice" (Webster \& Mertova, 2007, p. 33). It also seeks to highlight limits of this conversation and imagine ways of speaking beyond these limits.

In order to investigate university teachers' experiences of student diversity in their classroom teaching, I posed the following research questions:

- What does the term 'diversity' mean to university teachers in my study?

- What experiences do teachers narrate about diversity in their classrooms?

- How do they narrate these experiences and what meanings do they construct from them?

- How are notions of power and care implicated in their discussions?

- How do teachers' narratives position them in their teaching practice in relation to students, colleagues, institutions, cultural narratives and educational discourses $^{3}$ ?

- What elements in teachers' narratives point to alternative readings?

These questions guided the interviews, and provided the focus and starting point for the analysis of teacher's narratives. They also informed my consideration of research practices and ethics. Reading my journal entries and the literature prompted much thinking about notions of diversity, power and care, and led me to consider how these apply might to research practices as well as teaching. Research is undertaken with diverse researchers and participants, it involves relations of power and requires care for all involved (Webster \& Mertova, 2007), and it needs to recognize how the researcher and participants are positioned (Gunasekara, 2007). These considerations need to be acknowledged, and feedback from others has helped to expose some of my 'blind spots', those aspects of diversity, power, care and subjectivity that were routinely invisible to me as I undertook this study. My research questions, perspectives and practices are situated within social structures and educational discourses (Scott \& Usher, 1999). These need to be made explicit and, along with ethical considerations, are addressed in the chapter on methodology.

\footnotetext{
${ }^{3}$ The term 'discourse' in this thesis is being used in the sense of "a system of statements which constructs an object" (Parker, 1992, p. 5) that has effects on how people psychologically and physically experience their world (Willig, 2001).
} 


\section{5 'Voice': A key dilemma}

I began this research project with a desire to enable university teachers' voices to be heard in ongoing public conversations about teaching diverse students in higher education. However, I soon became aware that this purpose of research - 'giving voice' to a particular social group — has been both celebrated and critiqued (Sharkey, 2004). According to the literature, narrative has become a popular research method over the past few decades, and has become a popular way to give a voice to those who are not often heard (Chase, 2005; Cortazzi \& Jin, 2006) or who have been marginalized (Sharkey, 2004). Educational researchers had previously given little attention to teachers' voices, and narrative research has enabled teachers' perspectives, experiences and knowledge to inform our understanding of teaching (Cortazzi, 1993). As I read the literature, however, I found that the notion that research offers people the opportunity to have their voices heard has been problematized. Atkinson and Delamont (2006) are concerned that too often narratives are "collected and celebrated" (p. 166) without being critically analysed. Honouring the voices of research participants assumes that transcripts unproblematically represent participants' experiences (Lather, 2006), and the idea of an 'authentic voice' is underpinned by realist and essentialist epistemologies (Orner, 1992). Notions of 'voice' are also linked to notions of 'teacher empowerment' (Cortazzi, 1993), supporting constructions of responsible and autonomous individuals. Sharkey (2004) notes that because narratives are complex texts produced in political contexts, uncritical analyses of personal narratives can reinforce dominant ideologies. The ways we tell the 'truth' about people have powerful consequences (Ramazanoglu \& Holland, 2002) and therefore a critical approach is required for the analysis of narratives.

Recent approaches challenge a view of narrative as representing reality. Rather than simply reporting events, narrative is understood as a retrospective shaping of past experiences to give them meaning, and thus involves interpretation (Chase, 2005). An interpretivist perspective of 'voice' acknowledges that meaning is fluid and contextual, and that there is "no one, true representation of spoken language" (Riessman, 1993, p. 13). Some researchers sever the link with realism even further by viewing narratives as "verbal action" (Chase, 2005, p. 657) in which the narrator constructs and performs the self and experience. Individuals are never the sole authors of their narratives (Czarniawska, 2004); the stories they tell are constructed from available narrative and cultural resources 
(Polkinghorne, 1996). This means that analysing texts involves understanding the effects of language, and researchers need to consider the "absences and silences in our talk" (Davies, 2000, p. 35) and examine teachers' narratives for what they conceal as much as for what they reveal (Convery, 1999). I thus began to see that 'giving voice' to participants simply by collating what they had said, looking for common themes and discussing their implications would considerably limit my analysis. In particular, it would not enable scrutiny of taken-for-granted ways teachers 'speak and do' (Atkinson \& Delamont, 2006) diversity, power and care, or a productive analysis of the way participants are positioned by, and position themselves within, their university contexts. It would be too easy to end up simply reproducing existing educational narratives rather than disrupting them in order to imagine other possible educational narratives.

Tolich and Davidson (1999) note that the qualitative research process changes as what the researcher knows changes. In my case, an emerging awareness of poststructural approaches for investigating education and challenges to a realist worldview have led me to a more complex consideration of teachers' 'voice' in this research. As these insights were gained after I began this study, they were not brought into the interviews I conducted with participating teachers, resulting in a realist use of language in my interactions with them. When it came to analyzing the interviews, however, I decided to employ poststructural approaches to explore not only what teachers said, but how that saying opened up or closed down ways of understanding diversity. At the same time, the interviews with teachers raised issues that I felt were important and needed to be discussed by those involved in higher education, especially in leadership and policy-making positions. Teachers spoke to me because they wanted to be heard, and I wanted to (re)present their voices. I thus found myself caught between the rock of realism and the hard place of poststructuralism. This tension has remained throughout this thesis, and necessitated a search for ways to embrace these differing positions productively. I explore this further and explain how I work with these tensions in Chapter 5 where I discuss the methodology of this thesis. 


\subsection{Thesis structure}

This thesis incorporates several strands of thinking - my personal narrative of the research process, explorations of the literature, considerations of theory and methodology, conversations with participants in interviews, and analyses of the transcripts - into a particular narrative form, that of the doctoral thesis. These strands weave together in complex ways, and writing the thesis was an iterative process: spiralling backwards and forwards as I wrote and rewrote sections of the thesis; inwards and outwards as I explored fine details of the transcripts and broader social contexts; and sideways as I shifted my attention between what participating teachers said and what they did not. These movements coalesced into this particular thesis, located in a particular historical moment and in particular geographical and social spaces. Its specificity locates it but does not pin it down: while the methodology of this study does not enable the findings to be generalized, the thesis nevertheless offers insights from a specific context that can be considered throughout higher education and beyond, prompting reflection on teaching practice and perhaps helping to inspire transformative praxis.

This chapter has introduced this research study and Chapter 2 locates the study in relation to the social context by providing background information. It discusses student diversity in New Zealand, the significance of the Treaty of Waitangi, the internationalisation of higher education, neo-liberalism and the marketization of universities, and suggests that there are tensions between discourses of inclusion and neoliberalism. Chapters 3 and 4 locate the thesis in relation to the literature. Chapter 3 reviews the literature about teaching diverse students in higher education, and identifies several key perspectives used to talk about diversity. Chapter 4 investigates the various ways 'power' and 'care' are conceptualized within and beyond the higher education literature to enable the analysis of these concepts in study participants' narratives. Chapter 5 discusses the methodology of this research, considering the methodological framework underpinning this study, and explains the narrative approach employed to analyse data, and the study design and procedures.

In Chapters 6 to 9, the transcript data is analysed and discussed. Chapter 6 examines teachers' understandings of diversity and the discursive construction of difference. Chapter 7 analyses teachers' experiences of diversity in the classroom and the teacher identities these narratives produce. Chapter 8 continues the analysis of teachers' experiences and 
investigates narratives of learning to teach diverse students and how these construct teaching contexts and relationships with colleagues and institutions. Chapter 9 looks at how teachers respond to diversity with relational practices and explores how forms of care and power are produced in teachers' narratives about inclusive practices.

The final chapters of this thesis discuss the findings from the analytical chapters. Chapter 10 looks at how notions of diversity, power and care are constructed and performed in the narratives of research participants and considers possible alternative narratives. Chapter 11 situates the research findings and discusses changes in the social and economic context since this study began. It provides a synthesis of the key ideas in this thesis and suggests further directions for research, and reflects on my experiences of this research process. 


\section{Chapter 2}

\section{Background and context: Locating the study}

\subsection{Introduction}

Having identified a lack of research on how teachers experience student diversity and explained my personal motivation and interest in this research, I now look at how this project is located within the broader educational and political landscape, both national and global. This chapter begins by investigating the range of students enrolled in New Zealand tertiary institutions to give an indication of the diversity of students university teachers may encounter in their classrooms. I then look at policies and debates about the widening of participation in higher education, and discuss the notion of inclusion. I provide a brief overview of the Treaty of Waitangi and its place in higher education. International students are a significant part of the university student body in New Zealand, and I consider some issues the internationalisation of higher education brings. New Zealand is part of the global economy and this means that our higher education is influenced by international trends and financial pressures. The meanings of globalization and its impact on higher education have received a great deal of attention in the literature, and in this chapter I give a brief overview of some key ideas and issues. Finally this chapter considers the impact of neoliberalism and the marketization of universities, a key contextual factor for this research. Political and economic ideologies underpin the policies and funding decisions that shape the governance of universities, which in turn enable and/or constrain teachers' practices in the classroom. Students are also affected by political and economic ideologies and policies, influencing their expectations of higher education and their interaction with teachers. The teachers in this study are thus embedded in local and global flows of information and resources, politics and policies.

\subsection{Student diversity in New Zealand higher education}

Diversity is a complex and contested term in education (Zepke, 2008), and will be explored and critiqued in this thesis. As I began this research journey, I thought about student diversity in my own teaching and considered social group membership and 
personal characteristics such as gender, ethnicity, age, sexuality, (dis)abilities, religion, country of origin, socio-economic status, health, life experiences, previous academic experiences, technological access and ability, approaches to learning, and personality. The Ministry of Education keeps records for some of these characteristics, and research has been undertaken for some aspects of student diversity in New Zealand.

Students in higher education have a diverse range of cultural backgrounds. In 2009 the total number of students enrolled at universities was 177,157 and of these, 110,297 students identified as European, 15,128 as Māori, 9,872 as Pasifika, 42,219 as Asian, and 13,160 identified as other ethnicities ${ }^{4}$ (Education Counts, 2010). Domestic students dominated enrolments at New Zealand universities, with 154,866 enrolled compared to 22,291 international students. However, the number of international students is significant and contributes to the diversity of students in tertiary classrooms. Asian students were the highest regional grouping, numbering 13,922 at universities, with the highest number from China. International students also come from India, South Korea, United States, Malaysia, Japan, Germany, Saudi Arabia, Fiji, Vietnam, Philippines, Great Britain, Thailand, Canada, Tonga, France, Taiwan, Indonesia, Russia, Brazil, Singapore, South Africa, Sri Lanka and other countries. No figures for students' religious affiliation are available; however in my own time on campus in New Zealand universities I have met students who are Christians from a variety of denominations, Jewish, Buddhist, Moslem, Hindu, atheist, and Wiccan.

Tertiary student ages range from under 18 to over 40 , with the greatest concentration in the 18-24 age groups for full-time domestic students (Education Counts, 2010), while 23,738 students were aged 40 and over. Those studying in mid or later life have different challenges from recent school leavers (Davey et al., 2003). Many mature students juggle several roles such as parent, spouse, worker, community member or grandparent. These challenges are experienced differently by men and women, with many mature women at university juggling the responsibilities of caring for families and keeping house with paid work. For those over 60, university study can be a constructive way to use their retirement time. In a study of mature Māori students (Stephens \& Higgins, 2003, p. 73), these students "acknowledged their roles as bearers of knowledge to other members of their

\footnotetext{
${ }^{4}$ The total adds up to 3519 more than the total number of students enrolled, suggesting that these students have identified with more than one ethnicity.
} 
whanau ${ }^{5}$ and to people outside their whanau." In other words, they saw tertiary education not just something that benefited the individual but also as a collective good. However, whanau responsibilities were seen as one of the main barriers to participation in university life and study.

More women are enrolling at university than men, the statistics showing 101,550 female and 75,607 male enrolments in 2009 (Education Counts, 2010). However, some subjects are preferred by one gender. For domestic students studying for bachelor degrees in 2008, males outnumber females in Architecture and Building, Engineering and Information Technology, while females significantly outnumber males in Health, Society and Culture, Creative Arts, and in particular in Education where there are over five times as many females as males (Education Counts, 2008). This means that some teachers will find their classes dominated by one gender. This can be further complicated by the ethnicities and religious affiliations of students as there are many different cultural constructions and expectations of gender. Official figures do not include students who identify as transsexual or intersex, meaning that those students outside male and female gender categories are not counted.

Another important form of diversity is that of students with impairments. Of the 2009 domestic enrolments, 5595 university students acknowledged a disability (Education Counts, 2010). Universities provide support to students with impairments. At Victoria University of Wellington, Disability Support Services offer assistance to students with impairments to hearing, vision, movement or mobility, to those who have mental health conditions, injuries, chronic medical conditions, specific learning disabilities or those who are Deaf (Disability Support Services, 2006). The document 'Kia Orite: Achieving Equity' (Achieve, 2004) is a code of practice that aims to "assist tertiary education providers to create a fully inclusive tertiary education environment for students with impairments within New Zealand" (p. 11). Guidelines for teaching and learning form an important part of Kia Orite, including the requirement that "Teaching staff plan and employ teaching and learning strategies and reasonable accommodations to make course delivery as inclusive as possible for students with impairments, without compromising essential programme standards or components" (p. 35). When barriers to participation are removed and support

\footnotetext{
${ }^{5}$ A Māori word referring to the extended family or a family group that may include non-kin members.
} 
services provided, students with impairments perform well at universities in New Zealand (Claiborne \& Smith, 2006). However, Claiborne and Smith believe more research is needed and suggest that teachers' professional development programmes include methodologies for inclusive best practice.

Statistics are limited in what they can tell us about student diversity. The statistics from the Ministry of Education (Education Counts, 2010) do not include socio-economic status; however research from Strathdee and Hughes (2006) found that of first-year full-time tertiary students, those from low socio-economic status (SES) backgrounds were underrepresented in the three Christchurch tertiary institutions they studied. Compared with a 1987 study, middle-SES background students increased their participation at university while participation rates for students from low SES backgrounds remained the same. Access to ICT and the ability to use these technologies is another area that is not recorded in the statistics but may have a significant impact on student learning. Some student characteristics are personal and students may choose not to divulge them, for example, sexuality, health, family responsibilities, and life experiences. Thus teachers may not always be aware of the full range of diversities students bring to their learning experiences. Statistics also do not tell us about the impact of diversity on teaching and learning in New Zealand tertiary classrooms. What are the benefits and challenges of student diversity for teachers and students? How is diversity conceptualized and what are some alternative ways of talking about it? Should we even be concerned with diversity? Because there is little research about how tertiary teachers in New Zealand understand and experience diversity in their teaching practice, this research is important in giving a picture, albeit limited and partial, of this aspect of higher education.

\subsection{Widening participation in higher education}

An increasingly diverse population in contemporary Western democracies (D'Cruz, 2007) has seen greater numbers and diversity of students in higher education (Skelton, 2002). In New Zealand, Māori, Pacific and Asian populations are growing at a faster rate than that of European and other ethnic groups, resulting in a more diverse population (Department of Statistics, 2008). New Zealand has a tradition of broad and inclusive tertiary education (Ministry of Education, 2007) with open access for students over twenty. The Tertiary 
Education Strategy 2010-15 (Ministry of Education, 2010) seeks to improve the "efficiency of public investment in tertiary education" (p. 10) and places importance on course and qualification completion rates. In response to the current economic recession, funding is capped and the government is looking to link funding to performance, and this has led to some restrictions on university undergraduate enrolment which may result in a narrowing of participation in higher education. However, when I interviewed teachers for this research in 2008, open access was available and teachers had a wide range of domestic and international students enrolled in their courses.

Skelton (2002) considers that much of the literature on inclusive learning in higher education assumes a link between inclusion and access to institutions. But in recent years, the tighter economic environment has led to increasing concern about completion rates (Zepke \& Leach, 2007). The government has placed an emphasis on encouraging participation and successful completion by students of all ethnicities, ages and socioeconomic backgrounds, and the latest Tertiary Education Strategy (Ministry of Education, 2010, p. 18) states that universities are expected "to enable a wide range of students to successfully complete degree and postgraduate qualifications." It says, The tertiary education sector should respond to the diverse needs of all the groups it serves. In some cases, this will mean providing targeted services to create an inclusive environment for a diverse student body that includes, for example, students with disabilities. Groups of students with low completion rates, such as Pasifika, are likely to require tailored support to ensure success in tertiary education. (p. 6)

Māori students, Pasifika students and students with disabilities are singled out as requiring attention and extra funding is allocated to improve the participation, retention and success of these students. However Ross (2009) argues that this creates a discourse of deficit and conceptualizes these students as "in need of fixing" (p. 47), meaning that it is students who need to change to better fit into higher education institutions.

Some educational writers go beyond access to and completion of courses of study in thinking about inclusion. Drawing on situated learning theory, which describes learning as a social activity occurring within communities of practice (Lave \& Wenger, 1991), Baskerville and Bondy (2010) argue that if the situated nature of learning is disregarded, education may not be truly accessible to all students. They note, "Many students, including Māori, may encounter learning environments that are disconnected from their own lives 
and this might inevitably limit the effectiveness of learning" (p. 58). Zepke and Leach (2007) draw on Bourdieu's notion of cultural capital in their research with tertiary teachers to describe how inclusive teachers "value and legitimate the students' socio-cultural identity, their existing knowledge and ways of working" (p. 664). Other writers concerned with inclusion raise questions about who controls the production and legitimation of knowledge (Skelton, 2002), how the criteria for judging successful participation are determined (Nunan, Rigmor \& McCausland, 2000), and whether attrition of students is always a negative outcome (Te Tari Matauranga Māori, 2007). A broader notion of inclusion suggests that educational institutions need to consider how to enable full participation by diverse students, and Ross (2009, p. 51) suggests they develop "culturally diverse tertiary learning environments, curricula and teaching and support practices that enhance success for all students." This affirms a view of inclusion that involves more than access to higher educational institutions or completion of courses of study, and is inevitably linked to notions of social justice.

A liberal democratic approach to widening participation in higher education is based on an ethical framework of social justice where education is considered a public good and a fair distribution of educational benefits is aimed for (Olssen, Codd \& O'Neill, 2004). With a shift to a neoliberal market economy in the last two and a half decades and an increasing focus on the economic benefits of higher education in recent years, the rationale for widening participation has shifted to a focus on producing the human capital necessary for economic success (Nunan et al., 2000). This research study is located within the tension between these two approaches, and therefore it is necessary to provide some background on the rise and impact of neoliberalism in New Zealand and its influence on higher education. Firstly, however, I give a brief overview of the Treaty of Waitangi and its place in higher education in New Zealand. Then I consider the impact of globalization on higher education and the increasing numbers of international students attending New Zealand universities.

\subsection{The Treaty of Waitangi}

In New Zealand, educational institutions have a responsibility to act in accordance with the principles of the Treaty of Waitangi (te Tiriti o Waitangi). This treaty is considered the 
founding document of New Zealand (Aotearoa), signed in 1840 by chiefs of Māori iwi (tribes) and representatives of the British Crown (the colonisers) (New Zealand History Online, n.d.). This treaty marked the beginning of New Zealand as a nation state and was written in two versions, English and Māori. In the English version, Māori ceded exclusive sovereignty to the British Crown and in return were guaranteed rights of ownership of their lands, fisheries and other possessions, and given the rights and privileges of British subjects. However, not only have there been numerous serious breaches of the Treaty since 1840, but the Māori version interprets key concepts differently, for example 'sovereignty' and 'undisturbed possession'. Bishop and Glynn (1999) argue that since then the relationship between Māori and Pakeha has not been the partnership promised by the Treaty, but instead has involved

...political, social and economic domination by the Pakeha majority and marginalisation of the Māori people through armed struggle, biased legislation, and educational initiatives and policies that promoted Pakeha knowledge codes at the expense of Māori. (p. 14) Bishop and Glynn further argue that the guarantees of the Treaty have not been met, specifically “Article One's guarantee of shared power in decision-making; Article Two's guarantee of control over cultural treasures; Article Three's guarantee to Māori of equal benefits from participation in the new society" (p. 54). In the 1980s there emerged demands for a bicultural approach to recognize Māori as tangata whenua (indigenous people) of Aotearoa New Zealand and to honour the Treaty of Waitangi. The Tertiary Education Strategy 2010-2015 (Ministry of Education, 2010) states that universities and other tertiary institutions have "a particular responsibility to maintain and develop Māori language and culture to support Māori living as Māori” (p. 7). The Strategy acknowledges research evidence showing that "acknowledging and advancing Māori language, culture and identity is important in providing a basis for Māori success in all forms of education" (p. 7).

However many educators argue that education remains a European-dominated system that marginalizes Māori knowledge, language and culture. Zepke and Leach (2002) point to the hegemony of Western intellectual thought in higher education, and challenge educators to work in partnership with Māori to affirm Māori knowledge and pedagogy. Bishop and Glynn (1999) argue that educational practices operate under a pervasive assimilationist agenda, contributing to "persistent attacks on the integrity of Māori culture" (p. 16) and leading to relations of domination and subordination in New Zealand that perpetuate 
conformity to Pakeha norms. They have developed a model for evaluating power relationships in education that is based on five themes: initiation, benefits, representation, legitimation and accountability. Some key questions arise in relation to these themes. Whose interests and agendas does the education system promote? Who gains from the education system? Whose social reality is depicted? What authority does an education system or institution claim for its structure and processes? Who are educators accountable to, and what outcomes are measured and how? The development of Kaupapa Māori ${ }^{6}$ (Māori principles) calls for tino rangitiratanga (the principle of self-determination) as "the right to determine one's own destiny, to define what the destiny will be and to define and pursue means of attaining that destiny" (Bishop \& Glynn, 1999, p. 168). This has led to the development of initiatives and strategies that

....assert the validity of Māori knowledge, language, custom and practice, and its right to continue to flourish in the land of its origin, as the tangata whenua (indigenous) culture." (Wilkie, 2006, p. 47)

Universities have their own policies that set out how they will put their Treaty obligations into practice. For example, a Treaty of Waitangi Statute (Victoria University of Wellington, 2009) is published on Victoria University's website, and examples of the commitments it sets out include: affirming the contribution of Māori language and culture to the culture of the university; commitment to Māori student recruitment, retention, and achievement; and commitment to building Māori staff capability. How such policies are put into practice by higher education institutions in New Zealand is an area of ongoing research and discussion, and the Treaty of Waitangi remains an important part of the educational context.

\subsection{International students, internationalisation and globalization}

There is a great deal of literature about international students, especially regarding crosscultural differences in educational expectations and practices and in student behaviours, but less about how these impact on classrooms (Ward, 2006). Research findings suggest

\footnotetext{
${ }^{6}$ Henry (1999, p. 184) describes kaupapa Māori as "both a set of philosophical beliefs, and a set of social practices. These are founded on collective consciousness (whanaungatanga), interdependence between and among humankind (kotahitanga), a sacred relationship to the "gods" and the cosmos (wairuatanga), acknowledgement that humans are the guardians of the environment (kaitiakitanga), and the interconnection between mind, body, and spirit."
} 
that tertiary educators generally "make few, if any, changes in either the process or content of educational activities" (Ward, 2006, p. 2) in order to address the specific needs of international students. These students are often identified as bringing challenges to university teaching, thus "treating difference as a deficit" (Asmar, 2005, p. 291). However, many educators also stress the benefits international students bring to universities, their staff and students. As well as the economic benefits such students bring (Ward, 2006), other benefits include sharing and appreciating other cultures (Robson \& Turner, 2007), developing positive relationships in a socially connected world and countering prejudice (Summers \& Volet, 2008), internationalising the curriculum, and widening intellectual perspectives (Ward, 2006). Students develop the capacity for more critical and original thinking when they learn among diverse peers, and are better able to integrate different perspectives to solve problems (Kaufman, 2007). However, it is important not to view international students as a homogenous group. There needs to be an awareness of the interconnectedness and diversity of international and domestic students' identities and needs (Ippolito, 2007), the diverse cultural, linguistic, social and economic backgrounds of international students (Ryan \& Viete, 2009), and the heterogeneity and power differentials within and between international student groups (Mayuzumi, Motobayashi, Nagayama \& Takeuchi, 2007).

'Internationalisation' has become an important notion in higher education and has different meanings. It can refer to the movement of students and academics around the world (Asmar, 2005; Harris, 2005), the development of intercultural awareness and global citizenship (Kreber, 2009), a desire to equip students and staff with the knowledge and skills "to operate in international and increasingly multicultural domestic contexts" (Ippolito, 2007, p. 751), or the ways a university can become an "internationally-minded community" (Robson \& Turner, 2007, p. 42). While internationalisation is generally seen as enriching education (Kreber, 2009), research has shown that the presence of international students is not by itself enough to promote intercultural interactions or bring about changes in educational process and content (Ward, 2006). Universities need to take active measures to achieve educational and social internationalisation (Summers \& Volet, 2008), and Ward (2006) suggests that New Zealand has an opportunity to take a lead in research about how to maximise the benefits of internationalisation. 
International student enrolments are both a result of, and a contribution to, the globalizing of higher education. Globalization is a contested notion and has different and sometimes conflicting meanings for those in higher education (Burbules \& Torres, 2000; Dodds, 2008). Globalization is generally understood as a process rather than a condition (Held, McGrew, Goldblatt \& Perraton, 1999) whereby "worldwide economic and social forces supplant those of nation and locality" (McNair, 2001, p. 16), leading to "the emergence of interregional networks and systems of interaction and exchange" (Held et al, 1999, p. 27). Content analysis of articles in higher education journals undertaken by Dodds (2008) reveals three main ways that globalization is conceptualized by the articles' authors. In the first of these, globalization refers to an increase in global flows and global pressures. Global flows involve movement across national borders of people, financial capital, information and culture, while global pressures refer to the creation of new institutions and groups of people, such as transnational corporations and a "transnational capitalist class" (Dodds, 2008, p. 507).

A second way globalization is understood by these authors is as trends, in particular, that of marketization. This involves increasing economic interdependence, trade liberalisation and competition, and affects higher education institutions through an emphasis on competition between domestic institutions and the promotion of 'quality' and 'relevance' (Roberts, 2008). The third conceptualization identified by Dodds (2008) is that of globalization as ideology, especially neoliberalism (Burbules \& Torres, 2000), which has been used to justify higher education restructuring and reform (Dodds, 2008; Morrow \& Torres, 2000; Olssen et al., 2004). Some other ideologies linked to globalization are Westernization (Held et al, 1999) including the spread of the English language (McNair, 2001), a postmodernist emphasis on consumption and lifestyle choices (Usher, Bryant \& Johnston, 1997), and ecological perspectives (O’Sullivan, 1999).

Globalization brings opportunities and challenges for higher education (Jarvis \& Preece, 2001), and educators need to consider the implications of globalization on the shaping of educational policies and practices (Burbules \& Torres, 2000). The global economy generates pressures to provide flexible education linked to a rise in service jobs (producer, social and information services), a need for workers who can adapt to flexible work regimes and insecure employment (Morrow \& Torres, 2000), and an increase in graduate employment to meet the needs of a knowledge-based economy (McNair, 2001). The 
increasing globalization and liberalisation of trade markets has impacted on national economies, and the Tertiary Education Strategy 2010-2015 (Ministry of Education, 2010) argues that

A world-leading education system is an important first step towards a productive and growing economy that delivers greater prosperity, security and opportunity for all New Zealanders. (p. 6)

As Roberts (2008) notes, economic concerns dominate tertiary education policy in New Zealand and knowledge is increasingly being commodified. Tertiary educational reforms have been shifting universities into alignment with market-based economic policies, and therefore the influence of the neoliberal shift in New Zealand politics and its impact on higher education needs to be considered in order to understand the context this research study is situated in.

\subsection{Neoliberalism and the marketization of universities}

Education policies and practices have been influenced by the rise of neoliberalism in New Zealand politics since the mid 1980s (Roberts, 2009). Neoliberalism as a political and economic ideology promotes a reduction in the public provision of goods and services and the expansion of a market-based economy (Olssen et al., 2004). The market-place is seen as the best means of securing the interests of individuals, while the state's role is to ensure the conditions for the efficient and equitable operation of the market and protect individual liberties and property rights (Tobias, 2005). Market mechanisms are considered the best means of ensuring economic prosperity, bringing fairness and "economic justice" (Heywood, 2003, p. 56) whereby everyone has the opportunity to succeed or fail according to talent and effort. In practice this has most often led to growing inequality of wealth (Schirato \& Webb, 2003). People are seen as rational self-interested choice-makers who are responsible for themselves, and competition is the structuring mechanism that enables the efficient and fair allocation of resources and status. State support for egalitarian policy initiatives is "an attack on 'enterprise and endeavour', 'self-reliance', 'responsible selfmanagement' and 'personal sacrifice"” (Olssen et al., 2004, p. 138). As governments shed responsibility for welfare and stress the need for personal responsibility, individuals become risk aversive because there is little, or no, safety net if they make mistakes (Davies, 2009). Motivated by the need for personal security and survival, vulnerable 
individuals compete against each other in a deregulated labour market, providing a flexible and responsive workforce to meet the requirements of firms and corporations. Olssen et al. (2004) sum up the impact of neoliberalism:

...in the global economic era neoliberalism becomes a new authoritarian discourse of state management and control...Its overall rationale is to measure the costs of, and place a value on, all forms of human activity. It extends the market mechanism from the economic to the political to the social. Market exchanges now encapsulate all forms of voluntary behaviour amongst individuals. (p. 172)

What may seem at first glance to be an economic ideology reaches into all aspects of individual and social life, including educational practices and expectations.

Neoliberalism has led to reforms in New Zealand's education sector. The purpose of higher education has shifted from being a public good that provides for individual as well as social needs to being a private good that benefits individuals. Students are consumers who pay for the education they want in order to maximize their wealth and status (Boshier, 2001), and educational institutions are providers who should respond to student (consumer) demand (Olssen et al., 2004). Education is thus considered a commodity most efficiently regulated through market mechanisms (Nunan et al., 2000), with increased competition requiring individuals to perform at an optimal level and educational institutions to be efficient (Boshier, 2001). An increased focus on how higher education contributes to economic growth (Roberts, 2008) sees the knowledge that students gain as a form of human capital enabling them to compete in the labour market (Olssen et al., 2004). It has also led to increased competition between universities with the introduction of Performance-Based Research Funding (PBRF), and more recently through indications that part of university funding will be tied to student success as measured by course completion rates (Ministry of Education, 2010).

The level of funding for universities is an ongoing concern for those in the sector. Since the 1980s, there has been a big growth in demand for university education due to demographic changes as well as policies that seek to develop human capital for a competitive economy (Peters \& Roberts, 1999). The latest Tertiary Education Strategy states, "In a tight fiscal environment, the Government is unable to provide significant funding increases to meet the growing demand for tertiary education" (Ministry of Education, 2010, p. 10). Universities need to consider a range of income-generating 
initiatives and, alongside existing teaching and research activities, universities are becoming more involved in entrepreneurial ventures, such as partnerships with business and setting up campuses in other countries (Harris, 2005). A focus on resource management has meant "squeezing 'more' out of 'less"” (Hill \& Lee, 2009, p. 41).

With the marketization of higher education stressing innovation, greater productivity, efficiency and accountability, it is inevitable that academic staff will be affected by such changes. Recent moves to a more commercial and managerial university environment have been investigated by Harman (2005), whose research with social science academics in Australian universities found that they experienced increased workloads, greater administrative and reporting duties, deteriorating social relations within academic departments, and lower morale across their universities. Tierney's (2003) research with academic and other staff in Australian universities looked at the changing nature of academic work. Staff noted increasing workloads and less time leading to decreasing quality of teaching. Tierney's findings suggest a "disintegrating academic culture that gets reflected in less collegiality and a cycle of pessimism" (p. 374). Hill and Lee (2009) argue that a culture of competitive performativity has promoted an impersonal managerial style of leadership, undermining democratic processes in governance and fostering a culture of incivility, even bullying, in New Zealand universities.

According to Curzon-Hobson (2004), teaching in higher education has changed radically in the last twenty years due to "greater enrolment numbers, declining government funding, the introduction of student loans, increasing fees, and greater intra- and inter-institutional competition" (p. 220). He also notes that recent tertiary education policies devalue teaching through a failure to address the notion of higher learning, exacerbated by restrictions on the time provided for teaching due to growing demand on teachers' time for research, public service, marketing and administration. Harris (2005) argues that the marketization of higher education has also impacted on teachers' professional identity and eroded academic autonomy and expertise, with "instrumental and economic values rather than educational values... becoming central in defining professional identity and professionalism" (p. 425). Concern is also expressed by Schuck, Gordon and Buchanan (2008), who argue that tertiary teacher effectiveness is being reduced to lists of behaviours and standards that are measured by student satisfaction surveys, while Molesworth, Nixon and Scullion (2009) suggest that students' demands for educational products (degrees) 
conflict with teachers' desires for deep learning processes, noting that the uncertainty and discomfort that can accompany critical reflection and intellectual growth are not compatible with the instrumental orientation of many students. Peters and Roberts (1999) believe that many academics view education as "a complex, humanising social learning process with intrinsic as well as extrinsic benefits" (p. 159) that students participate in rather than as a product to be consumed. They consider that the commodification of higher education reduces the complexities of knowing to finite competencies which is "utterly dehumanising for both teachers and students" (p. 159). These authors all describe ways that academic culture is at odds with market-driven philosophies and practices.

This overview of the marketization of universities has taken a simplified and one-sided view of a complex phenomenon about which there are many points of view and to which there have been diverse responses. However, articles in higher education journals suggest many educators and researchers are concerned with the impact of neoliberal policies and practices on higher education. Since critical reflection is a key part of academic life (Barnett, 1997), it is not surprising that academics are challenging neoliberal reforms in higher education. Peters (2002) refers to a neoliberal metanarrative that has "successfully and imperialistically extended the principle of self-interest into the status of a paradigm for understanding politics itself, and in fact, not merely the market but all behaviour and human action" (p. 7). For those teachers concerned with inclusion and who see equity and social justice as values underpinning higher education, the intrusion of market philosophy into education is a serious matter.

\subsection{Conclusion}

The forces of internationalisation, globalization and neoliberalism have had a profound impact on higher education in recent years, and are likely to continue to influence educational policies and practices in the near future. The diversity of students attending New Zealand universities suggests that inclusive policies and practices have been effective if inclusion is understood as widening participation. However if inclusion is seen as the provision of diverse teaching and learning environments, inclusive curricula, a “democratisation of knowledge" (Skelton, 2002, p. 193), and practices of equity to ensure diverse students are supported in their study, then the ongoing efforts to lift the completion 
rates of groups such as Māori, Pacific and disabled students (Ministry of Education, 2010) suggest otherwise. A broad, social justice-based notion of inclusion is at odds with a market-driven education system driven by a discourse of meritocracy (Jarvis \& Preece, 2001; Nunan et al., 2000). The teachers in my study are working within the competing pressures of inclusion and neoliberalism, and how this emerges in their narratives of experience is explored in Chapter 8. 


\section{Chapter 3 \\ Diversity in the literature}

\subsection{Introduction}

The concept of diversity is central to this thesis, however diversity is a term that is widely used and its meaning often taken-for-granted. In education, it has been used to refer to people differing on particular dimensions of identity that they express themselves or that have been ascribed to them by others (Bird, 2004). Diversity can also refer to differences between individuals, groups, beliefs and practices, and ways of being in the world (Zepke, 2008). There are both observable and non-observable forms of diversity, and Lumby (2006) notes that visible differences are more likely to be met with strong reactions, especially if an aspect of difference is seen as problematic by a majority group. How diversity is viewed is therefore power-laden and "influenced by political and ideological standpoints" (Zepke, 2008, p. 5), with some differences counting more than others (Johnson \& Pihama, 1995). Lumby (2006, p. 152) reminds us to ask "who is deciding who is 'different', on what basis and to what end?" This chapter looks for some responses to this question in the literature on diversity in higher education, discussing key themes and identifying gaps in the research. Because a concept such as 'diversity' can be understood and used in many ways, I also need to consider the particular perspectives of diversity within the literature.

I begin this chapter by providing an overview of the academic literature on tertiary teachers' understandings and experiences of student diversity. I then look at the wider literature on diversity in higher education to identify and discuss several key approaches to how diversity is talked about in the literature. Finally I look at the implications of the review and how it situates this thesis. This review focuses primarily on academic journal articles and reports published in the last ten years, though some other relevant material is included. Most of this literature is written by academics discussing research that is relevant to my study topic and research methodology. It is important to note, however, that this review is limited and partial due to which literature I was able to find, what I considered as relevant and how I interpreted it, how I described and categorized it, and what was consciously or unconsciously excluded. Just as my review of the literature is constrained 
by my own perspectives, academic literature is always embedded in socio-political contexts and discourses that I may or may not recognize.

\subsection{Research on teachers' experiences of student diversity}

Manning (2009) argues that all educators have a perspective on diversity, articulated or not, that underpins their work. Yet while there is a great deal of research on student diversity, there is far less on teachers' perspectives of student diversity. Of the research on teachers, much of this is undertaken by teachers investigating their own practice rather than a researcher studying teachers. A notable exception is a New Zealand study undertaken by Zepke and Leach (2007) which surveyed 137 teachers of first-time-enrolled tertiary students and asked them about the issues, rewards and challenges of teaching students from diverse backgrounds and how they catered for diversity. Zepke and Leach found that most of their respondents recognized and valued student diversity and understood it in socio-cultural terms, attempting to adapt their teaching to value students' diverse cultural capital. A significant minority of respondents rejected notions of sociocultural diversity and instead understood diversity as individual differences, and would offer support to any individual student who needed it. Analysis of the data showed that regardless of their attitudes to diversity, teachers came up with similar strategies to support their students' learning needs. Zepke and Leach also found that teachers tended to refer to diversity in terms of deficits that needed to be remedied.

In other New Zealand research, Campbell, Künnemeyer and Prinsep (2008) studied tertiary teachers' perceptions of science and engineering learning communities and as part of their research looked at perceptions of the diversity and differences in learning styles of students. Participating teachers identified significant diversity in students' age, ethnicity, educational background and prior experiences and talked about their own roles and pedagogical approaches. The authors concluded that the teachers they interviewed identified factors contributing to student diversity but did not make it clear if they adapted their teaching approaches accordingly. These teachers did, however, stress the need for better resourcing. 
Turning to the international literature, Castañada's (2004) research with teachers from a US university investigated how they understood and addressed student diversity in their teaching practice. Twenty-nine teachers were surveyed and eleven of these interviewed. The author found that the teachers defined diversity in the context of their students, teaching and classrooms from a number of standpoints. These could be placed along a continuum of positions about diverse social group membership, experiences and perspectives, ranging from recognition and respect to contextualized understanding of multiple perspectives to a social justice perspective. In the interviews, participants considered issues of gender, race and social class and said that they adapted their course content and teaching methods in response to these forms of diversity. However, other forms of diversity such as religion, sexual orientation and ability were infrequently addressed in their teaching. Interview participants employed a variety of strategies to effectively teach diverse students and said that their teaching could be improved by reducing class sizes. Participants also said here was a lack of support for and valuing of teaching diverse students.

Research on university teacher identity in the UK by Hockings, Cooke, Yamashita, McGinty and Bowl (2009) found that while most participants aimed to be inclusive of students' social and cultural diversity, they did not always do so in practice. Teachers held a range of views about how to respond to greater student diversity, including addressing students' needs, being aware of the diversity of students' knowledge and experience, and using inclusive curriculum material. Some teachers used teaching examples that did not relate to all students or planned their lessons from a very basic level assuming that some 'diverse' students were not prepared for higher education. Overall, research participants felt that the issue of student diversity and how to develop their teaching practice to embrace it were not adequately included in teacher development programmes.

Also in the UK, Tomalin (2007) argues that teachers work with an increasingly diverse student population without sufficient support, training and resources. She surveyed higher education staff about cultural and religious diversity and found that many were concerned that a lack of sufficient knowledge about different cultures and religions could lead to ineffective teaching or unintentional discrimination. Research respondents talked about the challenges they faced, appropriate teaching and learning approaches, student participation, and institutional support. Tomalin concluded that her respondents placed a positive value 
on diversity but that the implications of cultural and religious diversity had not been taken seriously within their institutions.

Robson and Turner (2007) held discussions with academic staff in a UK university to reflect on teaching and learning in an internationalized faculty. The majority of participants were positive about the increasing diversity of students, believing it enriches teaching and learning. However, some perceived international students as a burden, voicing concern about the additional time and effort involved in supporting these students. Participants discussed the internationalisation of programme content and their teaching experiences and pedagogical approaches. Overall, they felt there was little time to reflect on teaching diverse students or adapt pedagogical approaches to consider diverse student needs, and the authors conclude that that there is a need for ongoing staff development opportunities based on reflective dialogue to facilitate the development of inclusive learning environments.

These research studies focus on teachers as individuals and as members of collegial communities, and most noted the importance of institutional support for academic staff in teaching diverse students. Some also reflected on the socio-political contexts of teachers' practice. The methods used by these researchers involved closed and open-ended questionnaires, interviews and/or focus groups. The analyses all appear to be contentbased, identifying themes and issues related to the research questions. The reporting of these studies takes a realist approach, and does not discuss the interpretive strategies or partiality of participants, the reflexivity of the researcher, or the methodological limitations of the research. They present a snapshot of 'how things are around here', reinforcing a dominant humanist ${ }^{7}$ model of responsible teachers who care about their (diverse) students (Claiborne \& Cornforth, 2010). Only Zepke and Leach (2007) and Tomalin (2007) provide theoretical discussions that identify conceptual approaches to understanding and responding to student diversity and open up space for critical analysis. In particular, Zepke and Leach discuss the power relationships inherent in notions of diversity and in teaching relationships.

\footnotetext{
${ }^{7}$ Humanism is described by St. Pierre and Pillow $(2000$, p. 5) as a grand theory that describes "the truth of things", in which individuals with a stable unified self use rational thinking to seek objective and universal knowledge and create a better world.
} 
At this point I need to note that while my research question focuses on diversity of students, it must be remembered that university teachers are also diverse individuals with different social group identities, such as ethnicity, age and gender, who therefore experience their work differently. Studies have identified differences in rates of representation, status and rank, approaches to curriculum and pedagogy, encounters with students and relationships with colleagues (Chesler \& Young, 2007). These differences occur within academic institutions where middle-class white male 'culture' is often privileged and provides the context within which individual teachers encounter and respond to diverse students. Those who teach in universities tend to have succeeded in the university system, and decisions about teaching and learning processes often reflect teachers' own learning preferences (Ritter, 2007). Because universities tend to reflect social power dynamics, they construct hierarchical positions among their members (Mayuzumi et al., 2007), and therefore teachers themselves are embedded in relations of power and discourses of diversity.

\subsection{Perspectives of diversity in the literature}

\subsubsection{Introduction}

In this thesis I analyse how study participants understand and talk about 'diversity', so before I do this I need to look at the literature in higher education to find how 'diversity' is talked about by academics and researchers in higher education. I have identified five different perspectives: assimilation, inclusion, critical transformative, post-structural and 'managing diversity' approaches. However, it is important to be aware that in defining these perspectives I am making generalisations and imposing labels on a range of attitudes and practices, and that the boundaries between these perspectives are "porous, merged and inseparable at points" (Zepke \& Leach, 2007, p. 666). Moreover, if diversity is a relational concept and therefore dynamic rather than static (Burbules, 1997; Young, 1990), the imposition of categories is always arbitrary and approximate, and in the interests of those who categorize. 


\subsubsection{Assimilation perspectives of student diversity}

With their European cultural heritage, New Zealand universities traditionally expected students enrolling in degrees to conform to their "institutional and pedagogic norms, values and practices" (Zepke \& Leach, 2007, p. 656). Widening participation in higher education means that a greater diversity of students has enrolled in university study. In seeking to address this increasing diversity, many discussions of student diversity in higher education literature focus on "headcounts of minority groups in the institution" (Mayuzumi et al., 2007, p. 581). In assimilation perspectives, diversity is usually viewed in terms of access to tertiary education and the inclusion of students from traditionally underrepresented social groups, but once diversity enters into the university it is then 'normalised' (Parker, 2007), in other words diverse students are expected to conform to the prevailing norms of Western academic culture and when necessary be given assistance to do so. In this deficit view of diversity, diversity is tolerated and managed as an 'add-on' to existing pedagogies and institutional practices (Tomalin, 2007) where the 'problem' is located within the student and remedial support is offered. This view of diversity as a deficit to be overcome is common (Haggis, 2006), and Zepke (2008) notes that even when institutions and teachers acknowledge diversity in their policies and discussions, they may still use curricula and teaching practices that act to socialise students into the norm of Westernised views of the world. Tomalin (2007) notes that teaching informed by assimilation perspectives tends to be didactic or teacher-led.

There were few articles in recent academic literature that supported or drew on an assimilation perspective of diversity, and those I did find focused on student performance or retention. One example is an Australian study by McKenzie and Schweitzer (2001) that looked at factors predicting academic performance in first year university students. This research identified personal characteristics of students, such as previous academic performance, self-efficacy and employment responsibilities, as well as integration into university as factors predictive of students' grades. The authors suggest that these findings can help improve the targeting of interventions and support for students with academic problems, and recommend that interventions to promote academic achievement are included in processes of integration into the university. A report by Prebble et al. (2004) that examined over 250 research studies about student support found that a majority of these studies identified difficulties students had adjusting to the independent learning 
required at tertiary level. Some studies called for teaching methods to assist the independent learning of students while others called for flexibility in teaching methods to cater for the needs of diverse students. This report stresses the importance of integrating students into higher education institutions.

There are a number of writers who take a conservative approach to assimilation that places a negative value on student diversity, most often writing outside of mainstream education journals. Some educators are alarmed by the increasing multiculturalism of higher education, concerned that it leads to erosion of standards and 'dumbing down' (Nieli, 2008), moral relativism (Irwin, 1996), cultural relativism and marginalisation of the scientific method (Windshuttle, 1997) and restrictions on academic freedom due to political correctness (Closson, 2002; Kerr, 1998). Some writers raise concerns that antidiscrimination and social justice-based pedagogies indoctrinate students (Wright, Ratliff \& Neal, 2006) while others are worried that affirmative action in universities leads to tension, conflict and separation between identity groups (Nieli, 2008). There are also calls for a return to traditional Western knowledge and academic values (Irwin, 1996; Wright et al., 2006).

In what I refer to as a progressive approach to assimilation, educators with positive views of diversity use assimilation as a strategy to enable students to succeed in higher education. They do this by teaching students to understand the nature of a specific academic discipline and master its practices (Haggis, 2006), to participate in unfamiliar professional discourses such as teaching (Suárez, 2008) or care professions (Northedge, 2003) in order to gain cultural and academic capital, or to value cultural diversity and increase student engagement with higher-level cognitive skills by using research-based teaching (Deakins, 2009). While the approaches of these educators loosely comes under the assimilation label, they involve a critical understanding of institutional barriers and power relations in higher education, and are thus linked to inclusion and critical transformative perspectives of diversity. 


\subsubsection{Inclusion perspectives}

Those who have an inclusion perspective of diversity seek to include all students in higher education, not simply by assimilating them into prevailing institutional culture and practices, but by considering how institutions and teachers can adapt their practices to meet the needs of these diverse learners. Higher education institutions recognize and accept students' existing cultural capital (socio-cultural identities, knowledges and ways of working), and teachers attempt to find ways to value diversity by adapting their teaching to be inclusive of the varied cultural capital that students bring into the classroom (Zepke \& Leach, 2007). Inclusion perspectives in education emphasize "dynamic, reciprocal changes in people's understandings and behaviour" (Claiborne \& Smith, 2006, p. 83), and differences between students, such as ethnicity, socioeconomic class, disability, age, prior educational experience, and approaches to learning, are acknowledged and valued in the classroom. Teachers tend to employ student-centred pedagogies to meet student needs and create learning environments that embrace student diversity (Tomalin, 2007), they celebrate difference and promote variety in learning, teaching and research styles (Badley, 2007), avoid "norming, labelling and pathologising learners" (O’Neill, Bourke \& Kearney, 2009 , p. 589), and acknowledge benefits of diversity for students, such as exposure to alternative viewpoints, more complex discussions and a broadened perspective (Castañada, 2004).

In New Zealand there has been an increasing focus on inclusive practices in education to provide learning environments enabling students with impairments to achieve (Claiborne \& Smith, 2006). Informing most New Zealand policy is a social model of disability that emphasizes external barriers as the cause of disability rather than individual deficits, but there is little research in New Zealand on how teaching practices impact on tertiary students with impairments. Claiborne and Cornforth (2010) discuss research undertaken at a New Zealand university which found a discrepancy between what teachers thought were best ways for teaching students with impairments, and what students with impairments wanted from teachers. For teachers, inclusion involved encouraging students to disclose impairments and being empathetic and helpful about students' learning needs; however students with impairments expressed ambivalence about self-disclosure and frustration about available technologies and staff ability to use these to make lectures accessible. Claiborne and Cornforth note that "diversity has its own expertise" (p. 259) and Thomas 
(1999) suggests that the embodied knowledges of disabled people need to be valued and have much to offer all people. Matthews (2009) considers that UK universities need to introduce a range of inclusive teaching strategies as part of everyday practice, and found in her research that raising teachers' and students' awareness of the social model of disability helped promoted inclusion. She recommends that teachers have access to clear and comprehensive information about their responsibilities for teaching students with impairments and the resources available to them.

Skelton (2002) points to the need to appreciate different cultural ideas about what constitutes appropriate knowledge and how it is produced and legitimated. He suggests that inclusive learning environments allow students to engage with and explore through dialogue a wide range of knowledges. Parker (2007) asks if academic staff can rethink their programmes to allow diverse students, such as those with autism or dyslexia, to engage differently with course content and assessments. She argues that universities should appreciate diverse intelligences and systems of knowledge production, and that this can lead to new questions being asked and the development of new knowledge. Chanock (2010) argues that Western assumptions about knowledge, the self, learning and manners can silence non-Western students, and teachers need to recognize and appreciate different forms of speaking and writing practices. Ryan and Viete (2009) and Zhou, Knoke and Sakamoto (2005) argue that non-Western linguistic and cultural knowledges are marginalised in classrooms, and argue for the inclusion of diverse knowledges and pedagogical practices. Barrington (2004) suggests that incorporating the theory of multiple intelligences into teaching and learning could improve the learning of students with diverse abilities. However, moving away from traditional academic forms of knowledge, addressing marginalised viewpoints and challenging normative assumptions and practices can be difficult in practice (Skelton, 2002).

The internationalisation of higher education offers opportunities for inclusive responses to student diversity. Instead of the current focus on how international students can be enabled to succeed academically—a deficit approach—educators could also explore how international students can contribute to an enhanced curriculum. Universities could internationalise all students by "educating them for a globally connected and culturally diverse world" (Asmar, 2005, p. 291), and use more imaginative pedagogies to equip all students to work in culturally diverse environments. An approach that promotes 
intercultural learning recognizes that cultural diversity is complex. It also recognizes a wide variation in international students' ability to communicate in English and acknowledges the increasing use of English as an International Language (EIL), both socially and professionally (Ippolito, 2007). The internationalisation of higher education has the potential to bring academic and social benefits to all students.

One particular pedagogical approach that is often referred to in the literature to support inclusion of diverse students is that of student-centred (or learner-centred) teaching. Hockings et al. (2009) maintain this approach is more able to engage academically diverse students than teacher-led approaches, and Zepke, Leach and Prebble (2006) suggest it improves student retention. In a student-centred approach, the teacher is seen as a facilitator of learning and designer of learning experiences rather than an instructor (Cheong, 2008; Weimer, 2002), and the student becomes a partner in the learning experience (Cullen \& Harris, 2009) and responsible for their own learning (Weimer, 2002). A feature of the student-centred classroom is the fostering of community through group work and other opportunities for students to learn from one another, as opposed to viewing the teacher as the single source of knowledge (Cullen \& Harris, 2009). Zepke et al. (2006, p. 593) describe a student-centred environment as "ensuring students feel valued, fairly treated and safe, and welcoming their diverse cultural capital." However, although student-centred and teacher-led pedagogies are usually portrayed as opposing poles of a continuum, Elen et al. (2007) found the students they surveyed saw studentcentredness and teacher-centredness as mutually reinforcing. When combined, these approaches could contribute to a high quality learning environment that "provides challenges with proper safeguards; it encourages students to work independently while concurrently providing ample support” (Elen et al., 2007, p. 115).

Institutional factors are also important for improving inclusion of diverse students in higher education. According to Tomalin (2007), research suggests that while teachers attempted to employ inclusive pedagogies to ensure participation of all students, many higher education institutions have an assimilationist attitude to diversity. Benseman et al. (2006) argue that it is the responsibility of institutions to provide educational facilities that will help non-traditional students succeed. They found that appropriate programmes for Pasifika students tended to have student-centred teaching that provides academic and social engagement between learners and teachers, a commitment to high achievement 
standards, the provision of academic support processes, access to resources and accessible pastoral care, and the provision of accurate, appropriate and timely information about academic options. In research on a programme to facilitate the development and implementation of inclusive policies in ten UK higher education institutions, May and Bridger (2010) found that a multi-pronged and systematic approach that included many stakeholder groups was needed to bring about a consistent uptake of inclusive practices across an institution. In particular, student input helped convince staff of the need for changes, and changing the language used (words, phrases or messages) helped promote an inclusive culture. They concluded that change is needed at both institutional and individual levels to bring about inclusive policies and practices.

While inclusion perspectives focus on how higher education teachers and institutions can adapt to provide effective teaching and learning environments for an increasingly diverse student body, there is often a deficit view of 'diverse' students implied within these perspectives. It is still about solving a problem (Reynolds \& Trehan, 2001), even if the outcome is acknowledged as being beneficial for all students. Too often inclusion is about accommodation and toleration (Chawla \& Rodriguez, 2007); however students want more than to be tolerated. Students want "to contribute to an enriched learning environment for themselves, their peers and perhaps even their teachers" (Asmar, 2005, p. 307). This means that there is a need to go beyond deficit approaches to diversity and inclusion perspectives that leave the dominant Western educational aims and values unchallenged or ignore the ways higher education might "perpetuate oppressive social and economic structures and relations" (Nunan et al., 2000, p. 65). Perspectives of diversity that challenge higher education institutions and staff to acknowledge their roles in perpetuating social injustice and in possibilities for transformation must be considered.

\subsubsection{Critical transformative perspectives}

While a focus on improving teachers' and institutions' practices to include diverse students is important, a lack of analysis of deeper assumptions and values means that change is limited (Haggis, 2006). In particular, there can be a lack of analysis of power relations involved in diversity, as "diversity is not only a powerful concept; it is a concept of power" (Zepke \& Leach, 2007, p. 664). Critical transformative perspectives are concerned with 
exposing how the practices of the dominant culture foster inequality and oppression, and they seek to develop a democratic vision that contributes to social justice. Teachers share knowledge in ways that challenge existing structures of domination both within and beyond the classroom, such as hierarchies of gender, race, class and religion, and they support learning that serves "to educate students for the practice of freedom rather than the maintenance of existing structures of domination" (hooks, 2003, p. 46). Teachers use student-centred pedagogies but also engage in a process of dialogue "to enable students to think critically about issues of power and inequality" (Tomalin, 2007, p. 625). Reynolds and Trehan (2001) describe critical pedagogies as processes of education which question assumptions and taken-for-granted knowledge, make power relations and vested interests transparent, acknowledge the social nature of experience and its authority in developing ideas, and promote the ideal of a society based on justice. Critical transformative perspectives can have an individual focus where students engage in critical reflection and draw on their own diverse identities and backgrounds to understand and change how they are positioned in the world, or a social focus that develops an understanding of relations of power and how social groups can change oppressive social structures (Zepke, 2008).

Influenced by Freire's pedagogy, Baltodano (in Darder, 2002) believes teaching can be a "subversive force and a political calling" (p. 208), which challenges not only students' beliefs and practices but calls into question a teacher's own social and ideological location. With other faculty members, she strives to create democratic classrooms enabling dialogue that supports personal and social empowerment. As teacher educators, they aim to prepare competent and critically aware preservice teachers who can become agents of change and social justice. Dialogue and developing student voice are important in critical transformative educational approaches but Mayuzumi et al. (2007) argue that discussions about diversity should not just be about voice - the ability to speak from differing positions - but also the need to be heard. As Japanese students at a Canadian university, they ask if they are listened to only when they talk about their ethnic background or international perspectives, and challenge educators to consider the notion of diversity within the power relations in higher education and the larger society.

While many teachers using a critical transformative approach promote dialogue across difference, some educators note that social power relations are reproduced in the classroom and these can prevent students from speaking (Ellsworth, 1989). Jones and Jenkins' (2007) 
questioning of who it is that desires dialogue in higher education led them to a different pedagogical approach to student diversity. They divided their undergraduate class into two groups that were taught separately for part of the time: Pakeha and Polynesian (including Māori students). They found that Pakeha students were upset that they were separated from their Māori peers, but most of the Māori students enjoyed the opportunity to develop ideas amongst themselves. Jones and Jenkins consider that, given New Zealand's colonial history, indigenous students may not want to engage in dialogue. Dialogue across difference may be difficult due to political, economic and cultural differences within most societies. In particular, since minority and indigenous students are already familiar with dominant Western views and interests, the value for these students of cross-cultural engagement in the classroom may be minimal compared with the value for students from dominant cultural groups who have less understanding of other cultures. The question is: 'whose needs are being served in cross-cultural engagement?' Jones and Jenkins suggest that parallel rather than joint critical inquiry into relationships between dominant and indigenous or minority groups can offer powerful opportunities for cross-cultural learning.

Another critical transformative approach in New Zealand is that of Kaupapa Māori pedagogies, which question the dominance of Pakeha interests in education and "assert the validity of Māori knowledge, language, custom and practice" (Wilkie, 2006, p. 47). One response to Pakeha dominance has been the establishment of wananga, higher education institutions providing programmes based on knowledge of ahuatanga Māori (Māori tradition) according to tikanga Māori (Māori custom). Another response has been the provision of support services for Māori within mainstream higher education systems. Bringing a Kaupapa Māori framework into higher education institutions can improve the participation and achievement of Māori students. Wilkie discusses a Kaupapa Māori intervention in post-graduate education that supports Māori doctoral students, arguing that the increasing number of Māori graduating with doctoral degrees benefits all of New Zealand.

A critical transformative approach that goes beyond simply including diverse students is proposed by MacDonald and Bernado (2005) who argue that far from being deficient, students whose identities are ignored or devalued by social power systems develop potentially powerful skills for critical inquiry. These authors define diversity as "a continually expanding awareness of the dynamics of difference in regard to social power, 
personal perceptions, and judgments about others" (p.2). They believe that educational practice can be enhanced by drawing on the unique competencies of students who live in multiple worlds, and especially those whose skills and knowledges are marginalized. Because marginalization is a product of social power, those with less power in a given context are more likely to be judged as deficient, but at the same time most likely will understand power dynamics better than those who hold more power. MacDonald and Bernado suggest that students who have creative responses to marginalization and skills to deal with multicultural identities be positioned in the middle of the curriculum to help others learn about power, critical inquiry and multiple perspectives.

Categories of difference such as ethnicity, class, gender, and ability are social constructions. The many ideas about what difference is, and how it is constructed, defined and employed in different contexts emphasize that difference is political (Johnson \& Pihama, 1995). The notion of difference therefore needs to be interrogated (Mayuzumi et al., 2007). It can be understood as inherent qualities within individuals or groups, as divergence from a norm, or as constructed within social relationships. Johnson and Pihama (1995, p. 75) note that "Difference has been constructed in ways which set up groups and individuals in oppositional contrasts to each other." The meaning of difference is only significant in a system where such differences matter; difference is socially constructed and defined from a particular position, usually that of the dominant social or cultural group. The dominant group occupies the positions of a norm against which other groups are measured and found deficient or deviant (Young, 1990). Dominant or privileged groups are perceived in neutral terms, while other groups are marked as different or 'other'. Otherness can be understood as "processes of marginalization in which those with more social power make inclusion/exclusion decisions about others or are unable or unwilling to even acknowledge them" (MacDonald \& Bernado, 2005, p. 3).

Some writers suggest that identity based on categories (such as ethnicity, gender etc.) is a double-edged sword (Humphrey, 1999). Because some identities experience oppression within the dominant Western culture, people who share a particular form of oppressed identity need to group together for safety, healing and celebrating their difference. However, that difference can end up being reinforced and sustained within the society that oppresses the group, and potential alliances with other oppressed groups may be disregarded. This approach fails to recognize the differences within groups, and can fix 
identities instead of realizing the fluid nature of any category (Thomas, 1999; Tomalin, 2007). This form of 'identity politics' can be seen as "reinscribing the very boundaries it seeks to challenge" (Thomas, 1999, p. 114), leading to greater divisions and increased tensions between identity groups (Rata \& Openshaw, 2006). These problems with structural approaches to difference and diversity, along with the awareness of the dynamic nature of identity and the multiple forms of difference that are ascribed to or chosen by individuals, have challenged educators and led to discussions about diversity from poststructural perspectives.

\subsubsection{Poststructural perspectives of diversity}

Poststructural approaches to diversity focus on how identities are generated through language and participation in a culture. Although 'sameness' and 'difference' can be seen as logical opposites, they can also be seen as interdependent, each requiring the other for its meaning (Bowser, Danaher \& Somasundaram, 2007). A relational understanding of difference rejects the idea of difference as a description of attributes of a group and instead sees it as a function of the relations between groups and allows for similarities and overlapping experiences (Young, 1990). In this view, what makes a social group is not who is included or excluded, but a social process of interaction and affinity that acknowledges differences within and across groups without essentializing them. Instead of difference as opposition, difference as variation relativizes the previously universal position of privileged groups. Bird (2004) considers that in order to avoid deficit perspectives that essentialize difference, issues of difference need to be presented as "messy, multiple, complex, and contradictory" (p. 23).

While some social categories may be visible, for example gender, ethnicity, age, and some disabilities, others such as sexual orientation, social class, other disabilities, personal and public identities (for example mother, bereaved person, teacher) may not be visible (D’Cruz, 2007). Members of any particular category will be diverse, they can belong to any number of categories, and these 'differences' involve all sorts of competing interests. A poststructural perspective argues that "vocabularies of difference will inevitably be unstable" (Jones, 2004, p. 281), exposing the fluidity of identities and relationships of privilege and marginality. This perspective understands diversity as a verb rather than a 
noun and rejects the idea of stable categories of difference, exploring how social categories are arbitrary and socially constructed (Chawla \& Rodriguez, 2007). When identities are critiqued and reconstructed, the notion of diversity shifts from static to dynamic, underlining "the dialectic and dual processes of being-made and self-making within the social power relations" (Mayuzumi et al., 2007, p. 582). Differences are perceived by understanding relational patterns rather than identity markers and social categories.

Educators using a poststructural perspective seek to understand diversity in ways that enlarge possibility (Chawla \& Rodriguez, 2007) and against essential categories of diversity that lock people into a set of fixed, mutually exclusive characteristics (Fine $\&$ Weiss, 2005). Instead they recognize the presence of multiple identities within every person, how these are positioned in various ways in relation to dominant cultural expectations, and the need for ongoing inquiry into the diversity of our world. Although poststructural perspectives tend to deconstruct categories such as gender, ethnicity and socio-economic class and focus on intersections between variable, multiple, unstable and contingent identities, some writers are concerned that this ignores power differences and the material effects that people from marginalized groups experience, delegitimizing their struggles for justice. Collins (2000) argues against disconnecting difference from power relations, noting "Individuals from groups that exercise real power run few risks in embracing identities organized around multiple differences, because they know that their power will remain intact" (p. 64). Although they reject 'putting people in boxes', Chawla and Rodriguez (2007) recognize that the social power of the dominant culture ignores, devalues or criticizes those who are different, and they stress the importance of solidarity with those who are marginalized and disenfranchised.

Some higher education teachers are developing new ways of teaching diverse students that draw on poststructural approaches to student diversity. Learning about diversity in higher education has often focused on how diverse groups are different from 'us' and what we need to know not to cause offence, but D'Cruz (2007) rejects this and focuses on exploring the processes of interactions with diverse people and the potential in these interactions to celebrate or oppress difference. Bird's (2004) teaching takes a 'queer' approach to diversity by being open to multiple perspectives in the collaborative construction of knowledge. Rather than focusing on categories of difference, her postgraduate course was framed around intersections of difference and sought to unsettle dualisms such as 
male/female, white/black, straight/gay, abled/disabled where the first term is dominant and the second term is marginalized. She found that a "multifaceted approach to diversity allowed for much open-ended discussion of numerous intersecting issues of oppression" (p. 18), an approach which helped students to see commonalities between positions and the possibility that change could occur through creating bonds and alliances across differences. A poststructural approach to student diversity sees learning as ongoing and situated within the uncertainties and opportunities of educational interactions (D'Cruz, 2007). Lather (1992) argues that educators need to open up the space of academic discourse to recognize "the paradox, complexity and complicity at work in our efforts to understand and change the world" (p. 132), and Kramer-Dahl (1996) reminds teachers that such efforts are always invested with their own political, social and personal interests.

\subsection{6 'Managing diversity' perspectives}

Recently a new perspective of diversity has emerged, influenced by neoliberal market philosophies. In the 1990s, 'managing diversity' became a way to address difference in organizations (Jones, 2004) as they sought to gain by increasing equity among diverse employees (Lumby, 2006). The benefits of staff diversity include improving competitive potential by attracting the best talent and having staff who relate to different market sectors (Jones, 2004), thus diversity becomes, as Thornton (2008, p. 67) explains, "another technology of power to be deployed in the interests of the organisation." Thornton notes that within corporatized universities, diversity becomes an "all-encompassing term" (p. 66) applied to students, staff, courses, and universities as each of these seek to profit from their endeavours. Mirza (2006) argues that this approach to diversity is "less about equity and more about diversity of higher education provision so as to secure the 'best fit' to meet the diverse needs of students, the economy and society" (p. 101). Grice and Humphries (1993, p. 142) contend that 'managing diversity' "promotes particular cultural values as implicitly superior to those of other cultures", in particular corporate cultures that feature market values and scientific management practices ${ }^{8}$.

\footnotetext{
${ }^{8}$ A system of management that involves analysis, classification, measurement and evaluation. When applied to education, programmes are required to set clear outcomes, have the means to ensure these are achieved, have access to dependable information that aids rational decisionmaking, and a system of auditing needs to be in place (Neyland, 2010). Education becomes a service provided for a client at minimum cost and maximum efficiency.
} 
When diversity is managed and valued as a human resource, it becomes something that can be measured through "technologies of audit, inspection and monitoring" (Ahmed \& Swan, 2006, p. 97). It can become a matter of ticking boxes and providing paper trails to indicate good diversity performance by the organization; however Ahmed and Swan argue that this acts to conceal actual inequalities. Because managing diversity draws on a meritocratic argument that seeks to treat everyone equally, ignoring pre-existing inequalities and power differences, issues of discrimination only require attention if they affect the profitability of the organisation (Grice \& Humphries, 1993). In higher education, this approach works to individualize difference and conceal ongoing systematic inequalities. Ahmed (2007) argues that when diversity is what 'others' have, social norms will be reproduced yet hidden from view. Depending on who defines what 'diversity' is and for whom, the notion of diversity can act to reproduce or challenge social privilege. When connected to the ideal of the global university and detached from social justice agendas, diversity can become "another way of 'doing advantage' within the context of globalization" (Ahmed, 2007, p. 244).

Research with post-secondary educational leaders in England by Lumby (2006) found that most respondents focused on personal aspects of diversity such as personality, leadership style, function, and experience, and either rejected or viewed negatively notions of diversity in terms of ethnicity, gender and disability. Lumby draws on a management perspective of diversity to explain her findings, arguing that such thinking allows people to avoid uncomfortable challenges to discrimination, for example racism and sexism, and focus instead on 'acceptable' aspects of difference. This means that power and inequity remain unchallenged and the privileged positions of the dominant group are camouflaged.

Sinclair (2000) argues that in Australian universities, gender issues are being subsumed under "the sexier banner of diversity and globalism" (p. 238). A broad understanding of diversity which includes all dimensions of difference is considered more inclusive, the outcome of which is that everyone is diverse. This trivializes systemic discrimination and marginalizes critical human rights issues, implying that "all differences can be managed according to equivalent processes" (p. 239). Differences of sex, ethnicity, disability and other visible forms of difference are sources of social inequities, yet when diversity is recast as an individual condition to be dealt with by individuals exercising choice, minor 
discomforts and major inequities are rendered equivalent and societal and organisational responsibilities are diminished.

When diversity is something that is embodied by colourful 'others', then the whiteness of organizations is concealed (Ahmed, 2006). In the UK, black and minority female academics are under-represented and marginalized, with campuses remaining “overwhelmingly white" (Jones, 2006, p. 152) and diversity seen as "skin-deep" (Mirza, 2006, p. 103). This enables racism to be maintained in higher education institutions. Topdown policies on equity mean that management and policymakers place responsibility for putting these policies in place on representatives of 'diverse' groups. This leads to high workloads for these staff, rather than sharing the responsibility across all staff (Jones, 2006). The consequences of a managing diversity approach mean that, as Jones argues, "despite increased access and participation, it is evident that inequalities of social class, race, gender and (dis)ability, among others, persist within the system" (pp. 145-146).

While I found a number of critiques of 'managing diversity' perspectives in the literature, unsurprisingly I did not find any articles in education journals that promoted this approach. Some writers did make suggestions about how to respond to managing diversity perspectives. Jones (2004) notes that managing diversity works in "complex and contradictory ways" (p. 281), and critical analysis can show what can be said and what is silenced in this perspective, as well as what possibilities are enabled or prohibited. Sinclair (2000) believes that it is possible to work with a managing diversity framework to critique and interrogate diversity and provide new impetus for equality and democracy in organisations. Since the marketization of universities is likely to continue, it will be interesting to see how notions of diversity are contested and how they inform higher education policies and practices.

\subsection{Conclusion}

The literature shows that diversity in higher education has been theorized and researched extensively, but that there are also gaps in the research. As well as a lack of research on teachers' understandings and experiences of student diversity, there is little that canvases the views of teachers and students which, as Claiborne and Cornforth (2010) show, can 
diverge substantially. Ethnic and cultural diversity dominated the writing I looked at, while issues of gender and disability were also discussed to a lesser degree. There was much less discussion of socio-economic class, sexuality, religion, age, prior learning experiences, and access to technology in higher education. This suggests that, for higher education teachers, the "visible and unmodifiable bases of difference" (Sinclair, 2000, p. 240) produce the greatest challenges and command the most attention.

Inclusion and critical transformative perspectives of diversity dominated the literature I read, but these may not necessarily be the primary perspectives that inform teachers' practices. Those who are accepted for publication in academic journals may hold a great deal of discursive power throughout the field of higher education, or they may have little influence on teachers in their daily practice. My reading was unable to provide any clarification of this. It is important to note that this discussion of perspectives of diversity is limited and simplistic and does not include some of the new or hybrid approaches, such as postcolonial or feminist poststructural perspectives of diversity. However, the perspectives of diversity discussed in this section provide a conceptual framework to assist my analysis of the transcripts of teachers participating in my study. This thesis draws on these perspectives of diversity and the research that has been reviewed here, confirming, rejecting or extending their discussions.

In the literature of higher education, notions of diversity and the experiences of teachers and students are talked about in various ways that shape educational practices and construct teachers and students as particular types of persons. At times, the literature discusses how teachers and students are situated within relationships of power. Less commonly, the literature also discusses how the experiences of teachers and students are embedded in relations of care, and in the next chapter I explore how notions of power and care are conceptualized and discussed in higher education. 


\section{Chapter 4}

\section{Concepts of power and care in the literature}

\subsection{Introduction}

To be a teacher is to be in relationships with students, colleagues, administrators and managers. As Noddings (2003) notes, 'teacher' is not a role, it is a relation. Reflecting on the literature about diversity in the previous chapter leads me to consider how teachers are positioned within relations of power and care and which theoretical frameworks might help understand these relations. Meanings of 'power' and 'care' are often taken-forgranted, but to investigate teachers' experiences of student diversity, I need to take a closer look at these concepts. As Walshaw $(2007$, p. 1) notes, "the conceptual frames we use to make sense of events and practices have consequences for how we go about our work within education." An investigation of power and care in the literature provides conceptual resources for my analysis of study participants' narratives about their experiences of student diversity. I look to the literature of higher education, education more generally, and from fields such as philosophy, politics, sociology, social policy and health.

In this chapter I begin by examining relations of power in education, the various ways 'power' is conceptualized, and dominant theoretical perspectives of power. I then examine relations of care in education and explore the various ways 'care' is conceptualized. While there is a great deal of literature that considers power, there is little written about care in higher education. This means that my examination of care draws more from outside this literature, and does not follow the same format as the discussion of power. I also consider how power and care are linked, and while this has been discussed in the literature in relation to schooling (Noblit, 1993; Parsons, 2001; Sernak, 2004; Uitto \& Syrjälä, 2008), there is a lack of exploration of the links between power and care in higher education. In this chapter, I begin an exploration of relationships between power, care and diversity in higher education. 


\subsection{Relations of power}

\subsubsection{Power in teaching}

Power is enacted within educational relations and produced by narratives of teaching practice. In the literature, many teachers have explored how power is implicated in their teaching practice and their narratives discuss issues such as: how power relations are reproduced within the classroom (Durie, 1996; Ellsworth, 1989; Hart, 1998) and operate in the curriculum (Kramer-Dahl, 1996; Macintosh, 2007; Sonn, 2008); discrimination experienced by non-white university students (Vacarr, 2001) and teachers (Jackson, 1995); student and/or teacher resistance to learning about racism, sexism and other forms of oppression (hooks, 1994; Srivastava, 1997; Ukpokodu, 2002); students' negative responses to teachers' attempts to introduce a more inclusive curriculum (Cochrane-Smith, 2000; Marsh, 2002); conflicts about cultural beliefs and practices (Grace, Gouthro \& Mojab, 2003); who speaks and who remains silent in the classroom (Anderson, Hoy-Mack \& Ross, 2000; Durie, 1996; Ryan \& Viete, 2009; Skelton, 2002); processes of 'Othering' (Koro-Ljungberg, 2007; MacDonald \& Bernardo, 2005); issues of teacher authority (Maher \& Tetreault, 2001; Reynolds \& Trehan, 2001); and opposing views on extra tutorial support for Māori and Pasifika students (Nakhid, 2006). Power may be an abstract concept, but it produces material effects in a variety of ways, some indirect or hidden (Lukes, 2005), and therefore it is necessary to consider how power is conceptualized.

\subsubsection{Conceptualizing 'power'}

The notion of power has multiple, diverse and contestable meanings that develop and function within particular moral and political perspectives (Lukes, 2005). Some very general definitions include power as "the production of causal effects" (Scott, 2001, p. 1) and as "the ability or capacities of an actor or set of actors to act" (Allen, 1999, p. 127). This suggests a first conceptualization of power, that of power-as-agency. Scott defines agency as the ability to "exercise causal powers that produce specific effects in the world" (2001, p. 1). Agency is usually considered a humanist notion; it is associated with autonomy and assumes a unitary, rational subject able to make choices (Davies, 1991), and is widely critiqued. However, the notion of agency underlies much of educational theory 
and practice (Usher et al., 1997), and when seen as the power to act and produce effects, agents need not necessarily be rational and autonomous.

Another common conceptualization is of power-as-domination. Scott (2001) explains that power occurs in a social relation between a principal, who exercises power, and a subaltern, who is affected by this power. Scott states that power relations must involve intention to produce particular effects, however, Allen (1999) argues that when considering what she refers to as 'power-over', it needs to be acknowledged that power can be exercised unintentionally when principals act in routine or unconsidered ways without awareness of the effects they bring about. Domination can occur not only on the interpersonal level, but also within institutional relationships, existing where "power is structured into the stable and enduring social relations that make up large-scale social structures....working through institutions to produce regular and persistent patterns of action" (Scott, 2001, p. 16). This means that power-as-domination occurs when it furthers, or does not harm, the interests of the powerful while producing negative consequences for the interests of those subject to it (Lukes, 2005). Scott (2001) explains that the anticipated effects of domination mean that a principal may not need to act to wield power. Power can be understood as a capacity that can be held until needed, thus subalterns can experience significant social consequences without intervention from principals.

Power-as-domination involves a conflict of interests, whether overt or covert (Lukes, 2005). Overt power involves external constraints placed on some people by others, whether through force or coercion. Covert power dominates through shaping peoples' beliefs and desires, leading to the adoption of internal constraints. Manipulation can occur when a principal sets the basis of conditions on which subalterns make choices, leading them to act in ways that the principal desires. Persuasive influences operate through signification (defining situations in particular ways) and legitimation (according a normative value to particular ideas or conditions), and this is sometimes known as ideological domination. An ideology can be understood as a set of ideas and beliefs that explain how society works, both in terms of a worldview and a vision of the 'good society' (Heywood, 2003). Ideology is often invisible because it provides the concepts "through which the world becomes intelligible" (p. 13). The notion of hegemony concerns dominant ideas embedded in a system of everyday practices that, while being in the interests of the 
powerful, are willingly taken up by people and seen as 'common sense' (Brookfield, 2005).

In the domination perspective, power occurs in social relations yet is often talked about as though it is a thing that can be possessed and wielded. But a problem arises with both these ways of thinking: if subalterns do not possess power, how are they to exercise the power required to change unequal relationships, and if power is a relation, how can subalterns create change from a subordinate position? Resistance to power involves individuals or collectives acting to challenge, subvert, or overturn systems of domination (Allen, 1999). Overcoming domination involves subalterns gaining knowledge in order to become free, and Freire's (1970) pedagogy of the oppressed is based on this idea. Those who are dominated and exploited internalize their oppressors' view of the world, and need to liberate themselves and their oppressors. Gaining critical awareness of oppression is essential in the struggle for emancipation.

The concept of power-as-domination has been challenged, notably by Foucault (1980; 1995). He argues that power is productive and says,

What makes power hold good, what makes it accepted, is simply the fact that it doesn't only weigh on us as a force that says no, but that it traverses and produces things, it induces pleasure, forms knowledge, produces discourse. It needs to be considered as a productive network which runs through the whole social body, much more than as a negative instance whose function is repression. (1980, p. 119)

For Foucault, power is everywhere; and individuals are vehicles through which power circulates, rather than sites where power is applied. Power is present in all human relations, and Foucault (1987) defines the exercise of power as the means by which individuals attempt to direct the behaviour of others. Power is thus about how "certain actions may structure the field of other possible actions" (Foucault, 2002, p. 343). Power is everpresent and fluid, and how power flows will depend on how different individuals, groups, institutions and discourses "negotiate, relate to and compete with one another" (Danaher, Schirato \& Webb, 2000, p. 80). Foucault (1987) describes states of domination as those in which flows of power are

...firmly set and congealed. When an individual or a social group manages to block a field of relations of power, to render them impassive and invariable and to prevent all reversibility of movement - by means of instruments which can be economic as well as political or military - we are facing what can be called a state of domination. It is certain 
that in such a state the practice of liberty does not exist or exists only unilaterally or is extremely confined and limited. (p. 3)

Dannaher et al. (2000) note that when power is enacted in non-egalitarian ways it acts on both those who dominate and those who are dominated.

Although sovereign power still plays an important role in contemporary societies, Foucault (2002, p. 345) argues that "power relations have been progressively governmentalized, that is to say, elaborated, rationalized, and centralized in the form of, or under the auspices of, state institutions." This concept of governmentality arises from the state's need to manage its population and resources economically and efficiently which requires knowledge of its citizens, thus the population emerges as "a datum, as a field of intervention, and as an objective of governmental techniques" (Foucault, 2002, p. 219). Governmentality involves regulation of citizen's lives by state institutions and discourses, and a need for individuals to be "educated to monitor and regulate their own behaviour" (Danaher et al., 2000, p. xii). Governmentality thus involves not only the state managing its population to ensure cooperation and productivity, but also citizens actively managing and regulating themselves. Governmentality is all-pervasive, constituting the subjectivities of individuals and shaping their actions (Usher et al., 1997). It is not only state governments that exercise this form of power; institutions such as schools and universities govern the daily practices of their members.

According to Foucault, networks of power relations produce 'regimes of truth', which comprise the discourses accepted as true, mechanisms that enable truth and falsehood to be identified, procedures by which truth is acquired, and the status of those who control what counts as truth (Foucault, 1980). Knowledge and power are intertwined: "there is no power relation without the correlative constitution of a field of knowledge, nor any knowledge that does not presuppose and constitute at the same time power relations" (Foucault, 1975/1995, p. 27). Foucault uses the term power/knowledge to emphasize this. Usher et al. (1997) explain that

Through knowledge or systematic thought, an aspect of the world is 'domained' into being, made the object of thought, and becomes a 'reality' which can be talked about, systematised, theorised, researched and evaluated. In effect an aspect of the world is knowledgeably discoursed into being. (p. 74) 
Truth is therefore not an absolute or essential meaning, but "a thing of this world" (Foucault, 2002, p. 131). Knowledge and the systems of power that produce it, as well as the effects of power that knowledge induces, form 'regimes of truth'. Foucault argues that it is impossible to liberate truth from systems of power; instead we need to identify how truth is produced.

Foucault's notion of disciplinary power has been very influential in recent academic writing. Usher et al. (1997) note that 'discipline' has two meanings, as regulatory power and as a particular body of knowledge. In disciplinary power, these meanings are brought together. Regimes of truth and surveillance combine to produce a disciplinary field that normalizes as it "compares, differentiates, hierarchizes, homogenizes, excludes" (Foucault, 1975/1995, p. 183). The human sciences in particular act as instruments of normalisation, continually persuading people into 'correct' forms of thinking and acting. Through practices of observation, surveillance and examination, disciplinary power renders persons as knowable subjects, and thus "discipline 'makes' individuals" (p. 170). Foucault's work undermines humanist notions of an agentic, autonomous and essential self, replacing this self with a subject who is produced by discourses, institutional practices and technologies of power. Individuals can identify these disciplinary processes and resist or challenge them. They can also employ what Foucault termed 'technologies of the self' (Sarup, 1996). These technologies

...permit individuals to effect by their own means a number of operations on their own bodies and souls, thoughts, conduct, and way of being so as to transform themselves in order to attain a certain state of happiness, purity, wisdom, perfection or immortality. (Foucault in Martin, Gutman \& Hutton, 1988, p. 18)

Through technologies of the self, individuals reinvent themselves and formulate tactics to live as best they can.

Notions of power-as-agency or domination and views of power as productive or disciplinary underlie different perspectives of power in higher education literature. However, these conceptualizations all lie within Western cultural constructions of knowledge and power. There are many other ways to understand power. For example, the Māori concept of tino rangatiratanga, or the principle of relative autonomy, involves control over one's life and cultural well-being (Bishop \& Glynn, 1999). The concept of whakamana is about the capacity to empower and involves effective leadership, advocacy 
and liaison to ensure access to and development of resources and assistance to enter the wider society (Durie, 1997). However my lack of knowledge of te reo Māori (Māori language) and kaupapa Māori (Māori ways of doing, thinking and being (Henry, 1999)) means that I cannot speak about Māori conceptions of power with any authority. In fact, trying to describe a particular cultural construct (power) in terms of another culture's language and worldview may not only be difficult (perhaps impossible), it may also be a form of colonization whereby I, as a Pakeha academic, appropriate Māori knowledge for my own purposes. Thus I wish to acknowledge here that there are other important perspectives of power that I do not include in my discussion and which limit it. However, the benefit of focusing on Western concepts of power (and care and diversity) in this thesis enables me to engage in critical analysis of my own culture and offer this to readers of all cultures to discuss, debate, critique, reject or elaborate in continuing educational conversations that aim to lead to greater cultural understanding and social justice.

\subsubsection{Theoretical perspectives of power in the literature}

In the higher education literature, I found that discussions of power have mostly been articulated within three broad theoretical perspectives: humanist, critical and poststructural (Brookfield, 2005; Kilgore, 2001). As well, there are many feminist analyses of power in higher education drawing from, or critiquing, these perspectives (e.g. Maher \& Tetreault, 2001; Tisdall, 1998). Postcolonial (e.g. Preece, Modise \& Mosweunyane, 2008) and indigenous (e.g. Bishop \& Glynn, 1999) perspectives of power are increasingly being articulated. Because humanist, critical and poststructural perspectives dominated the literature I read, I focus on these three and consider how notions of power as agency, domination, resistance, power/knowledge, and disciplinary power are produced within these perspectives. This analysis of the theoretical perspectives within which power is discussed in the literature informs my analysis of how power is found within, and produced by, study participants' narratives.

Power-as-agency is often linked to the notion of empowerment. Liberal humanist perspectives of empowerment focus on individual growth and learning, underpinned by a belief in the possibility and desirability of becoming what one is capable of becoming, that is, in reaching one's human potential (Merriam et al., 2007). Empowerment occurs through 
revealing and dissolving the blockages that prevent a realization of an individual's authentic self (Inglis, 1997). By drawing on experience to construct knowledge in a supportive environment (Tisdall 1998), individuals become self-directing and autonomous (MacKeracher, 2004). Becoming empowered involves gaining in self-confidence and selfexpression (Inglis, 1997), whereby a person can 'come to voice' (Tisdall, 1998) and express their personal truth. The notion of empowerment has been criticised, with Inglis (1997) noting that it is about individuals developing the capacities to act successfully within existing structures of power. This focus on individual needs and interests ignores structural inequities and cultural or socio-economic differences (Tisdall, 1998).

To challenge structural inequities, critical theories aim to expose how dominant ideologies limit and circumscribe people's lives (Brookfield, 2005). This knowledge encourages people to strive for emancipation by "critically analysing, resisting and challenging structures of power" (Inglis, 1997, p. 4). Critical approaches draw on notions of power-asdomination and the resistance to such power. In education, they analyse the historical, sociocultural and economic contexts of learning and teaching, and question assumptions about knowledge such as what counts as knowledge and who decides this, and how knowledge is acquired (Merriam et al., 2007). Critical approaches analyse social structures such as race, class and gender and their intersections, and seek to transform oppressive structures and practices within education. Because critical educators view power as repressive and reinforced by hegemony, learning involves critical reflection on hegemonic knowledge and participation in creating emancipatory knowledge that serves human interests more democratically (Kilgore, 2001) and liberates the voices of marginalised groups (Kramer-Dahl, 1996).

Critical perspectives of power have been critiqued by educators, with Tisdall (1998) suggesting there is an overemphasis on social structures and a downplaying of individual agency, and Brookfield (2005) noting that a critical perspective can become another orthodoxy claiming truth and universality. Ellsworth (1989) asserts that practices of critical pedagogy perpetuate relations of domination. She notes that despite intentions to empower students through dialogue, teachers and students come into the classroom with multiple social positionings that are subjective, partial and partisan. Orner (1992) questions attempts to empower students to articulate their own knowledge and calls for analysis of "whose interests are served when student speak is needed" (p. 87). She suggests that 
poststructuralist theories can provide tools for analysing local mechanisms of power and possibilities for change.

Many educators have drawn on ideas from Foucault and other poststructuralist philosophers to explore how power and knowledge are produced within educational settings. Because power is exercised rather than possessed, post-structural educators consider how power offers productive opportunities as well as oppressive constraints (Kilgore, 2001). This approach enables educators to analyse how power circulates in micro-contexts such as classrooms (Brookfield, 2005; Gore, 1998), and how it constitutes students and teachers as particular kinds of subjects (Davies, 2000; Usher et al., 1997). The notion of positionality refers to how "people are defined not in terms of fixed identities, but by their location within shifting networks of relationships, which can be analyzed and changed" (Maher \& Tetreault, 2001, p. 164). Poststructural educators consider their own subject positions as well as those of their students and how these produce relations of power in the classroom. Drawing on Foucault's (1980) notion of power/knowledge, they understand knowledge as "tentative, fragmented, multifaceted, and not necessarily rational" (Kilgore, 2001, p. 54), produced and legitimated within relations of power. Bodies of knowledge are disciplines that can be both systems of regulation and tools of enablement. Pedagogy is an exercise of power, and supposedly democratic forms of teaching such as classroom discussion and learning journals involve disciplinary power through the surveillance of students' learning and the overt and covert reinforcing of norms (Brookfield, 2005). Disciplinary power is productive, and Gore (1998) notes that in educational settings, techniques such as normalization, exclusion, classification and individualization work to construct knowledge, relationships, and particular subjectivities. The pervasive functioning of disciplinary power in everyday practices remains largely invisible, and it is through making it visible that educators can look for possibilities for change.

However, poststructural perspectives also raise difficulties for educators. Challenges to certainty and rationality can be confusing and disempowering for some educators, and others note it offers few suggestions for practice (Merriam et al., 2007). Post-structural philosophers are sometimes seen to have an academic agenda of "relativist deconstructions and abstracted theory" (Ramazanoglu \& Holland, 2002, p. 97) that appears to have little to do with everyday experience. Marginalized social groups question the deconstruction of 
identity that is a part of poststructural thought, arguing that it undercuts the political activism of previously silenced groups (Tisdall, 1998), for example African-American women (Collins, 2000) and third world peoples (Sawicki, 1994). Some educators have responded to these criticisms by continuing to explore forms of post-structural thought and linking these to other critical pedagogies such as feminist pedagogies (Durie, 1996; Tisdall, 1998). Power in higher education remains a contested notion, and teachers' understanding and experience of their classroom and departmental relations may seem distant from such theoretical debates in academic literature.

\subsubsection{Discussion}

This analysis of power is by necessity limited in scope and depth. The term 'power' is used widely within the higher education literature and often its meaning is assumed, thus scrutiny is required to reveal the different ways power is conceptualized. This enables me to analyse participating teachers' narratives about student diversity to see how they might construct power as agency, as domination and/or resistance, as power/knowledge, or as disciplinary power, and what the implications of such constructions might be. In the literature, discussions of power are also situated within broader theoretical frameworks. Humanist, critical and poststructural theoretical perspectives dominate the literature of higher education, and because university teachers are 'disciplined' by the field of higher education, these dominant theoretical frameworks are relevant for understanding 'power' in study participants' narratives about student diversity. Notions of diversity, as noted in the previous chapter, position people within relations of power; what counts as difference and the consequences arising from this matter (Johnson \& Pihama, 1995). Analysis of participants' narratives will also consider how relations of power situate the narrator within webs of educational relationships with students, colleagues, and institutions, and how these relations enable and constrain their practice. My analysis also enables me to consider how participants' narratives are exercises in power, and I am reminded that my position as researcher and interviewer is also embedded within and constructed out of relations of power.

Most writing on power in higher education ignores relations of care, which raises questions about why this might be so. Educators who write about power may be unaware 
of the literature on care, especially that which is outside the field of education. Care is often seen as part of the private realm and issues of power as belonging to the public realm, thus care could be seen as irrelevant. As well, care may be considered something that only children need, and that apart from occasionally seeking pastoral care, adult students are deemed independent or learning to become independent (both in learning and in their wider lives). Much of the writing on power is explicitly political, and while many, especially feminist writers, argue that care is also political, it generally remains invisible in political discussions. I now turn to the literature to explore how care is conceptualized.

\subsection{Relations of care}

\subsubsection{Care in teaching}

Care is an issue given much less attention in the higher education literature, and care is not a high profile area for research in higher education (Walker, Gleaves \& Grey, 2006). Some educational literature looks at care in education from the perspective of teacher concern for students' wellbeing. In her development of an ethic of caring, Noddings (2003) argues for "the maintenance and enhancement of caring as the primary aim of education" (p. 174).

She considers that intellectual learning can be achieved through various means but if these do not occur within relationships of care, then the teaching has failed the student. The student must realize that he or she is more important than the subject being taught. Likewise, Daloz (1999) believes that teaching is an act of care that involves nurturing the conditions in which trust and agency can occur. Research by Rossiter (1999a) with graduate students found that for these students, caring relationships were central to the learning process. Saavedra and Saavedra (2007) describe teaching behaviours that create a caring classroom climate essential in their teaching practice with minority students, such as getting to know students and creating a safe climate for communication. Care involves not just supporting students but also questioning and challenging them (Daloz, 1999; O'Brien, 2010), and can encompass empathy, cultural responsiveness and social justice (Walker et al., 2006). I concur with Gomez, Allen and Clinton (2004) who argue that theorizing care is important in understanding how teaching can promote the development and sustenance of students and teachers. 
In education, care is often viewed as a disposition of teachers or a way of conducting interpersonal relationships, but Gomez et al. (2004) argue that care involves personal, cultural, and institutional relations. They also note that teachers' gendered, cultural, ethnic and socioeconomic positions impact on how they enact care in their teaching. Female teachers are often more likely to be seen as nurturing and to engage in the pastoral care of students (Walker et al., 2006), and the ways care is enacted vary across cultures (Sernak, 2004; Thompson, 1998). A widening of participation in higher education has meant that a diverse body of students often needs more academic and pastoral support than university timetabling and support networks provide, consequently teachers undertake considerable amounts of 'caring work' (Walker et al., 2006). Teaching has traditionally been seen as a caring profession that emphasizes teachers' care for students but ignores other caring relationships and does not consider who cares for the carers. Institutional structures and discourses impact on teachers' caring (O'Connor, 2006; Walker et al., 2006), and Rossiter (1999a) suggests that teachers are more able to develop caring relationships with students and colleagues if they feel sufficiently cared for themselves and are valued and secure within their institution and, as O'Brien (2010) recommends, not regarded merely as an interchangeable component of the market economy. Rossiter and O'Brien consider that when a university fosters individualism and competition between staff, it can be difficult for a caring community to thrive.

Creating caring communities in the classroom and teaching students to care for each other has been discussed by teacher educators as they prepare students to become caring teachers (Gomez et al., 2004; Lake, Jones \& Dagli, 2004; Noblit, 1993; Rogers \& Webb, 1991). Goldstein (2002) considers that caring for students in teacher education must include interpersonal commitment, being part of a community of learners, and being passionate about the creative and intellectual aspects of teaching. Walker et al. (2006) note that it takes nurturing and attention to create classroom communities, and Meachem (1999) discusses how, in order to participate in an increasingly diverse world, students need to learn to care not only for each other within their own communities but also to care for those who are different. This is not merely about tolerating difference - as an African American student noted, "When I hear you talk about tolerance, I hear you telling me that I am something to be put up with" (Vacarr, 2001, p. 286) — but is, Meachem (1999) argues, about respecting and attempting to understand difference and supporting and defending those whose difference is denigrated. Care is based on a shared responsibility to ensure 
that all people can live fulfilling lives, yet it is often a disregarded aspect of university teachers' work (Walker et al., 2006).

\subsubsection{Conceptualizing 'care'}

How care is conceptualized varies, and yet most of the educational literature takes the notion of care for granted. I turn to literature from philosophy, political science and sociology as well as education to find out the different ways 'care' is theorized. Care is a “complex cultural construction" (Tronto, 1994, p. 124), with no agreement on what the terms means (Held, 2006) or how it should be put into practice (Hollway, 2006). Yet giving and receiving care forms a large part of people's lives and care is essential for sustaining life (Tronto, 1994). Held (2006) stresses that

...without care, there will be no human beings. Infants will not survive, and, unless they receive much more than a minimum of food and shelter, children will not develop at all well, even if they survive. To grow into adequately healthy persons, children need to be valued for their own sakes, to experience relations in which large amounts of loving attention are shared between caretakers and children. They need to be cared for responsibly as they develop the social relations into which they were born. Adults need to be engage in daily activities of caring for themselves and others to continue to exist or to live decently. (p. 133)

Care is essential for human societies, and at the individual level the experience of being cared for is essential for developing the capacity to care for others (Hollway, 2006). The personal experience of caring relations is necessary for the creation of caring relations in the public sphere (Bowden, 1997), and social conditions that enable care are necessary for the caring of individuals (Held, 2006).

Writers on care agree about its importance; however there are differing definitions of the term care, and varying descriptions of how care is practiced. Tronto (1994) provides a broad definition of what constitutes care. It consists of the activities that people do to ...maintain, continue, and repair our 'world' so that we can live in it as well as possible. That world includes our bodies, our selves, and our environment, all of which we seek to interweave in a complex, life-sustaining web. (p. 103)

This definition suggests that care is a common and widespread activity, and goes beyond simply meeting needs. The metaphor it provides - a 'life-sustaining web' — has the 
potential to enable care to be theorized beyond the contexts of care-giver and care-receiver dyads, however discussions of care more often focus on carers responding to the needs of others, and I begin by considering this perspective. Baines, Evans and Neysmith (1991, p. 11) refer to care as "the mental, emotional and physical effort involved in looking after, responding to, and supporting others." In considering how this is achieved, Clement (1996) describes care as having two components: "apprehending the reality of the other, and helping the other the best one can" (p. 35). Noddings (2003) explains the first component further.

Caring involves stepping out of one's own personal frame of reference into the other's. When we care, we consider the other's point of view, his objective needs, and what he expects of us. Our attention, our mental engrossment is on the cared-for, not on ourselves. Our reasons for acting, then, have to do both with the other's wants and desires and with the objective elements of his problematic situation. (p. 24)

Clement (1996) notes that while helping others requires apprehending their reality, we do not necessarily have to accept that reality.

Noddings (2003) describes caring as a relationship between the one-caring and the caredfor. This means that care is not only about what the one-caring does to meet the needs of the cared-for, but is also about the response of the cared-for. Noddings considers that a caring relation requires the cared-for to receive and recognize the care given as care (and not something else such as control or guilt), and if this does not happen, then the relation is not a caring one even though the one-caring believes he/she is acting with care. Phillips and Benner (1994) explain that those receiving care

are called upon to trust and appreciate the help that is offered. That, too, requires attentiveness, attunement, learning, and the relinquishing of obstructive control for the sake of care. (p. viii).

This model of care which is built around the care-giver/care-receiver dyad has been criticised as involving "isolated demand-response relations" (Bowden, 1997, p. 38) that position the cared-for as needy and thus deficient in some way. It has also been criticised for focusing on personal relations and ignoring the wider social contexts and asymmetrical power relations that care is constructed and enacted within (Hoagland, 1991). A paternalistic form of care objectifies the one cared-for and can "justify or conceal relationships of power and domination" (Narayan, 1995). Care, therefore, includes a political dimension. 
In her theorizing of care, Tronto (1994) aims to integrate the practical, moral and political aspects of care in society. She argues that care is not necessarily dyadic; it is an ongoing part of the processes of everyday life. Tronto also gives a detailed model of caring relations, describing four separate but interconnected phases of care:

caring about, noticing the need to care in the first place; taking care of, assuming responsibility for care; care-giving, the actual work of care that needs to be done; and care-receiving, the response of that which is cared for to the care. (p. 127)

Caring about is the recognition that care is needed. Attentiveness is necessary to recognize the needs that require care, and Tronto notes that a lack of attentiveness can lead to many social problems being ignored. Taking care of involves taking responsibility for the need that has been identified. It considers whether a need is able to be taken care of, and how this might happen. Care-giving involves meeting the needs for care, the 'doing' of care. Competence is needed for carers to provide good care. The care provided may be inadequate and not meet the needs it is responding to, and sometimes this may be due to insufficient resources available to caregivers. Care-receiving requires the responsiveness of the one cared-for, and provides caregivers with the means to know if the needs have been met. Tronto argues that the practice of care requires more than just good intentions; it is a practice that involves thought and action, is culturally shaped, and involves making judgements about how to respond to needs that may be conflicting.

Tronto (1994) looks at the way caring is distributed in society, noting that care work is gendered, raced and classed. She observes that caring-about and taking-care-of are often done by the powerful (for example doctors), while care-giving and care-receiving are the domain of the less powerful (nurses doing the hands-on care work). Held (2006, p. 69) notes that "providing care has always fallen disproportionately to women and minorities, who do the bulk of unpaid or badly paid actual work of caring for those needing it," thus marginalizing and devaluing care work. Caring helps to reinforce privilege when those who are powerful have their needs met by others. Caregivers are devalued because their needs are less important than the needs of those privileged enough to be able to pay others to care for them (Tronto, 1994).

Care is also devalued by being associated with vulnerability, emotion, and the private sphere. When autonomy and independence are socially valued and neediness seen as a burden, the reality of human interdependence will be denied and care will be marginalized. 
Sevenhuijsen (1998) argues that dependence on care is an integral part of human experience, and caring relationships occur in political contexts. Public dialogue and collective support are needed to avoid reducing care to private charity. Sevenhuijsen's notion of caring solidarity acknowledges that people are differently situated and aims to understand and enable "what people in particular situations need in order for them to live with dignity" (p. 147), thus placing diversity at its centre. Because people need support at expected and unexpected times in their lives, the notion of solidarity is needed to ensure social and political commitment to providing care when needed. Caring solidarity enables differently situated individuals to put their trust in political decision-making without always needing to be involved.

Another criticism of the caregiver/care-receiver dyad model of care concerns what Clement (1996) describes as the individualism of interests, which occurs when one's own interests are considered to be "sharply distinct from the interests of others" (p. 33). Clement argues that people are socially constituted and that "recognizing the extent to which our interests are interdependent with those we care for allows us to find ways to meet the needs of self and other, rather than one at the other's expense" (p. 35). Gilligan's (1982) ethic of care argues that a mature understanding of care is characterised by an understanding of the interconnectedness of self and others where care becomes a selfchosen principle informing both personal relationships and social concerns. Held (2006) also considers that those in caring relations act for self and other together, which is neither egotistical nor altruistic, and she reminds us to consider the well-being of the caring relation itself as well as those involved in the relation. This relational understanding of care opens up "the possibility of mutual realization, not a power discourse in which one person gives, helps, and does not learn from the other, while the other person merely receives and learns" (Phillips \& Benner, 1994, p. viii). Care can be transformative, it can shape persons with greater social understanding and the abilities to live cooperatively with others (Held, 2006), and thus "in the best caring practices both the community and the individual serve and are preserved" (Phillips \& Benner, 1994, p. viii).

Hoagland (1991) criticises the unequal relationships that are the focus of many models of care and a lack of critique of power in these models, and considers how care might be expressed in more egalitarian relationships. For Bowden (1997), looking at the complexity and variety of caring practices in friendships offers the potential to extend our 
understanding of care. Friendship is less structured and less formal than other types of caring such as mothering or nursing, but is more fragile due to a lack of a "supporting framework of rights and obligations" (p. 79). Porter (1996) argues that friendship is essential for everyday wellbeing, requiring "thoughtfulness, a considerateness of care, a concern for others, an attentiveness to others' needs, and careful reasoned thinking” ( $p$. 72). Aristotle's notion of philia provides one model of friendship that involves mutual concern and shared affection. It requires "mutual recognition of each person's separate character and well-being" (Bowden, 1997, p. 64) and fosters each others' enduring good. This enables the flourishing of the fullest expression of a person. The reciprocal selfdisclosure of friendship builds attachment, support, trust, and loyalty, and philia acts as a source of self-validation, self-understanding, and self esteem. Bowden also notes that care between friends involves "recognition and commitment to the intertwined values of attachment and autonomy" (p. 84). Sevenhuijsen (2000) suggests that discussions of care need to be extended from modernist forms of care that are based on familial care to a consideration of "postmodern caring practices situated in different social domains and in a diversity of lifestyles" (p. 30). Care would then be understood as a daily human activity undertaken in both public and private domains that enables and supports human flourishing.

\subsubsection{Contexts of care}

Much of the academic theorizing on care has been done by white feminists, who in many cases have not considered how care is culturally constructed. In Māori culture, manaakitia - the capacity to care - encompasses caring for children, the elderly and the sick with love and compassion (Durie, 1997). Manaakitia involves responsiveness to and responsibility for the less able, and acts to maintain the well-being not only of the individual but also of the whole whanau (extended family), thus caring is a communal activity ${ }^{9}$. African American writers have also exposed cultural assumptions that underlie a 'colourblind' approach to understanding care (Thompson, 1998), arguing that caring is both a public and private undertaking that involves commitment to recognizing and

\footnotetext{
${ }^{9}$ There is much more to understanding forms of care in Māori culture than what I have provided here, however as a Pakeha researcher with limited knowledge of Māori culture, I am unable to give a comprehensive and accurate discussion of care in this context.
} 
addressing differences and inequities through culturally affirming practices of care (Knight, 2004). Such communal and political caring "is deeply contextual, responsive to particular instances of injustice, and tied to concrete action" (Beauboeuf-Lafontant, 2005, p. 443). Caring-as-activism means that teachers see themselves as agents of change both individually and as part of a collective of teachers, administrators, students and communities. Beauboeuf-Lafontant (2008) argues that an assumption that good intentions lead to good actions means that the nature and purpose of one's caring are not interrogated, and social inequities may be conceptualized as problems located in certain students who need to be 'fixed'. Yet research with six African American teachers found that their caring involved "a combination of affect and advocacy focused on removing the human-made barriers to a student's range of choices" (Beauboeuf-Lafontant, 2005, p. 442). Just as other theorists of care note that it is always relational, Knight (2004) calls for a radical relationality which proposes that

...the split between the mind-body-spirit of humanity cannot remain as the relationships between teachers and students facilitate the academic, personal, social development of both the teacher and the student. Radical relationality also indicates a shift beyond the self-actualization of an individual and a community to a vision inclusive of a moral responsibility and accountability to one another (p. 224)

Radical relationality links the personal with the political within caring relations.

Claiborne and Cornforth (2010) argue that pastoral care, which involves teachers or other professionals supporting the wellbeing of students, often positions students as deficient in some way and in need of empowerment from 'experts'. Research by Claiborne et al. (in press) at a New Zealand university found that teachers who participated in their research understood caring as supporting the social inclusion of students, and willingly gave extra time to build relationships with students with impairments and support them through individual coaching. The students with impairments, however, spoke to the researchers about the need for appropriate technology and resources for their learning, and were often frustrated when these were not available or teachers did not have adequate technological skills. Claiborne et al. argue that a humanistic construction of care as warm feelings and social inclusion focused on developing supportive relationships renders invisible the technical competence of students with impairments and the barriers to learning they face. Their research indicates that caring for students with impairments (and, I would argue, all students) involves removing the barriers to learning as much as is possible and advocating 
for the resources that students need. In contrast, a focus on social inclusion suggests that students are excluded, thus positioning them as 'Other' and needing to be brought into the fold. Claiborne et al. (in press) ask, "Is it really the goal of inclusion to keep people feeling comfortable with their lot?" A caring-as-activism response would be a resounding "No".

\subsubsection{Care for oneself}

The discussion thus far has focused on caring in relationships. At this point it is productive to consider ideas about caring for one's self. Noddings (2003) believes that her ethic of care has no difficulty in promoting a "deep and steady caring for the self" (p. 99). An ethic of care is about maintaining a caring attitude and so that must always include the self, especially because to care for others, caregivers must pay attention to their own needs. As Noddings notes, "to go on sacrificing bitterly, grudgingly, is not to be one-caring" (p. 105). Other writers on care have also noted the interdependence of care for the self and care for others (e.g. Clement, 1996; Hollway, 2006; Koehn, 1998; Phillips \& Benner, 1994). This interdependence does not mean there are no conflicts between the needs of self and other. Hollway (2006) notes that conflicts can arise between caring for someone else and doing something for oneself, but this is a practical issue and does not negate the fact that one's own interests are linked to others' interests. Care for the self may also be difficult when caregivers lack resources and support, and Held (2006) argues that caring can become a burden when inadequate social assistance is provided.

Although it has been discussed in relation to models of care, there has been little written specifically about care for the self. Foucault is one writer who has addressed this, and his notion of care of the self came from his analysis of early Greek and Roman societies where the duty of the individual was to perfect the self through undertaking self-examination and gaining self-knowledge (Foucault, 1988). This was not only for self-improvement but also for the betterment of society. Thus, a person "who cared for himself correctly found himself, by that very fact, in a measure to behave correctly in relationship to others and for others" (Foucault, 1987, p. 7). Those who exercised a "tyrannical power" (p. 8) over others were slaves to their passions, and therefore not correctly caring for their selves. Care of the self required attention to the mind and the body, and could involve examining one's 
thoughts and actions, undertaking health regimens and physical exercise, seeking advice, and fulfilling one's social responsibilities (Foucault, 1988). It

...took the form of an attitude, a mode of behaviour; it became instilled in ways of living; it evolved into procedures, practices, and formulas that people reflected on, developed, perfected, and taught. It thus came to constitute a social practice, giving rise to relationships between individuals, to exchanges and communications, and at times even to institutions. (p. 45)

Care of the self enabled the formation of an ethical self and led to self-mastery and an enjoyment of the self "without desire and without disturbance" (Foucault, 1988, p. 68). De Marzio (2007) notes that it is important to distinguish between self-indulgence and care of the self, between "care for values external to the self, such as wealth, power, and prestige, and genuine care of the self, the continual quest for self-knowledge and learning" (p. 125). Care of the self for the ancient Greeks and Romans was about working on oneself to better oneself and gain wisdom.

In his later writings, Foucault argued that although selves are constituted through practices which are determined by social contexts, individuals mediate these through active processes of self-fashioning (Sarup, 1996). This leads to an 'aesthetics of existence' which aims to make one's life a work of art. There is much criticism of this idea, not least because, like the free male citizens of Greek and Roman societies, it is the elite who have the time and resources to cultivate the self. However, Sarup notes that Foucault could be seen as removing his aesthetics of self from a cultural elite and making it available to everyone. Foucault's notion of the care of the self offers a way for individuals to "resist the normalising effects of disciplinary power" (Sarup, 1996, p. 88) as well as a means to effect a power over the self that will regulate one's power over others (Foucault, 1987). The changes Foucault documents in ideas about care of the self can remind us today that how we construct, care for and regulate the self is open to analysis and change, and care of the self offers a way for educators to consider how 'technologies of the self' are enacted in classrooms (Golden, 1996).

Drawing on Foucault, Murray (2007) suggests that care of the self can be understood as a self-self relation that is open and inventive and questioning of the norms and constraints that produce the self. It is an ethical relation because it is concerned with how individuals live their lives, how one "conducts oneself with respect to oneself, others, and to the world 
in general" (n.p.). It offers an alternative to the notion of an ethical self that exists as "a preconstituted and self-contained, autonomous entity who would then use care as a technology" (n.p.), an alternative that understands the self as constituted in and by relations of care. If education is "a process of self-discovery, self-critique, and selfenlargement" (Moore, 2006, p. 107), Foucault's care of the self is a useful concept for teachers. Roach (1987) suggests that contemplation on the question 'Who am I?' will not be encouraged in a world that values techniques and quick fixes and which leads individuals to focus on the question 'what can I do?' Such an instrumental relationship of self to self is exemplified by discourses of 'self-care'.

Self-care is a concept drawn mainly from the health sector. Turp (2004, p. 109) describes self-care as "an individual's active concern for his or her physical safety, comfort, and wellbeing." Small (1993) notes that self-care encompasses all aspects of life and not just health, for example educational, social, vocational, and financial well-being, while DeFriese and Konrad (1993) point out that activities of self-care require social as well as personal resources. Self-care is prompted by the desire to maintain control of life with competence, autonomy, and self-reliance (DeFriese \& Konrad, 1993) and is based on a liberal humanist model of the self that is rational, autonomous, and the source of its own agency. This emphasis on the autonomous individual in discourses of self-care depoliticizes and privatizes the effects of social, political and historical power (Murray, 2007). Evans and Payne (2008) argue that the individual responsibility promoted by notions of self-care together with an increase in attempts by the state to micromanage issues related to physical and mental well-being "constitute a new societal discourse of growing intolerance toward specific behaviours and general lifestyles seen as threatening to present health or future longevity" (p. 328). This will affect professionals who are expected to maintain an adequate work-life balance and manage the stresses they experience in their work. DeFriese and Konrad (1993) suggest that the 'self-care movement' responds to the opportunities and necessities of wider cultural trends, so it will be interesting to see if the current neo-liberal responses to economic pressures promote discourses and practices of self-care in New Zealand society and how this might influence those who work in higher education. 


\subsubsection{Discussion}

This section on care has shown that it is conceptualized in various ways with the writers discussed above considering care primarily as a social practice rather than a disposition or virtue. Although caring-about may not involve actual care-giving, if a person says they care about something or someone but does not take any form of action, it will be difficult to accept that they really do care (for example if I care about climate change but do not consider my own use of energy resources). Care as a practice undertaken in a dyadic relationship between care-giver and care-receiver(s) is a common, perhaps the dominant, construction of care, one that implies unequal power relations and ignores the agency of those receiving care. However, this construction of care is extended by those who argue that relations of care can be mutual, they can enhance the interests of both care-giver and care-receiver, that those who are needy or dependent can also care for their care-givers, and that care for the self is important both in its own right and as a part of caring for others. Care also needs to be theorized as a political concept and practice. Who gives and who receives care matters in a society that promotes independence and autonomy and devalues dependence and neediness. Too often those who care for others are materially disadvantaged, demonstrating how relations of care have material effects. When we consider that individuals, such as teachers, are embedded within multiple relationships and contexts, notions of care can be extended to these relations. It can be surmised that, in taking time to do the interviews and reflect on their practice, the teachers in my study care about their students, their teaching, their field of study, their institutions, and my research. The different forms of care discussed in this chapter could, and should, be acknowledged as an integral part of all social life, and in the case of higher education, as a web of care that enables teaching and learning to take place.

In considering how care might be produced by study participants' narratives, I look at how the relationships they describe respond to needs and/or promote well-being. The terms 'needs' and 'well-being' can have various meanings, and these meanings are produced within caring relations and the contexts these relations are enacted in, and influenced by the perspectives of participants in the caring relations. For example, when the needs of a hearing-impaired student are viewed from a humanist perspective, teachers may enact care differently than if the needs are viewed from a critical perspective. It is important also to consider who defines the 'needs' being cared for, and whose needs matter. Caring relations 
include caring for self, for others and for our physical and social environment. Care theories often present an ideal picture of care, but those involved in care relations may have conflicting views of the care being practiced and the needs responded to, they may construct the notion of care differently, and practices of care may not always be appreciated. However, the relational nature of care means that it involves ongoing communication between those in caring relationships, which helps address these conflicts.

Another aspect of care that is important to consider is how participants in caring relations are conceptualized. In an individualist perspective they will be situated along a continuum of dependency, with high dependency at one end and independence at the other and understood as separate individuals who have caring relationships. Humanist perspectives of education stressing autonomy and self-direction (Usher et al., 1997) generally take such an individualist perspective. In a relational perspective, participants in caring relations will be understood as interdependent, even though their activities in caring relations will vary. In other words, both care-giving and care-receiving activities are engaged in by most people, and both care-giving and care-receiving can be experienced by an individual concurrently. If care is essential for human life to survive and to flourish, then it is worth investigating in all aspects of social life, including higher education. And if education involves "a process of discovering, analysing, critiquing, deepening, and transforming relationships with community and culture" (Moore, 2006, p. 109), then relations of care will acquire greater significance.

\subsection{Theoretical perspectives of care and links to power}

Earlier in this chapter, I identified three theoretical perspectives and discussed how power is produced talked about within these. There is very little higher education literature that considers how care is situated within these perspectives. However, it is possible to look at the different conceptualizations of care and consider how they might relate to humanist, critical and poststructural perspectives of higher education. Discussions of mentoring in higher education (Daloz, 1999), ways to nurture caring teacher-student relationships (O’Brien, 2010), supporting students to develop to their full human potential (Fitzmaurice, 2008), and care as a pedagogic action to raise students expectations of their own academic achievement (Walker et al., 2006), suggest care as care-giving and care-receiving. This 
form of care, along with pastoral care and self-care, aligns with humanist perspectives of education that aim to facilitate personal learning, support student autonomy and assist students to develop to their human potential (MacKeracher, 2004). Such practices of care enable power-as-agency, as individuals seek to improve themselves and live more effectively in their world.

A critical perspective of education seeks social change and collective empowerment (Usher et al., 1997). It aims to assist students to acquire awareness of social structures and injustices, and through this knowledge act to create a more just society. Aligning with this perspective, caring solidarity involves collective deliberation and decision-making about caring relationships in society, and caring-as-activism includes such actions as questioning power relations, providing advocacy, and working for social justice. These forms of care are based on the interdependence of all people and link care with social justice, acknowledging that relations of care are relations of power. hooks (2003) argues that teachers who care usually work within educational institutions that are based on power-asdomination, or in her words, dominator culture. She believes that caring teachers act as 'enlightened witnesses' for students, challenging dominator culture and offering alternative models of interaction. She says,

Committed acts of caring let all students know that the purpose of education is not to dominate, or prepare them to be dominators, but rather to create the conditions for freedom. (p. 92)

A caring educational environment values openness and dialogue, and fosters hope. It links care with power-as-resistance.

Care has received little discussion within poststructural perspectives. Caring as a practice occurring within diverse and dynamic relationships is mentioned by Sevenhuijsen (2000), however, I have found very little discussion of care from a poststructural perspective in the higher education literature. Foucault's (1988) care of the self fits within a poststructural perspective, and De Marzio (2007) suggests that care of the self can assist students to develop self-knowledge and wisdom. However care of the self and other forms of care can be subject to disciplinary power that shapes how they are enacted. Forms of care can also act as disciplinary power that enable and constrain educational practices. Considering the fluidity of identity and the multiple positioning of all people emphasized by poststructural perspectives (Davies, 1991) suggests that diversity is inherent in all relations. From a 
poststructural perspective, intersections of power and care in educational relations occur when teachers and students create classroom communities and negotiate their positions within these, when they construct and contest power/knowledge about matters that they care about, and when roles of teacher and learner are interchangeable and seen as belonging to all members of a classroom community.

Care and power interact in other ways. Because vulnerability and neediness are devalued in our society, care is seen as the concern of those who are less powerful (Tronto, 1994). Care in higher education is less valued than other aspects of teaching (Walker et al., 2006). It is related to seniority, with junior faculty staff more likely to actively care for students (O'Brien, 2010). Care is also gendered, with female academics more likely to be seen as nurturing and providing pastoral care to students than male academics (Walker et al., 2006). A devaluation of care is experienced by care-receivers as well as care-givers. Tronto (1994) notes that those who lack autonomy and need care can be objectified and seen as 'Other'. Such 'Othering' is 'filtered through existing structures of sexism and racism" (p. 124). This suggests that those who differ from the norm, such as 'diverse' students, can be disempowered through caring pedagogical practices that position diversity as a deficit. Throughout my analyses of participating teachers' narratives, I need to be alert to how power and care interact in ways that enable and/or constrain the well-being of teachers and students.

\subsection{Conclusion}

The discussions of power and care in this chapter provide background information for this research, but more importantly, they provide conceptual resources for analysing teachers' narratives. The previous chapter identified ways 'diversity' is talked about in higher education, and this chapter has examined notions of power and care. The various conceptualizations of power and care both enable and constrain how educational relations are spoken about and enacted. Teachers' relationships with diverse students will involve power and care, and this thesis brings power, care, and diversity together in order to consider what kinds of relationships are, and might be, enacted in higher education teaching. If notions of power and care are social constructions, this means that taken-forgranted and other possible ways of understanding these concepts need to be examined, not 
only for data analysis in this research, but also to inform educational practice. Education is a social practice and, as Bauman (2007) points out, what is made by humans can be remade, and this thesis aims to inform the theory and practice of teaching in higher education. The next chapter explains the research methodology and procedures employed in this study. 


\section{Chapter 5}

\section{Constructing the study: Research theory and methods}

\subsection{Introduction}

Investigating the social world is a complex undertaking, and any study needs to make clear the methodology that informs how the study is designed and conducted. As Riessman (1993) notes, any methodological approach is "partial, incomplete, and historically contingent" (p. 70). For this study of university teachers' understanding and experience of student diversity, I needed a methodology that is consistent with, and brings together, my underlying philosophical stance and my choice of narrative as an analytical tool, and one that enables me to answer my research questions. I begin this chapter with an explanation of the relational ontology and epistemology that informs the design of my research, and the importance of being reflexive ${ }^{10}$ throughout the research process. I then discuss narrative inquiry and methods of analysis. As indicated in Chapter One, a dilemma regarding a desire to both represent teachers' 'voices' and critically analyse these voices exposed a methodological incompatibility that I address in this section. I draw on a hermeneutics of faith and a hermeneutics of suspicion (Josselson, 2004) and explain how I combine these. The next section in this chapter discusses key elements of the research design, while the final section describes the procedures used in this study to collect data and addresses ethical issues for this research.

\subsection{Methodological underpinnings}

\subsubsection{Qualitative research}

In this thesis, I am investigating an aspect of the social world: higher education. My research approach is therefore guided by how best I can investigate this complex field in

\footnotetext{
${ }^{10}$ Earlier in the thesis I talked about teachers' reflection on practice, in which teachers think about, and construct meaning from, their practice. This is a common strategy in education, and assumes that it is possible to look at one's practice from a distance (D'Cruz, Gillingham \& Melendez, 2007). Reflexivity understands the self as an integral part of any practice, and in the research process this requires that a researcher's subjective involvement be acknowledged and critiqued.
} 
order to answer my research questions. Researchers understand their world through broad theoretical paradigms that structure their research and provide a set of basic beliefs or premises that guide their actions (Denzin \& Lincoln, 2008a). This qualitative study is underpinned by an interpretivist paradigm which is based on the assumptions that people actively construct and are constructed by their social world, that events and behaviour are embedded in contexts, and people make meanings of and through actions (Cohen et al., 2000). Constructions of reality are not true in an absolute sense but are "more or less informed and/or sophisticated" (Guba \& Lincoln, 1998, p. 206), and events and actions have multiple interpretations and perspectives. Therefore this study does not provide definitive and generalisable findings, but aims to offer insights into a specific aspect of higher education in a particular context and promote reflection and discussion by educators.

Teachers work in contexts involving the interaction of complex human beings immersed in diverse social and linguistic cultures where questions of meaning are paramount (Grimmett, Erikson, Mackinnon \& Riecken, 1990), and qualitative researchers recognise that we need to understand "the meanings that construct and are constructed by interactive human behaviour" (Usher et al., 1997, p. 181). Because people make meaning of their experiences through interpretive frameworks, all interpretations are relative to that framework and so are partial and perspective-bound. Scott and Usher (1999) note that interpretation is always prejudiced in the sense that it occurs through a pre-understanding, the interpretive framework that we bring to any experience. This circular quality of interpretation means that the construction of knowledge is best viewed as iterative, more spiral than linear, and that "explanations of social action must always remain indeterminate" (Scott \& Usher, 1999, p. 27). It also means that knowledge, including research findings, is co-constructed in social contexts that are local and particular, and is therefore always partial, incomplete and contestable and does not lend itself to generalizations. Rather than seeking truth, qualitative research aims to enlarge our understanding (Richardson, 2000). 


\subsubsection{Relational ontology}

All research is formed within ontological and epistemological perspectives. The ontological aspect of a research paradigm considers the nature of reality and the nature of human beings (Denzin \& Lincoln, 2008b). In this research, my understanding of the social world is informed by a relational ontology which begins with the assumption that relationships are primary. This means that anything (including human beings) is real only in relation to other beings or things (Bingham \& Sidorkin, 2004). Something that is not in relationship with anything else in the universe cannot exist, therefore relations form the "underlying fabric of the world, while things are but knots of relationality" (Sidorkin, 2002, p. 95). A relational ontology challenges essentialist ideas that phenomena are entities with a separate existence from their environment, and overcomes "the Cartesian split between the object and the subject, the person and the world, the knower and the known" (Stetsenko, 2008, p. 477). Every organism, including human beings, has a shared existence as facets of a unified reality and cannot be understood as separate and autonomous. The 'self' is an abstraction according to Sidorkin (2002), who describes it as

...the point of intersection of a multitude of relations. It has constancy and coherence to the extent that multiple relations have points of connection and intersection. The self is a means of connection among relations. In a certain sense, the self can be understood as a relation among multiple human relations. It is a meeting point, a place of interaction of various relations. (pp. 96- 97)

Noddings (2003) agrees that it is relations, not individuals, that are ontologically basic, and that individuality can only be defined within a set of relations. Gergen (1999, n.p.) describes selves as multiple-partials, "constituted by multiple facets, each reflecting a different domain of human conception, and each representing but a partial aspect of the whole", and identity is therefore a relational achievement. People can only understand who they are in relation to others. A relational ontology has a non-essentialist view of the self, and just as relations are fluid and dynamic, so too are relational selves.

Diversity is integral to a relational ontology. Because totally identical entities cannot relate to each other, relations are only possible in the presence of difference, and thus relation involves a meaningful connection resulting from plurality (Sidorkin, 2002). Identity is developed from the recognition of differences and similarities between ourselves and others (Watson, 2006). Gilligan (1982) explains that we know ourselves as separate only 
through living in relation to others, and at the same time "we experience relationships only insofar as we differentiate other from self' (p. 63). Gilligan uses the metaphor of a web of relations that involve difference, and posits that hierarchical ordering of relationships destroys the interconnections of the web, leading to inequality. Difference in itself is not the cause of inequality and social injustice; it is disparities in power and value placed on various differences that lead to injustices. To think about society relationally, Somers (1994) uses the idea of a relational setting which she defines as

... a pattern of relationships among institutions, public narratives, and social practices. As such it is a relational matrix, a social network. Identity-formation takes shape within these relational settings of contested but patterned relations among narratives, people, and institutions. (p. 626)

This notion of a relational setting is useful for this research, allowing me to consider the relations teachers are embedded in, both personal and institutional.

A relational ontology is a way of understanding the world rather than an ethical value; relations are seen as primary but these relations are not necessarily good (Bingham \& Sidorkin, 2004) and can be caring or exploitative. While the importance of relationships has been recognized by many writers and theorists in education and other social sciences, discussions of relational ontology are uncommon. Most often teachers and students are conceptualized as individuals who have relations rather than who are relations. Bingham (2004) notes that human actions are generally thought of in individualistic terms, and bringing a relational ontology to educational thinking and practice is very difficult. Although I attempt to think relationally in this research, I nevertheless continually fall into the more habitual and comfortable ways of thinking and writing that conceptualize self and society in individual, essentialist terms. Thus this study explores the taken-for-granted everyday ways of thinking and talking about diversity, teachers, students and teaching and considers how these can be reconceptualised relationally. A relational ontology has important implications for conceptualizing and studying phenomena in the social world, such as the self and identity and also knowledge (Stetsenko, 2008). I turn now to relational epistemology and how it is appropriate for this research. 


\subsubsection{Constructing knowledge relationally}

In a relational epistemology, knowledge is understood to be "socially constructed by embedded and embodied people who are in relations with each other and their greater environment" (Thayer-Bacon, 2004, p. 166). Because people do not exist independently, teachers and researchers can never take themselves out of educational or research relations to gain an objective viewpoint. Instead, people construct knowledge in relation with others and their environment. As people enlarge their connections with others and their world and further develop their understandings, they are able to create new meanings for their experiences. Such a relational epistemology is based on an assumption of fallibilityknowledge can never be complete and correct, and criteria and standards for evaluating knowledge are socially constructed. A relational epistemology "strives for awareness of context and values, and seeks to tolerate vagueness and ambiguities" (Thayer-Bacon, 2004, p. 166). The knowledge people construct is pluralistic, not only because there is no final answer to their inquiries, but also because knowers, as relational beings, are a limited and partial aspect of a greater whole, meaning that inquirers need to be "open and inclusive of others who help us compensate for our own limitations" (p. 166).

Biesta (2004) notes that communication among people is "not about information but about meaning” (p. 13). In this study, I understand human beings as meaning makers who construct knowledge relationally with individuals and groups, with cultural texts, with environments (physical, social, cultural), and with self (memories, thoughts and feelings). These relations all involve engaging with difference, opening people to new discoveries and challenges that can unsettle and require letting go of common sense ways of thinking (Moore, 2006). This approach acknowledges that human language and actions have no intrinsic or authentic meaning but acquire their meaning within specific relations (Bingham \& Sidorkin, 2004). Knowledge about relations is always partial and limited and can only be gained through dialogue; it exists as collective knowledge and is not a result of dialogue but is a process of dialogue (Sidorkin, 2002). This creates a 'polyphonic knowledge' whereby many voices are engaged in an ongoing complex dialogue. While this thesis is my writing, it is the weaving together of a multitude of narratives as I engage with the transcripts of my interviews and with the literature. A relational epistemology reminds me that it is through relations with others that I construct knowledge, and also deconstruct 
or unsettle that knowledge in order to ensure that my enquiry remains open, flexible and dynamic.

\subsubsection{Reflexivity}

Research is a social practice that is embedded and embodied (Scott \& Usher, 1999), and therefore researchers are part of the social world they investigate and cannot remove themselves from it. Researchers are socio-culturally and historically situated and cannot have a 'God's-eye' view (Usher et al., 1997). A reflexive stance is required for qualitative studies such as this research. Etherington (2004) describes reflexivity as "the capacity of the researcher to acknowledge how their own experiences and contexts (which might be fluid and changing) inform the process and outcomes of inquiry" (pp. 31-32). This means that critical reflection on the consequences of the researcher's presence in the research process (Ramazanoglu \& Holland, 2002) is necessary and should be made visible. As researcher, I need to consider how I am located and how this might inform this study. Being a mature female Pakeha $\mathrm{PhD}$ student with a particular life history undertaking a research study in a particular place and time (New Zealand, 2007-2011) and possessing certain skills, knowledge, values and interpretive frameworks means I bring a particular and partial viewpoint to this study. Throughout the research process, I am embedded in a complex and dynamic web of relations with study participants, academic communities, and the literature and other forms of knowledge production in the field of higher education. Thus I need to critically reflect on the research process as it unfolds. Usher et al. (1997) suggest that as researcher I ask: Why am I doing this research? How has this research been constructed? What is it silent about? What gives my thesis its narrative authority? What relationships of power produce the research and how does the thesis reproduce these relations? Throughout this thesis I consider these questions and attempt to make visible the assumptions underlying my own and others' constructions of knowledge.

It is important to recognise that power relations are involved in the research process. As a researcher I have made choices about research questions, theoretical frameworks, data collection methods and analyses. Even when researchers are oriented to participants' points of view, their analyses reflect their own interests, choices and concerns (Chase, 1996). Researchers are enabled and constrained by their social and cultural resources and 
the discourses embedded in their academic disciplines, as well as the audience they are writing for (Chase, 2005). Although I attempt to consider my own subjectivity throughout this thesis, any individual researcher's ability to be reflexive is limited, and Ramazanoglu and Holland (2002) suggest that reflexivity needs to be both collective and contested. They note that "At least as an intention, reflexivity opens up possibilities for negotiation over what knowledge claims are made, for whom, why and within what frame of reference" ( $p$. 119). Any knowledge claims I make in this thesis must be recognized as being produced from my own social and academic positions and as partial, historical and informed by my own interests.

\subsection{Narrative inquiry}

\subsubsection{Narratives in research}

There is a great deal written about narrative as a method for gathering and interpreting social data, and there are many approaches to analyzing narratives (Chase, 2005). Narrative research is useful for exploring the meaning that life events have for the person who experiences them. It views reality as "relational, temporal, and continuous" (Clandinin \& Murphy, 2009, p. 599), and explores how this relational reality is storied. Narrative is a fundamental mode of understanding by which people organise and make sense of their experiences (Polkinghorne, 1996), and understand and construct their selves (Rossiter, 1999b). The narratives that people relate about their experiences provide 'thick' description, and analysis of narratives reveals the meanings and interpretations that inform people's decisions and actions. Descriptions of life events provide "a retrospective, interpretive composition that displays past events in the light of current understanding and evaluation of their significance" (Polkinghorne, 1996, p.89). Narratives people tell involve characters who act within a setting, and who have motivations, beliefs, and values.

Time and change are essential elements of a narrative. As Mankowski and Rappaport (2000) note, a story includes a beginning, middle and ending, which cannot be reordered without changing the meaning of the story. Plot therefore involves a connection between elements in a story that is not simply succession, but that creates meaning and enables understanding of a situation (Webster \& Mertova, 2007). In analysis, coding is not used as 
it breaks down the internal features of a story (Mankowski \& Rappaport, 2000). The parts of a narrative can only be understood in reference to the whole, which means that preserving, not fragmenting, storied data enables researchers to explore how narrators tell their experiences and why they tell them the way they do. Narratives told in research interviews are not usually clearly bounded, and so locating them can be a complex interpretive process, and where a researcher chooses to begin and end a narrative will change its shape and meaning (Riessman, 1993).

When people talk about themselves and their lives, they speak within a social context and will shape their talk accordingly. What they say and how they say it will not only be contextually embedded and discursively bound but will also have explicit or implicit purposes. Sharkey (2004) emphasizes that narratives are social practices; people learn to tell stories ${ }^{11}$ that others will listen to and shape their stories in response to their audience and environment. Riessman (1993) considers that social actors seek to persuade themselves and others that they are a good person, and Convery (1999) argues that teachers have a desire to construct moral identities and elicit a sympathetic audience. Researchers need to investigate the ways in which teachers' narratives are 'performed' to understand how and why such narratives are told. This can provide valuable insights into education practices and contexts.

My analysis does not just focus on teachers' personal stories; it recognizes that individual experiences are embedded within social and discursive realities, and that personal stories are constructed from cultural stories (Polkinghorne, 1996; Riessman, 1993). People relate to each other through "a widely accessible (rather then 'shared') cultural repertoire" (Czarniawska, 2004, p. 50), and it is these resources that storytellers "draw on, mobilize, and sometimes struggle over" (Peterson \& Langellier, 2006, p. 177) to construct and perform their personal narratives. A narrative research approach thus allows for analysis of the social construction of selves, relations and experience. My analysis of study participants' narratives identifies different forms of narrative construction to explore the cultural narratives and social resources from which their personal narratives are formed. I

\footnotetext{
${ }^{11}$ While I use the terms narrative and story interchangeably, I mainly use 'narrative' since the word 'story' suggests a fictional creation rather than accounts of personal experience which describe the relationships between events and choices in people's lives and the meanings these have for the narrator (Polkinghorne, 1995)
} 
also consider how teachers' narratives are embedded within larger narratives including higher education narratives and social and political narratives.

\subsubsection{Analysis of narratives}

In narrative methodologies, there are many approaches to analysis. Watson (2006) analyses narratives in terms of content ('what' they contain) and construction ('how' they are formed). Mankowski and Rappaport (2000) add to this the functions or purpose of narratives ('why' they are told), and Peterson and Langellier (2006) describe the recent 'turn to performance' (how narratives are performed). Chase (2005) recommends that researchers firstly listen to the voices within each transcript and then look for themes across interview transcripts, and this is the approach I took. My analysis of the transcripts began by studying the contents of the narratives, investigating their topics and themes. Identifying themes involves looking for topics that are meaningful for the narrator. People often construct narratives about experiences in their lives where there has been some kind of breach between self and society or between an ideal and the real (Reissman, 1993), and this also alerts researchers to thematic material in transcripts.

My analysis of narratives investigates their construction to shed further light on how teachers interpret their experiences of diversity and position themselves within these interpretations. After looking carefully at the transcripts of my interviews with teachers however, I found that they only occasionally provide me with a full and coherent narrative structure, such as Cortazzi’s (1993) model of Setting, Event, Goal, Attempt, Consequence, Reaction and Function. I concur with Mankowski and Rappaport (2000) who note that narrative units are better thought of heuristically rather than as "precise forms that appear with clean boundaries in all settings" (p. 485). As well as identifying narratives of experience, I looked for 'small stories', which Georgakopoulou (2006) explains as "the smallness of talk, where fleeting moments of narrative orientation to the world can be easily missed out on by an analytical lens which only looks out for fully-fledged stories" (p. 123). Chappell et al. (2003) give an example of a very small story narrated in five words by a school principal: "We teach and they learn" (p. 45). This simple statement sequences two events and implies causality between them, and yields information about the identity of the speaker and his interactions with students, and the pedagogical discourse 
he draws on. The small story approach is useful for my analysis of participants' transcripts and has enabled me to consider the relationships teachers are embedded in and the meanings they made from these. As well as identifying narratives within the transcript, I also consider the whole interview as a narrative and look at what kind of story it tells.

My analysis also considers the performance of narratives, what the telling of particular stories achieves. As performances, narratives are socially situated and interactive, produced in a particular setting, for a particular audience and for particular purposes (Chase, 2005). Narrators perform various social actions when telling a story, for example they engage in arguments, putting forward their own views and challenging their interlocutor's views, or they attune their stories to the relational setting and flow of conversation (De Fina \& Georgakopoulou, 2008). As storied actions, narratives are the site of self and identity construction (Smith \& Sparkes, 2008), and are embedded in discourses and constrained by situational and material conditions (Peterson \& Langellier, 2006). Analysing narrative as a performance enables researchers to investigate why narrators tell stories the way they do, and what this can tell them about the subjectivities of narrators and the discursive resources that their narrative performances are produced from.

The transcripts of teachers' interviews provided much data that was not in the form of narratives, but was nevertheless important and addressed the questions I am investigating. Polkinghorne (1995) identifies two types of qualitative data: diachronic and synchronic. Diachronic data contain information about the sequential relationship of events, providing descriptions of these events, actions taken, and the reasons for these actions and their intended effects. Narratives of personal experience contain diachronic data. Synchronic data lack the temporal dimension; instead such data provide categorical answers to the interviewer's questions and information about a situation or the speaker's beliefs. While the analysis of narratives uses primarily diachronic data, in this research the synchronic data provided by participating teachers addressed my research questions and needed to be included in my analysis. I have identified when I have used such data in the analysis chapters.

In the first chapter of this thesis, I identified a dilemma regarding how to analyze and present the 'voice' of research participants. I showed that trying to accurately represent what participants were telling me, that is, allowing their 'voices' to be heard, assumed a 
realist and essentialist epistemology. This contrasts with understandings of narrative as a text or performance that requires an analysis of the effects of language (Davies, 2000) to consider the ways in which 'voices' are produced. In other words, we can view the storyteller as telling a story or as being told by the story (Squire, Andrews \& Tamboukou, 2008). This creates a dilemma that involves being caught between realist and poststructuralist perspectives that are ontologically incompatible. One approach that enabled me to work with these conflicting analytical approaches is discussed by Josselson (2004) who draws on Ricoeur's (1981) ideas of a hermeneutics of faith and a hermeneutics of suspicion. Josselson notes that meanings are essentially indeterminate and can never be grasped directly, and therefore interpretation is necessary. She defines hermeneutics as a system of interpretation, "a disciplined form of moving from text to meaning" (p. 3). The hermeneutics of faith and suspicion was an approach that helped resolve my analytical dilemma, and I use them as analytical lenses for analysing data.

\subsubsection{Hermeneutics of faith}

A hermeneutics of faith begins with an assumption that narrators communicate as best they can their subjective experiences and the meanings they make from them (Josselson, 2004). This approach involves "taking people at their word" (Josselson, 2004, p. 8) and foregrounds narrators' voices rather than the researcher's analytical voice (Chase, 2005). It does not seek 'authentic' accounts of reality but attempts to represent participants' meanings as accurately as possible. Phillips (1994) explains that engaging with a narrative "requires a leap of faith that suspends disbelief in order that what is told can be heard" (p. 10) with listeners immersing themselves in the narrator's world of "time, embodiment, relationships, meaning, and concern" (p. 10). While this process can be filled with opportunities for potential misunderstanding (Josselson, 2004) it nevertheless informs the way interviews are conducted and analysis is undertaken. I began this research project with this approach in mind, though at that stage I did not understand it as a hermeneutics of faith.

Applying a hermeneutics of faith to my transcripts means that I attempt to understand and represent participants' points of view through considering what the transcripts say and how they say it. I bring my own academic knowledge and teaching experience to this task as I 
consider teachers' talk about what is important to them and the meanings they make of their experiences. The questions I seek to answer through this analytic lens include:

- What does the term 'diversity' mean for teachers?

- What experiences do teachers narrate about student diversity?

- What challenges have they encountered?

- What support have they received?

- How has having a diverse student group helped or benefited teachers?

A hermeneutics of faith recognizes, but puts aside, the notion that interpretation occurs at every stage of the research process, that analyses are partial in both senses of the word, and that power dynamics are always present in the research process. Reflexivity for a hermeneutics of faith involves considering how I am involved in the production and interpretation of the transcripts as I attempt to present and explore the subjective and social worlds of research participants. Even with this awareness, a certain level of realism in my writing is inevitable as I attempt to (re)present teachers' viewpoints and concerns as faithfully as I can. The findings that emerge from this process of analysis could be valuable for informing teaching practice and policies.

\subsubsection{Hermeneutics of suspicion}

A hermeneutics of suspicion problematizes participants' narratives and seeks to 'decode' meanings that are disguised (Josselson, 2004). This form of hermeneutics is motivated by "a skepticism towards the given" (p. 3) and turns its attention towards what is concealed, omitted or contradictory in participants' narratives. It asks: What does the text do? This is not about contesting or refuting narrators' meanings but involves looking beyond them, placing the transcript text in a different context (Josselson, 2004) and considering possibilities for novel readings (Czarniawska, 2004). A hermeneutics of suspicion regards accounts of experience as constructions that include omissions and inconsistencies. Reading between the lines can expose taken-for-granted assumptions and attempts at persuasion in the narrative (Josselson, 2004). It can also illuminate relationships depicted in a narrative beyond those the narrator identifies.

In a hermeneutics of suspicion, poststructural analytical tools can be useful for analysing narratives. These consider how an object of study (such as diversity) is constructed 
through language and its social, psychological and material effects (Willig, 2001). This approach questions 'common sense' meanings, asking how these are constructed and in whose interests they work (Weedon, 1997), and considers how texts "make available certain ways-of-seeing the world and certain ways-of-being in the world" (Willig, 2001, p. 107). Teachers' narratives can show how cultural and institutional discourses construct available subject positions (Watson, 2006). This notion of positioning draws from the work of Davies and Harré (1990), who note that discourses provide subject positions and once a person takes up a particular position he or she will see the world through concepts, metaphors, storylines and moral judgements relevant to that discursive positioning. Positioning is relational; as a person takes up a particular positioning he or she invites others into particular positions in ways that elicit agreement or disagreement and more subtle affiliations with, and support of, larger frameworks of meaning (Winslade, 2005).

A hermeneutics of suspicion considers how narratives position the narrator within social, cultural and institutional narratives and available subject positions. The questions I seek to answer through a hermeneutics of suspicion lens include:

- How do participants' narratives construct 'diversity' and 'difference'?

- How do narratives position teachers, their students and their university context?

- What do the narratives avoid saying?

- How are power and care constructed in participants' narratives?

In my analysis, I explore the 'narrative orientations' of participants, how narratives position the teller in relation to students, teaching, their academic community, and the interviewer. Participants' narratives mostly present them in a positive light - even if they make mistakes or are incompetent at times, teachers portray themselves as competent and caring (Convery, 1999). In my analysis I take this into account and look beyond 'cover stories'. Conflicts or gaps that emerge between individual and cultural narratives can lead to the construction of cover stories where teachers may tell particular stories to fit in with how things are supposed to be (Olsen \& Craig, 2005). Narratives are exercises in power (Daya \& Lau, 2007), and in the analysis I consider whose interests are being served by and in teachers' narratives and how they support or resist dominant or marginalized institutional, social and cultural narratives. I also consider what is acceptable to talk about that affirms teacher identity, and what is prohibited, ignored, forgotten, or downplayed that threatens or subverts it. To be reflexive, I need to consider how I might be complicit in the performance of the text and the exercise of power. 
Using a hermeneutics of suspicion involves the researcher re-authoring the meanings of research participants' stories (Josselson, 2004), and this raises ethical issues. In this thesis I need to explain my position in taking the interpretation beyond that of participants, acknowledging when and why I do this, and making clear that the results of this analysis are my own ideas and not those of participants. As Chase (2005) notes, researchers have an authoritative interpretive voice based on their interests which are different to those of their participants. The researcher must persuade the reader of the case for a particular 'novel reading' of the text, and it is primarily a scholarly audience that judges the merits of the researcher's interpretations (Jossslson, 2004). By presenting quotations from participants' transcripts, readers of this thesis have the opportunity to make alternative interpretations. While the findings from a hermeneutics of suspicion could inform teaching practice and policies, they also have the potential to challenge how we think about teaching and the ways concepts such as 'diversity' are constructed.

\subsubsection{Combining the hermeneutic lenses}

Czarniawska (2004) and Josselson (2004) suggest that it is possible to interpret and interrogate the same text. This approach generally involves explicating participants' meanings before considering what they might conceal. An example of this approach is found in Court's (2004) analysis of narratives of primary school co-principalships in New Zealand. Her response to the dilemma between realist and poststructualist approaches was “two-pronged" (p. 579). It involved firstly using a narrative analysis that considered the meanings in participants' narratives and foregrounded their 'voices', followed by a discourse analysis of academic texts and policy documents and then of participants' stories. While this approach was not unproblematic, Court gained valuable insights from using both narrative and discourse analyses. For Swan and Linehan (2000), combining narrative and positioning approaches enables an understanding of the self as constructed through social processes but not determined by them. It "captures the relational nature of identity" (p. 425) and offers a way to understand the conflicting identity positions participants narrate and how cultural narratives shape their stories.

Josselson (2004) notes that while it is not possible to undertake a hermeneutics of faith and a hermeneutics of suspicion of a text at the same time, it is possible to shift between these 
interpretive positions in the analysis. However, it is important for researchers to indicate clearly when and how they shift from one approach to another. In each of Chapters Six to Nine, I begin with an analysis using a hermeneutics of faith and follow this with analysis grounded in a hermeneutics of suspicion, noting when this move occurs. I agree with Josselson (2004), who notes that creative narrative research involves

...both unearthing the intended meanings and viewing them from another perspective in which such meanings point to other meanings and thus enlarge our vision of some aspect of human life. (p. 24)

I aim for this thesis to 'enlarge our vision' of teaching in higher education by suggesting some answers to my research questions, posing further questions, and pointing to, and beyond, the taken-for-granted meanings in teachers' talk about student diversity.

\subsection{Research design}

\subsubsection{Interviewing}

Interviews are a good way to explore the ways subjects experience and understand their world (Kvale, 2007). Although what teachers say they do and actually do may differ, interview narratives give an insight into the meanings on which behaviour is based (Mankowski \& Rappaport, 2000). The relational epistemology I draw on resonates with Kvale's (2007) idea of the interview as inter/view, an interchange of views between two persons who negotiate meanings of their lived world and construct knowledge through their interaction. Watson (2006) describes the interview as a "collaborative construction in which the meanings and the way they are constructed depend on both the interviewer and the interviewee as 'active agents"' (p. 369). This does not necessarily lead to a joint, coherent construction of meaning; interactions and meanings can be complex and ambiguous, and the interviewee's narratives contradictory and inconsistent. As Gunasekara (2007) notes, both interviewer and interviewee have multiple, constructed identities, fluid and shifting.

As an interviewer, I recognize that I can never be a neutral data collector since I am "historically and contextually located, carrying unavoidable conscious and unconscious motives, desires, feelings, and biases" (Fontana \& Frey, 2008, p. 116). Researchers 
construct some questions and repress others (Scott \& Usher, 1999). The interviewer's responses to the interviewee, for example the prompts they use, changes in their level of attentiveness or choices about which aspects of the discussion are followed up and which are passed over, all influence the interview process. Non-verbal as well as verbal styles of communication play a part in the co-construction of the interview. The interviewee's own purposes, conscious and unconscious, also enter into the interview process. They may censor what they tell (Sharkey, 2004), and what they choose to include and exclude will be influenced by the level of trust and how comfortable they feel with the researcher. Interviews are therefore "negotiated accomplishments of both interviewers and respondents that are shaped by the contexts and situations in which they take place" (Fontana \& Frey, 2008, p. 144), however Kvale (2007) reminds us that research interviews involve asymmetrical power relations, with the interviewer/researcher defining the topic, shaping the interview process, and (in most cases) maintaining control of the interpretation.

My interviews with research participants were semi-structured and informal, and I tended to use an everyday conversational manner. I brought an individualist and realist approach to my questions and discussions with participants. Although an interpretivist methodology and a relational ontology are the theoretical underpinnings of this study, I nevertheless slipped into the easy familiarity of realist language in the interviews. Participants responded in kind, and generally narrated their experiences as though they were coherent, objective and transparent accounts of their social realities. This does not mean that my data is of limited value. Rather, it is of particular value in showing how meaning is socially constructed and in identifying the dominant narrative and discursive resources that individuals (including myself) draw on to construct and narrate their experiences.

Interviews need to be transcribed to produce a text that can be analysed. Transcribing involves interpreting a "live social interaction" (Kvale, 2007, p. 93) and translating it into a written text, a process that involves judgements and decisions about who transcribes, what transcription procedure is used, what is included and what is not, and what the transcription will be used for. There is no one true and accurate representation of spoken language and transcribing speech is always an interpretive practice, therefore what gets included in the transcribed text and how it is arranged and displayed has "serious implications for how a reader will understand the narrative" (Reissman, 1993, p. 12). 
Because transcript data is removed from the face-to-face research context it becomes decontextualized, and researchers develop a different relationship to the data than that with their research participants (Watson, 2006). The transcriptions of my interviews with teachers cannot be taken as accurate representations and must be understood as my attempts to make meaning from my research participants' talk.

\subsubsection{Texts of experience}

In this thesis I analyse participating teachers' narratives of experience. Experience has been considered an important source of knowledge and a means of constructing knowledge in adult and higher education. Jarvis (2006, p.6) writes that "Our action is always in the world, always engagement with the world (both the physical and the human social world) that we experience and these experiences become data for our own thinking." Many writers, however, have challenged the notion of experience as providing unmediated access to the truth of reality. Experiences are variably recalled, and they change in some way every time they are told (Zepke, 2003). Experience cannot be taken as a representation of a real world because each person's experience is limited, partial and socially located (Ramazanoglu \& Holland, 2002). Experiences are always interpreted, that is, we experience an event through our interpretive frames (Scott \& Usher, 1999). Scott (1992, p. 37) elaborates: "Experience is at once always already an interpretation and is in need of interpretation. What counts as experience is neither self-evident nor straightforward; it is always contested, always therefore political." Social interests and prevailing discourses govern interpretations of experience (Richardson, 2000), and Ramazanoglu and Holland (2002) note that making sense of diverse experiences is crucial to social and political transformation.

These critiques of experience lead me to view experience as a discursive construction whereby accounts of experience are not taken as "a transparent window on reality" (Kramer-Dahl, 1996, p. 253) but are interpretations of interpretations. Usher et al. (1997) suggest using the metaphor of experience as a text that can be read or interpreted but that has no definitive reading. 
Experience can have many meanings, some of them conflicting and contradictory...the meaning of experience is never permanently fixed; thus, the text of experience is always open to reinterpretation (p. 105).

People are meaning givers and meaning takers, influenced by different discourses that position the self in various ways. It can be argued that individuals do not have experiences but are instead constituted through experience (Scott, 1992; Usher et al., 1997). Experience is not the evidence for what is known, but instead is understood as "that which we seek to explain, that about which knowledge is produced" (Scott, 1992, p. 26). Thus my interviews with participants can be understood as sites of meaning making and production of texts of experience.

\subsubsection{Criteria for evaluating this study}

Because the research methodology I am employing does not lend itself to traditional criteria of evaluation, alternatives need to be considered. Narrative analysis, whether informed by a hermeneutics of faith or suspicion, does not seek to uncover the 'truth' about social practices; it is concerned with how people narrate themselves and their experiences and what that can tell us about social interactions. Because each narrative is unique, produced within particular social settings and told from a point of view, traditional research criteria of reliability do not apply. Validity as it is traditionally conceptualized is also problematic because it relies on realist assumptions. In narrative research, validity can be reconceptualised as validation, "the process through which we make claims for the trustworthiness of our interpretations" (Riessman, 1993, p. 65). This considers whether the analysis is grounded in and supported by the data that has been collected (Webster \& Mertova, 2007). Because narrative is retrospective and context specific, it does not provide results that can be generalized. The knowledge produced is "an unpredictable emergent rather than a controlled outcome" (Scott \& Usher, 1999, p. 28).

Although narrative analysis assumes that talk about past experiences is a selective reconstruction (Riessman, 1993), this does not mean that narratives are made up 'out of the blue'. People draw on culturally available and appropriate stories, and verisimilitude is often used as a criterion for evaluating analysis of these narratives. Webster and Mertova (2007, p. 90) define verisimilitude as when "the results have the appearance of truth or 
reality". Persuasiveness is another criterion is suggested by Riessman (1993), which considers whether the interpretation is reasonable and convincing. According to Reissman, Persuasiveness is greatest when theoretical claims are supported with evidence from informants' accounts and when alternative interpretations of the data are considered. (p. 65).

Lieblich, Tuval-Mashiach and Zilber (1998) discuss other criteria that have been suggested for narrative research, which include: comprehensiveness, whether there is adequate evidence for the interpretation or analysis; coherence, the way different parts of the interpretation create a meaningful and comprehensive picture; insightfulness, whether the analysis has generated comprehension and insight; and relevance, which considers how the research contributes to the field. Lieblich et al. conclude by proposing that a process of consensual validation, where researchers' views and conclusions are shared with their research community and other interested, informed individuals, should be accorded the highest significance in narrative inquiry.

There are some dangers to be aware of when employing narrative analysis. Connelly and Clandinin (1990) alert us to what they call "the Hollywood plot" (p. 10), a form of narrative smoothing to invoke a positive outcome regardless of the indications of the data. Another possible problem involves the intersubjective nature of narrative inquiry, where the "easy slipping into a commitment to the whole narrative plot and the researcher's role in it, without any appropriate reflection and analysis" (Webster \& Mertova, 2007, pp.108109) can distort and limit the findings. To counter these risks, critical feedback on and throughout the analytic process is necessary, and in my case has been achieved by feedback from my supervisors and through peer presentations. The reflexivity that challenges me to be more conscious of my own situatedness and to provide information about the contexts the research is embedded in can add rigour to my research (Etherington, 2004). Drawing on Richardson's (2000) discussion of criteria, I aim for this research to make a substantive contribution to the field of enquiry and provide a credible account of the social world I investigated. I aim to make the research procedures transparent and the results convincing (Kvale, 2002). Because all research is political (Lincoln, 2002), my hope is that this thesis will promote reflection and discussion on diversity, power and care in higher education, and enable the co-construction of better worlds. 


\subsubsection{Constructing a thesis}

A research text, for example a doctoral thesis, can be understood in various ways, such as a narrative, a cultural text, and an emergent process. Because the analysis of the data and the writing of this thesis involve interpretive acts and the construction of narratives, researchers are themselves narrators as they write their findings. The narratives they produce are

...enabled and constrained by the social resources and circumstances embedded in their disciplines, cultures, and historical moments; and they write or perform their work for particular audiences. (Chase, 2005, p. 657)

While the thesis is developed from the stories of many participants and the ideas of many writers, it is a story told by one narrator and thus I must take responsibility for, and critique, the findings at each stage of the research and the thesis as a whole (Webster \& Mertova, 2007). Although all interpretations are provisional and incomplete and qualitative research findings are never exhaustive (Denzin, 2002), conclusions can be still be drawn and these can form the basis of further educational conversations. In other words, the thesis does not provide definitive answers, resolution or closure, but remains open to new interpretations and more questions.

The thesis can also be understood as a cultural text that constructs (and deconstructs) meanings. Researchers "use and are used by language" (Fernandes, 2003, p. 311), and thus a researcher is "simultaneously narrator and narrated in her or his textual representations" (Atkinson \& Delamont, 2006, p. 169). Any 'tellings' are partial, historical, and discursively embedded. The doctoral thesis is a particular type of cultural text, constrained by academic conventions that vary from one discipline to another. When I began writing this thesis, I had a certain way of writing in mind that involved bringing theory, methodology, analysis and discussion together around key themes. However, as I wrote and rewrote, the structure of my thesis changed to one that is much more conventional. My writing was 'disciplined' by the textual requirements and discourses of Western academia, and has produced a recognizable cultural text.

Writing a doctoral thesis is an emergent process. Research writing is not just a matter of recording analyses and findings. The writing itself can be a method of inquiry (Richardson, 2000), and this has been the case for me with this thesis. Research writing as a means of 
discovery and analysis generates new ideas about the topic and new ways of being in relation to it. It includes "the asking of 'new' questions and the exploration of different connections and alternative understandings" (Cole, 2009, p. 566). Writing this thesis was not a linear progression; it was a spiral, iterative process as I wrote and rewrote sections or chapters. As Etherington (2004) notes, narrators perform multilayered stories, and therefore "linear representations become problematic, in that they create a false impression of order in what might be 'messy' and complex layered accounts" (p. 84). Somerville (2007) suggests that from the (inter)play between data and theorising, new ideas emerge and new knowledge is generated. Writing is a site of 'becoming', of the formation and transformation of selves. Somerville points out that there are times "when our predictable and known ways of being in the world are brought under challenge and we are changed forever" (p. 234), and this has occurred for me in the writing of the thesis. It has challenged what I know and how I know it, and is both a making and an unmaking of self and knowledge within multiple relations with research respondents, texts, academic supervisors and peers.

\subsection{Research procedures}

\subsubsection{Selecting participants}

In this research study, I interviewed 22 teachers from two New Zealand universities who had responded to an advertisement I sent to their universities. I obtained permission from the research departments of each university to send them an advertisement asking for participants. The advertisements were sent to the appropriate administration staff of various departments to circulate as an email or poster or both. I relied on teachers to respond, to email me indicating their interest, and thus my sample is self-selected and not representative. Sixteen respondents were female and six were male. ${ }^{12}$ Respondents were from faculties of business, education, humanities and social sciences. Time and other practical limitations meant that I did not approach all faculties in the two universities, and so there are no teachers of science, engineering or law, for example. ${ }^{13}$ In my

\footnotetext{
${ }^{12}$ I address possible limitations of this gender imbalance on the findings in the final chapter. ${ }^{13}$ I also address possible limitations of this in the final chapter. See Appendix A for further information about participating teachers.
} 
advertisements I asked for teachers who are employed by their university and teach on campus with at least some of their work involving regular teaching in small groups (less than 30 students). I wanted to ensure participants had face-to-face interactions with a range of students. I did not limit the subject matter, course level or department of participants in order to ensure a variety of teaching experiences and contexts. I did not specify teaching position or academic roles, and thus participants included lecturers and tutors with varying amounts of teaching experience. Most of those who responded to the advertisement were interviewed. Of those who were not interviewed, some did not have the teaching experience I was looking for while others had work commitments that made it too difficult to set up an interview.

\subsubsection{Interviewing and transcribing}

Throughout 2008, I conducted individual interviews with respondents at their university in a venue of their choice, usually their office. Each interview lasted about one hour and was audio-taped and transcribed. The interviews were semi-structured, and the main stem questions used to generate discussion were:

- What does the term diversity mean to you in the context of your students?

- Tell me about your experiences of diversity in your teaching practice

- What challenges have you encountered in responding to student diversity?

- What support have you received?

- How has having a diverse student group helped you as a teacher?

By asking these questions, I hoped participants would describe a variety of experiences related to teaching diverse students. I aimed to elicit data that would provide narratives of experience and also enable analysis of the meanings of 'diversity'. The question about support participants may have received aimed to encourage them to talk about their university context, and the question about how student diversity might have helped them as teachers aimed to provide a balance to the question about challenges. My questioning was intended to encourage participants to talk about their relationships with diverse students and their teaching practices. In asking the questions, I encouraged participants to describe salient experiences and to express their thoughts and emotions. In most of the interviews it was easy to encourage participants to speak, and generally I let them take their time to answer the questions and allowed them to elaborate as much as they wished. 
The questions I asked often generated detailed responses by participants and I spoke very little, only using prompts and further questions to guide the interview when necessary. In a few interviews, I needed to use more active questioning, such as asking participants to elaborate on what they had told me and asking them to provide more detail. Occasionally I needed to steer participants back to my questions if they got sidetracked.

The interviews were transcribed within four weeks of the interview taking place. I transcribed some of the interviews myself, but because of time constraints I also employed a professional transcriber. I checked all the transcriber's transcriptions to ensure as much accuracy and uniformity as possible in the interpretation of the interview tapes. I then gave all participants a copy of their transcribed interviews to check for errors and also for content that they wanted to exclude or add to the transcript. This enabled participants to co-construct the transcripts of their interviews. Some chose to make several changes and some made just a few minor corrections, while others made no changes. None of the participants made substantial changes or chose to remove their transcripts from my research.

The transcripts of the interview tapes include only a little of the verbal intonation and the non-verbal language of participants. The reason for this is that my analysis focuses on the narratives that participants construct, giving most attention to the content of the stories that are told and how they are constructed, rather than to applying a close examination of the linguistic details of the interview conversations. ${ }^{14}$ This research considers how participants in the interviews "impose order on the flow of experience to make sense of events and actions in their lives” (Riessman, 1993, p. 2). The 'broader brushstroke' I applied to the construction of interview transcripts will have lost some details, but it allows larger patterns to be discerned in the stories participants tell and how they are constructed. Thus transcribing is part of data interpretation and analysis, and must be acknowledged as such.

\subsubsection{Analysing the transcripts}

The first step in the analysis involved reading and rereading transcripts and identifying the narratives. No software packages were used in the analysis because I wanted to examine

\footnotetext{
${ }^{14}$ Transcribing conventions are explained in Appendix B.
} 
the narratives as a whole and look at the shape of the storylines and plots, as well as investigating the themes present within them. When using narrative methods of inquiry, Reissman (2008) notes that researchers "keep the 'story' intact for interpretive purposes" (p. 74) rather than thematically coding segments of narratives. While there are many ways of analysing narratives, there are few clearly prescribed methods and consequently I drew on several texts to guide my analysis. The analysis was an emergent process, unfolding as I worked with the transcripts. Josselson's (2004) article on the hermeneutics of faith and suspicion provided the overall analytical framework. Texts that provided me with guidelines and suggestions for interpreting and analysing narratives through a hermeneutics of faith lens included Mankowski and Rappaport (2000) and Squire (2008), and Riessman's (2008) discussion of thematic and structural analysis. Gergen and Gergen (1986) provided a model for identifying basic narrative forms. For analyzing the narratives using a hermeneutics of suspicion I drew on Czarniawska's (2004) suggestions for close readings of narratives and 'strategies of deconstruction' and Davies and Harré's (1990) concept of positioning. As with any form of narrative analysis, this bricoleur approach requires me to quote the relevant narratives, or segments of them, and document how I arrive at my interpretations throughout the analytical process.

\subsubsection{Ethical issues}

One of the key ethical issues that I have considered throughout this research project is that of confidentiality for participants. In a country the size of New Zealand, the academic community is small and well-connected. It would be easy to inadvertently reveal details that could identify a participant, in spite of the pseudonyms used in this thesis. I have taken a number of steps to avoid revealing details that could identify participants. These include pooling the transcripts from the two universities participants work at, removing details that could identify the university, and only identifying participants' faculties or broad area of teaching and not their departments or the specific subjects they teach. I also invited participants to check their transcripts to remove identifying details, and I have removed from my analyses any details that would identify participants' campus, courses, colleagues, research interests, or students. At times, I have not even used participants' pseudonyms when discussing transcript data that might link the pseudonym to a teacher, faculty or university. I have only provided a summary of interviewee characteristics (see 
Appendix A) rather than details of department, age, ethnicity and so forth for each participant's pseudonym. Ethical approval was gained from the Faculty of Education's Ethics Committee at Victoria University of Wellington where I was enrolled as a student to conduct this research. I also gained consent to advertise for participants from each university's research department and from each faculty concerned, providing them with information about the project and answering any questions they had. Consent forms and information provided to participants are included in Appendix C.

\subsection{Conclusion}

Research is a complex process that is constructed in certain ways, and this needs to be made visible in writing about any research study. In this chapter, I have discussed the methodology informing this study and the procedures used to collect and analyse the data. Chapters One to Four of this thesis have described the background to this study, discussed the academic literature that informs the study, and explained the theoretical frameworks underpinning the research. Having situated this study and explained the assumptions that underpin it, I now turn to the data analysis. The next four chapters analyse participants' narratives using a hermeneutics of faith and a hermeneutics of suspicion to answer the research question 'How do university teachers understand and experience student diversity'. 


\section{Chapter 6 \\ (De)Constructing diversity}

\subsection{Introduction}

My first research question investigates what the term diversity means to the teachers in my study. At the beginning of our interviews, I asked participants "What does diversity mean to you in the context of your teaching?" My emphases in this question (underlined) aimed to elicit responses from teachers drawn from their own teaching practice rather than what 'diversity' might refer to more generally. I did not specify how diversity should be conceptualized, however my questions and discussions with interview participants reified 'diversity' as something able to be identified and described. Prior to conducting the interviews with research participants, I did not consider alternative approaches and it is only through the analysis of transcripts that I began to question the notion diversity itself. This chapter therefore involves a heuristic process of 'writing my way through' in which analysing the data has resulted in unlearning assumptions and opening up new ways of thinking about taken-for-granted notions. Writing has become for me, as Richardson (2000) suggests, a method of inquiry rather than simply a matter of reporting research results.

In this chapter, I analyse the meanings teachers give to 'diversity' and how they talk about it. When teachers responded to my questions about what diversity means to them, they tended to talk about categories of difference (providing synchronic data) and only occasionally provided narratives with plotlines (diachronic data), so in this chapter I focus on what teachers said about 'diversity' and what they did not say rather than analysing the construction and performance of narratives. I employ a hermeneutics of faith to investigate the meanings of diversity these teachers recount, and I then employ a hermeneutics of suspicion to read between the lines of these accounts. This leads to an exploration of what 'difference' means and how it is constructed. I employ Burbules (1997) idea of a 'grammar of difference' and elucidate alternative ways of understanding difference. I also consider the implications of notions of difference and diversity, and argue that a critical awareness of how the concepts of diversity and difference are constructed is needed to expose and move beyond the unequal power relations these terms conceal. 


\subsection{Diversity}

\subsubsection{Categorization}

When I asked participating teachers what diversity means to them, they responded by talking about categories of difference in students. This categorization of diversity, unchallenged by myself or teachers during interviews, positions diversity as a 'definitive concept' (MacDonald \& Bernado, 2005) and diversity categories as bounded and stable. Defining concepts and putting them into categories is a way for people to make sense of their world. Young (1990, p. 98) explains that "Any conceptualization brings the impressions and flux of experience into an order that unifies and compares", and she suggests that Western reason and logic seek to classify concrete particulars as inside or outside a category, enabling category members to be identified and measured. Much discussion of diversity in the literature and in the public sphere takes this approach, though it is critiqued by some writers, such as Burman (2004) who argues that categorization will always impose "some degree of symbolic violence" (p. 297). In my interviews, teachers discussed categories of diversity that were significant to them, and spoke in ways that positioned these categories as real and unambiguous. I colluded with this in the interview conversations and thus contributed to participants' construction of 'diversity'. In this section, I analyze how diversity is categorized and talked about in teachers' transcripts.

\subsubsection{Participants' categories of diversity}

The categories of diversity discussed by participants were related to physical characteristics, relationships, social status, cultural heritage, and academic study. Looking at the transcripts overall, the most commonly talked about group were international students, and the most discussed categories include ethnicity and/or country of origin, language and academic participation. Domestic students' cultural diversity was also discussed. Other commonly discussed categories were gender and age, with some teachers talking about sexuality, generational differences, socio-economic class, religion and/or spirituality, and students who were parents or had family responsibilities. Physical impairments were discussed by several teachers, with a few mentioning health, mental health and learning disabilities. Many teachers talked about the background of students, 
which could refer to general life experiences, living situations, work, or previous academic experiences. Learning styles and level of participation and interaction in the classroom were identified as a form of student diversity by just under half the teachers, several mentioned academic ability and personality, and one talked about motivation and effort as a form of student diversity. A few teachers mentioned level of study or whether students were full or part-time.

Ethnicity is an important form of student diversity for most teachers. One of the study participants, Helen, has students of different nationalities in her class, while another participant, Grace, says that her classes are often mixed, with international and national students of different ethnicities and cultural backgrounds. Kiri talks about her students: It's a class that has got a wide range [of students] from different cultural backgrounds, a couple from South Africa, some from America, Canada, um, different parts of Asia as well as Pakeha New Zealand and Māori and Pacific Island [students].

Susan also describes the ethnic makeup of her class, saying ...we tend to attract new immigrants, you know for example Spanish, South African, Zimbabwean, Ethiopian, Somalian, and then more the traditional groupings in New Zealand from the Pakeha to Māori, Pacific Island.

These teachers speak of ethnicity and nationality as important categories that identify difference between students. They list a variety of ethnicities with a distinction made between international and domestic students. The international students are mentioned first, emphasizing their difference. Although it varied for individual teachers, narratives about international students provide much of the transcript material. Some teachers, especially on business courses, have high numbers of international students in their classes.

One issue that generated much discussion in interviews was the language difficulties of NESB (non-English speaking background) ${ }^{15}$ international students, some of whom struggle to understand and communicate in spoken and written English. Richard says that he has many students whose English is "extraordinarily poor". Sandy describes language as "a problem and a challenge", and says that when he is marking students' assignments he

\footnotetext{
${ }^{15}$ Using this term marks those who do not have English as a first language as different from an unstated norm, that of English language proficiency. It would make for a different discussion if I referred to English speakers as 'Limited to English Language' and left all other forms of language proficiency unmarked. While I do use NESB as a marker, I am aware of how this positions language use within my research context.
} 
finds it difficult to distinguish between a poor grasp of English and a poor grasp of ideas. Kareen says that his NESB students communicate better in writing than verbally. Grace talks about NESB students who share great ideas in class but need assistance with transferring them into writing, noting that often a lot more time is invested in those students. Grace also talks about trying to cross the 'language barrier' and "trying to include them in the classroom which can sometimes be a bit problematic". NESB students with difficulties in speaking English come into a monolingual academic environment requiring English proficiency for academic achievement. Teachers' comments raise questions about the entry requirements for NESB students, the support available to them and to teachers, and the appropriateness of teaching and assessment practices. Their comments also position these students as deficient 'Others' (Young, 1990) and ignore any literacy difficulties of English-speaking students.

Language difficulties and cultural differences could also lead to difficulties in participation in class, and this was discussed extensively by teachers in Business faculties. Liz explains that students who seem withdrawn in class may be struggling academically or they may be doing well but have language difficulties and it is difficult for her to know which is the case. Rachel has difficulty in getting her international students to speak in class, as does Sandy who says "for the most part I find that particularly the Chinese students with a few notable exceptions, tend to be reticent in class." Ray considers that some Asian students may not ask questions in class and they may not feel "sufficiently comfortable to come back and ask you what did you mean because that way is for their culture insulting." As a NESB immigrant teacher himself, Ray acknowledges that cultural differences position students differently in class and influence their relationships with teachers. Other teachers also talked about international students' relationship with teachers. Anne says that her international students, especially Chinese students

... have been brought up in a completely different education system and they look to the lecturer as sort of being God and they don't want to discuss anything and when they do like when they get to a postgrad course they're very keen, they do want to participate, they've got over this business of not wanting to talk but I can't understand them and their English is still limited.

Sandy thinks this attitude to the teacher can lead to a gulf between students and teachers and become a barrier to communication. He says

The expectation, particularly amongst the Chinese students I have taught seems to be that I'm going to stand up in the front of the class and talk and thereby transfer knowledge 
from me to them, and they will go away and remember as much as they can and be examined on it at the end of the term, and they'll pass the course um, and if they don't pass it's gonna be my fault. So I'm attempting to disabuse all my students of that notion. However, Liz considers that it is stereotyping international students to say that they do not want critical thinking and prefer rote learning. She describes how she insists on teaching critical thinking to all her students and has found that her international students 'love it'. This suggests that teachers' beliefs and attitudes play an important role in the pedagogies they employ and in the construction of teacher/student relationships.

Another issue that a number of participants talked about in relation to international students was plagiarism, and they had differing views on this. Sandy says,

I guess a very upfront, almost embarrassing challenge was their approach to intellectual property, and not for a moment do I suspect that most of them had any intent to deceive, but I found that many of my international students on a particular course were not following appropriate methods of citing and acknowledging sources from which they'd got material.

Sandy adds that there is a lot of debate among higher education teachers about "whether or not that is a cultural difference or whether it's just the consequences of how it's done elsewhere you know, a learned behaviour rather than a cultural value." Vanessa also considers that many Chinese students (and some domestic students) find it difficult to grasp the concept of plagiarism. Ann agrees but also thinks that some students cheat in order to pass the course. Ray notes the parental pressure on some Asian students to get good grades. Rachel offers a different view. She says that while teachers think that Asian students plagiarise more than other students she does not think that is the case and it is just that "students are really really slack about cutting and pasting." While the notion of 'Confucian thinking' referred to by Sandy can help to understand the differences Asian students bring to New Zealand university classrooms, many misconceptions exist about these students' approaches to learning, and these have been challenged by research (Chalmers \& Volet, 1997). As well, international students are often viewed as a homogenous group and the differences that emerge from international students' varying contexts and histories are ignored (Mayuzumi et al., 2007).

Most of the discussions about NESB international students portrayed them in deficit terms. However, some teachers talked more positively about international students. Helen says that different students' perspectives are "what helps keep things interesting in a class 
where you're teaching" and she positions diversity as variation rather than deficit when she talks about how her class has great discussions when students compare and contrast their cultures. Maria considers that the term diversity is often used in relation to ethnic minorities but she sees diversity as "being more inclusive of all groupings including mainstream." Susan draws on the cultural diversity of all students to enhance learning in her course, and says that it makes teaching easier when diverse cultures and languages are not 'remote differences' but a part of the classroom.

Study participants identified other forms of student diversity. The age of students is discussed by several teachers. Susan says that

...within the programme you know we have a huge age range. We have very few school leavers and we have people up to their mid 50s. So with the bulk of those maybe 35 to 45 . Michael's classes include many younger students and he notes how different their attitudes and experiences are to his. Gender was talked about by some teachers with Michael noting that he needs to be aware if the male students are dominating the conversation, or conversely, if they are in a minority and may need encouragement to speak up, thus demonstrating a commitment to gender equality in his classes. Grace has classes with mostly female students, so when she breaks the class into small groups for discussion, she tries to include a male in each group. She notes the challenges

...where I've only got one male in the class of 19 females, and it's like how are you going to make that person feel, you know, included and not like the only sort of male in the room. And those sorts of things and how can we bring the views of that male to this room full of females because their views are important and they're thinking in a different way.

While Michael talks about gender in terms of power dynamics (who spoke and who was silent), Grace portrays gender as involving inherent differences (males think in different ways). In Grace's narrative, the male student is marginalised by being the only male in the class and Grace draws on an inclusion perspective when she talks about overcoming this marginalisation. Gwen talks about her experiences with a transsexual student in one of her classes and was the only teacher to mention this form of gender.

Sexuality was identified as a form of student diversity by several participants. Michael considers that little is said about sexuality in university courses and he ensures it is included in his course curriculum. Elaine also addresses sexual diversity in her course, and Susan notes that on her courses, "Sexual orientation comes through and it's a critical thing 
we're having to address more now we've got the mix of the Islamic students in." Other teachers also talk about students' religious beliefs, such as Christianity or Islam, and how these might affect class discussions. Ala says that for some Muslim students, certain topics are forbidden. Gwen talks about when there was a march on Parliament by members of Destiny Church $^{16}$ and says that her class included some students who were from Destiny Church and other students who "thought this thing was ridiculous and so elements of a person's faith ended up ... becoming relevant." Michael notes that ...we had a discussion around spirituality. And I thought everybody there would be able to talk about it probably okay. And, it just didn't occur to me that some people, because of their deep religious commitment would find that a difficult conversation to have. And I guess the university environment is so sort of secular generally, you just don't, give religion much of a, much consideration.

These teachers' comments suggest that religious faith does not easily fit into 'secular' university classrooms. This may be due in part to possible conflict with an academic emphasis on evidence-based knowledge and critical thinking.

The socioeconomic status of students is mentioned by a few teachers, with Gwen and Susan talking about how some students face financial difficulties in their studies. Susan says she has a number of students who "have lived a struggling life or been on benefits." Gwen explains:

I had a student come to me in tears, you know, on the day saying oh I won't come, I won't come, because she, there was just no way she was going to be able to afford the $\$ 15$ to get her to that trip. Aside from field trips I've had students, there's an attendance requirement of course, and I've had students who have sent me an email saying look I can't attend class today, I can't actually afford to get to [campus], you know I live out in $\mathrm{X}^{17}$, I live out wherever and I can't afford to actually get to class. So that, you know, that becomes an issue.

These students in Gwen's class are prevented from accessing their education fully by a lack of financial means, something that Maria believes is not recognized enough by universities. Chris observed that "middle-class western white students" find it easier to

\footnotetext{
${ }^{16}$ The march on Parliament by members of Destiny Church in 2004 protested against the legalisation of civil unions. Marchers' style of dress, chanting and body language were seen as aggressive and frightening, and were compared with Nazi stormtroopers by the media. It is unusual in New Zealand for religion to be so publicly political, and the march provoked much public debate at the time.

${ }^{17} \mathrm{I}$ use $\mathrm{X}$ in various places in the thesis to protect the confidentiality of teachers and their campuses.
} 
adjust to academic expectations. She talks about students who are the first one in their families to attend university, and those who "couldn't do it when they started but actually come back after they failed the first paper and have another go. When you see them graduate, it's really, that's a reward." These teachers show that the socio-economic status of students can have a big influence on their participation and success at university, but looking at the transcripts overall there was little attention given to this aspect of diversity.

Some students had health difficulties or impairments that participants spoke about. Cassandra and Susan have had deaf students with interpreters in their classes and Tina has taught blind and visually impaired students. Grace and Helen talk about students with speaking impairments needing support to speak in class. Tina has had students with medical conditions that impair concentration. Several teachers note learning difficulties such as dyslexia, and others mention mental health issues. Cassandra says,

I had somebody in the class this year, practical class that was really challenging for him, who suffered from depression, from depression for a long time. And that was really interesting in terms of finding ways to try and help him do the work.

Cassandra's use of the word 'interesting' suggests that she views her student's depression as an impetus to make her teaching more inclusive rather than as a problem that causes her difficulties. Gwen talks about a big student whose size made it difficult for him to sit at a desk. Her response to this was to bring in a different kind of desk but the student stopped attending. She says that a person's physicality is "another element of diversity" that she had never really noticed before or had to adjust her teaching for until she had this student in her class. The way that teachers in this study talked about impairments suggests that it was through experience with individual students that teachers developed awareness of and responses to particular impairments. In other words, inclusion of students with impairments was a response to need rather than general teaching practice.

Learning styles are mentioned by a number of teachers but little detail is given. Susan mentions "trying to keep the variety in there of the visual and the auditory and the active" and Cassandra notes that "some of them are quite visual, some of them write quite well." Cassandra also says that students have differing purposes for and expectations of study, and some of her students come from non-academic backgrounds. Kiri talks about the diversity of learning needs and says 
I think the main thing I deal with is the diversity of their learning needs and how some of them need a lot of support and a lot of information and others are quite independent and have studied before, or have got good learning, good study habits.

Kiri says she tries to provide information via a range of media to deal with the diversity of learning needs. For Elaine, a form of diversity is students study level-undergraduate, postgraduate, and $\mathrm{PhD}$. None of the teachers I interviewed mention the cognitive developmental level (e.g. Perry, 1970) of students as a form of diversity; however several talk about developing critical thinking in their students.

Teachers talked about the different backgrounds students have. This could involve varying knowledge of subject area (Elaine), students' work experiences (Grace and Tina), and different disciplinary backgrounds (Helen). Technological background is discussed by several teachers who note that younger students have greater ICT skills than older students and older teachers, and Kiri considers that "the generation gap's immense" in ICT skills. For Gwen, "The exposure to prior learning is really relevant", and Susan discusses the academic background of students.

We've got diversity in academic ability um, from those that have been shining stars in their secondary years to those that have even dropped out in their secondary years that have come to understand a focus about what they want to do in terms of a career and how they want to work within society, that are coming back to give it a go but have a very definite focus about what they want to do. So there's huge range of ability...also a lot of people that have been out of education for some time, they've been, had time out raising a family and that know what they want to do but doubt their ability to do it.

Family background is mentioned and several teachers said that students who had children sometimes missed classes or asked for assignment extensions when their children were sick. Tina also mentions students with other care-giving responsibilities. Ala talks about the difficulties students with refugee backgrounds face, including family responsibilities and inadequate educational backgrounds, and how they often lack the ability to organize their time because of traumatic experiences that include "living in refugee camps in which tomorrow doesn't matter because if you survive today you're the happiest person in the world." Teachers' discussions of student backgrounds suggest that students do not leave their home contexts at the classroom door, and awareness of these differences is important for inclusive and effective teaching. 
While teachers' discussions often showed the complexity of diversity, only a few explicitly talked about this. Liz talks mainly about international students in her interview, but recognizes that diversity is broader than this. She says,

I think the fact that we've got so many international students makes it visible, so straight away you're thinking OK how am I going to help the international students, how am I going to make sure that my teaching accommodates their different needs. And I think then from there you start stepping off and thinking about well it's not just international students who have different needs. We've got Māori and Pacific Island students who are based in New Zealand but they have different needs, we've got people with different backgrounds, you've got mature students who've got lots of work experience and straight from high school students with no work experience and you start to think about, that diversity is more complex than just international students but I think because the international student group is so visible in our area, if forces you to think about diversity in the first place.

Ray refers to diversity as multidimensional, and Gwen and Elaine talk about diversity as having many layers. Helen says

...diversity's one of those words you think you know what it is and when you start to think about it, kind of all these different angles come into it. You know the first thing is those you think about, things like ethnicity or disability or nationality even but, yeah I mean those obvious sorts of things about diversity. But there are other sorts of things I think that um, kind of that variety aspect of the word diversity that comes - that I find with the students, you know things like perspectives, background and experience, learning styles and preferences, all those sorts of strengths and weaknesses and things like that. Students that talk a lot and students that are quiet and a bit retiring but still really bright and got a lot to offer and yeah I guess um, you know when you think about it there's all those different sorts of angles to diversity in the classroom.

The narratives of Liz and Helen illustrate the 'variety' of student diversity and suggest that teachers need to 'think about' it to understand its complexity. Some teachers' discussions show how different aspects of diversity intersect. Differing cultural expectations of gender roles are discussed by Gwen and Maria, and the influence of religion on attitudes to sexuality is discussed by several teachers. A link between ethnicity and participation in class was discussed by some teachers, with others cautioning against creating stereotypes or having assumptions about students.

Overall, teachers talked about the aspects of diversity that were most salient for them. For teachers with large numbers of international students in their classes, particularly those 
from Business faculties, discussions of student ethnicity, culture, and English language proficiency tended to dominate their discussions. Teachers whose curriculum included issues related to diversity talked a lot about these aspects of diversity, for example a teacher of a health-related subject talked about mental health issues, a language teacher focused on language issues, and a teacher with a multicultural curriculum talked about cultural identity. Teachers also talked about personal aspects of diversity, for example a gay teacher talked about sexual diversity, a Māori teacher about aspects of Māori culture and identity, and an older teacher talked about generational differences. Some teachers are practitioners in their field as well as being academics, and some taught students who were preparing to be professional practitioners. ${ }^{18}$ A practitioner focus influences teachers' curricula and pedagogies and also their discussions of diversity. For example, teachers of students studying to be health or education professionals included various aspects of diversity in their curricula and talked about this in their interviews, whereas many business classes tended to involve more computational work and less discussion, and therefore teachers focused on academic forms of diversity and less on personal characteristics or social group membership.

While teachers identify a range of student diversities, their discussions vary in terms of how wide or narrow a range of diversities they talk in depth about. I identified three different approaches to speaking about diversities and grouped teachers accordingly. The first group includes nine teachers who offer a broad definition of diversity, discuss many of these categories and illustrate this with examples. A second group of nine teachers talk about a narrower range of student diversities in their transcripts, focusing on the characteristics of students that most impact on their teaching. Several teachers in this group are practitioner teachers. For teachers in the second group, the most talked-about characteristic of student diversity is that of ethnicity. They mention other characteristics but give them less discussion, except for Vanessa who focuses equally on ethnicity and age. Sandy identifies an aspect of diversity in his teaching that no other teachers mentioned, "the distinction between people of a scientific bent, you know, the hard scientist positivist kind of thinker versus the classical interpretivist type of people." Another teacher in this group taught in both a faculty of Business and a faculty of

\footnotetext{
${ }^{18}$ In this research I use the term practitioner to refer to those who practice in, or are learning to practice in, professions such as teaching, accounting, and various health-related professions. This is to distinguish them from teachers and students who focus on more general academic qualifications not tied to professional body requirements.
} 
Humanities and Social Science (FHSS), and said that his business students often took an instrumental approach to learning, having paid for a product (the degree) to be delivered, while his humanities students were more interested in the knowledge itself.

A third group of teachers focus on academic skills and/or participation rather than the categories discussed above. There are only four teachers in this group. Bob is one of these teachers. When I asked him what diversity means to him, he spoke about the ways he groups students and says "I try not to put people in a box", preferring to construct his own categories of difference. He says:

I mean at the end of the day the characteristics that concern me would be those, those three of interest, activeness in terms of participation and I suppose indicative level of intelligence.

Chris also notes academic participation as important. She mentions a number of characteristics of student diversity, such as age, gender, disability, and ethnicity, but for her, these characteristics are less important than

...how successful can this student be on my course. So I'm motivated to give them whatever it might take for them to succeed or to-and I guess a lot of those things are about the student at the struggling end.

Emily discusses a range of student diversities, but says that in her teaching she focuses on being inclusive of all students, that "they are just all students to me" and that the only thing that differentiates students is ability, which she says is not connected to other forms of diversity. Richard's teaching involves team work and for him, the key categories of diversity relate to roles within the student groups. While he notes language difficulties and differing levels of commitment and time that students bring to their study, he focuses on categories of difference related to skills and personalities. The approach of these teachers involves a kind of 'smoothing' of diversity in terms of the most common categories of difference talked about in the interviews and in diversity literature generally. These teachers reduced a wide range of diversities to a much narrower range. Although they rejected conventional categories, none of these them questioned the categorization of difference. It could be that this 'smoothing' strategy enables these teachers to manage diversity in their classes in ways congruent with their philosophical and pedagogical approaches to teaching. 


\subsubsection{Discussion}

The overview of participants' discussions of student diversity has shown what counts as diversity for these teachers. The emphasis on ethnicity indicates that for most teachers this is the primary form of diversity. Ethnicity was frequently linked to the need for international students to adapt to New Zealand academic culture. It was also, as Liz notes, the most obvious category of diversity that teachers were initially aware of. Other aspects of diversity were often talked about as teachers considered the topic throughout the interview. As D'Cruz (2007) notes, forms of difference are displayed or concealed by student (and teacher) bodies. Ethnicity, gender and age are generally (but not always) visible and language is made audible in conversation. Some forms of physical or mental health and impairment are obvious while others are not, and students may choose not to disclose their health status. Tina says that she only became aware of the medical conditions and learning disabilities of some students when these impacted on their ability to concentrate in class. Sexual diversity was only mentioned by a few teachers and this may be because students did not disclose their sexuality in class, it may be due to heteronormative assumptions, or it could relate to the topic being studied-discussions about sexuality may seem irrelevant to teaching and learning in accounting or information systems classes but important when educating health or education practitioners.

One approach to how diversity is constructed by teachers is whether it is spoken about as an inherent quality within individuals or as a socially constructed category of difference (Chawla \& Rodriguez, 2007). Participants speak of sexuality as an inherent characteristic that evokes varying societal attitudes. Gender roles and attitudes are portrayed as culturally constructed by several teachers, and as inherent qualities by Ray, who speaks of gender differences in approaches to numerical problem-solving, and Grace, who talks about male students having a different way of thinking to female students. However, gender and sexuality are taken for granted as real and stable categories by all teachers except Gwen who has taught a transsexual student. Her experience has made her aware of how the male/female binary is problematized by those who do not fit neatly into one category of gender. Teachers' discussions of ethnicity portray it as inherent in students, but characteristics related to ethnicity are often portrayed as culturally constructed, for example Asian students' approaches to learning. Those teachers who said they preferred not to categorise students according to ethnicity (diversity 'smoothing') still used the 
category of ethnicity in their interviews. While several teachers spoke about how students' social or cultural background influenced their characteristics of diversity, teachers did not talk about how the categories of diversity themselves might be socially constructed. As interviewer, I did not open up this avenue of conversation and this will have limited teachers' discussions. ${ }^{19}$

Having explored what participating teachers talked about in the transcripts using a hermeneutics of faith, I now turn to a hermeneutics of suspicion to look at how what is not talked about allows constructions of diversity and difference to be revealed. As Josselson (2004, p. 13) notes, "a told story conceals an untold one." For example, sexuality was only discussed in terms of homosexuality not heterosexuality, thus producing heterosexuality as the unmarked norm. Disabilities were talked about but not able-bodiedness, and the socioeconomic status of poor students was discussed in some detail while there were only brief mentions of middle-class students. The picture that emerges from the transcripts of the unmarked and therefore 'normal' student is a male or female Pakeha New Zealander with English as a first language who is heterosexual, middle-class, able-bodied with good physical and mental health and learning ability. He or she actively participates in class, understands the 'rules' and expectations of academic culture, requires little or no extra assistance from teachers, does not bring religion into the classroom, is not a mature student and does not have care-giving responsibilities. Much of participants' discussion of student diversity was generated by divergences from this norm and often portrayed in deficit terms. As Usher et al. (1997, p. 81) note, norms function by excluding; "by defining a standard and criteria of judgement [a norm] identifies all those who do not meet the standard." What is considered as diversity is power-laden and therefore political (Johnson \& Pihama, 1995). Davies (1994) explains that those positioned in unmarked categories do not need to be aware of their categorisation, and can "see themselves simply as a person whom anyone else is free to be like" (p. 18), while those who are members of marked categories are aware of their difference. In their interviews, participants mostly talked about marked categories of difference, and only a few teachers spoke about the power

\footnotetext{
${ }^{19}$ Exploring this lack of critical awareness in the interview transcripts is not about evaluating participants' understanding of issues of diversity and difference; rather I aim to reveal the 'common sense' talk produced when taken-for-granted notions are discussed in conversations that do not critique such notions or open up alternative discourses.
} 
relations experienced by those in such social categories. Difference is a power-full concept, and how it is constructed and employed needs to be examined.

\subsection{Constructing difference}

\subsubsection{Participants' constructions of difference}

What is considered 'different' can only be conceptualized in terms of what is 'notdifferent'. Notions of difference position individuals or groups in relation to others and confer meaning on these positions (Ramazanoglu \& Holland, 2002). Difference is therefore relational rather than an essential property. Furthermore, to compare differences implies some form of commonality; Burbules and Rice (1991) note that when differences that divide people are seen from another point of view, these differences may seem arbitrary or less noticeable than the similarities. Instead of being viewed as logical opposites, difference and commonality are better understood as mutually dependent and interactive (Bowser et al., 2007). Difference is thus contextualized; it becomes significant depending on which individuals or groups are being compared and why, and who is making the comparisons and from what point of view (Young, 1990). A relational epistemology understands diversity as produced by teachers in relations through the experiences they narrate, and in this section I look at how 'difference' is produced in participants' talk about diversity. Teachers in this research mostly speak about difference in terms of pre-existing characteristics arising from comparisons with other students, academic norms, teachers' expectations, or teachers' own characteristics. These differences are constructed in a number of ways.

One common construction of difference is that of difference as 'divergence from a norm' (Young, 1990). Characteristics are categorized and one is seen as 'normal' or 'good' while other characteristics are seen as abnormal or undesirable. The underlying assumption is that sameness is a good thing and difference is problematic. This construction of difference includes 'diversity as deficit' approaches, as well as instances when teachers see the divergence more positively, for example, when Grace talks about how the contributions from "students who don't sit inside our mainstream sort of education system" enrich class discussions and student learning. Often however, differences that diverged from a norm 
were experienced as challenging. Students with disabilities, health problems and learning difficulties were implicitly contrasted with a 'normal' healthy and able-bodied student. Several teachers spoke of ethnic and cultural diversity in relation to a Pakeha norm. Other aspects of diversity constructed as divergence from a norm included religion, which was mentioned when it challenged the secular academic curriculum or culture, and the socioeconomic status of students with financial problems. While participating teachers' discussions of difference as divergence from a norm often position 'different' students as deficient, this did not imply a negative relationship with those students. One teacher who spoke in deficit terms of the difficulties she experienced with Chinese students also talked about how well she related to these students and how much she enjoyed them. This study does not evaluate participants' relationships with their students but focuses on the ways student diversity is constructed and negotiated within narratives of teaching.

Difference can also be constructed as 'variation' (Burbules, 1997). For the teachers in this study, variation involves a category having several members which may or may not be valued equally but are not judged against a norm. Some participants spoke of students' nationality, culture and ethnicity in terms of variation. They described how they liked to mix up students of different ethnicities in small group work, and how this led to many educational benefits as students learned about each others' cultures and experiences. Other student characteristics described in terms of variation included learning styles, level of study, full or part-time students, disciplinary backgrounds, life experience, work experience and living situations. Michael constructed difference as variation when he spoke of how he tries to foster all voices in classroom discussions. Difference as variation may be more equitable in its valuing of differences, but the matter of who defines what constitutes difference remains problematic. It also ignores issues of boundaries and exclusion that are involved when one group defines, or is defined by, another (Komesaroff, 2005).

Burbules (1997) suggests another construction of difference, that of 'difference as degree'. Here difference is seen as a point along a continuum of qualities, for example, academic ability was discussed by many teachers in terms of degree. Gwen says that there is a "vast spectrum of levels of ability in the subject area" she teaches, and Chris notes how her teaching needs to support the students who are struggling as well as "giving a good deal to the middle students through to extending and keeping interested the bright students." 
Cassandra and Gwen talk about the range of academic backgrounds students bring to their classes. Several teachers noted a range of ages in their classes, and some teachers talked of participation in class in terms of degree. Susan mentioned the range of socio-economic backgrounds of her students. Difference as degree can be inequitable when there are preferred points on the scale, such as higher ability and greater participation in class, thus how scales of difference are constructed and for what purpose is pertinent.

Difference can also be viewed as 'opposition' (Johnson \& Pihama, 1995). A category, for example sexuality, is divided into two opposing characteristics, with one usually being an invisible norm (heterosexuality) and the other the marked difference (homosexuality). In such binary constructions of difference, one part of the binary is often considered superior and the other inferior, affecting those categorized by such characteristics in various ways. While teachers in this research did not devalue homosexuality, they did position it as the marked difference. Gender is another example of difference as opposition and was mostly mentioned when there was an imbalance in numbers or in participation in class. Greater gender equality in student participation and success at university has meant that the traditional marking of femaleness did not occur in the narratives of participants, and for faculties of Education with high numbers of female students, it is more likely that maleness is the marked gender. However, for teachers in my research, the gender binary of male/female dominates how gender is conceptualized. While some teachers spoke of a range of student ages, others constructed age differences in terms of young and older students who had very different perspectives and experiences. The difference in ITC skills between younger students and older teachers was particularly noted. Sandy positioned positivist and interpretivist thinkers as oppositional, and both Susan and Sandy spoke of high and low achievers in oppositional terms.

Constructions of difference can be seen as powerful means of positioning individuals and groups within social contexts in ways that can value and support or devalue and marginalize them. It is important to remember that although categories of difference tend to become reified and static, Burbules (1997) points out that multiple dimensions of difference interact and their margins are contested. He notes that looking at the ways difference is talked about enables reflection on, and reconsideration of, the categorization of difference. Analysis of teachers' talk about diversity reveals that difference is 
constructed in various ways within classroom relations, pedagogical practices, institutional contexts, and socio-economic discourses.

\subsubsection{Metaphors of difference}

Teachers in this research employed a variety of metaphors when talking about student diversity, but the most common were spatial metaphors. Lakoff and Johnson (1980) consider that most fundamental concepts are organized in terms of spatial metaphors. In participants' transcripts, a common metaphor saw forms of difference, especially language difficulties, acting as a barrier that needed to be eliminated. Examples include phrases such as "try to eliminate the barriers" and "sometimes I've hit brick walls with student learning" (Bob), "I don't want to lose a student's ideas in behind the language barrier" and the teacher "may not be able to reach and close a barrier for every student" (Grace). Sandy says international students' attitudes to lecturers can be a "significant barrier to communication" and he refers to "trying to overcome the language hurdles." Liz also comments on the "language barrier" for international students.

Another commonly used metaphor was that of difference as a distance. Vanessa says that “there's a big age gap between myself and most of my students and...I try to sort of at least meet them halfway." Michael also talks about the generation 'gap' and says "I assume then they sometimes don't know what I'm talking about too, across that generation divide. But like all diversities we can bridge those divides." Gwen talks about the "professional distance which I'm required to maintain", and Sandy speaks of a "huge gulf between me as the learned teacher and themselves as the humble student" when referring to Asian students. Liz refers to different teaching approaches as "poles apart." Susan says "instead of being someone from a different religious belief being someone over there or out there, to realise that someone actually a part of my educational group is from a different group to me." Susan also talks about 'building a bridge' between students to facilitate students connecting with each other.

The use of these barrier and gap metaphors suggests that difference can make it difficult for teachers to 'connect' with students and for students to 'connect' with each other. Many of the teachers talked about how to remove the barriers and close or bridge the gaps, 
implying that this is important for effective teaching and indicating that they care about students. The language they used indicates that effort is required; the connections with and between students that teachers desire must be worked for. 'Barriers' and 'gaps' position students as 'apart from' instead of 'a part of' the class due to their 'difference'. Spatial metaphors underpin the language of inclusion as teachers seek to include, incorporate, and accommodate difference. Yet the term inclusion contains within its very definition the existence of exclusion and shows the binary logic informing and limiting educational practices. In a discussion with fellow PhD students, I was reminded how inclusion is a Western response to Western constructions of difference when a Pasifika student pointed out that inclusion is not talked about in her country and there is no concept of inclusion in schools because it is taken for granted that all students are included. Fijian writer Maciu Raivoka (2009) talks about a 'village approach' to learning, in which students need to be members of a community before they begin learning, which then follows naturally within this supportive environment. These alternatives to inclusion enable dominant educational perspectives in New Zealand to be seen more clearly, and indicate how my research participants' discussions of difference and diversity are situated.

\subsection{Beyond diversity}

\subsubsection{Diversity and social justice}

The discussions in this chapter show that notions of difference and diversity are socially and culturally constructed, and have implications for higher education in New Zealand. When difference is constructed in relation to a preferred norm, those outside the norm are devalued. When this translates into curricula and pedagogy, the interests of dominant groups can be consolidated. Inclusion approaches seek to ensure all students are valued in the classroom, and consider that teachers and higher education institutions need to adapt to meet diverse students' learning needs; however such approaches generally do not consider how difference and diversity are constructed and how power relations are implicated in this process. Nor do they challenge the material bases of inequality (Ramazanoglu \& Holland, 2002). Most teachers participating in this research talked about student diversity using the language of inclusion, but some also drew on critical perspectives and acknowledged power relations between dominant and marginalized groups within and 
outside of the classroom. Michael considers that gender, sexuality, ethnicity and socioeconomic class are fundamental issues for social sciences. He notes that power relationships in the classroom can make it difficult for students from marginalised groups to speak up, and so he tries to find ways to ensure that all voices are heard. Maria considers that the way the term 'diversity' is generally used is problematic because it focuses on minority groups and sees them, rather than dominant groups, as responsible for their situation. She argues that diversity should be

...more inclusive of all groupings including mainstream and that it's everybody's responsibility in the support and welfare of communities that are diverse or have um, have these needs that are somewhat different to mainstream groupings.

Maria challenges everyone, not just those in minority groups, to discuss diversity otherwise if "it's just one grouping doing it within an institution then it's always going to be their responsibility, no-one else is going to take it on board." Maria positions the need to address student diversity as central to educational institutions rather than as a marginal issue.

Although universities seek to be inclusive of all students, participants' discussions of diversity suggest that notions of diversity and difference are constructed in various ways, some of which act to support social hierarchies and marginalize some groups. Inclusion perspectives may avoid addressing power relations, thus limiting the inclusion they aim to achieve and perpetuating inequality. However, Michael argues that academic traditions of "freedom, tolerance and liberality" provide an environment where "all sorts of diversities can be acknowledged just as a matter of course." Other teachers in faculties of social sciences and education investigate power within social relationships in their curricula. Teachers in business courses generally did not take a critical perspective in their discussions but some talked about how they avoided stereotyping students and challenged assumptions about particular categories of students. Several teachers from various faculties spoke of challenging discriminatory practices in their classes, and some teachers' curricula included learning about anti-discrimination. Another way some teachers work towards social justice is by getting students to explore and understand their own identities. Maria values and promotes students' appreciation of “other people's cultures but also reinforcing their own identity and cultural identities." Susan's students do work around identifying their own worldview and where they have come from, and Elaine gets her students to think about their own positioning in terms of gender, ethnicity, sexuality and socio-economic 
status in order to help them work with those in similar and different circumstances to themselves. In these participants' discussions of diversity, caring-as-activism is suggested through their concern for, and actions towards, justice and equity.

The power to define difference is not equally available to all individuals and social groups. Johnson and Pihama (1995, p. 76) note that what counts as difference "is only significant in a system where such differences matter" and argue that dominant groups define and control what counts as difference in ways that further their interests. An illustration of this is how the able-bodied design of university spaces, resources and pedagogies positions differently-abled students as visible and 'needy', as shown in Gwen's example of the big student who chose not to use the special desk she provided for him. University policymakers and teaching staff need to be aware of the power involved in constructing notions of difference, and consider the implications of policies and practices for equity and social justice.

\subsubsection{Beyond limiting notions of difference}

Burbules (1997) argues that a 'grammar of difference' that develops a range of ways to talk about difference is necessary to move beyond deficit approaches. Drawing on his writing, I propose that 'difference as opposition' could be reconstructed as 'difference in relation', which argues that something can only be understood in relationship with what it is not, for example, I can only know myself as a woman by knowing men. Likewise, the category 'homosexual' only has meaning in relation to the category 'heterosexual', and 'deaf' only exists in relation to 'hearing'. As Burbules (1997, n. p.) notes, “A thing is also partly what it is not, what it is differentiated from." This way of understanding difference relativizes the previously universal position of dominant groups, whereby only devalued groups were marked as different (Young, 1990) and contextualizes difference. 'Difference in relation' makes visible the overarching commonality of characteristics, for example, women and men are all human beings, different religions all have beliefs and practices, and secular and religious people all have worldviews. Difference and commonality always exist together. Difference can therefore be understood as "the relatedness of things with more or less similarity in a multiplicity of possible respects" (Young, 1990, p. 99). What makes a social group, according to Young, is not who is included or excluded, but a social 
process of interaction and affinity that acknowledges differences within and across groups without essentializing them. An understanding of how difference is always relational can enhance the connections between people without erasing or smoothing difference, and lessen the 'barriers' that need to be removed or the 'gaps' that need to be bridged. While none of the participating teachers talked explicitly about this construction of difference, a few interview transcripts hinted at 'difference in relation', for example Bob notes that how the way he interacts with his students influences how they interact in class.

Another way of constructing difference that offers opportunities to challenge dominant perspectives is that of 'difference against' (Burbules, 1997). A sense of difference is created when groups actively differentiate themselves from prevailing norms and beliefs and critically analyse them. This heightened sense of difference means that the "assumptions and gaps of a dominant discourse are reflected back to it by contrast with a discourse and set of experiences quite alien to it" (Burbules, 1997, n. p.). 'Difference against' disrupts taken-for-granted practices, raise questions about power and injustice, and inserts subjugated knowledges (Foucault, 1980) into majority spaces. Some of the teachers in my research draw on this perspective of difference, such as Maria, who believes it is important that non-Western students' knowledges are "really validated, and acknowledged and reaffirmed within a predominantly Western structure such as the university." Several other teachers talked of including the perspectives of marginalized groups in their curricula, or of creating a classroom environment where students can share experiences not normally talked about, such as living in a refugee camp or living with a mental illness.

A particularly pertinent example of 'difference against' is described by one teacher whose subject has a particular cultural focus. This teacher found that students from this cultural background relate more easily to the curriculum than other students. Students of the majority culture find themselves as a minority in the class and they begin to understand the experiences of minority students and appreciate looking at the subject from another perspective. Education involves change; and learning such as in this example can be transformational. Difference is necessary to this process. As teachers and students, we learn how we are different from others as well as seeing how they are different from us, and thus by 'seeing the 'other,' we are presented with alternative ways of being in the world" (Hutchinson, 2004, p. 76). University education encourages the questioning, 
reinterpreting and creation of knowledge, and Burbules (1997) suggests that analysing systems of difference is an essential part of education itself, offering us insights about ourselves and our social worlds. By presenting issues of difference as "messy, multiple, complex, and contradictory" (Bird, 2004, p. 23), teachers can avoid essentializing difference and move away from deficit perspectives. As Jiang (2005, p. 229) notes, "the greatest 'problem' of diversity is seeing it as 'a problem to be managed', instead of as an asset."

\subsection{Conclusion}

Analysis of teachers' talk about diversity has shown how notions of diversity and difference are constructed. They are not the innocent terms I initially assumed, but are powerful ways of positioning people within or outside of categories, in relation to dominant norms, or in ways that challenge such positioning. Therefore, a critically aware approach to how diversity is talked about in higher education is needed to go beyond the unequal power relations implicit within many discussions of diversity and to open up discussion about alternative conceptualizations of difference. While power is implicated in processes of categorizing and ways of talking about difference and diversity, care is less visible. It is mainly found in participants' talk of inclusion and in discussions that acknowledge how inequitable social structures position some students. Relationships in educational contexts involve multiple and shifting patterns of difference and commonality, and I consider that teaching and learning will benefit by moving beyond simplistic notions of diversity categories. This chapter provides the basis for further analysis of teachers' transcripts. A consideration of what teachers mean by 'diversity' and how they construct difference is necessary for analysing their narratives of experience, which begins in the next chapter. 


\section{Chapter 7}

\section{"What's going on here?" Challenge narratives and the production of teacher identity}

\subsection{Introduction}

In their research with tertiary teachers in New Zealand, Zepke and Leach (2007) found that most of their participants acknowledged the diversity of their students and employed a range of strategies to support students' learning. My research echoes this, with the teachers I interviewed talking about how they attempted to cater for a diversity of learning needs. Their discussions suggest that they value inclusive teaching highly but often experience difficulties with putting it into practice. This leads me to ask how the narratives teachers relate about their challenges and successes in teaching diverse students produce certain teacher identities and not others, and how this might enable teachers to deal with any tensions that arise from their expectations that they teach inclusively and the difficulties they face in doing so. While the teachers I interviewed self-selected for this research, and thus are a biased sample who care about student diversity and consider it important, their discussions nevertheless offer insights into teaching practice with increasingly diverse university student populations. This chapter therefore asks, in the words of Cassandra, "What's going on here?"

In my interviews with teachers, I asked them to tell me about their experiences teaching diverse students. Most teachers responded by relating narratives about their experiences, though a few tended to talk about their teaching programme, department, students or their own teaching background and avoided narrating specific classroom incidents, providing primarily synchronic data and few or no narratives for analysis. Many of the experiences teachers did narrate were about challenges they faced, their responses to these challenges, and their experiences of successful teaching. This chapter discusses these 'challenge narratives' and 'success stories' on the basis that narratives of experience are not representations but active constructions narrated in particular ways for particular purposes. The analysis considers the teacher identities these narratives produce and the cultural narratives teachers draw on in the making of these narratives. 


\subsection{Participants' challenging experiences of student diversity}

In their interviews, participants spoke about a variety of challenges they face teaching diverse students, either in direct response to my questions about the challenges of student diversity or generally throughout their discussions. I begin my analysis of teachers' experiences of student diversity using a hermeneutics of faith to provide an overview of the key challenges teachers discussed in their interviews. As noted in the previous chapter, many participants spoke about teaching international students, especially students' difficulties with speaking and understanding English. Teachers were challenged to find ways to communicate effectively with their NESB students. Some teachers also discuss international students' attitudes to the teacher (teacher as 'God') and how this disrupted their preferred methods of teaching. Other challenging issues were plagiarism, lack of participation and speaking in the classroom, and reluctance to ask for help. Three teachers identified a difficulty for international students in understanding the New Zealand content of the curriculum.

Six of the twenty-two teachers I interviewed are immigrants themselves, and Cassandra and Elaine speak of challenges in learning about Māori culture. Elaine, Emily and Maria speak about understanding issues of biculturalism and its relationship with multiculturalism. As Maria puts it, “we still don’t really understand ourselves as a bicultural country and many people say 'oh no we're multicultural', so we have to understand biculturalism before we understand multiculturalism." Elaine and Emily note that their experiences of multiculturalism in their home countries do not easily translate to the New Zealand context.

Religion and differences in worldview are identified as challenging by several teachers. Maria notes that some of her international students come from "strong faith-based religions which also means that they have particularly different outlooks" and that this can be difficult for teaching some aspects of her curriculum. Ala raises the issue of tolerance between students, but generally this was not problematic and several teachers talked about promoting respect in the classroom for all students and viewpoints, with some saying they would intervene if students were disrespectful. Discussion about religion was limited to some teachers in FHSS and Education courses, as these were the classes that were more likely to raise topics that could be controversial for religious students. 
While international students and cultural issues dominated discussion overall, these did not provide the only challenges that participants talk about. Other challenging issues relate to teachers' understanding of, and interacting with, students of different ages, background knowledge, academic abilities, physical and mental health issues or impairments. Many of the examples of challenges teachers talked about in these areas relate to differences between teachers and students, for example Michael talks about how his younger students have a very different perspective on a topic than he has and how this challenges him to understand their point of view. A few teachers talked about being challenged by younger students with greater ICT skills than they had. Other areas of challenge for teachers relate to students with issues that affect their attendance, their participation in class, or their ability to communicate difficulties with their learning. These aspects of diversity could include impairments, health problems, poverty, and family commitments, which could provide significant challenges for teachers but were generally given less discussion by participants.

Looking at the different challenges participants narrated shows that some issues were experienced as a single instance, such as a student who could not attend class due to lack of money for transport, while other challenges were experienced as an ongoing issue related to a significant number of students - such as NESB students - that impacted on the teacher's pedagogical approaches and on classroom dynamics. This could be a reason why discussions of international NESB students dominated the transcripts of many participants. Teachers' discussions of their experiences of student diversity often construct diversity in deficit terms, as difference from a norm rather than difference as variation or difference-inrelation. Analysis of the content of teachers' narratives provides insight into the issues that are important to them in their teaching, but analysis of how these narratives are constructed using a hermeneutics of suspicion is needed to explore what they achieve in their telling, and in particular in this chapter, what teacher identities are produced and what effects these might have for teachers. 


\subsection{The narrative production of teacher identity}

\subsubsection{Introduction}

Speakers construct experiences through narrative but narratives also construct speakers, that is, people construct and perform the self through narratives (Chase, 2005). Narrative researchers explore how narrators shape their identities, and the subject positions and social locations they speak from. Chase explains:

...narrative researchers view stories as both enabled and constrained by a range of social resources and circumstances. These include the possibilities for self and reality construction that are intelligible within the narrator's community, local setting, organizational and social memberships, and cultural and historical location. (p. 657) In this chapter I explore how teachers' narratives produce some identities and not others. However, I need to explain what I mean by 'identity' and how it is produced in narratives. When a person narrates their experiences, they make themselves the subject of their story (a self-narrative). Chappell et al. (2003) describe two interdependent processes of narrative identification that narrators engage in. Reflexive identification refers to the way a person understands himself/herself as a unique individual with a past, a present and a future. This is not to posit an essential self, such as in a referential approach to narrative where identity is understood as the unfolding of a pre-existing self that is more or less true (Bamberg, 1999). Instead I draw on a performative approach in which narrative involves the 'doing' of identity (Swan \& Linehan, 2000) and the narrative produces that to which it refers (Peterson \& Langellier, 2006). This narrative approach considers how a narrator reflexively constructs an identity that endures through their story, something that Western cultural forms of narrative generally require (Gergen, 1998).

The self that narrators construct is unique but is not original, because the resources drawn on to define a self must be culturally available (Chappell et al., 2003). Thus the second process of narrative identity formation is that of relational identification, a process whereby identity is created through its location within or against available emplotted stories. For example, to tell a story that positions the narrator as a teacher requires that 'teacher' is a social identity already available to the narrator. However, what being a teacher means is contested and changing. Identity is therefore an ongoing and dynamic process, not a static achievement. Chappell et al. (2003) summarise this approach: 
A person's identity is thus both centred and decentred, such that although one can say 'I am me', the 'me' that is referred to is always constructed out of socially and culturally available identities and their attendant practices. (p. 49)

Considering teachers' narratives as performative means looking at how they are concerned with constructing and presenting preferred identities (Convery, 1999). It involves asking which teacher identities are produced and which are concealed. If selves are greater and more complex than can be expressed in narrative, then some identities will be revealed and some hidden (Day Sclater, 2003), and drawing on a hermeneutics of suspicion to analyse this can help understand the social resources and constraints out of which preferred identities are produced and reveal rejected or devalued identities. For example, if a preferred teacher identity is one where teaching practice is undertaken in the best interests of students, then this will have implications for teachers in how they talk about their experiences of teaching and will give insights into the discursive contexts that form such identities. This chapter focuses on exploring teacher identities, and the contexts they are produced in are explored more fully in the next chapter.

Teachers used a variety of narrative forms when they discussed the challenges of student diversity. One way to analyse these forms is to consider how the plot of a narrative progresses over time. Gergen and Gergen (1986) identify three basic plot formats. These are: the 'progressive narrative' where the story advances steadily (the situation being talked about gets better); the 'regressive narrative' in which the plot involves a course of deterioration or decline (things get worse); and the 'stable narrative' in which the plot remains steady (things stay the same). Complex plots can include any combination of these three basic formats. While some writers have suggested other forms of narrative, such as Frank's (1995) 'chaos stories', I found Gergen and Gergen's basic plot formats the most relevant for analyzing how participants in this study narrate their experiences of student diversity.

\subsubsection{Challenge narratives}

Analysis of teachers' transcripts identified several types of challenge narrative. The first of these I refer to as 'diversity is difficult narratives'. These narratives speak of difficulties 
and challenges that teachers could not resolve and are stories without progress or a 'happy ending'. Most fit Gergen and Gergen's (1986) stable narrative format, though some display a regressive format. Many of the narratives teachers told about challenges experienced with international students are of the 'diversity is difficult' type. Chris talks about some problems with teaching international students and her narrative ends with no resolution.

...some of the international students, they expect that there is a right answer, that you will tell them how to think about something and that there is a right answer that you will then want them to produce in the exam. And if they say but, so what is something or other, and you say 'well you think about it and these are the issues' and they can get very frustrated probably with you - I don't think they show it — but that you don't tell them there is an answer because you're the sensei or you are the teacher, you know the answer, why not just tell them and then they can repeat it for you and I think this has come out.

In Chris's narrative, she is positioned by her international students differently from how she positions herself as a teacher in a New Zealand university. The narrative contrasts a transmission of knowledge pedagogy with Chris's preferred approach that involves students in the construction of knowledge. This narrative produces difference as opposition and positions Chris as a 'frustrated teacher'.

A narrative from Sandy also produces these opposing teacher/student positions, when he says that some students "can't get over their perception of a huge gulf between me as the 'learned teacher' and themselves as the humble student." This 'gulf' in perceptions of teacher identity causes difficulties with pedagogical practices for both Sandy and Chris. Another narrative from Sandy constructs New Zealand academic teacher identity with less distance than that afforded by international students. Referring to supervising an international postgraduate student, Sandy says,

You're somehow or other put on a pedestal and it's rather difficult to talk down from the pedestal to the student. You need him to have the attitude that 'you're doing the research, you're going to be the subject expert in this particular area'.

He also says that domestic postgraduate students are more comfortable with the idea of "university as a place where knowledge is debated amongst people of a reasonable level of equality." Here the preferred teacher identity is that of 'co-constructer of knowledge', a positioning within a student-centred discourse of teaching that invites students to take up a position as co-constructor of knowledge in preference to the 'humble student' position offered by an 'expert teacher transmitting knowledge' discourse. 
Ann is another teacher who describes the challenges of teaching NESB international students.

...one of the problems with having foreign students, overseas students I find is that, particularly the Chinese students, I'll talk about them first because they've been sort of more dominant over the last few years...Their basic English is good but it very much changes the way you have to teach, you know, I've got to give them time to understand what it is that they're reading whereas if you've got a local student, New Zealand student, or an English speaking student, you've got none of those difficulties to contend with. The upshot of that is that if you've got a class that's dominated by Chinese students, then you've got to teach in a fashion I think that suits them which doesn't suit our local students, they get pretty cheesed off. So that I think is the major problem.

Ann's narrative implies a change for the worse (a regressive plot) to which she adapts, ending with a dilemma that she has no answer for, thus there is no 'happy ending'. This narrative takes an assimilation perspective of diversity when it notes limits to the accommodation of international students' learning needs and the dissatisfaction of domestic students. Narratives that do not talk about the difficulties students might share or the learning needs they might have in common reinforce the international/domestic student binary, but may not accurately reflect teachers' awareness of the complexities of students' approaches to learning and learning needs. As Polkinghorne (1996) notes, human experience consists of multiple and simultaneous events, and constructing a narrative about a particular experience involves 'flattening' (omitting details and condensing some parts), 'sharpening' (elaborating and exaggerating other parts), and 'rationalization' (making the narrative consistent and compact). Teachers' storytelling in this study tended to reduce their lived complexities to more simple plotlines and characters. Although teachers related their narratives in response to my interview questions, regarding these narratives as performances means that I need to consider the purposes which these narratives fulfil, bearing in mind that these narratives are always limited and partial reconstructions of events.

Storytelling in many of the 'diversity is difficult' examples provided an opportunity for teachers to express frustration and failure, something they may not feel confident doing with colleagues or managers. Convery (1999) suggests that teachers may fear being exposed as inadequate as teachers in relation to perceived stereotypes of 'good teachers' who are "always totally committed, struggling with and actively challenging students, sublimating their personal needs to the needs of their students" (p. 141). I do not know to 
what extent my interviews allowed teachers to 'offload' frustrations about teaching to a sympathetic researcher with confidentiality assured. As Watson (2006) notes, interviews can be cathartic or therapeutic and are a ubiquitous part of Western societies, and "there seems to be a ready acceptance, eagerness even, both to be interviewed and to watch others' selves unfolding” (p. 368). This 'unfolding of self' acts as a confessional practice where, according to Foucault (1976/1990), people confess their sins and troubles, thoughts and desires, and reveal what they find difficult to talk about. Foucault describes confession as "the formidable injunction to tell what one is and what one does" (p. 60) and argues that it has become one of Western society's most valued techniques for producing truth. If interviews involve confession, then they are not just cathartic but are an effect of disciplinary power (Watson, 2006). Usher et al. (1997) explain that confessional practices "work through the bringing forth of one's self which becomes an object of knowledge" and are "implicated with the achievement of an empowered and capable self" (p. 19). Confession thus acts as an individualising and disciplining process whereby the social construction of selves is constrained into producing some identities and not others. In applying these ideas to the interviews with my participants, I consider how teachers' narratives portray an 'empowered and capable' identity and how that identity is threatened or compromised.

Some 'diversity is difficult' narratives talked about domestic students as well as international students. In a narrative that constructs difference relationally, Emily talks about the influence of her age and gender.

You accept that, for example, sometimes men and women of an older generation find it difficult to accept someone who's younger than them or someone who's female in a kind of authority position and that's still an issue for some with that... I think also for some younger students they, I think one of the things that they sometimes find difficult and again I don't think this is related to, you know to any particular group of students but I think it's just negotiating a different relation that you have with a university lecturer, in a sense it's more grown up sort of interaction that you have and sometimes that is a difficulty negotiating that I think and they have to kind of learn how to manage those new boundaries because you're not quite a school teacher and you don't want to be you know quite a school teacher.

This narrative describes the different understandings Emily and her students have of 'teacher', positioning Emily differently in relation to older and younger students. It portrays differences in age as involving power relations and the construction of teacher 
authority. Gwen talks about similar challenges. Her narrative describes her as a relatively young academic who has experienced difficulties with younger students wanting to be her friends, and who have "a lack of perception of the fact that there is actually this professional distance which I'm required to maintain." She says that some of her older students have difficulties when she asserts her authority and "feel as though they've been told off by a youngster.” Expectations around what constitutes a 'professional' are raised here by the narratives of Gwen and Emily, showing that, like with the 'teachers-on-apedestal' examples, teacher identity is produced and negotiated in relationships with students in particular university contexts and educational discourses.

These narratives show that identities are constructed from what a teacher is not, as well as from what a teacher is supposed to be. A 'professional teacher' needs to balance being not too distant (up on a pedestal) with being not too close (being a friend), which, as Gwen's words "I'm required" suggest, implicitly delineates the boundaries of teachers' relationships with students. A university teacher should also be different to a school teacher, and Emily's narrative suggests that this involves a 'more grown-up sort of interaction', and she talks about this saying,

I think if they're just beginning university study they're a little ah, some of them, not all of them, some of them are a little less comfortable with, you know, interacting with each other because they're used to sort of sitting in class and you know the teacher does all the talking and so on so they find that a bit more difficult.

Emily relates another narrative about helping first-year students understand what is expected from them in university study and integrating them into academic culture. Emily's narratives produce her preferred form of university teacher/student relationship in which students are positioned as interactive participants in learning and she is positioned as the facilitator of learning. Many teachers spoke of their efforts to encourage students to actively participate in class, suggesting that this is necessary for effective learning. In Chapter 9, I explore how this emphasis on participation can be understood as a disciplinary practice (Foucault, 1975/1995).

Vanessa also refers to a 'school teacher' identity in a narrative about age differences. Last year one of my C classes, I had three adult women and they sat at the back and they, everything they had to do they did it really well. They did everything you know, participated and, but it was a very amusing contrast between one or two of the younger students. One of whom was a young man who obviously had major problems, I would 
guess either health or, mental health probably. I never found out too much but he was extremely intelligent but rarely there and when he was there, if he started talking you couldn't shut him up and he would drift off and, and then there was the girl in the class who spent her entire time with her phone under the table you know, texting and I was a school teacher for many years and this sort of behaviour tends to bring out the school teacher in me. And, the worst thing I could do was catch the eye of these lovely women at the back of the class because they would be giggling amongst themselves knowing what I was coping with and thinking 'God I'm glad I'm not up there' and, and I'd been trying to persuade the girl to actually pay attention and, the boy to shut up and stick to the point you know and, so I mean in some ways it was frustrating but they, I felt they were with me all the way you know and because they understood, they could put themselves in my shoes and knew what I was coping with. So yeah, that was really nice. This year I've got one woman who's probably mid-thirties with a couple of young children, so again it's nice to deal with someone mature like that because um, even if they've got a few problems, you can talk to them in a different way from some of the young things who are just out of school.

This narrative positions Vanessa (a mature teacher) as similar to mature students (depicted in positive terms), and as different from younger students (depicted in negative terms). When Vanessa is shifted into a schoolteacher identity, her distance from the younger students is increased, and the reference to them as 'young things' further increases this distance. The narrative portrays the mature students as allies whose support helps Vanessa deal with the difficulties of younger students, thus positioning students as with or against her. The plot acts to identify teaching difficulties and explain the cause, and ends with the moral of the story, that mature students are 'nice to deal with'.

Vanessa's narrative takes a complex teaching situation (for example what about other students in the class) and constructs simplified characters and plot. This raises the question of what such narratives achieve in their telling. Through the descriptions of the difficult students, Vanessa's narrative constructs an ideal student-conscientious and attentiveand an ideal relationship with such students - the teacher can communicate easily with students and focus on her teaching. The fact that this ideal is compromised in actual teaching practice suggests that the narrative is a strategy to manage the difficult and messy nature of teaching, something, I argue in the next chapter, that university teachers receive little support for. If the stereotype of the good teacher acts to constrain teachers' public discussions of problems in teaching (Convery, 1999), then setting up a dichotomy between 
good and difficult students could enable teachers to defuse threats to their identity as competent teachers and focus on finding ways to deal with problems.

Difficulties in teaching are the subject of a number of narratives. Kareen talks about his efforts to encourage Chinese and Pakeha students to interact in class. He says

I try and mix them up but it's, honestly it's like trying to mix mercury and water. It just keeps separating out, it really does. It's very hard to get that mixture going. And no-one actually seems to resent being mixed up, they just obviously feel like, and maybe it's a comprehension thing, they just can't understand what's going on, so they gravitate towards people that they can relate to.

The word 'honestly' points to the confessional nature of this narrative and the metaphor of 'mercury and water' constructs and emphasizes differences between international and domestic students. The stable plot portrays Kareen's efforts towards, and lack of progress in, his goal of student interaction, positioning him as a 'fallible teacher' whose efforts to be a 'competent teacher' are frustrated. The effort involved in teaching diverse students is also talked about by Susan, who says:

So there's all these - my god, it's exhausting. There's all these different balls you're keeping up in the, in the air all the time and constantly when you're teaching trying to keep those to the forefront.

Many other teachers also used effort words in their narratives, such as 'try', 'effort', 'challenge', 'difficult', 'hard', 'hurdle', 'overcome', and 'cope'. In the narratives, teacher identity is constructed as conscientious and hardworking, even when the desired outcome is not achieved. Convery (1999) suggests a perception of the 'good teacher' as one who is deeply committed to students. The narratives of teachers who participated in my research suggest that this ideal of the 'conscientious, hardworking teacher' is a preferred identity.

This identity was also found in another form of stable challenge narrative, which I call 'there are limits to what I can do' narratives. In these, teachers talk about the constraints they experience in teaching diverse students. Bob gives an example:

...normally with office hours we'd say okay we have set office hours, but on this day and it's only one hour. But on test times I wanted the students to make sure, okay I give you flexibility, you can come at any time throughout Tuesday, it is devoting the day to you. And I'd find that maybe there'd be two extra students that take me up on my offer. And so even though I wanted to try and cater for them, I wasn't able to, just because from their side, I try to show that I was as willing as possible and try to eliminate the barriers as 
much as possible. So from their side, I still wasn't able to cater for them as much as I

liked when trying to counteract the time constraint.

This narrative portrays a teacher doing the best he can for his students, and the emphasis on the words 'wanted' and 'try' and use of the word 'devoted' underline Bob's efforts to help his students and portray him as a caring teacher. The plot shows such efforts being met with a lack of student response and constrained by a lack of time. This and other 'there are limits to what I can do' narratives portray teachers as conscientious and dedicated, doing the best they can to meet the challenges of teaching diverse students in difficult circumstances, and produce a moral teacher identity. Gergen (1998) argues that narratives of the self function to construct a moral identity where the narrator portrays himself/herself as worthy and acceptable in relation to cultural values. Social status and professional authority can be accomplished through narratives (Atkinson \& Delamont, 2006), inadequacies in living up to ideals of the 'good teacher' can be managed (Convery, 1999), and the moral purposes of teaching (Fitzmaurice, 2008) can be affirmed. Narratives of 'doing the best you can' can therefore help teachers maintain a moral identity when their efforts to teach students are not achieving the desired result, and their 'competent teacher' identity is compromised.

Another form of challenge narrative with a stable format is the 'it's not the students' fault' narrative. Here difference is described in deficit terms but the problems are caused by something outside the students' and teacher's control. For example, Kareen says

I'm thinking particularly of those students where English is not their first language and they are not fluent at it by any stretch of the imagination. I think that brings them some real difficulties, particularly when they come from cultures that require excellence, so their parents are expecting them to get As and it's not that there's not an A inside them, it's that they're having such difficulty in comprehending what's being spoken to them that it just doesn't make any difference. It doesn't matter how clever they are the thoughts aren't getting into their heads. And I think that's really unfair on the students.

Kareen then says that universities should not enrol students lacking adequate English proficiency. This narrative places a lack of English proficiency combined with high parental expectations as the cause of problems for the students and teacher, but suggests that the university is also responsible. A narrative from Maria also points to limitations in how her university supports students. She says that some of her students come from lowincome families and experience problems such as 
... not having the homework space at home, larger families, overcrowding, poor health.

I've had students that don't have enough money to come on the train to university or have lunch, and um, let alone afford a computer and so they'll spend nights at university sleeping. And this is quite a common occurrence and in my honest opinion I still don't think the university recognizes that type of diversity across students.

The phrase 'in my honest opinion' points to the interview acting as a confessional practice allowing Maria to talk about how her university does not take notice of her concerns. Maria's and Kareen's narratives recognize 'unfairness' but their narratives finish without solutions and position them as teachers who are up against a system that is too powerful for them to change. These narratives position teachers within a network of power relations where they and their students are enabled and constrained by the effects of institutional and state policies and practices.

A few teachers talk about how difficulties are not the students' fault and consider how they can understand and help their students. Cassandra says

I tend to look at it that every time I'm having a problem with a student or I can see that I'm not reaching them and they're not learning what they need to learn, that I consider that a signal for me to step back and go 'what's going on here' and try and find a different approach. And so it is actually just trying to be self aware and have some humility, you'd go I'm not going to blame it on the student. It's actually something that I need to find a different way through because there are so many different cultural things. Same with assignments. If anybody hands things in late I can't just assume that they're lazy. It may be that they've got family responsibilities or cultural responsibilities and those kind of things.

The focus in this narrative on the teacher's role in understanding students' difficulties and adapting her teaching approach positions Cassandra with power-as-agency in the teaching relationship and maintains a 'competent teacher' identity. It also positions her as a caregiver who seeks to assist needy students, producing a 'moral teacher' identity. Although the narrative talks about 'not blaming the student', it nevertheless positions the 'many different cultural things' as problematic. The narrative points to an academic context with little flexibility for 'family or cultural responsibilities' and portrays Cassandra mediating between academic requirements and students' lived circumstances. The "I can't just assume" stance in this narrative is taken by some other teachers, whose narratives emphasize the importance of understanding students' circumstances in order to respond 
appropriately to their difficulties, even if they are unable to help students resolve problems that originate beyond the classroom.

All teachers told at least one challenge narrative, with some telling many. Challenge narratives produce a 'fallible teacher' identity within a plot that describes a challenging experience - a breach between real and ideal practice - and attempts to explain why this situation exists. Because these challenge narratives do not have positive resolutions, teachers as protagonists in their stories often fail to maintain a 'competent teacher' identity. In my interviews with teachers, most describe diversity positively when talking about it as a concept but their narratives of experience often portray aspects of diversity as problematic. If teachers are influenced by inclusion perspectives of diversity, in which teachers should adapt their practices to meet the needs of diverse learners, then there will be a tension between fallible and competent teacher identities. One of the key ways the challenge narratives attempt to manage this tension is through the production of moral teacher identities. Describing themselves as conscientious and hardworking, dedicated and caring, and actively involved in understanding and solving difficulties in teaching diverse students, teachers' narratives allow them to confess their shortcomings and construct an empowered and capable self.

\subsubsection{Narratives of overcoming challenges}

As well as the stable and regressive narrative forms used in the challenge narratives, some teachers related progressive narratives about 'difficulties overcome'. These were not as numerous, nor found in all teachers' transcripts, but they provide a contrast to the many unresolved difficulties teachers discussed and show how they were successful in meeting some of the challenges of teaching diverse students. In these narratives, the plot consists of a challenging or difficult situation, the teacher's response to it, and a successful outcome, though not always told in that order. For example, Elaine describes an issue of cultural representation that came up in class:

Another situation that I've had in a group of about twelve students was using a narrative from a Māori woman, and there was a Māori woman in the group and she actually stopped me and said 'I need to talk to you outside' and came outside and said 'you can't, you can't misrepresent me and my people in this way' and um, she was really angry with 
me for using a particular um, ethnic representation I suppose. On that occasion, those students hadn't done Māori models [of the topic] or anything so um, I said to her 'look we need to, you know, this is the reality of practice and this is who people are going to meet so I need to know their cultural competence about what they're thinking about in terms of how they'd approach this woman and whether they're actually um, ready to go and meet people like this' and sort of invited her to co-teach with me so that she could do a bit of work around the cultural stuff that I didn't know, and that worked quite well actually.

This narrative describes an inclusive response to a teaching challenge, and an outcome that benefits student (and teacher) learning. It portrays a protagonist who, when her position is challenged, responds by acknowledging the limits of her knowledge. The phrase 'cultural stuff' portrays unknown knowledge as things, suggesting the simplifying of complex cultural processes into teachable content in a predominantly Western academic context. When Elaine invites her Māori student to co-teach, the narrative affirms subjugated knowledge and decentres to some extent the teacher's position as a Western academic. This is an example of Burbules' (1997) concept of 'difference against.' In another 'difficulties overcome' narrative, Michael narrates his experience of conflict in the classroom during a discussion between "very committed Christians and the non-religious people who hadn't liked the reference to God." He tells how he helps the students maintain respect while disagreeing, which adds to "the richness of the learning," and says that conflict can add to the learning experience. These 'difficulties overcome' narratives position teachers as problem-solvers and conflict-managers, show problems turned into benefits for student learning, and produce 'empowered and capable' teacher identities.

Some 'difficulties overcome' narratives portray the teacher 'making a difference' in some way. These narratives are uplifting and inspiring, and show the results of teachers' care for their students. They were narrated by six teachers, four of whom told more than one 'making a difference' story. In some stories this involved providing support for a vulnerable student. Susan tells how she made a difference.

...often I will make little personal contracts with students as well, that might be struggling and there's one at the moment, who is an African student and he calls me Miss, he can't call me by my Christian [name], and that's fine and we've agreed that's okay. But he came to me, he's, reluctant in class to initiate himself into a group or to talk first, so we've just got this little contract that he's going to talk within the first five minutes of a lecture. And it's cool. It's really working with us. And I said 'I'll just keep my eye out for 
you' and he said - and the more he said things, the more he's got recognised by other students and therefore the more when, when I say 'hey get into a group of three or four', the more they will turn to him. So he's being more included because he's just being a little more vocal. And he's a very able student which is, the others were tending to, to think that maybe he wasn't. But he's able to display he does actually know what people are talking about and so there's, so that's cool.

This is a narrative of inclusion that tells how an outsider becomes an insider and describes what 'works' in that situation. The plot involves the identification of a challenge, the protagonist's response to it, the action taken, and the outcome. Other teachers also use this plot. Grace gives two examples of how she responded to problems that an international student had with their studies and how that led to the student succeeding on the course when they would otherwise have failed or withdrawn. Cassandra talks about a student “who's been not an easy student but he's actually been quite a delight. He suffers from a number of motor issues and a form of autism", and she explains how this student received encouragement from teachers which enabled him to succeed and undertake further study overseas. Helen tells a story about an African NESB student with a speech impairment whom she assisted to give a class presentation successfully. These narratives portray teachers as responsive to students' needs and as instigators of change who act with agency to successfully achieve an outcome. The narratives position teachers as care-givers in their support of vulnerable students and as dedicated to students in their willingness to put in extra effort to help students. These narratives produce moral and agentic teacher identities, and act to confirm the power of teachers to make a difference.

Other 'making a difference' narratives describe responses to teaching challenges that affect more than one student. Elaine's teaching includes challenging discrimination. She gives an example of a female student who used the word 'gay' in class in a derogatory way and so Elaine challenged her about this. Elaine explains that earlier in the class a gay student had talked about how difficult it was to be 'out' at university, and after class he thanked her for standing up against a form of discrimination that affected him. Elaine was concerned about the female student she had challenged and says

I was really aware that she was horrified and mortified. It was Friday afternoon at four o'clock and off she went you know, so I knew that I was going to see her on Tuesday morning and um, I had to do just a little bit of taking care of that situation and her in terms of 'are we OK' and 'are you going to carry on' and [she] said 'yeah I'm alright thank you'. 
This narrative portrays Elaine acting with care and concern, both for the perpetrator and victim of the derogatory remark. The narrative positions her as an advocate for those who are marginalized (care as activism) and as caring teacher for all students (care-giving).

Liz is another teacher who initiates change. She has large classes with many international NESB students, and says

...there's started to become a prejudice or a view that international students don't want critical thinking, that they want rote learning, it's what they're used to and if you give them critical thinking they'll hate it, and it won't work and it's just going to be a disaster, and I came into my teaching with a view that I was going to put more of this stuff in there whether they wanted it or not because goddammit this is a university, and I don't care if it's their spinach it's good for them and they're gonna eat it you know and so I went into my classroom and my lectures with that attitude, 'you're all going to do this, this is what it's about' and trying to get them to think about different points of view and think about how do we put these things into practice and applications, just pushing the thinking into areas that when I was a student we didn't go. Now I'm still I'm talking about second year but appropriate for second year, pushing them in ways, and, to my surprise the international students love it, love it, and I think it just goes to show that that, I think we underestimate them so often.

Liz's narrative positions her view of international students and her teaching approach in opposition to a general view of teaching international students. Although Liz's teaching method pays off, the words 'to my surprise' suggest that the outcome could have been different. The metaphor used, that students 'eat their spinach', the comparison with Liz's own student experiences, and the narrative's plot all act to position Liz as a competent and authoritative teacher who produces successful students. The moral of the story is that teachers should not underestimate the ability of international students to learn critical thinking, in other words, to successfully engage in Western academic practices. The narrative creates a moral identity of an inclusive teacher who contests the myths about a particular group of students. The narratives of Liz and Elaine produce caring-as-activism through the portrayal of teachers risking unpopularity for doing what they believe is in the best interests of students. They also describe learning environments high in both support and challenge which, as Daloz (1999) notes, enhance student growth and learning.

Narratives of overcoming challenges describe critical incidents from which teachers produce practical knowledge and construct empowered and capable selves. These 
narratives produce competent teachers who act to include marginalised students, negotiate classroom conflicts and facilitate student learning. Their actions 'make a difference' and produce forms of care that support vulnerable students. The progressive plot of the narratives depicts teacher/student relationships as transformative, and produces inspirational stories of teaching in higher education classrooms. A 'triumph over adversity' plot is common in Western thought and acts to provide teaching with a sense of meaning and purpose (Convery, 1999).

\subsubsection{Success stories}

All of the transcripts included stable format narratives that depict the narrator successfully teaching diverse students. These 'success stories' of teachers' competence provide a contrast to the challenge narratives. They position teachers as professionals with expertise and experience in their field and employ various narrative strategies to do this. One of these strategies involves the positioning of teachers as facilitators of student learning. In many of these success stories, teachers talk about the use of small group work to enable diverse students to relate to and learn from each other. Emily uses group work to make her teaching more effective. She says:

...what I quite often do will try to use group work to break that sort of, you know that sense that they've always got to be talking to me and that every interaction has to be between me and them. And it breaks the ice between them and makes them more comfortable also about airing their views in class so that what they can do is they can come up with an idea or something amongst themselves and they have shared responsibility for it.

In this narrative, Emily places importance on interaction in the classroom to avoid portraying herself as the sole possessor of knowledge. The narrative positions her as a competent teacher who successfully employs strategies to enable her preferred pedagogical approaches. Several other teachers spoke of being facilitators of student learning and encouraging students to share their knowledge. Cassandra says to her students "I don't have all the answers and we're learning through this together." This construction of a 'facilitator of learning' identity was identified mostly in the transcripts of FHSS and Education teachers, though some Business teachers also narrated this form of teacher 
identity. It positions teachers as student-centred and constructs this as superior to teacherled approaches to teaching.

Other narratives also depict student-centred approaches to teaching. For example, Bob describes how talking to his students enables him to understand their learning needs and "customize" his teaching style. However, some success stories show that while teachers are student-centred, they also maintain an 'authoritative teacher' identity. In the narrative from Emily in the previous paragraph, she describes being student-centred. In another narrative she says:

What I do not, what I will not have is people being disrespectful to other students in the class and belittling then or laughing at them in any way and if I think that's happening then I will do what I can to put a stop to it. I'll either speak to the students involved or I will say something straight out-I'll say this behaviour is not acceptable.

This 'authoritative teacher' stance is depicted as working in the interests of students to ensure a safe learning environment and allowing the teacher to take a student-centred approach in her teaching. Other teachers related similar experiences. Elaine talks about how she mixes students up into small groups and encourages communication between diverse students, noting that "I'm aware that some voices need promoting." Helen talks about needing to be both flexible and authoritative and notes the importance of communicating her expectations to students clearly. These examples of teachers' successful teaching strategies position them as competent teachers who are both authoritative and student-centred, providing what Elen et al. (2007) refer to as powerful learning environments, that is, classrooms that are both safe and challenging.

Another way that some teachers' narratives produce competent teacher identities is by positioning them as approachable and accessible to their students. Kiri says

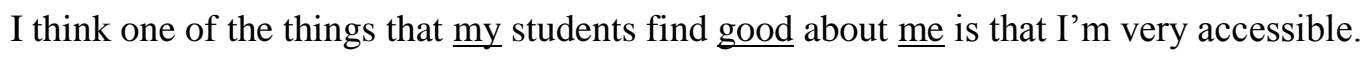
So for those who need follow-up conversation or who need to have someone read through the draft of an essay for example with them when they're- because some of them are just learning... And so when they're learning to write I am accessible and available to, to help them with those kinds of things.

This narrative positions Kiri as a conscientious teacher who is accessible to her students, and the emphasized words make this specific to Kiri, suggesting that other teachers may not be so accessible. Tina says "I think I come across as fairly approachable", and Cassandra says "I always try to be relaxed and have a laugh and they know they can come 
and talk to me about stuff in the hope that we can stop things before they become an issue." This 'approachable and accessible' teacher identity is a position within inclusion perspectives and student-centred pedagogies that invites a response from students which they may not accept, as Bob noted in a challenge narrative discussed previously. As Swan and Linehan (2000) note, positioning illustrates the relational nature of identity; people always define themselves in relation to something or someone else. Approachable teachers might be available to assist students, but students must do the approaching, as shown by Ala who says to her students, "well I can help you with that but you need to come and ask."

Another narrative strategy found in some success stories involves teachers comparing themselves with colleagues. Susan positions herself as a hardworking, student-centred and competent teacher, in contrast to some other colleagues.

... being older you know, I've got to be careful I'm not keeping my, you know, keeping with it in terms of my perceptions of society and trying to keep in touch with what their experiences are. And listening and working with what they're saying and what they're experiencing. Which is problematic. Well it's not, it's interesting but it is also tiring. And from some of my colleagues, you know, it almost, you almost think they go and deliver a lecture and students take it or leave it.

Susan's narrative refers to diversity as tiring and using up energy, and positions her as making an effort to understand students as opposed to just delivering content, in spite of the energy this requires. The narratives of several other teachers compared them with colleagues to show how their teaching approaches are more inclusive and/or effective. Liz says that she prefers her tutorials to be interactive rather than a mini-lecture, and says I'm not going to stand up here and tell you the answers and you write them down and that's what it used to be like, a lot of the tutorials in the subjects are still like, but it's not what mine are like.

Rachel also wants interactive tutorials and says

But, when you get a tutorial group which is spoon-fed by someone else, who doesn't push for everyone to respond and if they don't answer a question quickly gives them the answer, you encourage a form of behaviour which actually is not engaging the students in the act of learning and I don't get good assessments always because I don't tolerate that. I'd rather sacrifice my personal assessment and know that I have encouraged them to engage in a safe environment. I don't care about my assessments. It's going to count 
when I go for promotions. But I'd really really rather be known as a teacher who gets the students to engage in active learning.

Rachel's narrative positions her as a teacher who values effective teaching and learning over being liked and as persistent in her efforts to engage students, and at the same time tells how she aims to present a particular public identity, that of a competent studentcentred teacher. The narrative takes a moral stance and provides an opportunity for Rachel to espouse her beliefs about teaching, a function that was found in a number of teachers' narratives. Teachers espoused beliefs and actual practices may differ (Merriam et al., 2007), and this research focuses on teachers' talk and considers what teachers' narratives achieve in the telling. In the narrative above, Rachel constructs a principled and competent teacher identity that stands against other teachers' identities.

Success stories allow narrators to display their competence as teachers and position themselves as student-centred and authoritative, as approachable yet encouraging student initiative, and as better teachers than some of their colleagues. Success stories reinforce the notion of an empowered and capable self, and allow teachers to espouse their teaching ideals and describe how they live up to them, in contrast to challenge narratives which portray a breach between teachers' ideals and the reality of their teaching practice. Success stories were a key part of most interviews, and given that the teachers who volunteered to participate in my research were interested in student diversity, the telling of success stories allowed them to reinforce their preferred teaching identities and demonstrate their commitment to inclusive teaching.

\subsubsection{Discussion}

Expectations of teachers' competence will shape the construction of their narratives. Churchman and King (2009) argue that academic narratives are ...constructed in a critical environment where members are scrutinised through a multiplicity of lenses. They are scrutinised as teachers by students, as workers by management and administration, as researchers by their peers and as a critical voice by the broader community. (p. 513)

The teachers I interviewed construct competent identities in their narratives of teaching experiences, and also, I argue, use the interviews as a confessional practice where they can 
produce a fallible teacher identity without being subjected to scrutiny. I suggest that they manage tensions between competent and fallible identities by constructing a moral identity of the dedicated, hardworking teacher who tries to understand diverse students and adapt his/her teaching practices to meet students' learning needs, drawing on inclusion perspectives and student-centred pedagogies to do so. In some narratives, teachers displayed authoritative teacher identities, but these were produced in the interests of students. Identities that were not produced in the narratives included 'teacher-centred' identities, such as the teacher who acts in their own interests above that of students, the teacher who puts in the minimum time and effort required to teach adequately, or the teacher who uses a didactic style of teaching. Such teachers would have been unlikely to participate in my research; however an understanding of identity as complex and dynamic suggests that these and other denied identities could coexist with other more socially acceptable identities. Indeed, for the job to be sustainable, teachers most likely will need to take care of their own interests, set limits on caring for students, and consider their longterm career prospects, thus needing to be 'teacher-centred' in some ways. In some narratives teachers did talk about self-care, and other interests may have been seen as not relevant to the interview or were not given an opportunity to be discussed. However, the identities that teachers produced in their narratives of teaching diverse students appear to be constrained by student-centred and inclusion approaches to diversity, suggesting the dominance of these perspectives in talking about higher education teaching contexts.

\subsection{Cultural narratives}

Teachers do not tell stories in a vacuum; they draw on available cultural narratives to talk about their experiences. As well as analysing the smaller narratives of experience found within teachers' transcripts, I consider the whole transcript as a narrative and analyse this to see what kind of overall plots and teacher identities these contain. These larger plots and the way they position their teller gives an indication of the cultural narratives informing teachers' identities. Beck and Beck-Gernsheim (2002) argue that contemporary globalized society requires individuals to adapt to the changing demands, controls and constraints of social institutions. Identity must be worked for: "The choosing, deciding, shaping human being who aspires to be the author of his or her own life, the creator of an individual identity, is the central character of our time" (Beck \& Beck-Gernsheim, 2002, pp. 22-23). 
The creation of an empowered and capable identity in teachers' narratives fits the requirements of an individualized society. When the modern myth of progress is replaced by postmodern uncertainty (Usher et al., 1999), “individualism, diversity and scepticism are written into Western culture" (Beck \& Beck-Gernsheim, 2002, p. 23). However teaching is about planned change (Usher et al., 1999), which presumably is a change for the better, in other words, some kind of progress. This raises questions about how transcripts as narratives position teachers in relation to the 'modern myth of progress' and how they might portray teachers as creators of their own identities.

Some transcripts as narratives took a regressive form overall. Three teachers' transcripts contained more discussions of difficulties than successes or benefits in teaching diverse students. Kareen's transcript focuses on students' difficulties with English language, numeracy, and essay writing that have made teaching more difficult. Sandy's transcript depicts him struggling with similar issues and says that teaching diverse students has given him "some battle scars", suggesting an identity as a struggling hero who makes little headway. Ann's transcript mainly discusses problems that have arisen in her teaching with increased numbers of international NESB students at her university. She has been 'forced' to change the way she teaches and assesses students. The implication of these regressive transcripts is that being a tertiary teacher was better before there was such a diversity of students, in particular the diversity of English language proficiency and academic ability that has made the job more difficult. These transcripts portray teachers as competent but struggling, and the narrative voice is sometimes sceptical or disillusioned. These teachers all taught in courses with high numbers of NESB international students.

Six teachers had transcripts about competence with an overall stable format, like a large form of the success story. Grace's transcript portrays hers as a caring and competent teacher who is student-centred and who aims to understand and meet students' needs and provide students with extra support when she can. The focus is on Grace's successes in teaching diverse students and even when she discusses challenging situations, there is always a solution or partial solution. Richard's pedagogical approach relies on successful collaboration between diverse students, and his transcript as a success story reflects the way his classes generally run 'smoothly'. The transcripts of Chris, Ray, Rachel and Emily discuss their teaching approaches, the students they teach and their institutions in ways that include difficulties and successes in teaching but with an overall emphasis on teacher 
competence and dedication. Such transcript narratives produce empowered teachers in storylines of empowering students to achieve success in their learning.

The remaining transcripts as narratives had an overall progressive format, and were about teachers facing challenges and overcoming them, trying out ways to improve their teaching, and experiencing successes as well as failures in teaching diverse students. They position the narrator as a hero who faces numerous challenges and struggles to overcome them, and this form of heroic storyline is considered a key myth of Western culture (Campbell, 1949). The challenge could be seen as a 'dragon', and possible responses include slaying the dragon, taming the dragon, befriending the dragon, or understanding the dragon (Pearson, 1991). Bob's version of the heroic narrative portrays him as a flawed hero who battles numerous odds to understand and manage the dragons of diversity. Meeting challenges involved in teaching diverse students and overcoming them constructs a competent and moral teacher identity for Bob. The emphasis on improving his teaching draws on the cultural myth of progress, a myth that holds up as desirable an autonomous self that takes responsibility for its failures and successes. Ala's transcript also depicts her as a flawed hero who struggles with the challenges her diverse students present. She seeks to understand diverse students' needs and acts as a problem-solver who takes responsibility for helping her students to succeed. Like Bob, she attempts to understand and manage the 'dragons' of diversity. Gwen's transcript depicts many challenges in teaching diverse students but the narrative focuses on progress through learning from experiences and improving teaching. Helen's transcript describes a number of challenges around student diversity but portrays diversity as beneficial for student learning and depicts the ways Helen deals with challenges. The transcripts of Helen and Gwen describe attempts to befriend the dragon of diversity and make it a valuable part of teaching and learning. Vanessa's and Tina's transcripts also do this but to a lesser extent.

Several heroic transcripts were like quest narratives where the hero/narrator battles adversity as he or she seeks an important 'treasure' or goal. In three transcripts, this hero is an activist who draws on critical transformative perspectives of diversity to attain a goal related to social justice. Elaine's transcript portrays a quest to educate students about equality and overcome discrimination, and to produce competent and socially aware professionals. Michael's transcript has an emphasis on academic freedom and tolerance, and depicts a quest to promote awareness of gender and sexuality issues and the 
acceptance of diverse sexualities on campus. In Maria's transcript the quest involves increasing cultural awareness and social justice in and beyond the classroom. Rather than taking an individual heroic voice like most other teachers' transcripts, Maria's transcript positions her in social networks within and outside of her university that are working for social transformation and justice.

Another form of quest narrative is that of the hero as dedicated teacher whose goal is for students to learn and grow and succeed. While all teachers want their students to do well, this particular narrative format made it the central theme with teachers passionate about what they were trying to achieve. The transcripts of four teachers took this narrative form and all were educating their students to be practitioners. The quest in Kiri's transcript involves teaching her students to be competent professionals who understand and respect diversity. Liz's transcript depicts her as passionate about breaking down stereotypes of international students, setting high expectations of academic achievement for all her students, and encouraging international and domestic students to relate to and learn from each other. The transcripts of Kiri and Liz have an individual narrative voice. Cassandra's quest is less of an individual journey, some of the narratives in her transcript include her colleagues and other narratives portray her classes as learning communities where there is a high degree of interaction and support between students. Susan's transcript also has a strong focus on creating a classroom community where diversity is valued. Her narratives position her as a catalyst who "opens the door" for students to talk about social issues, and who is passionate about educating her students to understand and respect diversity. These quest narratives are progressive in format because teachers relate stories of overcoming challenges and making a difference, even though their quest is ongoing.

These larger narrative forms show a variety of responses to student diversity and point to cultural myths that teachers draw on to produce narratives of experience. The teacher as a heroic individual struggling with the dragons of diversity was far more common than the teacher as a member of a community (be it a collegial community or a community of learning in the classroom) with many voices and perspectives that position diversity as integral to human relating. Narratives that portray teachers taking a high level of responsibility for meeting students' learning needs suggest a cultural narrative of dedication and service in 'caring professions' and produce moral teacher identities. In the changing contexts that participants are located, they construct narratives that depict their 
actions in dealing with the challenges of teaching diverse students and act to provide 'noble' identities (Convery, 1999), even when their attempts to address these challenges do not provide the desired results. Teacher identity must be worked for and continually (re)constructed within the relational settings of higher education institutions.

\subsection{Conclusion}

Asking research participants about their experiences of student diversity resulted in the construction of narratives about challenges and successes in their teaching. In their narratives, 'diverse' students are those who differed from the expected student norm. Thus the narratives are about how teachers responded to the needs of these 'different' students, and unsurprisingly, stories about NESB international students dominated discussions. As well as reinforcing a student norm, teachers' narratives also construct a teacher norm through the preferred identities they produce. This norm is a moral one-inclusive, student-centred, hardworking, conscientious, and dedicated. A fallible identity is produced when teachers are not always able to meet the challenges of teaching diverse students. But all teachers produce competent identities that position them as effective and skilled professionals. The balance of fallible and competent identities varies, however most of the narratives construct an impression of an essential teacher-self, one that is or seeks to be empowered and capable.

Convery (1999) argues that in the telling of narratives of experience, teachers invite their audiences to affirm a 'noble' teacher identity. The teachers in this study created noble identities whether or not they succeeded in overcoming the challenges of diversity. However, it is important to note that a different interview with a different interviewer in a different setting would have produced different transcripts, and the narrative plots and identities within these may have produced alternative storylines and identities. Until I began the narrative analysis of teachers' narratives, my own unexamined assumptions about diverse students, teacher identities and teaching practices reflected dominant humanist discourses of an autonomous essential self seeking improvement and attempting to empower others. Such assumptions inevitably construct difference as divergence from a desired norm. Therefore this thesis cannot represent study participants' experiences as 
'what is [really] going on here', but instead it seeks to identify dominant conceptual, narrative and discursive resources that produce certain types of teachers, teaching, and diverse students. This chapter has identified some of these resources. In the next chapter, I consider the relational settings that construct and are constructed by teachers' narratives of student diversity. 


\section{Chapter 8}

\section{"As good a teacher as I can be": Learning to teach diverse students}

\subsection{Introduction}

The narratives discussed in the previous chapter included stories of how teachers overcame challenges encountered in teaching diverse students and the successful strategies they employed. I was therefore interested, especially in the light of my own teaching experiences, how they gained the knowledge and skills that enabled them to teach a diverse range of students. This became one of the interview questions, and I also asked participants what support they received for teaching, especially regarding student diversity. In this chapter, I begin with an overview of teachers' answers to these questions. Their narratives talked about classroom settings as well as the wider institutional contexts of teachers' experiences, inviting further analysis to explore how teachers' narratives construct these settings. As Walshaw (2007) notes,

Every pedagogical practice is influenced by the complex social relations that exist between teachers, students, institutional culture, and all are nested within the larger social world. Teaching turns out to be not so much an individual determined product, as a negotiation between these complex relations. (p. 111)

The second section of this chapter therefore considers how narratives about learning to teach diverse students position teachers in relation to their university contexts and what the telling of these narratives achieves. Thus this chapter also poses and attempts to answer the question: How do participants' narratives about learning to teach diverse students construct their teaching contexts and relationships with colleagues and institutions?

\subsection{How participants learn to teach diverse students}

\subsubsection{Developing teaching skills}

My analysis begins by using a hermeneutics of faith to investigate what teachers' narratives say about learning to teach diverse students. University teachers are not generally required to have teaching qualifications or training, and although professional 
development opportunities in teaching are offered within their universities, these are usually optional. Teachers may not see the need for these, or if they do, they may be too busy to attend. Teaching workloads vary; some academic staff do little or no small group teaching, while others are employed in a full-time teaching role. In my interviews with teachers I asked how they had learned to teach diverse students. The most common answer was that they learned primarily through trial and error and over time built up teaching skills from experience. Maria says that for her "firsthand experience has been key", Elaine says "it's about working on your toes", and for Cassandra, "a lot of it has just been trial and error." Liz says,

I'm very experimental still. I try things and see if they work and if they don't work that's fine and if they do work, that's great. And I try and kind of build a portfolio of techniques and things that work for me.

Feedback from students has also been important for several teachers. Some teachers take the end-of-course evaluations seriously, as Grace describes:

I very much encourage my students to fill them in honestly, to put any comments down. I also let them know that we do use those forms to alter and change what we're doing and so I try and very much to learn from that, what I've done well, what I need to do and that sort of thing.

Other teachers place more importance on informal feedback. Cassandra asks her students for feedback in her classes and says that "it is really useful when you get some students who will say you know, 'that didn't work' or 'I didn't think that was such a good idea'." Likewise Elaine invites her students to "to critique what I'm saying and how I'm doing it." Maria says that

...the best way is to learn is from the students themselves, ask them, talk to them, you know, what's happening, how can I do this better for you, how can I be a better teacher um, in helping you understand key concepts regardless of your background.

Kiri seeks informal feedback from her students on a regular basis, and says I'm not waiting for the one formal time to get feedback. I mean it's an ongoing thing that I — it just enables me to integrate and build into how I can adapt to suit this particular class.

Kiri also notes that “feedback's all very well but if you're not prepared to reflect on it then it's not going to have any impact whatsoever." Nearly half of the teachers I interviewed spoke about reflecting on their teaching practice in order to improve it. Gwen says that student diversity has reinforced the principles of reflective practice, and reflection on her teaching has helped improve her course. Susan explains her reflective practice: 
And I think it's always after I've finished a session with the students and that's what I find often that's the time when I'll stop and just take ten minutes and say hey, I did this this way which will be slightly different and so I must remember that next year, identifying why it worked that way.

Grace says that she uses reflective practice, evaluating what went well in her teaching, and Maria ensures that she constantly reflects on and rethinks her teaching practices. A few teachers mentioned using journal-writing for reflecting on their teaching.

Reading and attending conferences were other ways teachers learned about their diverse students. For Ala and Emily, reading has been helpful, and Emily says that she has got interesting feedback and suggestions about teaching at conferences. Maria says that conferences can help her gain better insights into her teaching practice, and Helen says she has gained knowledge about student diversity from conferences. A few teachers have used professional development courses at their university. Helen has found workshops on teaching have helped her with the challenges she has experienced with some students. Grace says that

...you go to workshops and you get ideas back on how to be inclusive and work with challenges and things in the classroom. So I'm very open to the kind of professional development side of it as well as my own experience as I go through.

For some teachers, professional development courses have been helpful for their teaching, but not necessarily for particular issues related to diversity. Gwen has found such courses mostly helpful but not for some specific cultural communication issues within her classes. Kareen says that at his university, the courses he went on gave participants "a whole lot of really useful tips and ideas about how to handle different situations", but student diversity was not addressed.

Tina has attended a tutor induction programme as well as workshops run by the Disability Service and says,

That was certainly good to I guess um, make you a bit more aware of things or just having that time within the workshop to talk about it and find other people that have similar experiences in their teaching. But it wasn't, it didn't come down to the point where there were something specific that you could take away for your particular teaching situation.

Ala says that she has not been to any workshops "due to having a little bit of an overload most of the time." A variety of professional development courses were available at 
participants' universities but not all teachers attended them, or when they did attend, they did not necessarily gain insights on teaching the diverse students in their classes.

Many teachers in this study gained insights from discussions with colleagues. Ann has "a lot of discussion around the morning and afternoon tea table with other colleagues", and Ala finds sharing experiences with colleagues is supportive. Grace says "I do tend to talk to my colleagues and my peers and I say "what works for you?" Elaine says, "So we share stuff all the time, we teach into each other's postgrad papers as well. So that's a huge massive sense of strength." Not all teachers find discussions with colleagues helpful. For Liz, discussions with colleagues focus on lecturing rather than small group teaching, and there is little support in her department for teaching. Vanessa and Maria say that they work with very supportive colleagues, but Gwen finds some colleagues are approachable while others are less so. A few teachers spoke about having mentors. These were either people on campus who supported their development as a teacher, or people that they had worked with or been taught by in the past and who provided a good role model for them. Three interview participants had previously been school teachers and one teacher explains that she has taken what she learned about teaching in secondary school into her tertiary teaching, and this has been the main source of her teaching skills. Another teacher also draws on his teacher training and says, "I've had a long, long whole career of working with people in classrooms and in groups. And so all of those techniques really that develop as a school teacher, I simply transferred into the university environment." A third teacher takes a different kind of teaching approach with adult students than with the school pupils she taught.

Many participants found the student support services at their universities very helpful and referred students to them. As Grace notes, "Sometimes I might not be the right person [to help a student], so sometimes it's a matter of saying if there's a Pacific Island or a Māori liaison person, student learning support, those sorts of things." Susan has found Disability Support and Student Learning Support have been helpful for students, and Gwen says that Disability Support has been 'fantastic' and helped her to provide support for her students. However, many teachers felt that their universities did not offer enough support for teachers to learn how to teach inclusively, or, according to some teachers, they were indifferent to this need. Gwen says that “addressing students' diversity is, I think, usually considered to be a nice thing to do as opposed to a necessary thing." Michael says he has 
not received any support for dealing with diversity challenges and would not know where to go to find it. When I ask Ann about support for herself as a teacher she says, "Don’t be silly!" and laughs. Liz uses irony when she says, "there tends to be a feeling that tutorial teaching will take care of itself. I mean that, it's not rocket science-you turn up, you deliver the material, you leave, how hard can it be?" The focus of discussions in her department is on lecturing as they have very large classes, and she says "So I mean I can't really think about many times that I've even spoken to anybody about tutorial teaching, at all." Bob went to a one-day training course when he started his job but "other than that, we were not given any direction." Some teachers were more positive about their departments. Rachel teaches large classes and says there is teaching development support for staff willing to take advantage of it. Emily says that her colleagues and the Course Convenor have been very supportive regarding issues that arise in her teaching. Overall, however, many of the teachers in this study experience little institutional support for teaching diverse students and small group teaching seems to be less valued than lecturing.

Some participants make use of external support. Two teachers spoke about receiving counselling from outside the university. One said that she was ...seeing so many students with um, you know, quite heavy problems from depression to drug abuse etc. So because I became the first point of contact you know seeing this counsellor um, she really helped me clarify some of these issues for the students, also to keep myself safe, and look after me but now if you want that at the lecturing level you have to go and seek it out yourself.

Being the 'first point of contact' put added responsibilities on this teacher and she needed the support of a professional counsellor. Another teacher thought that if regular professional supervision was provided by the university, it would be very helpful. One teacher talked about personal development gained from his participation in community organizations, and another said that her involvement in her cultural community has been very supportive and helped her in her teaching. Several teachers have travelled and/or taught in various countries overseas and found this helpful in understanding their international students. Participants' discussions show that they use a range of resources to help them understand and relate to diverse students and care for themselves as teachers. This range of strategies and supports supplement the professional development opportunities available for teaching staff and the support services available for students. 


\subsubsection{Discussion}

The participants in my research have an interest in small group teaching and the inclusion of diverse students, and their discussions indicate that they consider it an important part of their academic work. Yet this is not reflected in all their departments and with all their colleagues. For research participants, the university as an institution, its management and policymakers, seem to have little involvement (or possibly even interest) in inclusive teaching in small group contexts and therefore in academic staff as teachers of diverse students. In spite of the universities' awards for excellence in teaching and the availability of professional development workshops, many of the teachers I spoke to did not feel that their efforts to become inclusive teachers were particularly valued or supported. Teachers' emphasis in their interviews on learning to teach diverse students through experience adds weight to suggestions of a lack of institutional support, something Jawitz (2007) found in his research, noting that new teachers learn through experience by being "thrown in the deep end" (p. 190) which resulted in a feeling that undergraduate teaching was not valued. However, this learning 'on the job' might be an effective means of becoming an inclusive teacher. This was not a question my research asks or is able to answer, and needs to be left for other researchers to consider.

The discussions of teachers in this study suggest that informal learning through various means such as experimenting in the classroom, reflecting on their teaching, student feedback, discussions with colleagues, and their own research or interest in student diversity was more helpful than formal learning opportunities such as teacher development courses, conferences, or other institutional incentives. This was also found by Viskovic (2006), whose research showed that New Zealand tertiary teachers participating in her study gained most of their teaching knowledge and skills from informal, experiential learning on the job and much less from attending formal teaching development courses or activities. The greatest support received by these teachers was from colleagues, which my research also finds. Viskovic notes that there is little discussion in the literature on tertiary teachers' informal workplace learning, and the value of informal learning at her study participants' institutions was not explicitly acknowledged. The teachers in my study did not mention the value of their experiential learning being recognized by their universities, suggesting that teaching knowledge and skills are not adequately acknowledged and valued by university leadership. The lack of institutional support that some teachers in this 
research noted was not so much about inadequate professional development opportunities but more about their university's lack of acknowledgement of the challenges that student diversity can bring to teaching, especially small group teaching, and the time and resources that might be needed to deal with such challenges.

\subsection{Teaching contexts and relationships}

\subsubsection{Introduction}

The experiences people describe in narratives occur in relational settings and for the teachers in my study these are classrooms, their departments, and the university. Somers (1994) defines a relational setting as "a pattern of relationships among institutions, public narratives, and social practices" (p. 626). Relations of power and care among diverse people will be integral to any relational setting. Many study participants' discussions about learning to teach diverse students talked about the support they received (or did not receive) from their colleagues and universities in this process. In exploring tertiary teachers' professional development, many writers (such as Hockings et al., 2009; Viskovic, 2006; Warhurst, 2008,) draw on theories of situated learning within communities of practice (Lave \& Wenger, 1991). According to Wenger (1998), a community of practice is more than just a group of people who interact; it also involves a jointly negotiated and defined enterprise and a shared repertoire of meaning-making resources such as stories, concepts, members' identities, and ways of doing things. Through regular interaction in a community of practice, members participate in an activity system, and share language, social practices and norms (De Fina \& Georgakopoulou, 2008). Thus narratives can be viewed as an integral part of a community of practice, acting to confirm and contest members' understandings of and actions in the community, and their identity (or how they belong) within that community.

Churchman and King (2009) note that institutions are sites of multiple narratives that include public and private stories, however the 'authorised' public stories of an institution and the private stories of its members are not always congruent. Andrews (2002) refers to 'counter-narratives' that offer resistance to dominant cultural narratives and offer possibilities for "finding meaning outside of the emplotments which are ordinarily 
available" (p. 1). Teachers participate in academic communities of practice, and Warhurst (2008) argues that although teaching is often seen as an individual accomplishment, it can be better understood as a situated socio-cultural practice that has meaning only in relation to colleagues and students and, I would add, the university as an institution. This section explores how participants position themselves, and are positioned within, their relational settings. It employs a hermeneutics of suspicion to analyse what their narratives achieve in the telling, and also considers how participants narrate their stories in relation to the public narratives of their universities and the meta-narratives they and their universities are positioned within. This analysis explores how participants' narratives construct the settings in which they make meaning of their experiences of learning to teach diverse students.

\subsubsection{Classroom settings}

As already noted, experience on the job was the most common form of learning how to teach diverse students for the teachers I interviewed, and thus the classroom is a key relational setting. In the first two transcript excerpts I analyze, I have included my questions as well as participants' responses. Bob talks about becoming a better teacher through his experiences.

Clare: So would you say when you're thinking about the diversity of students in your classes and, and your teaching interactions with them, would you say that a lot of your learning is just through experience as you teach?

Bob: Yeah. I suppose, yeah, a lot of it is just from experience. Accumulated, just generally, hopefully I've gotten better because being exposed to the different situations of, this person, that person. At the end of the day when you're, when, I suppose most people who are teachers hopefully when you face a problem and you can't figure it out then, then afterwards you stick with it and you try and figure out what would I do next time. I suppose it's just that accumulation of facing the different problems so to speak, facing I suppose the different aspects of diversity, that you, you learn how to manage it a bit better.

Emily also learns through experience.

Clare: How have you learned um in terms of your teaching about diversity? What I mean is that the ways you've found really, that work really well in your teaching in addressing a diverse student group, how have you learned those? How did you come to them? 
Emily: Talking to colleagues but really just trial and error. Trial and error. I mean I started off teaching um, in a, I mean in different various areas of the humanities and I think that that gave me a kind of flexibility, a sort of adaptability in my teaching practice that maybe you know perhaps if you were very fixed into a certain kind of way of doing things, I don't know, I mean I can only speak for myself but I think it gave me that. And um, I mean I just try things out.

When considering these narratives, the first point to acknowledge is the individualist assumptions in my questions. I do not offer Bob or Emily the possibility that learning to teach diverse students is a social process, and instead frame my questioning in terms of teachers' individual learning, inviting a response from a similar position. While they could respond to my questions in many possible ways, the concepts of 'teacher', 'learning to teach' and 'diverse students' are elements in a dominant cultural narrative (meta-narrative) of progress that produces a 'responsible individual' who is positioned, and who positions himself/herself, as becoming a better teacher through his/her own efforts. This 'responsible individual' positioning is central in most teachers' narratives.

Bob's narrative has a progressive format that begins tentatively ('Yeah. I suppose') and involves a storyline about an ideal he wants to reach ('hopefully I've gotten better'), how he progresses towards that ideal ('you face a problem', 'you stick with it', 'you try and figure it out') and the outcome of his efforts ('you learn how to manage it a bit better'). The narrative positions Bob as 'exposed' to challenges, suggesting these challenges pose a risk that must be dealt with. The phrase 'at the end of the day' can be both literal (a time when teaching has finished) and metaphorical (the ultimate responsibility lies with Bob). In Emily's narrative, talking to colleagues has contributed to her teaching skills, and she also learns from experience as emphasised by her repetition of the phrase 'trial and error'. Emily's narrative produces the 'flexible and adaptable teacher' as a desirable teacher identity. The storyline tells how she 'gained flexibility' and how she puts it into practice in the present, and also employs a progressive plotline. The phrase 'I mean I can only speak for myself' emphasizes an autonomous teacher position as well as positioning the narrative as specifically Emily's and not generalisable. In both Bob's and Emily's narratives students and colleagues are absent, and teaching challenges are the teacher's problem and must be resolved through their own efforts. Through their plotlines, subject positions and metaphors, Bob and Emily retell metanarratives of progress and individualization in their narratives of university teaching. 
Kiri is another teacher who values flexibility. She talks about learning from student feedback. With one particular group of students that she found difficult at times, she explains:

...they said that they do like to be directed about things like that because something I found with that group is I was giving them way too much choice and the choosing caused the conflict and so if I say 'this is how it's going to be', with that particular group it's much better than saying 'this is what we could do, what do you think?' which would be my usual consensus style of interacting but that group it just doesn't work and I don't do that anymore in that group - that's not to say that I would not do it with another group but that was a big learning thing for me.

Kiri's narrative is a story of a conflict and resolution, and what is learnt from this. It tells how Kiri's preferred position of a 'teacher who uses consensus' conflicts with the students' preference for an 'authoritative teacher'. Resolving the conflict involved changing Kiri's positioning to fit with students' preferred teacher position. However, the narrative makes it clear that in another situation she might continue with her 'usual consensus style of interacting', portraying her as a flexible and student-centred teacher. In Kiri's narrative, 'choice' proves to be problematic, and does not always lead to effective teaching and learning. Her narrative shows that teacher positioning is socially negotiated within the classroom and constructed from available discourses, such as student-centred pedagogies. When student choice is seen as desirable, it can act as a disciplinary practice that constrains teachers' teaching and relationships with students. The outcome of Kiri's narrative is a 'big learning thing' that offers Kiri alternative teacher positions and reinforces teacher flexibility.

While not all participants told individualizing narratives, the dominant storyline in many narratives about learning to teach diverse students has as its protagonist the individual teacher who is challenged to learn and adapt his or her teaching in order to accommodate the learning needs of students. It reiterates the heroic narrative style discussed in the previous chapter, and also provides further desired and desirable teacher identities - the 'responsible teacher' and the 'responsive (flexible) teacher.' Through narrating this plot structure and these subject positions, participants construct empowered and capable identities that align with dominant cultural narratives of personal responsibility and progress. These narratives act as resources for teachers as they strive to achieve their goals of inclusive teaching and yet they also constrain the possibilities for alternative storylines and teacher identities. In particular, learning to teach diverse students could be emplotted 
as a process shared by all members of the classroom community involving relationships among diverse and complex people that are unpredictable and 'always becoming', rather than a 'teacher overcomes problems with students' (or is unable to) plotline. Such an alternative construction of teaching diverse students would move away from a deficit view of diversity by decentring difference and sharing relational power in networks of care. However, my questions and dialogue in the interviews drew on dominant narratives of progress and individualization and therefore will have made it less likely that the interviews could be sites for construction of alternative narratives.

\subsubsection{Departmental settings}

For many participants their primary workplace setting is their department where they interact with colleagues, discuss their teaching, undertake administrative duties, and plan and organize courses. Departments can be understood as communities of practice (Wenger, 1998), and the narratives teachers produce will draw on the conceptual resources of such communities (for example notions of reflective teaching), and on the metanarratives and discourses that teaching is embedded in. Participants' narratives of learning to teach diverse students positioned them in various ways within their departmental communities. One of these positions was that of 'novice teacher' who learns effective teaching strategies from more experienced teachers (positioned as role models). Several teachers gave examples of this, including Maria who says:

...the staff that I've come into contact with and also students have helped me open up my eyes further into teaching strategies...and one person who did that really well and I learnt from her-it was a role modelling thing you know because she was one of my lecturers and I saw her do that so well and then when you learn about it, you see it, you read about it more you start to embed it in you as a teacher and I think that's the one thing is that sort of observation that's really important because you can't really learn it from a textbook all the time you know.

Maria's narrative illustrates the idea of situated learning within a community of practice. It depicts her learning from experiences with students, from interactions with other teachers, and from observing a particular teacher who acts as a role model. This involves participation in a community which shapes her identity ('a role modelling thing'), actions ('you start to embed it in you'), and understanding ('open up my eyes'). Maria's narrative finishes with the moral of the story, that "you can't really learn it from a textbook all the 
time", suggesting that one purpose of her narrative is to contest the notion that 'textbook learning' is sufficient for teachers' professional development and counter a public narrative in which tertiary teachers' subject knowledge and research expertise equates with skill in teaching that subject.

Many teachers spoke about discussing teaching issues with colleagues. Rachel says, Now there are a lot of staff members who will never go to a course, but, they can't avoid the ideas, the standards filtering through because you talk at morning tea, you talk to other staff members teaching with you and we always have two people on the course. And so you're paired up with a whole range of different staff members and that person will bring their ideas and their prejudices and their beliefs and all that, which would have the effect of not of homogenising everything.

Rachel's narrative depicts a passive form of collegial community where ideas 'filter through' to teaching staff and co-teaching brings teachers with different ideas together. The outcome of this is the 'effect of not homogenising everything', worded as a negative rather than a positive (such as, creating diversity). Learning about teaching diverse students for Rachel and her department is incidental rather than purposeful. In contrast, Susan's narrative positions her and her colleagues as active in their collegial relationships. She says that

...amongst people teaching within the programme there is that collegial support of one another, and the sort of recognition about what one another are trying to do and discussing, your little, little strategy you've used. And especially if it, if there's any dilemmas around particular people. For example, there's someone [a student] I'm thinking about at the moment has had a lot of um, things going on, health, personal issues, that has developed a very questioning mode within class which is, you know a really needy response so a group of us have discussed it and a strategy that we're each working and so it's supporting, and that will be done often. Um,,, and often that's done in negotiation with the student as well, that we'll contract with them.

Susan's narrative emphasizes purposeful interactions, not just with colleagues but with students as well. It positions her as a collegial teacher who values and engages in shared problem-solving, unlike the narratives of most teachers I interviewed which position them as personally responsible for resolving the challenges involved in teaching diverse students. In Susan's narrative, the responsibility for learning to teach diverse students is distributed across the teaching staff and can involve students as well. This collective approach acts as a strategy of care for teachers and students producing a form of 
communal care, and Susan's narrative presents an alternative to the dominant cultural narrative of individual responsibility.

In most teachers' narratives about collegial interaction, however, the protagonist is positioned as an autonomous individual. When I ask Vanessa how she has learned about good teaching practice with her diverse students, she replies

Exchanging ideas. Talking to colleagues and saying um, I'm having this, this and this problem with these students because their attendance is poor or because they, their English is poor, whatever and, and finding out you know how different people cope with the different challenges. I've always been one to sort of share ideas, resources. I find-at the moment I teach the same courses year after year, I mean I'm always revising my materials. Always. I re-read it and I think why did I do it that way, you know. I'm not sure that that really explains what I'm trying to say, this activity didn't work, or try another. But even when I was a school teacher, you know, I was all in favour of it because there are always teachers in life who hoard things, who don't share. But I think it's not a competition.

Vanessa's narrative emphasizes reflection on practice and positions her as a dedicated teacher who continually improves her courses. It constructs her as a moral teacher who shares her knowledge and resources with other teachers through a contrast with other teachers who 'hoard things and don't share'. The phrase "it's not a competition" implies that there are teachers who are competitive within their department, and through this contrast Vanessa constructs a collaborative identity. In another narrative Vanessa says

I was just helping the other colleague of mine, she's new to this course and so she's struggling a bit with it and so I'm sort of trying to help her. So in a way now I'm the senior except I'm not, but um, but helping others I think helps me as well rethink my ideas.

This narrative shows Vanessa's position of 'helper' to her colleague is at odds with her actual position in the departmental hierarchy. Both narratives link a storyline where being a 'learner' within a collegial community and reflecting on teaching positions Vanessa as a 'good teacher' with a storyline in which being a 'teacher' to her colleagues by sharing resources and guiding them positions her as a 'good colleague'. The narratives describe strategies of care that include sharing teaching resources and offering assistance to other staff, and strategies of power that include resisting competitiveness and challenging departmental positioning. Although the narrative is about 'sharing' and 'helping', it is constructed with an individual voice as shown by the dominance of 'I' and the lack of a 
relational construction of self and actions. The narrative draws on humanist discourses of agency and empowerment as it positions Vanessa as a caring individual and thus it acts to individualize teaching even as it promotes support between teachers.

When I ask Tina if working in a team of colleagues has been helpful in her teaching, she responds with a pause, and then says

It is to a certain extent. I guess 'cause you're not sort of left alone and everyone has got their area where they contribute to the course. But in the end it's more about communicating what each of us is doing or what has come up in the week, maybe you know, the students having some problems or whatever that we communicate about it but then the way we teach is um,, yeah obviously we talk about OK I did this last week and that's where you can carry on or, but the actual teaching in the class itself it's my own teaching.

Tina's verbal and nonverbal response suggests she is ambivalent about how collegial relationships help with her teaching, and this narrative portrays limits to collegial community and the isolation of classroom teaching. It positions Tina both as 'not left alone' and as 'being on her own' in a storyline of university small group teaching where teaching staff contribute their expertise to areas of the course, communicate with each other about students and teaching methods, and then go into their classrooms and work alone. Teaching may be a social activity in relation to students, but is usually undertaken independently of colleagues. In the dominant university teaching narrative, students and staff are positioned as distinct groups, and Tina's narrative highlights how this results in the construction of a complex teacher identity that is both collegial and independent.

A tension between independence and isolation is found in a narrative from Gwen that was produced within a discussion about support for teachers working with diverse students. Gwen says, ...yeah to be honest just part of what I love about this job is the fact that I'm given a lot of scope to be able to change the course I'm teaching as I please. And as I see fit in order to meet the overarching objectives of both the course and of the [subject] major in particular. For me they're sort of funnel end points. In saying that however, because there is this great degree of trust which is put into the teaching staff, there's also that degree of, some degree of isolation that's coupled with that, you know, there's a trust that you're going to be able to make this happen. 
In the first sentence of this narrative, the phrase 'to be honest' signals a confession, and suggests that Gwen's assertion that she loves being able to change the course 'as I please' may not be a completely comfortable position. This position of having power to make changes is then modified to include responsibility from the trust bestowed on her and the isolation of actually teaching the course. The narrative creates a multiple positioning that involves authority, responsibility and isolation. Gwen's department is portrayed as valuing the professional identity and expertise of academic staff.

According to Olssen et al. (2004), professionalism involves institutions delegating authority within relationships of trust. The expertise of professionals enables them to make decisions within their workplace where their work is undertaken for the 'public good', in this case the education of students. For teachers, professionalism requires autonomy and expertise, which as the narratives in this section show, can also involve isolation.

However, Olssen et al. note that the trust necessary for professionalism is a "relational concept" (2004, p. 192), and Schuck et al. (2008) argue that professionals need to develop relational agency, defined as "a capacity for joint working towards shared goals" (p. 545) and which involves shared responsibility and support. I argue that relational agency also requires narrative storylines that construct relational rather than autonomous selves and that de-individualize teaching, which is after all a socially situated (Warhurst, 2008) and relational process. The narratives of Tina and Gwen position classroom teaching as an activity that is undertaken by an individual teacher independent of colleagues. This suggests that teachers leave their departmental community of practice at the door of the classroom, and then are 'alone' in the classroom. Even if the classroom is also understood as a community of practice, teachers' narratives suggest a clear division between collegial and classroom communities and their distinct roles, activities and relationships.

\subsubsection{Institutional settings}

Universities are large and complex organizations with numerous faculties and departments, sometimes spread across multiple campuses, and with staff employed in a variety of roles. This institutional context may at times seem removed from classroom teaching, but teaching practice is nevertheless always embedded in the wider institutional setting and its policies and regulations. Because the interviews focused on classroom teaching, some 
teachers did not talk about the larger university context. Those who did were mostly (but not always) critical, and their narratives generally portrayed a breach between the 'real' and the 'ideal'. As noted earlier in the chapter, several teachers consider that small group teaching is not valued by their university. When I ask Kiri what support she has received for teaching diverse students and any challenges that brings, she responds,

Very little, and that was one of the main motivators for participating in your study, um, for me because I felt that tertiary, providing that tertiary level education is,, it does call for a lot of skills I think in the lecturer or the tutor but I don't necessarily think there is a lot of support for us. Certainly when I first started here three years ago, I encountered things that I hadn't anticipated I was going to encounter in front of my classes and had very little support from the then Head of Department here or from any of my colleagues. I was pretty much just left to it to find my own way through. There was no formal support. Kiri then explains that a staff member from the Teacher Development Unit ${ }^{20}$ was very helpful during that time, but could not provide ongoing support. In her department ...we have regular team meetings to talk about our workload and how we're managing students and students of concern and who we need to be following up with but not so much about how do we deal with diversity in the classroom. I actually don't think there's very much, you have to find your own way. [she laughs]

In Kiri's narrative, receiving support for teaching and finding one's own way are placed as opposing poles in terms of learning to teach, rather than as separate factors in a complex process where learning to teach a wide range of students can involve both formal support and individual experiential learning. Kiri's narrative not only provides a motive for her participation in this study but creates a storyline about her professional development in relation to the support she received using the metaphor of 'finding your own way,' and her laugh at this point suggests that this is not desirable. As the protagonist in her storyline, Kiri is positioned as a new teacher looking to her department for assistance in developing the necessary teaching skills and finding her department unresponsive. Kiri's narratives act as a strategy of empowerment and self-care as she repositions herself from a struggling, isolated teacher in the past to an experienced teacher now.

Sandy and Susan also talk about a lack of institutional support. Sandy thinks that "the university is fundamentally research-focused, it provides little in the way of support for

\footnotetext{
${ }^{20}$ Each of the two universities participants worked at had a department that researched and taught teaching knowledge and skills. I have used the term Teacher Development Unit for both of these departments but it is not the actual name of either.
} 
teaching — most of us are content specialists who've never been taught to teach." Sandy says that informal discussion among colleagues is "perhaps the most effective and probably really the only practical available help" for teachers. Susan agrees.

There's not a massive amount of support. In a way you're left to your own devices and say for example here I'm responsible for some other staff members that I will encourage them to say how's it going in the classroom, you know, what is happening, what are the difficulties you're finding. And talk with them [about] what they might want to try differently 'cause a lot of people that come into the university don't actually have a teaching background.

Susan's narrative depicts her countering the lack of support with a strategy of care that actively promotes collegiality and attempts to overcome the isolation of classroom teaching. It portrays new teachers as inexperienced and needing support, which Susan, as a 'responsible colleague', provides because the university as an institution does not. The private narratives of Sandy, Susan and Kiri point to and contest a public narrative in which the subject knowledge and expertise of new academics automatically equips them to teach. Several other teachers related counter-narratives that depict teaching as a skill that needs to be learned and supported by their universities.

Some participants talk about the pressures of high workloads and lack of time. Maria says that acknowledging the diversity of all students takes time, and

I don't think as lecturers at university you get enough time to really do that. You know, the pressure now is on research and research and the time that you want to spend with students is actually cut down because of the expectations of the university structure.

Because the focus of my interviews was on teaching, participants' research commitments were only mentioned in passing. However, in the narratives of Maria and Sandy (and some other teachers), universities are portrayed as valuing research and neglecting teaching, which is unsurprising in the current Performance-Based Research Funding (PBRF) system. When teaching is positioned as a devalued activity, by implication 'teacher' will be a devalued identity and researcher will be a preferred identity. Maria's narrative argues that teaching diverse students involves 'taking time' but if teaching is not a valued and valuable (in financial terms) activity, then universities will be less likely see time involved in understanding the diversity of student learning as a priority. Gwen says,

But quite often, you know, any attempts to address students' diversity are usually made on a good faith basis. So it's an understanding that you can do your job without really 
having to necessarily address these different terms of student diversity, but it's nice if you do.

This brief narrative positions Gwen's university as indifferent to the needs of diverse students and the staff who teach them. Addressing student diversity is a 'nice' thing to do but not necessary to teaching students. This is counter to 'authorised' public narratives such as university policy documents, including those from one university where research participants work which set out requirements for supporting students from diverse backgrounds and providing learning environments that enable successful participation by all students. Gwen's private narrative positions her as addressing student diversity on the basis of her own beliefs rather than university policies, pointing to a breach between policy ideals and actual practice.

Several participants spoke about communication with management. When I ask Maria how she would like to see the university understand and support diversity, she replies,

Well! [she laughs] How long have you got?! Interesting and I always think about this and in an ideal world, it would be for people who are in the managerial leadership positions to come down, come and talk to the staff who are involved in diverse communities, talk to the students, get to know them, understand their needs, rather than sort of making decisions, um, without sort of any consultation. I think that's the key word.

The introduction to Maria's narrative suggests its topic is an important but neglected issue. The description of Maria's 'ideal world' is contrasted with her 'real world' where managers lack adequate communication and consultation with teachers and students. The suggestion that managers 'come down' to talk to staff and students has a literal meaning in that managers are physically located on a higher level than her department is, but it also can be understood metaphorically with managers having a higher level of power and status than staff and students. Maria's narrative offers consultation - 'the key word' — as a means of lessening the distances between managers and staff and between her real and ideal worlds.

Kiri also talks about a lack of communication between management and teaching staff. I think if universities want their staff to be working well then they need to be better supported at the ground level because we-you know the hierarchy of the university system is just mind-blowing and yet we here on the bottom floor it's us who are the interface, who do all the provision and I don't think there's much thought about what it's like for us in the classroom and if those people way up the ladder were ever down here 
they've long forgotten it and I don't know that there's much um, much encouragement for lecturing staff to upgrade their skills so that there are some people who have been teaching here for a long long time, the same material and are very closed about how to deal with individuals in the classroom, because it's survival, and I don't like feeling, thinking that I might become like that, that I might have to step out of my very much individual approach.

Kiri's narrative also draws on a metaphor of vertical power and status with teachers positioned on the 'bottom floor' and at 'the interface' whereas managers are 'way up the ladder.' The narrative depicts a large gap between these two groups in the places they occupy in the university hierarchy as well as in terms of communication and interaction. It positions some teachers as closed-minded and rigid in contrast to Kiri who has a more individual (that is student-centred) approach, producing a 'moral teacher' identity. This identity is reinforced by the narrative's positioning of teachers as dedicated and hardworking, as unsupported but 'doing all the provision.' The narrative places Kiri in a moral but isolated position. Power is constructed as power-over, however a reading of the narrative with power understood as a network of relations suggests that teachers are powerful in 'doing the provision', regardless of which teaching approach they use. If power relations are understood as fluid and dynamic, this could open the situation described in Kiri's narrative up to changes in the relationships between characters.

Teachers' narratives construct their institutional setting as deficient in several ways: in support for teachers in the classroom, in consultation by management with teaching staff, and in recognition of the importance of addressing student diversity in teaching. Participation in my research interviews enabled teachers to create narratives of resistance through the construction of moral teacher identities within storylines of struggle and inadequate institutional support. It may be that teachers are more likely to tell narratives of struggle within an interview than narratives of 'ease'. As well, I make the assumption that many of the teachers who volunteered to participate in this research have issues of concern and the interview therefore provided an opportunity to have these heard. The dominant storylines situate dedicated and hardworking teachers who 'find their own way' (either individually or collegially) to teach diverse students in spite of a lack of support, time or teacher education within an institutional setting where management are positioned as distant and uncommunicative. Teachers' private narratives thus contest the 'authorized version' of their institutions. 


\subsubsection{Political context}

Universities are embedded in a larger political context. They are bound to government policies and regulations and dependent on state funding. In the current neo-liberal political environment in New Zealand, education is discursively constructed as the production of knowledge capital required for competing in a global market in order to receive economic gains for individuals and the country as a whole. This promotes the increasing marketization of universities, with education becoming a consumer-driven system (Harris, 2005). Several participants' narratives reflected this. Kiri talks about her students.

Here they're paying good money to learn and they expect, you know they expect a lot actually for what they're paying, so thinking about how I'm going to appeal to a wide range of learning needs.

When the student is positioned as a customer buying a product (the course or degree), the teacher is repositioned from a facilitator of learning to provider of a product. In this consumer model, teachers must strive to meet customer requirements, in this case students' 'learning needs'. With the diversity of students, this means a wide range of needs must be catered for. A discourse of marketization and a storyline in which students 'pay good money' positions Kiri as a provider of an educational product and requires her to respond to students' expectations as customers. She does this by considering how she can "appeal to a wide range of learning needs", which links a market discourse of education with a student-centred discourse of teaching. Kiri's narrative talks about this in terms of personal rather than collective responsibility, and suggests the increasing influence of neoliberal ideas in higher education.

Emily also considers the impact of student fees. She says, ...a lot of the kind of structures of how lecturers interact with students is obviously getting impacted on by the whole medium of fees and payment and everything, that obviously is having an impact on um, the way in which the student is perceived by the university, the student is seen much more as a customer and therefore there are things that you have to, you know, in a sense you say well you know they're paying for it it's up to them whether they do the work or not, in the end I mean it does come down to that and in the end that's the attitude I've started to adopt. They are grown up when they get here supposedly um, and so you know my attitude's very much well okay, you know, you can choose not to do the work but that, you know, then the consequences will be yours. So, and that's really the most I think that I feel I can do. 
Emily's narrative has a regressive plotline in which the impact of fees has created an undesirable student identity, that of the student as 'customer'. It suggests that the interaction between lecturer and students was better before the introduction of fees. In the storyline, Emily has to respond to a change she does not like, one that has been imposed on students and which consequently changes the student-teacher interaction. Emily's response is to encourage students to make choices about their study practices and to be mature and responsible self-directed consumers of education, which positions her as more of a provider than a teacher. The narrative thus repositions Emily and her students in the preferred subject positions of a market discourse of education.

Kareen teaches both business and humanities students. He says There's a huge difference between business students and the um, than [humanities] students. The business students, I mean I remember asking question and that was in a [subject] class and we were discussing customer satisfaction and I said to the class well how would you measure this particular course that you're on in terms of customer satisfaction and whether you know, whether it was meeting your needs. And almost unanimously they said that we pass, and there was nothing in there about what they might have learnt or what they might have achieved during the year and all of those sorts of things, it's just that they passed. One of the things that I noticed more with the business students is that they pay for the course so they expect the product to be delivered and product delivery is a pass, it's not knowledge. I think that's very worrying for the university.

Kareen's narrative is also regressive, and tells a story about the marketization of university education. The business students commodify learning and desire a specific productpassing the course - which they expect to receive because they have paid for it. The narrative contrasts this with learning as a process of gaining knowledge, and aligns Kareen with this viewpoint rather than the 'product delivery is a pass' viewpoint of his students. In this narrative, the business students draw on a neo-liberal economic discourse to construct their understanding of education. In both Kareen's and Emily's narratives, the introduction of student fees has repositioned students from learners to customers, which in turn requires a repositioning of teachers to product deliverers. Though he does not explicate his own response to this repositioning, Kareen's narrative suggests that he prefers to resist it. Although most teachers did not refer to a larger societal context in the interviews, those who did spoke critically about the marketization of education. Their narratives acted as strategies of resistance and/or adaptation to a business metanarrative of education that 
positions universities as providers, teachers as deliverers and students as consumers of educational products within a storyline where personal responsibility and effort leads to private gains.

\subsection{Conclusion}

Participants' narratives about learning to teach diverse students portray their experiential learning as creating expertise that does not appear to be valued by universities. If the emphasis in higher education is on research outputs and subject knowledge, and teaching is not considered an important skill, much of teachers' expertise will remain largely invisible. Yet the narratives in this and the previous chapter portray a wealth of knowledge and skills developed through participation in the practices of teaching within collegial communities. Many of the 'learning to teach diverse students' narratives discussed collegial support, and those teachers who talked about sharing their experience and offering assistance to other (especially newer) teachers did not mention that this was valued by their university. Most teachers, however, spoke of learning to teach diverse students in terms of personal responsibility, as a kind of heroic struggle. Their institutions were generally seen as offering inadequate support, in particular, there was a 'me versus them (department, institution)' or an 'us (colleagues) versus them (management, institution)' positioning in many of the narratives. The narratives showed that, within a departmental community of practice, some teachers actively encouraged collaboration with their colleagues while others spoke about such communities in more passive terms. The university as an institution can also be seen as a community of practice with its policies, practices, language and values, but teachers' narratives did not speak of this as actively supporting them in terms of teaching diverse students. While some teachers talked about professional development opportunities, the narratives generally position the university (as an institution) as distant and largely indifferent to classroom teaching and those who engage in this work. This in turn reinforces participants' positioning of themselves as heroic individuals struggling to deal with the challenges of student diversity.

The narratives of teachers participating in this research suggests that much of the work involved in bringing an increasingly diverse range of students into academic study at university falls on individual teachers. The public narratives of universities, expressed 
through policies that seek to improve teaching and recognize good teachers, are at odds with the private narratives of teachers who often do not feel valued and supported. The significance for universities of these findings is that they may need to consider why teachers' narratives differ from the 'authorised version', and how better to ensure teachers are supported in the challenges they face teaching students from a wide range of backgrounds and with diverse needs and approaches to learning. As well, they may need to acknowledge the skills and knowledge that teachers gain through their teaching practice, and recognize the value of this for all students who enrol in programmes of study and for the university as a whole.

Teachers construct their narratives and position themselves within those narratives in terms of the narrative and discursive resources available to them. As well as dominant cultural narratives, these resources include the questions I asked participants, and the very notion of a 'teacher learning to teach diverse students' that holds individualistic assumptions and a notion of progress. Counter-narratives offer the opportunity to create different plotlines and positions. If student diversity is seen as a benefit rather than a deficit throughout the university, and if staff throughout universities understood the various levels of their institution as communities of practice, then teachers might position themselves in terms other than a struggling hero. They could position themselves as active participants in various communities such as classroom, department, faculty and institution that in turn collaboratively supported them in their teaching. This requires a shift from individualist thinking to relational thinking, from hierarchies of coercive power to networks of productive power (Foucault, 1980) and from care as a pastoral duty (for certain staff) to care as networks of relational practices throughout the whole university. The next chapter considers relational practices and the strategies of care and power in participants' narratives. 


\section{Chapter 9 \\ Inclusive practices: Acts of care or means of discipline?}

\subsection{Introduction}

Inclusion of diverse students has been a dominating theme in study participants' narratives. This is reflected in much of the educational literature about diverse students, which considers how teachers can appreciate diversity, adapt their practices to meet the learning needs of a wide range of students, and create classroom environments that enable students from diverse backgrounds to feel valued and able to participate in learning activities. Inclusive teaching by its very definition is relational, and Bingham and Sidorkin (2004, p. 2) argue that "meaningful education is possible only when relations are carefully understood and developed." Relational thinking is sometimes equated with ideals of harmony, cohesion and community, which avoids issues of difference and division (Ross, 2002). This is not what relational theories offer us; relations of various qualities constitute human life and social interaction and can lead to harmony or strife, inclusion or inequality. Humanist pedagogies, such as those critiqued by Claiborne et al. (in press), often focus on providing support and creating harmonious relationships in the classroom. Humanist pedagogies are not based on a relational ontology; they involve autonomous individuals having relationships with other autonomous individuals. This differs from the relational theorizing that I am using which posits that relations are primary, in other words, "we do not have relations, relations have us" (Bingham \& Sidorkin, 2004, p. 7). Pedagogy is a web of educational relations within which teaching and learning are enacted. However, humanist discourses of autonomous selves remain dominant in education (Usher et al., 1997) and, as noted previously, in my own discussions with teachers in the interviews.

I begin this chapter by considering the practices study participants engage in to create and maintain relationships with students and ensure all students are included in classroom activities and communities. I employ a hermeneutics of faith to identify and discuss these teachers' 'narratives of connection' and the relational practices they enact in response to student diversity. Such practices are rarely discussed in the literature but are common in many of the participants' narratives, and need to be explicated. After this analysis I employ a hermeneutics of suspicion to analyse 'narratives of inclusion' to see how they produce 
acts of care for, and means of disciplining, teachers and students. As I argued in Chapter 4, care is an important aspect of teaching that has not received adequate attention from higher education writers and researchers. Ross (2002, p. 408) argues that "what is fundamentally missing from education is empathy, caring social imagination, and personal connectionan ethics of care". It could be argued that inclusive teaching is an act of care; by seeking to ensure the teaching/learning context supports and challenges the learning of all students, teachers show they care about and for students. However, my analysis problematizes this and asks not only what forms of care are produced, but how they act on teachers and students. It also considers how power is produced by the narratives, and in particular, how disciplinary power positions teachers within relations of face-to-face teaching. This chapter also considers how different forms of power and care are connected in classroom relations.

\subsection{Relational practices}

\subsubsection{Narratives of connection}

The analysis of participants' narratives so far has shown that teaching diverse students involves academic and relational challenges and rewards. Teachers' narratives of their experiences are primarily about their interactions with students. Biesta (2004) argues that education is not about what teachers or students do but is what occurs in the interaction between teacher and students. In this section I employ a hermeneutics of faith to analyse participants' 'narratives of connection' and identify the relational practices they use in teaching diverse students. In these narratives of connection, participants discuss how they connect to students, how they connect students to each other, how they create classroom communities, and the support and care they give to students. Often they give examples of their successes and failures with these relational strategies, and I have included excerpts from some of their narratives. 


\subsubsection{Teachers connecting to students}

Forming relationships with students is important to the teachers I interviewed. As Ann says, "I think that everybody here connects with their students...you don't stay in the profession unless you're interested in your students I suppose." There were a number of narratives about how teachers tried to connect with their students. One way of building relationships was through teachers sharing their own experiences with students. Ala's narrative tells how her travel experiences help her relate to her international students, and how staying up-to-date with current events from the places she has travelled provide topics for class discussion. Vanessa talks about her travel experiences with her students and how she sometimes shares other interests with them, saying that "it just builds the relationship". She also talks about having fun with her students and sharing humour in the classroom. Tina is another teacher who says she likes to joke and have fun with her students and links this with being approachable to her students, while Cassandra says "I always try to be relaxed and have a laugh and they know they can come and talk to me about stuff'. These teachers' narratives describe the activities they engage in to help students feel comfortable with them, which implies they are in a position of power that could make it difficult for students to approach them and so a caring response is needed.

The importance of getting to know students was mentioned by several participants. Cassandra says "I think part of the task of teaching diverse students is to try and get to know them all individually." Liz explains that she has large classes and makes sure she spends some time with each student so they feel they are making a connection with her. When I ask Maria about understanding diverse students in her classes, she says

And just have a stronger sense of perspective of them and understanding their differences, and similarities actually. So it is quite hard! Doing it all the time, I know it should just be part of your way of operating but sometimes you have to be so conscious, really conscious of what you do and say so that they are learning the best, and this is trying to acknowledge every individual as being diverse.

Maria's narrative notes students' similarities and differences, and affirms the importance of understanding students and the challenge this represents. Michael also notes the importance of getting to know his students as individuals. He says that the relationship between teacher and students needs to be strong, and "like lots of teachers I put quite a lot of effort into building rapport in tutorial groups." The narratives of these teachers show 
that they think about how to build relationships with their students and make an effort to do so. This is in line with Prebble et al.'s (2004) literature review which finds that student success is enhanced when students have "regular and meaningful contact with teachers, both inside and outside the classroom" (p. 62), and which notes the importance of respecting, affirming and valuing student diversity.

Empathy is another way participants build relationships with students. Empathy is often described as 'feeling with' another person and can be understood as projecting oneself into another person's reality to consider how one might feel in such a situation (Harms, 2007), or as receiving another person into oneself and seeing and feeling with that person, which Noddings (2003) terms 'engrossment'. Some teachers' narratives give examples of these forms of empathy. Cassandra talks about the experience of being a foreign student in another country and says that she can empathize with students who are studying in their second language. She understands some of the difficulties living in a foreign country and experiencing different cultural values. Ala is an immigrant teaching in New Zealand, and she knows what it is like for international students adapting to a new country and learning environment. She explains how she tries to empathize with her students, saying "sometimes I'm trying to think about students from their point of view, what their experience in the class as being part of a very, um, diverse, very varied class." Ala also shares her own experiences of being a student with her class. She says "I guess just sometimes saying, oh don't worry guys, you know I remember myself making those mistakes and I'm not perfect." Bob tries to empathize with his students, saying

I try to consider myself as an understanding person, to try to put myself in other peoples' shoes, to have been put through quite a few experiences so that I can understand where someone else is coming from but they-people are people - there's limitations to who you are and how understanding you can be.

Bob's narrative uses the metaphor "put myself in other peoples' shoes" to describe empathy in his relationship with his students, but qualifies this by noting that because of human fallibility, empathy is limited. This portrays individuals as never completely knowable, and Bob was the only teacher to note this. 


\subsubsection{Connecting students to each other}

Participants talked about helping students form and maintain relationships with each other. Emily says she uses group work to make her teaching more effective and to ensure that her students feel comfortable in sharing their ideas. Michael says he starts tutorials with icebreaking exercises to foster relationships within the class. Grace talks about tutorials:

This is 50 minutes in a week they see each other and so it's like how do we get them to at least know one or two people in the class so they don't feel so isolated at university. And there are different ways to do that and by changing the groups and getting them collectively together I've actually found that that seems to work and they know each others' names. So I think at least if you know one person in your class you'll feel less isolated.

Grace's narrative points to the impersonal nature of a large educational institution and the importance of student relationships, portraying her as a teacher who takes action to overcome this isolation. Susan also talks about promoting connection between students, and actively encourages those students who seem isolated to connect with other students. The narratives of Michael, Grace and Susan describe relational strategies that bring students together and avoid isolation. These and other teachers spoke of attempting to create classroom communities where interaction benefits students' academic achievement and personal well-being. Kiri refers to her class as "a family group with all the dynamics that involves", implying that a classroom community is a site of conflict as well as caring.

Ensuring that students relate to diverse peers was discussed by half the teachers I interviewed. Several teachers' narratives show them taking an active role in 'mixing up' students. Elaine says she likes to mix students even if it is a bit uncomfortable for some because "we know the key to understanding each other is by talking to each other". Dialogue as a strategy for creating relationships between diverse students was discussed by several teachers. Elaine and Michael note that some student voices need promoting in class discussions as students may not feel comfortable or confident sharing their ideas, and that classroom interactions involve power relations. Grace says that when she teaches in the classroom, she often splits the class up into smaller groups and ensures that these small groups are "blended". The advantage of this is that students can "share their ideas collectively and feed off each other." Here learning as 'feeding off others' is about 'consuming' knowledge, and diversity provides this knowledge. In the narratives of Grace 
and other teachers, encouraging students to learn from each other is depicted as a key pedagogical strategy. Group work can also encourage diverse students to find ways to work together. Richard considers that diversity requires the students in his class to collaborate. His students told him that when they realised how different they all were, they thought about how to deal with their differences. They make sure they speak carefully to each other and have increased respect for one another. Richard's narrative depicts students actively engaging in relating across difference and seeing the benefits of this rather simply responding to teacher initiatives as shown in other teachers' narratives.

While many participants value mixed-group work, their narratives suggest that not all find it easy to put into practice. Ala says she tries to mix students up rather than let them stay in their own groups, but this is not always successful.

I've used all sorts of tricks, like giving them you know different coloured papers, and putting them in expert groups and it worked, when they, when there is no choice and they have to do it directly, I ask directly, they do it, no problem, but um, on their own, it takes time.

Ala depicts herself as reluctantly assuming an authoritative position in relation to her students and having to use 'tricks' to encourage student participation. Kareen says he also has difficulties in 'mixing up' his students, noting like Ala that they do not resent being put into mixed small groups but left to themselves "they gravitate towards people they can relate to." Ann says that students "tend to stick with their own ethnicity if there's a large cohort of them", and she thinks this is because they are more comfortable with others like themselves. Helen says that "students often feel safer in more homogenous groups" but she says that this can limit the opportunities for them to learn from students who are different, so she favours mixing students. These teachers' narratives show a breach between real and ideal practice as they attempt to put into place a pedagogical strategy they consider important.

Brookfield (2006) argues that grouping similar students and grouping diverse students are strategies that are necessary and useful at different times. Grouping similar students together makes it easier for them work with each other, while mixing students has benefits because it matches the conditions of real life where people work with and relate to a diverse range of people. It also provides opportunities for students to learn from each other, for example by being faced with different perspectives to their own. Grace's 
comments echo Brookfield's when she notes that getting diverse students to work together can be challenging for the students, but Grace says she believes students need to learn to work with others whom they don't agree with and that this is part of life beyond the classroom. Grace's' narrative shows that pedagogical practices are influenced by sociopolitical imperatives for education to prepare students for the 'real world'.

\subsubsection{Supporting students}

Providing support to students was a theme in many narratives. About half the participants spoke about providing academic assistance to students who were struggling. Ala talks about giving extra sessions to some international students. Bob says he offers extra time for students to see him but has found that not many students take up his offer. Liz says she spends time with each student in tutorials and asks if she can help them. Tina explains how she supports her students learning.

...in the tutorials there's always time while they're working to go round and just sort of reassure whether they're okay with what they're doing. Also before class or after class just to take them aside for even you know just a minute and just ask them whether things are going well.

Tina's use of the word 'reassure' links academic support with emotional support for students. In a narrative about an international student, Cassandra depicts emotional support as vital for a student's academic achievement and social integration. She describes this student as "very closed off" and explains that a number of the other students found him very difficult to get to know and were upset that he was going to be in the class with them again the next year. Cassandra says that one week in class she talked about visiting this student's country and really enjoying it.

And when, every time I gave an example I'd say 'oh I saw this in X', this young guy's eyes would light up and this semester there's been a total change in him and I assume, which you know it's just an assumption, but I think he's had a really hard time being from X, "cause a lot of people see the Xs as the aggressors in the war with Y. So to have somebody actually talk positively about his country was probably mind-blowing 'cause he's just a different person now and everybody, even people in the class who had major problems with him last year have just said 'oh he's changed so much' and this is so nice. Cassandra's 'making a difference' narrative depicts her actions as not only assisting a marginalized student to belong to a classroom community but also improving his sense of 
self-worth. It portrays learning as not just a cognitive process but one that involves whole persons in social relationships, and the teacher as being in a powerful position to influence classroom relations through enacting care for students' personal and academic wellbeing.

While participants said they found the support services for students at their universities very helpful and referred students to them, some teachers also gave pastoral care and advice to students. In education, pastoral care refers to the promotion of students' personal and social well-being and development (Best, 1995). Ala tells how she gives her class a learning activity that allows students to write about challenging personal issues providing her with an opportunity to give students advice or to refer them to student support services. Cassandra talks about how her students

...feel quite happy coming and talking to us about things and,„, yeah I've had some pretty lurid confessions over the years of problems or concerns or whatever they sort of had. So I mean they often feel comfortable I think coming and talking to us about stuff.

Cassandra's narrative portrays her as available for students who need assistance whereas Vanessa's narrative depicts her taking an active approach, saying "I like to keep in touch with my students". She contacts them if they are absent to see "if they are okay" and know what they need to be doing for the course, and she also notes that there are limits to her caring for students. Like other teachers, her narrative shows that academic support and pastoral care are linked and that teachers are a primary point of contact for students. If teachers encounter students with personal problems they can refer them to support services, however they may choose to assist the student at the time, particularly if the issue relates to classroom interactions. Teachers' narratives reflect findings from Zepke and Leach (2007) whose study of New Zealand tertiary teachers showed that many of their participants gave pastoral care to their students. Sawir et al. (2009) suggest the pastoral care tradition views the student as "a dependent subject in a paternalistic relationship with the educational provider" (p. 46), in other words, as deficient and needy. However, the narratives of teachers in this study depict pastoral care in a more positive fashion, depicting it as empowering and supportive for students.

Supporting students can involve being an advocate for students, though this was mentioned less than other forms of support. Kiri talks about organizing an external mediator for a class experiencing conflict between students, and her narrative gives this a successful outcome. Maria talks about supporting international students who 
... experience a massive culture shock. English is their second language, usually, and then they come to a system that is not theirs culturally and then they come to another system which is the university and that's even more scary, and they feel lost, they feel more marginalised than ever before but they're scholarship students, you know, these are the scholars of their countries and so when they come in we try and make sure we know who they are and develop a relationship from the onset and bring them in, into our place of learning and support them, orientate them, advocate for them to the university, help them settle in, more so than the university provides I suppose in terms of their orientation. And this has got to be, this is the long-term, this is not just the short-term.

Maria's narrative describes students' difficulties with the transition to a different culture and the need for ongoing support. Her university does not have the same perspective, and so the support is provided by Maria and her colleagues. Maria's narrative shows that some students are vulnerable within the culture of the university and need support to 'fit' into this foreign culture. A different form of advocacy is suggested by Foley (2000), who notes that teachers can be an advocate of missing perspectives. A few of the teachers I interviewed said they made an effort to include the viewpoints and knowledges of marginalised groups such as Māori and Pasifika, gays and lesbians, or people with mental illnesses.

\subsubsection{Respect}

In several participants' narratives, respect is depicted as key to creating classroom communities that are caring, safe and challenging, and which promote student learning. Teachers' narratives construct the notion of respect in line with humanist ideas, such as Harms' (2007) definition of respect as acknowledgment of the intrinsic worth of a person. Liz says that all students have "something to bring to the classroom" and everyone's ideas should be treated with respect. Michael considers that teachers should foster respect for individual students, "acknowledging them for who they are in whatever sort of diversity they represent." The narratives of Michael and Liz portray respect for and between students as important pedagogically as well as relationally. Emily says that she tries to treat her students with respect and insists on students treating each other with respect. Although she likes her classes to be informal,

...there is a certain line that I will not allow to be crossed and that you know is when it comes to manners and respect or something like that which I just think are things that you 
know everyone should have for everyone and it's absolutely irrelevant you know, any issue, I mean people should just have that for other people and it doesn't really matter whether it's a question of you know what group that you belong or what area of diversity you represent or whatever, it's just a human interaction that I believe should be made to, you know, it should be encouraged.

In Emily's narrative, the notion of respect emphasizes similarities between students and minimizes differences. Student diversity is 'smoothed' over. Kiri depicts student diversity as a "really positive thing" in her classroom,

...something to be acknowledged and um, treasured, and treated respectfully and I think that's part of the ground rules when we're setting up in the beginning is that we all come from diverse backgrounds and we going to have respect for each other's different ideas and setting it up so that their difference is celebrated, but encapsulated so that the course material can be delivered and they can learn and interact in a safe way throughout their time.

Kiri's narrative implies that creating a safe classroom community will enable difference to be 'encapsulated' and rendered manageable. This suggests that diversity is potentially 'dangerous' in spite of the positive way it is depicted at the beginning of the narrative. Some educational writers take issue with such notions of safety in the classroom. KoroLjungberg (2007) contends that safe classrooms "create closure and definite outcomes that can hinder the construction of learning community and unity built on diversity, risk-taking, and complexity" (p. 740), and hooks (1994) argues that a 'safe' classroom may be comfortable for those from dominant social groups but 'unsafe' for those from marginalized groups to express their perspectives. Thus while safety and respect may be considered important relational practices, challenge also has an important place in classrooms. The potential of 'diversity' to unsettle classroom harmony can lead to critical learning if it is given space to do so.

\subsubsection{Teachers challenging students}

Teaching involves challenging students academically, stretching them beyond what they think they are capable of, inviting them to "think afresh" (Daloz, 1999, p. 217). Several teachers' narratives reflected this. Chris explains her view: 
And I think that's one of the challenges of tertiary education is to get students to think about that the way they've always thought about things and done things isn't the only way, isn't the only right way.

Teachers also challenge students in other ways. Ala says, ...teaching is not only about you know going in and having a good time and teaching something. Teaching is about making the students um, not better people but ah making them believe in themselves as well very often, especially for the X students, I love challenging them, um, again sometimes it works and sometimes it doesn't. I throw challenges at them and I praise if they do take it up um,, and I don't say anything if they don't.

Ala's narrative alludes to the way learning can enable the personal growth of students, drawing on the notion of empowerment. The praise offered to students who take up her challenges is linked to her desire to build her students' self-confidence, especially since some of her students struggle to adapt to life and learning in New Zealand. Teachers' challenges can also be directed at students' behaviour. Michael says he sometimes has male students who dominate class discussions and so "often I have to say just hold on and let other people have a word". Several teachers said that they challenge any disrespectful or discriminatory remarks students make in classes to ensure a safe and respectful learning environment. For Elaine, such challenges also help educate all her students about discrimination in society. Some teachers' narratives show that care is not only about support and forming good relationships, but includes awareness of and challenges to the ways power can be present in classrooms. Diller (1996, p. 143) argues that "to nurture well and to care wisely" in the classroom includes inquiry, investigation, critique and criticism, and Daloz (1999) considers that good relationships with students involve a mix of support and appropriate challenge. Such challenges can be academic, emotional, relational, or about issues of social justice.

\subsubsection{Discussion}

Not all transcripts included narratives about relational practices, and this does not mean that these participants do not use such practices. It simply means that they did not discuss them with me in our interview. Rather than critiquing participants' practice, this section has explored how their narratives of teaching diverse students reveal some of the relational practices they employ. Participants' narratives describe challenges they experience in 
teaching diverse students and they also show how they use a variety of relational strategies to support students, create classroom communities and enable effective teaching and learning. Although teachers do refer students to various university-provided services, at times they deal with students' academic or personal difficulties themselves as these arise. Their narratives depict face-to-face teaching as much more than delivering and assessing a curriculum, yet I would argue that the holistic nature of teaching is not often acknowledged. It needs to be remembered that we teach students, not courses. The relational skills teachers have developed and employ in their practice often remain invisible and are mostly excluded in discussions of teacher competence and good teaching practice. Yet if teaching is a relation and not a role (Noddings, 2003), relational practices need recognition. This analysis of participants' narratives reveals some of the relational practices they employ and, I hope, will encourage further research by other educators.

\subsection{Narratives of inclusion}

\subsubsection{Introduction}

While diversity remains the central theme of this thesis, notions of power and care are also important and are present in participants' narratives. The analyses of narratives up to this point have given some brief attention to how power and care are talked about. In this section I employ a hermeneutics of suspicion to analyse how notions of power and care are produced in narratives about inclusive teaching. Teacher's narratives of inclusive teaching include two key themes, student participation and supporting vulnerable students. I analyse these narratives to see how different forms of care are produced by teachers in narratives about their teaching, and consider the effects of such care for teachers and students. I also look at how disciplinary and other forms of power are produced in their narratives, and consider how notions of care and power are connected. Throughout this discussion I consider the norms narratives of inclusion produce and the effects of these on teachers and students. 


\subsubsection{Narratives of participation}

For many of the teachers in this study, a great deal of importance is placed on student participation. Schultz (2009) argues that "classroom participation is a ubiquitous idea in education, yet it is rarely defined or elaborated" (p. 1). Usually it focuses on students' verbal activity. When I asked Helen what sorts of challenges arise in the classroom with her diverse students, she replied:

I guess probably, like the main thing in the classroom would be making sure that everyone's engaged and everyone's involved. And when there are language, you know second language issues that can be quite, that can be a bit challenging especially with, you know, it's quite a small group and you want to get a bit of, you want people to contribute and get some class discussion going, sort of trying to provide the opportunities and encouragement of second language students to participate. But also not wanting to put them on the spot either 'cause for some of them, that's their, you know, their worst nightmare and I can identify with that. [she chuckles] Suddenly they can't think of anything and your mind goes blank. So, but I mean that could even be an English speaking student who, um, that's a bit shy about participating in class as well but still wanting people to be able to share and feel involved and making sure everyone has the opportunity and feels encouraged to do that.

In Helen's narrative, all students need to be 'engaged' and 'involved' in the classroom. A key part of this participation involves speaking to the class, which is portrayed as challenging for NESB students or shy students. The expectation that all students should contribute to class discussions suggests a norm in classroom teaching, one that defines learning as active and demonstrated through verbal fluency and activity. The emphasis is on talking rather than listening, and silence is not seen as part of the learning process. In this narrative, silence can mean that the student is fearful of speaking up and their 'mind has gone blank'. But Helen is portrayed as showing empathy with 'shy' students and demonstrating her concern for them by not 'putting them on the spot'. Helen says she wants all her students to feel involved and encouraged, positioning her as a care-giver and her students as care-receivers. While the use of the words 'encourage' and 'opportunity' portray Helen as a 'facilitator' of student learning, she nevertheless regulates her classroom to ensure adherence to the norm. Helen, like other teachers, is disciplined by Western pedagogical discourses that constitute subjects as active, responsible and autonomous, and lead teachers to assume that when students do not speak in the classroom they are not learning (Schultz, 2009). Such discourses leave little room for alternative 
pedagogies that may better suit some students, for example those from Confucian heritage cultures (Chanock, 2010; Zhou et al., 2005).

Brookfield (2005) argues that disciplinary power is present in pedagogical practices such as group discussion that are designed to be democratic and participatory. He describes an influential norm of good discussion where

...everyone speaks intelligently and articulately for roughly equal amounts of time, and all conversation is focused on the topic at hand. Silence is rare. Conversation focuses only on the relevant issues with a suitably sophisticated level of discourse...Everyone listens attentively and respectfully to everyone else's contributions. People make their comments in a way that is informed, thoughtful, insightful, and unfailingly courteous. (p. 147)

Brookfield argues that this norm is covertly reinforced by the non-verbal cues teachers communicate to students which show when they are close to or moving away from the norm. This 'good discussion' norm was found in several participants' narratives. For example, Michael talks about ensuring that certain students do not dominate discussion and quiet students have the opportunity to speak, and Emily talks about ensuring respect and good manners in class discussions.

Liz relates a narrative about how she encourages her international students to participate in discussions. She says

When I want them to talk or express themselves I often get them to talk to the person next to them rather that out in front of the whole group. And then once they've had a chance to do that we might do a whole group discussion when they've had a chance to practise what they might want to say and then that tends to build up their confidence a bit more. Or I'll do things where we've got, everybody has to contribute something so then they'll feel like 'oh if everybody has to it's all right for me to have to as well' and they feel a bit more comfortable. And I'm often surprised by how effective just little tricks like that are in getting them to participate and contribute and get involved with a learning style that often is quite uncomfortable for them, quite foreign.

This narrative describes a variety of 'tricks' Liz employs to ensure that her students speak up in class. She acknowledges that the participatory learning style of New Zealand university classrooms is foreign to her international students, but enforces it nevertheless. The word 'tricks' in the narrative suggests the use of 'quiet coercions' (Dannaher et al., 2000) to achieve participation and illustrates the disciplinary power of participatory pedagogies. I need to stress that I am not judging the merits or otherwise of such 
pedagogies and the teachers who use them, rather I am interested here in the disciplinary practices found in New Zealand higher education. Because "educational sites are regulated through discursive and material practices" (Usher et al., 1997, p. 79), recognition of such practices can enable educators to consider alternatives. Requiring students to participate in class discussions may well support effective learning, but understanding how such a practice functions as disciplinary power means that teachers acknowledge their own position within flows of pedagogical power and consider how diverse students are positioned by particular pedagogical practices. Disciplinary power is not necessarily negative; Foucault (1980) stresses the productive nature of power, and in teachers' narratives disciplinary power not only constrains but also produces the subjectivities and practices of teachers and students.

Teachers' power to open up or close down student discussion is discussed by Elaine. She talks about issues around

...always giving people the opportunity to speak and have a voice about stuff um, and trying to weigh that up - it is about working on your toes isn't it, then trying to work that out about how it sits within the group and that can be a bit pragmatic at times as well, and whether to pursue it or not pursue it or allow somebody to have a say, and then closing it down and thinking 'I'm not sure about this' [she laughs] 'let's just put it to one side and I'll have a think about it for a bit and come back to it' or um, but always allowing the voice you know is probably the key thing and then thinking about how it impinges on other people and whether you can allow it or not allow it and control it or not control it I suppose.

Elaine's narrative emphasizes the importance of allowing students' 'voice', noting that these voices can 'impinge on other people', in other words, speaking is powerful and may need 'controlling'. Orner (1992) notes that power relations will impinge on what is sayable and doable in a classroom, and Elaine's narrative designates some things as not sayable in class, although she does not explain what these are. The narrative places students in positions of potential power in relation to other students, and the teacher in a position of power over students. The teacher is the judge of what can and cannot be said in the classroom and judgments are 'pragmatic' and aimed at enhancing the best interests of all students. Elaine's laugh at the point of 'closing down' discussion she is 'not sure about' highlights the uncertainty and perhaps discomfort this causes for her. Time is needed to consider these judgements carefully. The narrative thus shows concern for students' academic and personal well-being, and produces a 'teacherly' care for individual students 
and for the group as a whole. It links care and power in a storyline of trying to do the best for students.

A narrative from Maria provides an example of the fluid nature of power relations in a class that included a group of students from another country.

I have mainly $\mathrm{X}$ students in this tutorial at the moment and they congregate together, they stick together because they know each other, you know it's their group it's their friends and you start to see the dynamics change where before it would be the Pakeha students who would dominate the discussion and suddenly they've become on the periphery and they even sit on the periphery of the tutorial classroom - they sit on the edge. I've never seen that before and the $\mathrm{X}$ students sit within the middle and um, they almost hog the power of discourse there, so at the moment they're presenting seminars and they'll talk specifically to their peers you see and they won't even make eye contact with the other students in the classroom and I think that's challenging for me as a tutor to help break that up so that everyone's learning from everyone and also that um, you don't want the other students to feel marginalised. I think you know, everyone's identity should be reaffirmed and yeah, and it's interesting. Suddenly the dynamics have changed, as a teacher you have to start to learn quite fast as to what their needs are but also they have a different approach to study.

Maria's narrative positions her as a caring teacher who seeks to address students' needs to be included, to have their cultural identities affirmed and to have their particular learning approaches catered for. She acts to support students' wellbeing by preventing them feeling marginalised. Yet doing this requires breaking apart the cohesion of the $\mathrm{X}$ students who have become too powerful. This narrative constructs power in a number of ways. It is shown though non-verbal communication such as eye contact and the physical placement of students. Those in the centre dominate while those on the periphery physically are also on the periphery socially. Power is produced verbally - who is addressed and who is not addressed, and who 'hogs the power of discourse'. Maria is positioned as a powerful teacher who can choose to intervene and change the relational dynamics in the classroom and the narrative points to a caring-as-activism stance. It draws on a discourse that equates fairness with equal participation - everyone should be able to speak and be addressed in the classroom. Maria notes how Pakeha student domination in the classroom has been reversed in this particular situation, revealing by its transgression the norm in university classrooms. 
A narrative from Helen raises the issue of fairness in relation to the inclusion of students who are different from the norm. It describes Helen considering the challenges she experiences in her teaching:

I guess there are, yeah, there are challenges involved, as well I think in terms of um, always being able to accept different sorts of perspectives or ways in which students, you know different things that students bring and different needs that they have. Because you know while on one hand you want to be able to accommodate that diversity, on the other hand there's, you know, that sense of, there needs to be some sort of fairness and too that you can't be seen as over-favouring some students because they have particular needs in ways that may seem unfair to other students in your class, does that make sense? So I guess it's finding that balance as well between um, accommodating things and encouraging some students by having this sort of, an overall sense that everyone's being treated fairly and equally, which isn't always easy. [she chuckles]

In this narrative, the emphasis on the words 'challenges' and 'accept' and Helen's desire to 'accommodate' diversity draw on an inclusion perspective of diversity. This is then contrasted with a need for 'fairness' which involves treating all students equally and not 'over-favouring' students with 'particular needs'. Helen's narrative positions a discourse of fairness at odds with a discourse of inclusion and she tries to find a balance between them, yet she is subject to the disciplinary power of both. Her chuckle at the end of the narrative suggests a certain irony about this. This issue also arises for Ann, and when I asked how she deals with the language difficulties of international students, she says I always make sure that they've got all the information the week before so that they've got time to read through it, have a talk about it with their mates and make sure that they understand it properly. And that's really all I can do I think because I can't give them preferential treatment.

In this narrative, providing extra support to some students is positioned as unfair and in order to be a moral teacher Ann must not 'give preferential treatment'. It suggests that being a 'fair teacher' is at odds with being a 'caring teacher' who supports students with extra learning needs and, as with Helen's narrative, illustrates the disciplinary power of discourses of fairness and inclusion.

The importance of encouraging participation is found in a narrative from Bob. When I ask him about challenges in his teaching related to student diversity, he responds:

I suppose some techniques that I try and use sometimes aren't that successful, and in general with the small classes where- one training development course I went to said 
encourage your students to interact because I mean at the end of the day if they're sort of more involved in learning, it's going to mean more to them. And some of the methods that I have tried don't pay off that well. I mean, there's limitations depending on I suppose, how participative some students are. And sometimes that is affected by their confidence levels of, 'am I going to get this right or am I going to get this wrong'. And unfortunately I suppose from my point of view, sometimes when they get it wrong, I haven't been able to deal with it the right way and sometimes I've just [said], 'sorry that's wrong' and eventually that, that I suppose in turn, affects how willing they are to participate.

In Bob's narrative, the expert view is that students need to interact for effective learning and Bob tries to do this, however his 'techniques' are 'not that successful'. His narrative constructs student participation as verbal interaction, and shows that when Bob's own verbal interaction is ineffective it will affect students' 'willingness to participate'. The narrative portrays 'participation' as interactional and Bob's actions as powerful in opening up or closing down opportunities for participation. Bob occupies positions of 'teacher' and 'learner' as he attempts to facilitate effective student learning, but the narrative depicts him as limited in the knowledge and ability he needs to achieve his goal.

When I asked Bob how having diverse students has helped him as a teacher, he says: For a start it's made me a better teacher. From a problem solving perspective, having the diversity leads to, on one hand leads to problems. But dealing with those problems leads to having the experience of being able to face those problems in the future. You want to have experience at the end of the day-diversity's going to happen whether someone likes it or not. So it's better that you've learned how to handle it now rather than having to try and face all of a sudden in the future in terms of, you know, you can be instructed in theory, of how to deal with some situations but unless you've been through it yourself, you're not really properly prepared. And I suppose, wanting to be a good teacher, I prefer to be prepared now so that I can be as good a teacher as I can be in the future.

This narrative constructs diversity as inevitable and problematic, motivating the development of better teaching. While several teachers spoke about their ongoing learning and development, only Bob's narratives exemplify Foucault's (1988) care of the self. The storylines of narratives such as the one above are about ongoing attempts to become a better teacher, and in other narratives Bob talks about "trying to improve myself" and giving himself "a culture of continuous improvement". He refers to "the faults with my teaching", and says he tries to learn from these situations. His narratives have more of a 
focus on the future, on 'becoming', than other teachers whose narratives were primarily about past experiences and present issues. Education can be understood as a "process of self-discovery, self-critique, and self-enlargement" (Moore, 2006, p. 107), depicted in Bob's narrative through his teaching leading to his learning. Narratives about attempting to meet the expectations of 'good teaching' norms discipline Bob's practice and position him as a 'faulty' teacher, and at the same time they generate his care of self and create a moral teacher-self.

\subsubsection{Narratives of supporting vulnerable students}

Several participants told narratives about supporting students who were needy or vulnerable in some way. A narrative from Helen brings together several relational practices and shows how they combine in a caring pedagogy. Helen describes how she facilitates an inclusive learning environment for a student with an impairment:

In tutorials every student has to give a presentation and so that's, you know everybody has to get up and speak and, and that was interesting too because I felt, you know I was quite concerned for the chap with the stutter, but I thought he still has to do it you know and spent a lot of time with him making sure that he was, that his presentation was well prepared and that he knew what he was talking — wanted to say and that sort of thing. And he was a good student in the sense that he would come and ask for help which you know, which always makes it, I think that's always great. And I, I love working with students who are, they want to come in (....) and he was well organised and that sort of thing. And I felt a bit sort of, nervous for him but on the day, yeah he did well and the other students were all very, you know, he did stutter at times but other students um,, all reacted very well and, I guess there could be some concern that people would be a bit, I mean not rude to him but, yeah there could be some awkwardness in the class. But everyone was really good and participated in the discussion he ran afterwards and was really encouraging, that sort of thing.

This is a narrative of overcoming challenges, both for Helen and the student. It positions Helen as a care-giver of a vulnerable student and as a facilitator of care between students. The storyline shows how Helen's care enables the student to succeed, drawing on a discourse of empowerment whereby a skilled and knowledgeable person assists someone less knowledgeable to develop the ability to act successfully within a particular social system (Inglis, 1997). In this narrative, the requirement that all students give a presentation 
determines what is desirable and possible in the classroom. Helen does not say who has set this requirement, but her narrative reflects the 'pedagogical imperative' (Lee, 1998) to speak in university classrooms. The outcome of the narrative was that the 'diverse' student succeeded and 'everyone was really good', and the emphasis on the word 'rude' suggests the potential for it to be otherwise. The narrative portrays the good student as wellorganized and willing to ask for help, the good classroom as one where everyone participates and is accepting and encouraging of vulnerable students, and the good teacher as one who provides academic and personal support to students. In Helen's narrative, both care and disciplinary power produce active teachers and students and create cohesive classroom communities.

Grace relates a narrative about helping a student succeed and the feedback she received. She says

I had an incident one year with another student who was a Chinese student who was really really struggling with her language but there were moments of almost brilliance in some of the things she said but she just really couldn't get there and I gave her quite a bit of support and her second assignment hadn't improved and I went to my coordinators and I said look, I really want to work with this student and I'd gone into her record and seen that she'd not done very well across most of her courses and I sensed there wasn't a lot of investment of time in her, that she'd been sent from her country to this country to get her degree. She was an international student and I really invested a lot of time in her and eventually she came out of that course with a good pass mark and she wrote an email to me afterwards and she said I was, this was her experience, she said I was the only person that ever took that extra moment to really work with her and that when she had sent her grades back to her parents they were really happy and blown away. But it took $\underline{\text { much }}$ more time to work with that student than it did with any of the others at that time.

This narrative of overcoming a challenge shows that 'investing time' in a student has a positive outcome, but the narrative qualifies this by acknowledging the limits to such support. It tells a story of how concern and effort overcome obstacles for a 'diverse' student and lead to rewards. Care in the narrative is constructed as care-giving, involving investment of a resource (teacher's time and expertise) in the care-receiver. A storyline that portrays Grace as going out of her way for the student contrasts her care with a lack of investment by other teachers and positions Grace as a 'heroic carer' of her student, as does the emphasis on the words 'really', 'eventually', and 'much'. The storyline also shows 
how care is a form of disciplinary power, one that induces teachers into giving extra support to struggling students and that produces rewards for them and their students.

In a narrative from Susan, inclusive teaching involves bringing students together to learn from each other.

When a situation comes up in diversity, then what I generally do is, is say hey, maybe there's someone here that could respond to that for you. Because often what I—we're just sort of coming back to the Muslim, there was someone and they were talking from a Christian base and said 'oh but I don't know how we're going to deal with Muslims', you know that sort of a comment, so I said oh, maybe there's someone in the room that's familiar with that. And the student, it hadn't crossed their mind that there was actually a Muslim in the class. It hadn't — we'd been together for several weeks, so just to give that person an opportunity to respond. And the whole thing really changed instead of being someone from a different religious belief being someone over there or out there, to realise that someone actually a part of my educational group is from a different group to me.

The narrative sets the scene ('a situation' involving student diversity) and difference is described in terms of a distance ('over there or out there') that is closed through relationships. Susan's narrative transforms categories of difference into classroom relations, linking academic learning with social awareness. It suggests that 'diverse' students are positioned differently within dominant educational contexts and action on the part of the teacher is necessary to change that positioning. Susan is positioned as a facilitator of both classroom relationships and student learning.

In another narrative, Susan says ...we try and keep an eye on people who seem to be a bit isolated, and intervene. Like speaking to them and saying who, who do you feel connected with here, and talking to them about keeping that connection. Very occasionally they've, another student came to me saying they're worried about so and so. Again building that bridge between them or having them as the bridge between that student and others.

This narrative depicts Susan supporting and caring for students by helping them form relationships with each other, using the 'building a bridge' metaphor. Power is present as Susan 'intervenes' when she sees students who are isolated and therefore less powerful in the classroom community. The use of the word 'we' indicates that Susan works with her colleagues to ensure student well-being, and portrays a communal form of caring. Many of Susan's narratives construct caring as an activity that is initiated by her but which acts to 
connect students and enable them to care for each other. Even when she relates narratives about caring for an individual student using a care-giving/care-receiving model of care, Susan still places this care within a web of communal care. This depiction of communal care positions Susan as more of a care-facilitator than a care-giver, and an advantage of this might be that caring is shared and not the sole responsibility of one teacher. Such a deindividualization of care is a step towards to moving care from being a marginalized activity to occupying a more central position in higher education.

Conflict in the classroom is discussed by Michael. This narrative describes conflict that arose between Christian and non-religious students over references to God in a discussion about spirituality.

It was quite a real sort of conflict there, but then of course that adds to the richness of the learning if you can manage it and just make sure that everyone gets a chance to speak and just remind everyone that you know in a university discussion everyone can acknowledge all their ideas they have and acknowledge difference and I don't agree with you but you're welcome to say it and all of that stuff. So um, I don't think we should be too anxious about conflict like that 'cause it can add to the learning experience but um, it does need to be managed carefully and you wouldn't want someone to go away, one of the Christian people for example to go away feeling like they' $\mathrm{d}$ been dissed as the kids say, that somebody's trampled over what they believe, so I treat that very carefully. One of the students in particular who seem to feel strongly about it, I made a point of saying 'are you okay with that discussion' and it was alright in the end. But you know I thought it was a really good part of her learning too that she could hold as dearly as she wanted to her own religious beliefs but she needed to appreciate that she was in an environment where not everybody shared those views and she had to somehow deal with that. And that other people could talk about stuff that she held dear in a different way and that's okay I mean it wasn't a challenge to her, it was simply a discussion.

Michael's narrative describes an incident that illustrates several of his concerns: respect; inclusion of and caring for students; including all voices in the classroom; promoting academic discussion of diverse ideas and viewpoints; and learning to accept difference. The narrative illustrates the 'rules' of classroom dialogue underpinning democratic education and critical pedagogies. According to Ellsworth (1989), these 'rules' require that students are respected and feel safe to speak, there is equal opportunity for all students to speak, and their ideas are accepted and subject to rational critical assessment. Michael's narrative portrays conflict as beneficial for learning when "managed carefully." It links 
Michael's support of students - ensuring respect, encouraging all students to express their viewpoints, being attentive to students' vulnerabilities - to challenging them to learn about and accept difference. It produces a 'tough' form of care that depicts learning as having the potential to transform students' perspectives and promote acceptance of diversity, with teachers positioned as agents of change who should not back down when encountering student resistance.

Michael's care-as-activism is also produced in another narrative describing his surprise that "even at a tertiary institution" gay and lesbian people are very anxious about "coming out'. He adds,

...with our traditions of academic freedom and tolerance, liberality and all this stuff that we have at the university, that um, you know this seems to me an environment where there ought to be a place where all sorts of diversities can be acknowledged just as a matter of course. So, yeah, so I mean that's just one of my little campaigns.

This narrative shows a breach between Michael's ideal and the university's actual practices. It positions him as 'caring about' his students, inclusion and social justice, and it produces 'care-as-activism' as he acts on his concerns through 'campaigns' responding to how universities 'ought' to be for 'all sorts of diversities'. Care-as-activism acknowledges that an individual's well-being is influenced by social, cultural and political factors and relations of power, and that injustice and harm to people require acting for change. Such care is therefore not about fixing problems within students but involves facilitating a greater understanding of and respect for diverse people and working for social justice. Care in Michael's narratives is shown to involve conflict and challenge as well as support, and is linked with power-as-resistance and power-as-agency as he attempts to put his ideals into practice.

\subsection{Discussion}

Participants' narratives of inclusive practice describe how they respond to the needs of 'diverse' students, that is, students who are positioned as different, vulnerable or needy. In narratives of participation, emphasis on students' verbal activity produces a norm that disciplines teachers' practice and students' learning and excludes alternative teaching practices. Schultz (2009, p. 14) notes that "expectations for classroom participation emerge 
from culturally situated norms", and teachers' narratives position diverse students in relation to a pedagogic norm of verbally interactive classroom relations. The absence of consideration of other forms of verbal and non-verbal pedagogical practices suggests an area for further study that could lead to opening up teaching practices in ways that benefit all students.

Narratives of inclusive practice produce various forms of power. Power-as-agency is produced when the narratives describe teachers acting to employ particular pedagogies, influence classroom relations, and support students' learning. Power-over is produced when teachers describe using their authority to insist on student participation or to manage conflict in class, and when they talk about opening up or closing down discussion.

Resistance to power-as-domination is produced when teachers challenge discrimination, act for justice and contest university policies and practices. Disciplinary power is produced when narratives depict teachers using 'quiet coercions' to encourage adherence to norms of participation. Resistance to disciplinary power is suggested in some narratives that point to the unruliness of participatory practices when norms are (or threaten to be) transgressed. Teachers' narratives show how relations of power produce teacher and student subjectivities and generate pedagogical practices.

Participants' narratives of inclusive practice also produce forms of care. Care is produced in storylines where teachers become aware of the vulnerability or needs of students in relation to teaching and learning practices or classroom relationships, leading teachers to respond by initiating changes and providing support for students. This illustrates care as care-giving, and was the dominant form of care produced by narratives. Teachers' care for students is depicted as nurturing or tough, dyadic or communal. While some teachers who were positioned as facilitators of caring relationships situate their care within networks of caring relations, in most cases teachers narrate "stories of heroic, independent acts" (Phillips, 1994, p. 10). Narratives of inclusive practice position teachers as knowledgeable and powerful, as skilled practitioners who identify and attend to students' academic, emotional and pastoral needs, yet they also position them as limited in knowledge and influence when experiencing difficulties in teaching diverse students effectively and when they talk about improving their teaching practice. 
Relations of care produced in participants' narratives involve relations of power; those who care influence the behaviour of others in various ways. Teachers enact power-asagency when they employ relational practices, act on their concerns and seek to empower students; teachers have power over students when they identify student needs and institute caring interventions; and pedagogies of care act as disciplinary practices when they define what 'care' is and persuade teachers to think and act in particular 'caring' ways. Several narratives depicted humanist perspectives of care as support and empowerment while other narratives draw on critical perspectives that construct care as activism in the pursuit of social justice. However in some narratives, these forms of care are found to be opposed by discourses of fairness that require equal treatment for all students.

\subsection{Conclusion}

The storylines in narratives of inclusive teaching tend to affirm culturally preferred pedagogies. They position inclusion as something teachers initiate and maintain, and do not talk about students' role in this. Analysis of participants' narratives shows how teaching involves relations of power and care, and how relations of power and care produce particular teaching practices. The ubiquity of power and care in narratives of classroom teaching initially surprised me; however on reflection I realize it could not be otherwise. While a great deal of research and literature looks at power in higher education, an equal consideration is needed of the ways care is enacted and how it enables and constrains teaching and learning in higher education, and how relations of power and care work together.

The title of this chapter, "Inclusive practices: Acts of care or means of discipline?" asks a question that is addressed by the analysis of participants' narratives. The analysis shows that these teachers' narratives position inclusive practices as both acts of care and means of discipline. The narratives of inclusive teaching produce acts of care through talking about attending to students' needs and wellbeing and also, in some instances, to teachers' needs and wellbeing. Narratives of inclusive teaching practices also produce forms of power, and analyses of these narratives show that inclusive practices discipline, and are disciplined by, what is sayable and doable in higher educational practices. Relations of power and care can be understood as fluid and dynamic, and as interacting in complex ways. However, 
much of the way we talk about teaching diverse students does not portray such complexity, and perhaps is unable to within current discourses of higher education teaching practice.

This suggests that "working with language differently" (Britzman, 2000) could be worthwhile, and I address this in the next chapter. 


\section{Chapter 10 \\ Speaking and doing diversity}

\subsection{Introduction}

The central question informing this study is: 'how do university teachers understand and experience student diversity?' Interviews with twenty-two teachers have provided a range of answers to these questions, and given 'voice' to their ideas and concerns using a hermeneutics of faith. However, as noted in Chapter One, this way of analysing narratives of teachers' experiences provides limited insights into teachers' understanding of themselves and their practices and the contexts these are produced in. Usher et al. (1997) argue that since teachers must speak and write about their practice, it is necessary to be aware of how "practices are 'governed' by the ways in which they are described" (p. 67) both in everyday conversations and in more deliberate theorising. I therefore employed a hermeneutics of suspicion which considers narratives as accounts that construct particular versions of events and as performative acts in which identities are enacted and actions are justified (Atkinson \& Delamont, 2006). This has enabled me to investigate how participants' narratives 'speak and do' diversity and how 'power' and 'care' are produced in these narratives, and has revealed the norms that are constructed by participants' narratives. In this chapter I reflect on the results of my analyses of teachers' talk about diversity. I consider the construction of narratives and the discourses that shape this process. I also explore how it might be possible to 'speak and do' diversity differently by considering how counter-narratives could be constructed.

\subsection{Interpreting teachers' voices}

This study has given participating teachers an opportunity to talk about how they understand and experience student diversity. Using a hermeneutics of faith, analysis of synchronic and diachronic data has revealed a depiction of diversity as categories of difference, where difference is often positioned as divergence from a norm. While most teachers identified a wide range of 'diversities', their narratives of experience focused on the 'diverse students' who produced the most challenges (and sometimes rewards) in their 
own teaching practice. Teachers in this study said that they valued student diversity, but often their narratives of experience portrayed it in deficit terms. Inclusion perspectives of diversity informed much of teachers' talk about diverse students, and teachers' narratives provided storylines of struggle and/or success as they found ways to adapt their teaching practices to support students' learning. Some teachers' narratives also drew on critical transformative perspectives of diversity in storylines of seeking change in their classes or universities towards greater equity and the valuing of subjugated knowledges. Some teachers' narratives described their actions to change unjust relations of power rather than trying to 'help' students or change their own teaching practices. In many narratives, diversity was depicted as a deficit located in the student that needs to be 'fixed', whether through integrating students into academic culture, adapting teaching practices to meet diverse learning needs or ensuring respect and equity for diverse students, which often acted to reinforce the power of dominant Western academic practices. This positions 'diverse' students as 'Other' and can make it difficult for alternative pedagogical and cultural practices to thrive in our university classrooms. At times teachers' narratives also located deficit in the teacher, when he or she is depicted as responsible for meeting students' diverse learning needs and who struggles (or fails) to do so. This positions individual teachers as responsible for developing the knowledge and skills they need to teach a wide range of diverse students within a university context that generally remains aloof to such matters.

The prevalence of narratives about international NESB students raises several issues. The marketization of New Zealand universities and the pressure to find sources of revenue additional to state funding means international students are a valuable economic resource. However some participants' narratives suggest that this influences the admission of international students to universities, enabling those without the English language proficiency required for university study to be enrolled. Whether this is the case or not, some teachers face difficulties in teaching and communicating with students who have limited English language proficiency, which adds to their workload and for which they do not necessarily receive extra support. Several narratives included generalisations about 'Asian learners' though some also contest these. Some participants may not have had access to recent research on teaching NESB students that describes teaching practices that make learning difficult for these students (e.g. Ryan \& Viete, 2009), challenges assumptions about Asian learners (e.g. Chanock, 2010; Kember, 2000) and suggests 
effective pedagogical approaches (e.g. De Vita, 2000; Zhou et al., 2005). This is an area where support and development could be made available to teachers. Teachers may want to keep up to date with research about teaching NESB students but find it difficult with their teaching, research, and administration commitments, and reading the literature in their discipline will most likely take priority over reading pedagogical literature. Universities exist within a globalized higher education context and need to become intercultural through valuing the perspectives, knowledge and cultures of international students (as some participants noted), and by creating curricula and pedagogies to equip all teachers and students to study, work and live in culturally and linguistically diverse environments. Jiang (2005) describes interculturalisation as an emancipatory process that "emphasises non-discriminative cultural reciprocity based on equality and respect" (p. 223). She suggests that promoting interculturalisation will encourage the expression and appreciation of different worldviews and values rather than assimilating 'Otherness' and attempting to create a common culture. A process of interculturalisation inevitably brings up tension, incompatibility and misunderstanding, however coping with these difficulties "kindly and openly" (p. 231) is recommended by Jiang.

Participants' narratives of experience portray teachers as skilled practitioners who learn through experience and develop an understanding of 'diverse' students and their learning needs. Yet a number of narratives point to a lack of acknowledgement by university management of the challenges that teaching diverse students entails, especially in relation to small group teaching, and the time and resources needed for dealing with these challenges. If, as participants' narratives suggest, teachers' informal learning is more effective than formal learning opportunities in developing skilled teaching practice, then such informal learning should be recognized, valued and supported by their institutions. Participants' narratives contest the public narratives of universities that talk of recognizing and supporting excellence in teaching practice and they suggest that university management may lack an awareness of teachers' experiential knowledge and skills. This indicates a need to strengthen relationships and communication between teaching staff and management. The willingness of participants to voice their ideas and concerns in this study suggests that there may be a lack of opportunities for them to speak about such issues and be heard, especially regarding small-group teaching which may be taken for granted or devalued. Opportunities for teaching staff to discuss their concerns with managerial staff 
without feeling vulnerable to scrutiny could benefit teachers, students and the university as a whole.

Participants' narratives suggest that there is a lack of appreciation for teachers' practical knowledge gained through experience, such as through 'trial and error', reflection on practice, feedback from students, and discussions with colleagues. Weimer (1997) argues that universities have a "vast repository" (p. 56) of teaching experience but this is a resource that is mostly untapped. Too often, the knowledge teachers gain through experience is considered "anecdotal, individual and eclectic" (p. 57) and therefore not recognized as a valuable resource that could be preserved and shared, prompting wider reflection on teaching practice. Teachers often engage in individual professional development, but Lewis (2005) recommends communal professional development and an increased use of collaboration over individual problem-solving. She argues that "reflective professional inquiry, through frequent interaction among staff, is acknowledged as essential in converting individual unspoken or tacit knowledge into shared knowledge" ( $p$. 107). The Teaching Community model (Macdonald, 2001) and mentoring circles (Darwin \& Palmer, 2009) are examples of initiatives that enable academic staff to meet on a regular basis to share ideas and discuss the challenges and opportunities of their work. Individuals learn in relationship with their peers and in the case of mentoring circles, collaboration across faculties is encouraged. For initiatives such as these, teaching staff need to have time and the support of their institution to be involved in such programmes. Massey University is one institution that has introduced mentoring circles for academic staff (Massey University, 2010).

\subsection{Revealing the norms}

Applying a hermeneutics of suspicion to teachers' narratives of experience reveals several norms. Looking at what teachers did not speak about as well as what was unmarked in their narratives revealed a student 'norm' - a young, middle-class, heterosexual male or female Pakeha student, who is able-bodied with good health, and who understands academic culture and actively participates in class. When differences (such as nonEuropean ethnicities, homosexuality, NESB) are marked and talked about as divergence from a norm, as variation, as degree or as opposition, then diversity becomes a powerful 
way of ascribing social status and concealing power relations. However this does not mean teachers support dominant social power relations; many teachers' narratives contested social hierarchies and educational norms. What it does indicate is that universities operate within particular discursive frameworks and practices that position students differently, and that the language educators use to talk about difference has material effects, often constructing diversity as a deficit within educational relationships and practices. The narratives of some participants took a stance critical of a deficit approach to diversity, and all participants' narratives showed they care about all their students. The disparity between this valuing of all students and the ways the narratives constructed notions of diversity and difference shows that dominant educational, political and cultural discourses govern how we talk about 'diversity' and that this knowledge, as Foucault (1980) noted, induces relations of power.

Reflection on my analyses of teachers' narratives of experience reveals a preferred pedagogy for teaching 'diverse' students in universities. This can be summarized as follows: the construction and critique of knowledge by students is favoured over the transmission of knowledge from teachers to students. Verbal participation in classroom settings is considered important for learning while silence is not valued. Respect for different viewpoints and for individuals in a classroom is stressed, and encouragement is given to enable all students to 'voice' their ideas in class. Differing or conflicting viewpoints can provide valuable learning experiences but must be carefully managed. In this preferred pedagogy, teachers are available to provide academic support (and sometimes pastoral care) to needy or vulnerable students, at the same time they are 'fair' and do not favour particular students. Teachers use a variety of relational practices to connect to students, to help students connect with each other, and to create classroom communities. Teachers prefer an informal but authoritative teaching style and do not like to be didactic. This preferred pedagogy draws on inclusive teaching approaches, critical pedagogies that promote marginalized voices, and a humanist discourse of active, autonomous learners and empowering teachers. It is congruent with Western academic culture; consequently some students from other cultural backgrounds may struggle with aspects of this pedagogy. In this thesis I do not judge the merits or shortcomings of the preferred pedagogy, but $\mathrm{I}$ believe there is value in revealing the construction of pedagogical norms in order for teachers to consider how such norms discipline their 
teaching, in whose interests they act, and whether alternative pedagogical approaches need to be considered.

Analysis of participants' narratives also provides insights into the contexts they teach within. Some narratives portray and contest a changing context of higher education in which a neo-liberal discourse of marketization positions students as customers of educational products and teachers as deliverers who strive to meet customer requirements. Such positioning goes against a preferred pedagogy in which teachers facilitate the active construction of knowledge by students and encourage critical thinking, and where education has intrinsic value rather than being seen primarily as a means to employment ends. Both inclusion discourses and neo-liberal market discourses of higher education focus on meeting students' needs, however the notion of 'needs' requires critiquing. Teaching to meet students' needs does not always correspond with effective teaching practice, and 'needs' are socially and discursively produced. Whose needs are visible and whose needs remain invisible, and decisions about which needs are responded to and how, are governed by (and reinforce or contest) dominant educational discourses and power relations in the university, from policy-making through to classroom teaching practices.

Telling narratives of experience enabled participants to articulate their teaching ideals and values and construct preferred teacher identities. Narratives of successful teaching portray teachers as professionals with expertise and construct competent teacher identities, and narratives of overcoming challenges construct agentic and moral teacher identities. Challenge narratives that do not have successful outcomes produced fallible teacher identities when teachers' efforts to teach diverse students 'failed' in some way, but these narratives also produced moral identities through the construction of hardworking, conscientious teachers committed to their students. The storylines of most narratives of experience are about a teacher's progress toward a desired teaching goal, drawing on and affirming a humanist discourse of autonomous subjects who act with agency to empower themselves and others. Only a few teachers constructed narratives with a relational teacher identity and a storyline of teaching and learning practices in classroom and departmental communities. Narratives of personal experience act to portray the narrator as acceptable and worthy in relation to cultural narratives (Gergen, 1998) and thus offer insight into educational contexts and the discourses they are formed in and from. Participants' narratives suggest that dominant narratives of teaching are underpinned by a heroic, 
individualist storyline that emphasizes progress towards specified criteria rather than stories of communal actions and relational identities, open-ended inquiry and uncertainty.

\subsection{How the narratives 'speak and do' diversity}

\subsubsection{The construction of narratives}

In the interviews with participating teachers, the questions I asked and my responses to participants influenced what they talked about and how they talked about it. Questions I asked included:

- What does student diversity mean to you in the context of your teaching and your students?

- How do you work with this variety of students?

- How have you learned to teach diverse students?

- What kind of challenges have you encountered regarding student diversity in your teaching?

- What do you do to deal with these issues?

- How has having a diverse student group helped you as a teacher?

- What support have you received for working with diverse students?

- $\quad$ Do you have discussions with colleagues about teaching diverse students and does that help?

These questions construct autonomous teachers and individualized teaching practices. They reify 'diversity' and assume a shared and taken-for-granted meaning of this concept. The use of words such as 'issues', 'challenges', 'deal with', 'work', 'support', and 'help' portray diversity as potentially troublesome. As a result, when I ask teachers about their experiences, I have set the scene for narratives of heroic struggle and the construction of 'noble' teacher identities. Teachers could, and occasionally did, construct different storylines and position themselves in other ways, however, their narratives are best viewed as "a collaborative construction in which the meanings and the way they are constructed depend on both the interviewer and the interviewee as 'active agents' in the interview" (Watson, 2006, p. 369). Thus my analyses of teachers' narratives provide insight into my own changing understanding of diversity as well as that of participants, and the discourses that shape what can be known and what can be said. This thesis is as much about my own 
'speaking and doing' diversity as it is about how participants' narratives speak and do diversity. It shows that "my own telling is partial and governed by the discourse of my time and place" (Britzman, 2000, p. 32), yet open to ways of retelling in the construction of this thesis.

\subsubsection{Speaking and doing diversity}

Participants in this study tell a variety of narratives about teaching diverse students. When teaching is understood as educational relations, diversity is always present; human relations are complex and dynamic and knowledge of relations is always partial and limited (Sidorkin, 2002). This means that, as Bingham and Sidorkin (2004, p. 7) note, "Human words and actions have no authentic meaning; they acquire meaning only in a context of specific relations." As well, anything that is spoken about cannot have meaning unless it is differentiated from something else (Young, 1990). The categories we use to make sense of our world emerge from our interactions with other people and our physical and social environment (Lakoff \& Johnson, 2003), and how difference is categorized varies across cultures (Lakoff, 1987). In participants' narratives, 'diversity' is produced through constructing categories of difference. When differences between groups or individuals are emphasized, there can be a lack of acknowledgement of the similarities between individuals or groups or the diversity within groups, or the multiple positioning of all individuals. This can act to support some identities and some social groups and to marginalize others, or to contest such positioning. The categorization of difference therefore produces power/knowledge that enables and constrains what is sayable and doable.

A hermeneutics of suspicion takes my analysis beyond participants' descriptions of their ideas and experiences. What might at times seem critical is not aimed at the teachers who generously told their stories to me and who care a great deal about their students and their teaching and showed in their narratives much knowledge, skill and passion for teaching. What my critical analysis does is reveal the discourses, hidden norms and taken-forgranted meanings producing the ways we speak and do diversity and that govern teaching in higher education. One way to consider the knowledge produced by teachers' narratives is suggested by Stengel (2004). She notes, "Knowledge of any kind or quality enables one 
to act but also limits potential response; it opens up vistas even as is sets up horizons" (p. 32). She refers to this as a 'double movement'. This notion of 'double movement' can be seen as teachers' narratives construct categories of difference that enable them to speak about diversity but at the same time constrain what they can say. Their narratives act as strategies of 'inclusion' through stories of teaching to enable all students to participate in the classroom and to support needy and vulnerable students, yet in a 'double movement' the narratives also act to produce forms of 'Othering' whereby certain forms of difference are marked and set apart for special attention so as to be brought 'into the fold'. This shows the limitations of inclusion and indicates a need to find ways to speak about diversity that do not produce marginalized 'Others'.

Participants' narratives describe a variety of student-centred teaching strategies and responses to challenges in classroom teaching. These narratives 'do diversity' through the production of preferred teacher identities - conscientious, competent, and flexible - and through the production of norms of inclusive teaching. Participants' narratives also depict the different contexts that experiences of teaching are enacted in, and show how their experiences are always both enabled and constrained by these contexts. Stengel (2004) refers to another form of 'double movement' that occurs in actions within educational contexts. She explains that often teachers have to respond to circumstances that are not of their own making, and yet at the same time must take responsibility for their actions. Being responsible is about taking some control over a situation, while being responsive implies a lack of control. This double movement of being responsive and responsible requires teachers to be response-able within educational relations that they both shape and are shaped by. It links the power to influence situations with care for and in educational relations, and suggests that participants' narratives function as a response to situations they find themselves dealing with and, at the same time, as a means of reinterpreting and reshaping their teaching practice and their teacher identities.

\subsubsection{Speaking and doing diversity powerfully}

Narratives of teaching diverse students talk about power in certain ways, such as power-asagency, power over, resistance to domination and disciplinary power. Maria's phrase 'hogging the power of discourse' has stayed in my mind as I write this thesis. When 
'discourse' is understood as including not only what is said, but what is sayable and not sayable, then 'hogging the power of discourse' refers to the ability to define what can and can't be said, what can and can't be done, and who belongs to the centre and who is on the margins or is invisible. The narratives teachers related showed how talking about diversity is inevitably power-full, and how that power might be produced, enacted or contested. At the same time, in a 'double movement', participants' narratives are subject to disciplinary power through the narrative and discursive resources they are constructed from, shaping what they can and cannot say. This enables and constrains the narrative production of teacher identities and the relations between teachers and students, as well as notions of diversity and difference.

Narratives of teaching diverse students enact forms of power through their telling. Narratives of overcoming challenges and learning to teach diverse students in progressive plots and narratives of effective teaching in success stories produce competent teacher identities and act to empower teachers as they reflect on their practice. Narratives of experience that produce capable and competent teacher identities within storylines of problem-solving and taking the initiative enact power as agency, while narratives that contest institutions' 'authorized versions' of teaching, dominant educational discourses, or cultural metanarratives enact power as resistance. Disciplinary power is produced through what was sayable and not sayable in the interviews, how the narratives are constructed and performed, and the ways that notions of diversity and power are understood.

Although my analysis has shown how power is produced within/by teachers' narratives, generally in the interviews the teachers and I drew on humanistic discourses of education with notions of autonomous selves and progress towards desired ideals, which shaped the construction of the narratives. Only some interviews produced narratives where power was talked about explicitly. Usher et al. (1997) note that

The most effective forms of power are those which are not recognised as powerful but as enabling or 'em-powering'. These forms of power are cloaked in the 'objective' knowledge of expertise and the humanistic discourse of helping and facilitating. (p. 87) My part in the production of teachers' narratives of experience certainly facilitated this; however, my ongoing learning about critical and post-structural approaches to thinking and talking about power have enabled the retelling of these narratives in my analyses to 
make explicit the relations of power and the resistance they produce and enable a consideration of other ways that educational relations can be enacted powerfully.

\subsubsection{Speaking and doing diversity carefully}

Narratives of teaching diverse students produce and enact forms of care. Like Foucault's (1980) insistence that power is productive, I argue that care is also productive. If we did not care we would not give something our attention and act to create, maintain or enhance it. Caring about or for someone or something may have altruistic or selfish motives, it may be effective or ineffective, and those in the caring relation may not always agree about how care should be enacted. However, care is an essential part of human relations, and that includes teaching. Although participants' narratives of teaching diverse students do not often discuss care directly, their storylines nevertheless produce various forms of care, such as care-giving and receiving, care-about, care-as-activism, communal care, and selfcare. Teachers' narratives of experience portray them caring about and for their students through relational practices and supportive strategies that aim to meet the needs of vulnerable students or enhance the academic achievement and personal well-being of all students. Such narratives often draw on humanistic discourses of pastoral care whereby teachers support and empower needy students. Critical transformative approaches to education in which caring actions are those that seek social justice were also drawn on in the construction of narratives, producing care-as-activism. Narratives that situate the experiences they describe within communities of practice often produced communal forms of care, while some narratives included a teacher's self-care in their storylines. All these forms of care produce particular teacher identities, such as the dedicated and conscientious teacher. They also shape relations between teachers and students, offering particular subject positions to students, such as care-receiver, activist, or carer of other students.

Participants' narratives 'do' care in various ways. Through participation in this research study, sharing their ideas about diversity and narrating stories of experience, and in their interest in diversity and teaching practice, participants enacted 'care about' higher education. They enacted 'care-giving' for me as a researcher as they met my need for participants and supported my study, and they enacted 'care of the self' through reflecting on their teaching and examining their practice, seeking knowledge of themselves as 
teachers, and working on themselves to gain knowledge and wisdom. Teachers also enacted self-care when they voiced their concerns about teaching, students, their institutions and the political discourses that govern their practice, and through constructing dedicated, conscientious and competent teacher identities.

The narrative and discursive resources participants draw on to construct their narratives discipline how teachers speak and do care. Humanistic discourses of care that seek to 'empower' students often produce a paternalistic form of power-over, while discourses of student-centred teaching induce teachers to provide care-giving for students that may be at odds with ensuring their own self-care. Both humanistic and neoliberal discourses of education produce ideals of autonomous individuals, which means that those who require care, and those who enter into relationships to provide that care, are positioned as not fully autonomous and therefore by implication as lesser persons. Even critical transformative approaches to education which seek to liberate individuals or groups from oppression and marginalization can also produce ideals of independence. How care is enacted in speaking and doing diversity therefore depend on how the self and its relations with others are discursively constructed.

\subsection{Speaking and doing diversity differently}

As well as revealing the ways participants in this study 'speak and do' diversity, this thesis provides an opportunity to consider counter-narratives that attempt to go beyond the limits of dominant storylines of teaching diverse students and "expand the restricted domain of language" (Noddings, 2003, p. 2) used to talk about diversity. As Gergen (1998, n.p.) notes, "narratives function both to reflect and to create cultural values". Counter-narratives contest dominant narratives and offer different ways to make sense of ourselves and our experiences (Andrews, 2002). A counter-narrative about teachers' experiences of student diversity will need to include and reconstruct notions of diversity, teacher identity, teaching, and university contexts. It will need to construct emplotments outside of those that are "ordinarily available" (Andrews, 2002, p.1) and place diversity as central. Counter-narratives will be underpinned by awareness that there is no "God's-eye view of the world" (Thayer-Bacon, 2003, p. 254) and that all narrators are embedded and embodied in specific contexts. Counter-narratives of teaching diverse students therefore 
need to be reflexive and multiple, and involve a 'double movement' (Stengel, 2004) that acknowledges their situatedness and specificity while simultaneously opening up possibilities for reimagining teaching students in higher education.

A relational epistemology provides a framework to construct narratives differently. Instead of focusing on individuals who are placed within categories of diversity, a counternarrative would understand selves relationally, whereby self and other(s) are mutually constitutive rather than mutually exclusive. A counter-narrative would construct diversity as inherent in relationships, and thus as a fact of existence in this world rather than as a deficit located in the student or the teacher, or in the institution. When difference is understood relationally, each party in a relation is different from the other in some way(s). This means that rather than considering how a person or a particular practice or point of view differs from a norm, counter-narratives of teaching diverse students will acknowledge that all parties are positioned in relation to one another and that all viewpoints are partial. It will note "the multiple voices and contradictions present in specific sites at specific historical moments" (Orner, 1992, p. 80), and acknowledge that relations are never fully known or describable (Thayer-Bacon, 2003). It will also understand that because difference is relational, it is contextual, situated and historically constructed.

Experiences of teaching are experiences of educational relations. The challenges and successes involved in forming and maintaining educational relations to facilitate effective teaching and learning and enhance the wellbeing of those in the relation would become the storylines of counter-narratives. These diverse relations include commonalities as well as differences, and may at times be uncomfortable and involve conflicting points of view. Counter-narratives will therefore be stories of conflict as well as stories of harmony and accord. Because relations are dynamic and fluid, counter-narratives will not always include plots of progress towards desired outcomes. Storylines of heroic struggle will be only one form of available plot, and others, such as stories of communal actions or stories that are polyvocal, will better enable narratives of the diversity of educational relations to be told. Counter-narratives will not require happy endings but will include storylines without clear resolutions, that embrace uncertainty and that are open to contestation and reinterpretation. Although conventional plots, those that are progressive, regressive and stable, enable a wide variety of stories to be constructed, a counter-narrative could also be one of 
disruption and fragmentation (Andrews, 2002), enabling stories from the margins to be told. Counter-narratives that contest dominant discourses and insert subjugated knowledges will open up ways to 'speak and do' teaching in higher education.

The teacher identities that counter-narratives produce will recognize "the simultaneous presence of multiple identities within every individual" (MacDonald \& Bernado, 2005, p. 6). These identities will be more or less prominent, more or less problematic in relation to the dominant cultural narratives of understanding and acting in the world. In counternarratives, teacher identities will be both 'fallible' and 'competent' and will not always need to be 'noble'. Because identities are always produced in relations, counter-narratives will depict these identities as embedded and embodied and produced through a web of relations of power and care rather than only through dyadic teacher-student relations. Because people are not only in relations with other people but are also in relations with cultural knowledge, social structures and their physical environment, counter-narratives will include these relations and talk about how they might support or harm those involved. Thus they will view these relations as relations of power and ask questions about who benefits from and who is marginalized within such relations. Counter-narratives of teaching will talk about how educational relations are enacted in multiple and overlapping communities of practice. Educational relations will be depicted as situated within networks of care where care is understood as a 'life-sustaining web' (Tronto, 1994). Teachers would be positioned as active participants in various communities, such as classrooms, departments, faculties and institutions, and their narratives will describe how well these communities support them as teachers.

Many of the suggested elements that could construct counter-narratives of educational relations in higher education can be found in the narratives of participants in this study. While my analysis of participants' narratives identified dominant storylines and teacher identities and the discourses that they were produced within and from, there were also narratives that contested these and/or provided alternative ways to speak and do diversity. As this research shows, narratives are always interpreted and reinterpreted by listeners or readers, and thus meaning is never singular or fixed. There are many ways that counternarratives of teaching in higher education could be constructed, enabling a range of meanings to be produced about how teachers 'speak and do' student diversity. My aim is for this thesis to inform teachers and others in higher education of a greater range of ways 
to speak about teaching diverse students, and for this to challenge and support educational relations and the development of effective teaching and learning practices.

\subsection{Conclusion}

In this thesis, analysis of the literature and of participants' narratives has revealed multiple ways to 'speak and do' diversity. These 'speakings and doings' are sometimes complementary and sometimes contradictory, they interact and diverge, and they are always embedded in relations of power and care. This thesis does not seek a synthesis of these different ways to speak and do diversity, nor does it attempt to construct a model that they can be slotted into. Instead I leave these 'speakings and doings' in dynamic relation with one another in the belief that this is the best way to keep conversations in higher education open and creative, and to enable university teachers to continue to think about, and research, their diverse educational relations with students. It is also a reminder that any knowing is always a partial knowing; knowledge is constructed by people who are in relations with other people and with their environment, and is always unfinished (ThayerBacon, 2004). Using a relational epistemology to construct counter-narratives of diverse educational relations enables teachers to go beyond deficit perspectives of diversity, and a reflexive stance encourages teachers to consider the diverse ways they are positioned in their relations with students, colleagues, universities and the wider social and political context. 


\section{Chapter 11}

\section{Conclusion}

\subsection{Situating the study findings}

This study addresses a gap in the literature of higher education, looking at how university teachers understand and experience student diversity. The methodology in this study enabled me to present and analyse teachers' views, concerns and experiences and to look beyond these to reveal taken-for-granted ways of speaking and doing diversity. The findings show how discourses of inclusion can act to reinforce the marginalization of some students, and how the ways teachers conceptualize diversity shape how they enact their relations with students and the pedagogical practices they employ. This thesis continues conversations about power in higher education and broadens the understanding of care in higher education. It puts the case for understanding teaching and learning as educational relations and for drawing on a relational epistemology in research. It affirms the importance of a critical approach to analysis of narratives of experience, showing how this can lead to a greater understanding of the contextual factors, cultural resources and discursive positionings that produce narratives of teaching and concepts of diversity.

This study has a number of limitations that constrain the findings. The sample was small, self-selected and not representative, and participants came from only a few faculties, therefore the narratives I analysed in this thesis may be limited in their content, the ways they are constructed and the epistemological frameworks that underpinned them. Would teachers of 'hard' sciences, such as maths and physics, talk about student diversity differently? Participants consisted of sixteen female teachers and only six male teachers, thus the findings may be biased if female teachers have different perspectives on some topics than male teachers do. Apart from some literature that considers the effects of gender on higher education teachers' care (e.g. Walker et al., 2006), the literature I looked at gave no indication of how gender might influence teachers' understanding and experiences of diversity. This would be an interesting area to research further. In this study I am unable to draw any conclusions about whether women were more interested than men in participating in research on teaching and/or on diversity. 
In the interview transcripts there was more data than could be included in the analysis, and so the choices I made about what was included and excluded further limits this study. Individual interviews with teachers provide particular snapshots of 'what is going on' in teaching diverse students in the higher education contexts of this study, but do not provide narratives of students' experiences, or the views of faculty administrators or managers. Individual interviews are also limited in that they do not provide data from interactive conversations between more than two people, such as a focus group would do. Because observation of teaching practice was not undertaken, any differences between what teachers say they do and actually do is not identified, consequently the focus in this study is on spoken and written 'texts of experience'. Further research could be undertaken to add these other perspectives to academic conversations about teaching diverse students in higher education. Further research should be undertaken to investigate relations of care in higher education, as well as how relations of power and care interact.

Since this study began, the context of higher education has continued to change. New Zealand, along with other countries, has felt the effects of global economic downturn and recession, and this has recently been exacerbated by the extensive damage from the Christchurch earthquakes in September 2010 and February 2011. This has added to the pressure on state services, including universities, to 'make do with less'. Universities are unlikely to receive significant boosts in government funding in the near future and factors such as staffing levels, performance-based research funding, capping of domestic student enrolment, international student enrolment, and the tightening of student loan eligibility will shape higher educational policies, student expectations, teacher workloads and pedagogical practices. Continuing global flows of information, people and communication technologies will require that universities respond to global as well as national changes and challenges, and the diversity of people, knowledge and cultural practices interacting in sites of higher education will also increase. Ongoing development of e-learning technologies will bring people together and bridge physical distance, changing teaching and learning practices which will impact on different groups of students (and teachers) in differing ways. Inevitably all these changes will benefit some more than others, and I suggest that higher education will continue to have a role to play in working for social justice at global, national and local levels. Understanding educational relations as diverse relations of power and care offers a way for teachers and others in higher education to 
engage with the challenges of changing contexts for teaching and learning in the twentyfirst century.

\subsection{Final reflections}

This research study has been as much about my own understanding of student diversity as it has been about that of study participants. In the first chapter I included a vignette of a teaching experience from early in my university teaching career which raised a number of questions about teaching diverse students and informed this study. Reading the literature, analysing the data and writing this thesis has been a process of learning, unlearning, and relearning. My analysis of teachers' narratives has also been an analysis of my own takenfor-granted ways of speaking about diversity, teaching students and teacher identity. As Usher et al. (1997, p. 212) note, "research can be viewed as the practice of writing and rewriting selves and the world." As I come to the end of this research project, I ask myself how I will 'speak and do diversity' now. Since the critical incident of my vignette (see Chapter One), I have developed greater subject knowledge, a wider range of teaching methods, and a greater awareness of how students are different from and similar to each other. I have also learned that there are no right or wrong ways to teach, that teaching is always unpredictable and dynamic, and that building relationships with students that challenge and support their learning is an ongoing, enjoyable and, at times, daunting process. Through writing this thesis, I have a greater understanding of the ways that university teachers, myself included, construct notions of diversity and difference, and the discursive resources that shape how we 'speak and do' diversity. I now realize that these matter a great deal, and that much of the discomfort I felt in my critical incident was due to the dual processes of inclusion and 'Othering' my teaching produced, as well as the ways my teaching was disciplined by the discursive contexts I was embedded in.

Thinking relationally about teaching, power and care has the potential to open up ways to teach that avoid positioning 'diverse' students as deficient in relation to a norm, that affirm the multiple ways all students and teachers are positioned, and that acknowledge the overlapping communities of practice teachers work within. Creating respectful educational relationships with diverse students is, as Maria puts it, “everybody's responsibility". In this thesis, the analyses of how teachers speak and do diversity suggests that, in the words of 
Elaine, "it's very complicated", however as Helen notes, diversity is "what helps keep things interesting in a class" and Susan reminds us that "in teaching it's just often the very simple things" that enable effective teaching and learning to occur. The educational relationships university teachers enact are multiple, dynamic and situated, and need to be researched in all their diversity. 


\section{References}

Achieve (2004). Kia Ōrite, achieving equity: New Zealand code of practice for an inclusive tertiary education environment for students with impairments. Wellington: Ministry of Education.

Ahmed, S. (2007). The language of diversity. Ethnic and Racial Studies, 30(2), 235-256.

Ahmed, S. \& Swan, E. (2006). Doing diversity. Policy Futures in Education, 4(2), 96-100. Allen, A. (1999). The power of feminist theory: Domination, resistance, solidarity. Boulder, CO: Westview Press.

Anderson, J., Hoy-Mack, P., \& Ross, C. (2000). Adult(s) learning: Power, paradox and possibility. New Zealand Journal of Adult Learning, 28(2), 100-116.

Andrews, M. (2002). Introduction: Counter-narratives and the power to oppose. Narrative Inquiry, 12(1), 1-6.

Asmar, C. (2005). Internationalising students: Reassessing diasporic and local student difference. Studies in Higher Education, 30(3), 291-309.

Atkinson, P., \& Delamont, S. (2006). Rescuing narrative from qualitative research. Narrative Inquiry, 16(1), 164-172.

Badley, G. (2007). For and against diversity in higher education. Teaching in Higher Education, 12(5-6), 781-785.

Baines, C., Evans, P., \& Neysmith, S. (1991). Caring: Its impact on the lives of women. In C. Baines, P. Evans \& S. Neysmith (Eds.), Women's caring: Feminist perspectives on social welfare (pp. 11-35). Toronto: McClleland \& Stewart.

Bamberg, M. (1999). Is there anything behind discourse? Narrative and the local accomplishment identities. In W. Meiers, B. Bayer, B. Duarte Esgalhado, R. Jorna \& E. Schraube (Eds.), Challenges to theoretical psychology (pp. 220-227). North York, Ontario: Captus University Publications.

Barnett, R. (1997). Higher education: A critical business. Bristol, UK: Open University Press.

Barrington, E. (2004). Teaching to student diversity in higher education: How Multiple Intellingence Theory can help. Teaching in Higher Education, 9(4), 421-434.

Baskerville, D., \& Bondy, A. (2010). A bicultural approach to teaching and learning for diversity. In V. Green \& S. Cherrington (Eds.), Delving into diversity: An 
international exploration of issues of diversity in education (pp. 57-69). New York: Nova Science Publishers.

Bauman, Z. (2007). Liquid times: Living in the age of uncertainty. Cambridge, UK: Polity Press.

Beauboeuf-Lafontant, T. (2005). Womanist lessons for reinventing teaching. Journal of Teacher Education, 56(5), 436-445.

Beauboeuf-Lafontant, T. (2008). Politicized mothering: Authentic caring among African American women teachers. In L. Bartolomé (Ed.), Ideologies in education: Unmasking the trap of teacher neutrality (pp. 251-264). New York: Peter Lang.

Beck, U., \& Beck-Gernsheim, E. (2002). Individualization: Institutionalized individualism and its social and political consequences. London: Sage Publications.

Benseman, J., Coxon, E., Anderson, H., \& Anae, M. (2006). Retaining non-traditional students: Lessons learnt from Pasifika students in New Zealand. Higher Education Research \& Development, 25(2), 147-162.

Best, R. (1995). Concepts in pastoral care and PSE. In R. Best, P. Lang, C. Lodge \& C. Watkins (Eds.), Pastoral care and personal-social education (pp. 3-17). London: Continuum.

Biesta, G. (2004). "Mind the gap!" Communication and the educational relation. In C. Bingham \& A. Sidorkin (Eds.), No education without relation (pp. 11-22). New York: Peter Lang.

Bingham, C. (2004). Let's treat authority relationally. In C. Bingham \& A. Sidorkin (Eds.), No education without relation (pp. 23-38). New York: Peter Lang.

Bingham, C., \& Sidorkin, A. (2004). Manifesto of relational pedagogy: Meeting to learn, learning to meet. In C. Bingham \& A. Sidorkin (Eds.), No education without relation (pp. 5-7). New York: Peter Lang Publishing.

Bird, L. C. (2004). A queer diversity: Teaching difference as interrupting intersections. Journal of Queer Studies in Education, 1(1). Retrieved 7 May, 2008, from http://jqstudies.oise.utoronto.ca/journal/viewissue.php?id=1

Bishop, R., \& Glynn, T. (1999). Culture counts: Changing power relations in education. Palmerston North, New Zealand: Dunmore Press.

Boshier, R. (2001). Lifelong learning as bungy jumping: In New Zealand what goes down doesn't always come up. International Journal of Lifelong Education, 20(5), 361377.

Bowden, P. (1997). Caring: Gender-sensitive ethics. London: Routledge. 
Bowser, D., Danaher, P., \& Somasundaram, J. (2007). Indigenous, pre-undergraduate and international students at Central Queensland University, Australia: Three cases of the dynamic tension between diversity and commonality. Teaching in Higher Education, 12(5-6), 669-681.

Britzman, D. (2000). The question of belief: Writing poststructural ethnography. In E. St. Pierre \& W. Pillow (Eds.), Working the ruins: Feminist poststructural theory and methods in education (pp. 27-40). New York: Routledge.

Brookfield, S. (2005). The power of critical theory for adult learning and teaching. Maidenhead, Berkshire: Open University Press.

Brookfield, S. (2006). The skilful teacher: On technique, trust, and responsiveness in the classroom (2nd ed.). San Francisco: Jossey-Bass.

Burbules, N. (1997). A grammar of difference: Some ways of rethinking difference and diversity as educational topics. Retrieved 13 September, 2009, from http://faculty.ed.uiuc.edu/burbules/papers/difference.html

Burbules, N., \& Rice, S. (1991). Dialogue across differences: Continuing the conversation. Harvard Educational Review, 61(4), 393-416.

Burbules, N., \& Torres, C. (2000). Globalization and education: An introduction. In N. Burbules \& C. Torres (Eds.), Globalization and education: Critical perspectives. New York: Routledge.

Burman, E. (2004). From difference to intersectionality: Challenges and resources. European Journal of Psychotherapy, Counselling \& Health, 6(4), 293-308.

Campbell, A., Künnemeyer, R., \& Prinsep, M. (2008). Staff perceptions of higher education science and engineering learning communities. Research in Science \& Technological Education, 26(3), 279-294.

Campbell, J. (1949). The hero with a thousand faces. Princeton: Princeton University Press.

Castañada, C. R. (2004). Teaching and learning in diverse classrooms: Faculty reflections on their experiences and pedagogical practices of teaching diverse populations. New York: RoutledgeFalmer.

Chalmers, D., \& Volet, S. (1997). Common misconceptions about students from SouthEast Asia studying in Australia. Higher Education Research \& Development, 16(1), 87-98.

Chanock, K. (2010). The right to reticence. Teaching in Higher Education, 15(5), 543-552. 
Chappell, C., Rhodes, C., Solomon, N., Tennant, M., \& Yates, L. (2003). Reconstructing the lifelong learner: Pedagogy and identity in individual, organisational and social change. London: RoutledgeFalmer.

Chase, S. (1996). Personal vulnerability and interpretive authority in narrative research. In R. Josselson (Ed.), Ethics and process in the narrative study of lives (Vol. 4, pp. 45-59).

Chase, S. (2005). Narrative inquiry: Multiple lenses, approaches, voices. In N. Denzin \& Y. Lincoln (Eds.), The Sage handbook of qualitative research $\left(3^{\text {rd }}\right.$ ed., pp. 651679). Thousand Oaks: Sage Publications.

Chawla, D., \& Rodriguez, A. (2007). New imaginations of difference: On teaching, writing, and culturing. Teaching in Higher Education, 12(5-6), 697-708.

Cheong, F. (2008). Using a problem-based learning approach to teach an intelligent systems course. Journal of Information Technology Education, 7, 47-60.

Cherrington, S., \& Green, V. (2010). Educational implications. In S. Cherrington \& V. Green (Eds.), Delving into diversity: An international exploration of issues of diversity in education. New York: Nova Science Publishers.

Chesler, M., \& Young, A. (2007). Faculty members' social identities and classroom authority. In M. Kaplan \& A. T. Miller (Eds.), Scholarship of multicultural teaching and learning (pp. 11-19). San Francisco: Jossey-Bass.

Churchman, D., \& King, S. (2009). Academic practice in transition: Hidden stories of academic identities. Teaching in Higher Education, 14(5), 507-516.

Claiborne, L.B., \& Cornforth, S. (2010). Supporting diversity, difference and inclusion in higher education. In V. Green \& S. Cherrington (Eds.), Delving into diversity: An international exploration of issues of diversity in education (pp. 255-263). New York: Nova Science Publishers.

Claiborne, L.B., Cornforth, S., Gibson, A. \& Smith, A. (in press). Supporting students with impairments in higher education: Social inclusion or cold comfort? International Journal of Inclusive Education.

Claiborne, L.B., \& Smith, A. (2006). Tertiary education for students with impairments: A Code of Practice at the beginning of the journey. In I. Livingstone (Ed.), The New Zealand annual review of education (pp. 73-87). Wellington: Victoria University of Wellington.

Clandinin, D. J., \& Murphy, S. (2009). Relational ontological commitments in narrative research. Educational Researcher, 38(8), 598-602. 
Clement, G. (1996). Care, autonomy and justice: Feminism and the ethic of care. Boulder, CO: Westview Press.

Closson, D. (2002). Politically correct education. Retrieved 12 June, 2009, from http://www.leadereru.com/orgs/probe/docs/pc-educ.html

Cochran-Smith, M. (2000). Blind vision: Unlearning racism in teacher education. Harvard Educational Review, 70(2), 157-190.

Cohen, L., Manion, L., \& Morrison, K. (2000). Research methods in education (5th ed.). New York: RoutledgeFalmer.

Cole, B. (2009). Gender, narratives and intersectionality: Can personal experience approaches to research contribute to "undoing gender"? International Review of Education, 55, 561-578.

Collins, P. H. (2000). What's going on? Black feminist thought and the politics of postmodernism. In E. St. Pierre \& W. Pillow (Eds.), Working the ruins: Feminist postructural theory and methods in education (pp. 41-73). New York: Routledge.

Connelly, F. M., \& Clandinin, D. J. (1990). Stories of experience and narrative inquiry. Educational Researcher, 19(5), 2-14.

Convery, A. (1999). Listening to teachers' stories: Are we sitting too comfortably? Qualitative Studies in Education, 12(2), 131-146.

Cortazzi, M. (1993). Narrative Analysis. London: The Falmer Press.

Cortazzi, M., \& Jin, L. (2006). Asking questions, sharing stories and identity construction: Sociocultural issues in narrative research. In S. Trahar (Ed.), Narrative research on learning: Comparative and international perspectives (pp. 27-46). Oxford, UK: Symposium Books.

Court, M. (2004). Using narrative and discourse analysis in researching co-principalships. International Journal of Qualitative Studies in Education, 17(5), 579-603.

Cullen, R., \& Harris, M. (2009). Assessing learner-centredness through course syllabi. Assessment \& Evaluation in Higher Education, 34(1), 115-125.

Curzon-Hobson, A. (2004). The marginalization of higher learning: An interpretation of current tertiary reform policy in New Zealand. Teaching in Higher Education, 9(2), 211-224.

Cushman, P. (2006). Primary school teaching as a second career choice for men: The choice and the challenges for adult learners. New Zealand Journal of Adult Learning, 34(1), 104-122.

Czarniawska, B. (2004). Narratives in social science research. London: Sage Publications. 
Daloz, L. (1999). Mentor: Guiding the journey of adult learners. San Francisco: JosseyBass.

Dannaher, G., Schirato, T., \& Webb, J. (2000). Understanding Foucault. Crows Nest, NSW: Allen \& Unwin.

Darder, A. (2002). Reinventing Paulo Freire: A pedagogy of love. Boulder, CO: Westview Press.

Darwin, A., \& Palmer, E. (2009). Mentoring circles in higher education. Higher Education Research \& Development, 28(2), 125-136.

Davey, J., Neale, J., \& Morris Matthews, K. (2003). Conclusion - Common themes and policy pointers. In J. Davey, J. Neale \& K. Morris Matthews (Eds.), Living and learning: Experiences of university after age 40 (pp. 178-188). Wellington: Victoria University of Wellington.

Davies, B. (1991). The concept of agency: A feminist poststructuralist analysis. Social Analysis, 30, 42-53.

Davies, B. (1994). Poststructuralist theory and classroom practice. Victoria, Australia: Deakin University Press.

Davies, B. (2000). A body of writing 1990-1999. Walnut Creek, CA: Altamira Press.

Davies, B. (2009). Introduction. In B. Davies \& S. Gannon (Eds.), Pedagogical encounters (pp. 1-16). New York: Peter Lang.

Davies, B., \& Harré, R. (1990). Positioning: The discursive production of selves. Journal for the Theory of Social Behaviour, 20, 43-63.

Day Sclater, S. (2003). What is the subject? Narrative Inquiry, 13(2), 317-330.

Daya, S., \& Lau, L. (2007). Power and narrative. Narrative Inquiry, 17(1), 1-11.

D'Cruz, H. (2007). Working with 'Diverse Bodies, Diverse Identities': An approach to professional education about 'diversity'. International Journal of Inclusive Education, 11(1), 35-37.

D'Cruz, H., Gillingham, P. \& Melendez, S. (2006). Reflexivity, its meanings and relevance for social work: A critical review of the literature. British Journal of Social Work, 37, 73-90.

De Fina, A., \& Georgakopoulou, A. (2008). Analysing narratives as practices. Qualitative Research, 8(3), 379-387.

De Marzio, D. (2007). The care of the self: Alcibiades I, Socratic teaching and ethics education. The Journal of Education, 187(3), 103-127. 
De Vita, G. (2000). Inclusive approaches to effective communication and active participation in the multicultural classroom. Active Learning in Higher Education, $1(2), 168-179$.

Deakins, E. (2009). Helping students value cultural diversity through research-based teaching. Higher Education Research \& Development, 28(2), 209-226.

DeFriese, G., \& Konrad, T. (1993). The self-care movement and the gerontological healthcare professional. Generations, 17(3), 37-41.

Denzin, N. (2002). The interpretive process. In A. Huberman \& M. Miles (Eds.), The qualitative researcher's companion (pp. 349-366). Thousand Oaks, CA: Sage Publications.

Denzin, N., \& Lincoln, Y. (2008a). Introduction: The discipline and practice of qualitative research. In N. Denzin \& Y. Lincoln (Eds.), Collecting and interpreting qualitative materials (pp. 1-43). Thousand Oaks, CA: Sage Publications.

Denzin, N., \& Lincoln, Y. (2008b). Paradigms and perspectives in contention. In N. Denzin \& Y. Lincoln (Eds.), The landscape of qualitative research (3rd ed., pp. 245-254). Thousand Oaks, CA: Sage Publications.

Department of Statistics (2008). National ethnic population projections: 2006 (base) 2026. Wellington: Department of Statistics.

Diller, A. (1996). Is rapprochement possible between educational criticism and nurturance? In A. Diller, B. Houston, K. Morgan \& M. Ayim (Eds.), The gender question in education: Theory, pedagogy, \& politics (pp. 135-143). Boulder, CO: Westview Press.

Disability Support Services (2006). Services and support for disabled students. Wellington: Victoria University of Wellington.

Dodds, A. (2008). How does globalisation interact with higher education? The continuing lack of consensus. Comparative Education, 44(4), 505-517.

Durie, J. (1996). Emancipatory education and classroom practice: A feminist poststructuralist perspective. Studies in Higher Education, 18(2), 135-146.

Durie, M. (1997). Whanau, whanaungatanga and healthy Māori development. In P. Te Whaiti, M. McCarthy \& A. Durie (Eds.), Mai i rangiatea: Māori wellbeing and development (pp. 1-24). Auckland, New Zealand: Auckland University Press.

Education Counts (2008). Participation. Retrieved 11 January, 2008, from http://www.educationcounts.govt.nz/statistics/tertiary_education/participation 
Education Counts (2010). Provider-based enrolments: Field of study. Retrieved 14 June, 2010, from http://www.educationcounts.govt.nz/publications/?a=41704

Elen, J., Clarebout, G., Léonard, R., \& Lowyck, J. (2007). Student-centred and teachercentred learning environments: What students think. Teaching in Higher Education, 12(1), 105-117.

Ellsworth, E. (1989). Why doesn't this feel empowering? Working through the repressive myths of critical pedagogy. Harvard Educational Review, 59(3), 297-324.

Etherington, K. (2004). Becoming a reflexive researcher: Using our selves in research. London: Jessica Kingsley Publishers.

Evans, Y., \& Payne, M. (2008). Support and self-care: Professional reflections of six New Zealand high school counsellors. British Journal of Guidance \& Counselling, 36(3), 317-330.

Fernandes, F. (2003). A response to Erica Burman. The European Journal of Psychotherapy, Counselling \& Health, 6(4), 309-316.

Fine, M \& Weiss, L. (2005). Compositional studies in two parts: Critical theorizing and analysis on social (in)justice. In N. Denzin \& Y. Lincoln (Eds.), Sage handbook of qualitative research (3rd ed., pp. 65-84). Thousand Oaks, CA: Sage.

Fitzmaurice, M. (2008). Voices from within: teaching in higher education as a moral practice. Teaching in Higher Education, 13(3), 341-352.

Foley, G. (2000). Teaching adults. In G. Foley (Ed.), Understanding education and training (2nd ed., pp. 34-58). St Leonards, NSW: Allen \& Unwin.

Fontana, A., \& Frey, J. (2008). The interview: From neutral stance to political involvement. In N. Denzin \& Y. Lincoln (Eds.), Collecting and interpreting qualitative materials (3rd ed., pp. 115-159). Thousand Oaks, CA: Sage Publications.

Foucault, M. (1980). Power and knowledge: Selected interviews and other writings 19721977. New York: Pantheon Books.

Foucault, M. (1987). The ethic of care for the self as a practice of freedom. In J. Bernauer \& D. Rasmussen (Eds.), The final Foucault (pp. 1-20). Cambridge, MA: The MIT Press.

Foucault, M. (1988). The history of sexuality (Volume 3): The care of the self. London: Penguin Press.

Foucault, M. (1990). The history of sexuality: An introduction (Vol. 1). New York: Random House. (Original work published 1976). 
Foucault, M. (1995). Discipline and punish: The birth of the prison. New York: Vintage Books. (Original work published 1975).

Foucault, M. (2002). Power: Essential Works of Foucault 1954-1984 (Vol. 3). London: Penguin.

Frank, A. W. (1995). The wounded storyteller: Body, illness and ethics. Chicago: Chicago University Press.

Freire, P. (1970). Pedagogy of the oppressed. London: Penguin Books.

Georgakopoulou, A. (2006). Thinking big with small stories in narrative and identity analysis. Narrative Inquiry, 16(1), 122-130.

Gergen, K. (1998). Narrative, moral identity and historical consciousness: A social constructionist account. Retrieved 9 October 2009, from http://www.swarthmore.edu/Documents/faculty/gergen/Narrative_Moral_Identity_ and_Historical_Consciousness.pdf

Gergen, K. (1999) Social construction and the transformation of identity politics. Retrieved 5 April 2011, from

http://www.swarthmore.edu/Documents/faculty/gergen/Social\%20Construction_an d_the_Transformation.pdf

Gergen, K., \& Gergen, M. (1986). Narrative form and the construction of psychological science. In T. R. Sarbin (Ed.), Narrative psychology: The storied nature of human conduct (pp. 22-44). New York: Praeger.

Gilligan, C. (1982). In a different voice: Psychological theory and women's development. Cambridge, MA: Harvard University Press.

Golden, J. (1996). The care of the self: Poststructuralist questions about moral education and gender. Journal of Moral Education, 25(4), 381-395.

Goldstein, L. (2002). Commitment, community, and passion: Dimensions of a care-centred approach to teacher education. Teacher Education and Practice, 15, 36-56.

Gomez, M., Allen, R., \& Clinton, K. (2004). Cultural models of care in teaching: A case study of one pre-service secondary teacher. Teaching and Teacher Education, 20, 473-478.

Gore, J. (1998). Disciplining bodies: On the continuity of power relations in pedagogy. In T. Popkewitz \& M. Brennan (Eds.), Foucault's challenge: Discourse, knowledge, and power in education (pp. 231-251). New York: Teachers College, Colombia University. 
Grace, A., Gouthro, P., \& Mojab, S. (2003). "Thinking the Practice": Academic adult educators' reflections on mediating a summer institute as a multicultural learning journey for graduate students. Studies in Continuing Education, 25(1), 51-73.

Grice, S., \& Humphries, M. (1993). Managing diversity: A wolf in sheeps [sic] clothing? Paper presented at the Conference on Racism, Aboriginality, Ethnicity and Gender, Sydney, Australia.

Grimmett, P., Erickson, G., Mackinnon, A., \& Riecken, T. (1990). Reflective practice in teacher education. In R. Clift, W. R. Houston \& M. Pugach (Eds.), Encouraging reflective practice in education: An analysis of issues and programs (pp. 20-38). New York: Teachers College.

Guba, E., \& Lincoln, Y. (1998). Competing paradigms in qualitative research. In N. Denzin \& Y. Lincoln (Eds.), The landscape of qualitative research: Theories and issues (pp. 195-220). Thousand Oaks, CA: Sage Publications.

Gunasekara, C. (2007). Pivoting the centre: Reflections on undertaking qualitative interviewing in academia. Qualitative Research, 7(4), 461-475.

Haggis, T. (2006). Pedagogies for diversity: Retaining critical challenge amidst fears of 'dumbing down'. Studies in Higher Education, 31(5), 521-535.

Harman, G. (2005). Australian social scientists and transition to a more commercial university environment. Higher Education Research \& Development, 24(1), 79-94.

Harms, L. (2007). Working with people: Communication skills for reflective practice. Melbourne, Australia: Oxford University Press.

Harris, S. (2005). Rethinking academic identities in neo-liberal times. Teaching in Higher Education, 10(4), 421-433.

Hart, M. (1998). The experiences of living and learning in different worlds. Studies in Continuing Education, 20(2), 187-200.

Held, D., McGrew, A., Goldblatt, D., \& Perraton, J. (1999). Global transformations: Politics, Economics and Culture. Cambridge: Polity Press.

Held, V. (2006). The ethics of care: Personal, political, and global. New York: Oxford University Press.

Henry, E. (1999). Kaupapa Māori: Locating indigenous ontology, epistemology and methodology in the academy. In V. Tapine (Ed.), Building research capacity within Māori communities (pp. 177-190). Wellington, New Zealand: NZCER.

Heywood, A. (2003). Political ideologies: An introduction (3rd ed.). Basingstoke, UK: Palgrave Macmillan. 
Hill, D., \& Lee, G. (2009). Hegemony and education: Dialectical considerations of bullying in the academy. Journal of Adult Learning Aotearoa New Zealand, 37(2), $32-46$.

Hoagland, S. (1991). Some thoughts about "Caring". In C. Card (Ed.), Feminist Ethics (pp. 246-263). Lawrence, KA: University of Kansas.

Hockings, C., Cooke, S., Yamashita, H., McGinty, S., \& Bowl, M. (2009). 'I'm neither entertaining nor charismatic...': Negotiating university teacher identity within diverse student groups. Teaching in Higher Education, 14(5), 483-494.

Hollway, W. (2006). The capacity to care: Gender and ethical subjectivity. London: Routledge.

Holmes, E., \& O'Steen, B. (2008). Getting that college spirit: A particular challenge for adult learners? New Zealand Journal of Adult Learning, 36(1), 75-81.

hooks, b. (1994). Teaching to transgress: Education as the practice of freedom. New York: Routledge.

hooks, b. (2003). Teaching community: A pedagogy of hope. New York: Routledge.

Humphrey, J. (1999). Disabled people and the politics of difference. Disability \& Society, 14(2), 173-183.

Hutchinson, J. (2004). Democracy needs strangers, and we are them. In C. Bingham \& A. Sidorkin (Eds.), No education without relation (pp. 73-89). New York: Peter Lang.

Inglis, T. (1997). Empowerment and emancipation. Adult Education Quarterly, 48(1), 3 17.

Ippolito, K. (2007). Promoting intercultural learning in a multicultural university: Ideals and realities. Teaching in Higher Education, 12(5-6), 749-763.

Irwin, M. (1996). Minority and majority cultures in education. Paper presented at the Conference on Curriculum, Culture and Society. Retrieved 15 June 2010, from http://www.nzbr.org.nz/documents/speeches/speeches-95-96/scaa-final-2.pdf

Jackson, S. (1995). Negotiating self-defined standpoints in teaching and learning. In S. Jackson \& J. Solis (Eds.), Beyond comfort zones in multiculturalism (pp. 128-147). Westport, CO: Bergin \& Garvey.

Jarvis, P. (2006). Towards a comprehensive theory of human learning. London: Routledge. Jarvis, P., \& Preece, J. (2001). Future directions for the learning society. In P. Jarvis (Ed.), The age of learning: Education and the knowledge society (pp. 217-223). London: Kogan Page. 
Jawitz, J. (2007). New academics negotiating communities of practice: Learning to swim with the big fish. Teaching in Higher Education, 12(2), 185-197.

Jiang, X. (2005). Interculturalisation for New Zealand universities in a global context. Policy Futures in Education, 3(2), 223-233.

Johnson, P., \& Pihama, L. (1995). What counts as difference and what differences count: Gender, race and the politics of difference. In K. Irwin \& I. Ramsden (Eds.), Toi wahine: The worlds of Māori women (pp. 75-86). Auckland: Penguin.

Jones, A., \& Jenkins, K. (2007). Cross-cultural engagement in higher education classrooms: A critical view of dialogue. In D. Palfreyman \& D. McBride (Eds.), Learning and teaching across cultures in higher education (pp. 133-152). Basingstoke, Hampshire: PalgraveMacmillan.

Jones, C. (2006). Falling between the cracks: What diversity means for black women in higher education. Policy Futures in Education, 4(2), 145-159.

Jones, D. (2004). Screwing diversity out of the workers? Reading diversity. Journal of Organizational Change Management, 17(3), 281-291.

Josselson, R. (2004). The hermeneutics of faith and the hermeneutics of suspicion. Narrative Inquiry, 14(1), 1-28.

Kaufman, S. (2007). The history and impact of State initiatives to eliminate affirmative action. In M. Kaplan \& A. T. Miller (Eds.), Scholarship of multicultural teaching and learning (pp. 3-9). San Francisco: Jossey-Bass.

Kember, D. (2000). Misconceptions about the learning approaches, motivation, and study practices of Asian students. Higher Education, 40(1), 99-121.

Kerr, R. (1998). Academic freedom and university accountability. Access: Critical Perspectives on Cultural and Policy Studies in Education, 18(1), 32-39.

Kilgore, D. (2001). Critical and postmodern perspectives on adult learning. In S. B. Merriam (Ed.), The new update on adult learning theory (pp. 53-61). San Francisco: Jossey-Bass.

Knight, M. (2004). Sensing the urgency: Envisioning a black humanist vision of care in teacher education. Race, Ethnicity and Education, 7(3), 211-227.

Koehn, D. (1998). Rethinking feminist ethics: Care, trust and empathy. London: Routledge.

Komesaroff, L. (2005). Category politics: Deaf students' inclusion in the 'hearing university'. International Journal of Inclusive Education, 9(4), 389-403. 
Koro-Ljungberg, M. (2007). 'Democracy to come': A personal narrative of pedagogical practices and 'Othering' within a context of higher education and research training. Teaching in Higher Education, 12(5-6), 735-747.

Kramer-Dahl, A. (1996). Reconsidering the notions of voice and experience in critical pedagogy. In C. Luke (Ed.), Feminisms and pedagogies of everyday life (pp. 242262). Albany, NY: State University of New York Press.

Kreber, C. (2009). Different perspectives on internationalization in higher education. New Directions for Teaching and Learning, 118, 1-14.

Kvale, S. (2002). The social construction of validity. In N. Denzin \& Y. Lincoln (Eds.), The qualitative inquiry reader (pp. 299-325). Thousand Oaks, CA: Sage Publications.

Kvale, S. (2007). Doing interviews. London: Sage Publications.

Lake, V., Jones, I., \& Dagli, U. (2004). Handle with care: Integrating caring content in mathematics and science methods classes. Journal of Research in Childhood Education, 19(1), 5-17.

Lakoff, G. (1987). Women, fire, and dangerous things: What categories reveal about the mind. Chicago: The University of Chicago Press.

Lakoff, G., \& Johnson, M. (1980). Metaphors we live by. Chicago: The University of Chicago Press.

Lather, P. (1992). Post-critical pedagogies: A feminist reading. In C. Luke \& J. Gore (Eds.), Feminism and critical pedagogies (pp. 120-137). London: Routledge.

Lather, P. (2006). Paradigm proliferation as a good thing to think with: Teaching research in education as a wild profusion. International Journal of Qualitative Studies in Education, 19(1), 35-57.

Lave, J., \& Wenger, E. (1991). Situated learning: Legitimate peripheral participation. Cambridge, UK: Cambridge University Press.

Lee, A. (1998). Critical thinking for the new millennium: A pedagogical imperative Retrieved January 27, 2011, from http://www.eric.ed.gov/PDFS/ED429913.pdf

Lewis, M. (2005). Moving tales: Acculturation experiences of migrant women staff entering a New Zealand polytechnic. Higher Education Research \& Development, 24(1), 95-108.

Lieblich, A., Tuval-Mashiach, R., \& Zilber, T. (1998). Narrative research: Reading, analysis and interpretation. Thousand Oaks, CA: Sage Publications. 
Lincoln, Y. (2002). Emerging criteria for quality in qualitative and interpretive research. In N. Denzin \& Y. Lincoln (Eds.), The qualitative inquiry reader (pp. 327-345). Thousand Oaks, CA: Sage Publications.

Lukes, S. (2005). Power: A radical view (2nd ed.). London: Palgrave.

Lumby, J. (2006). Conceptualizing diversity and leadership: Evidence from 10 cases. Educational Management Administration \& Leadership, 34(2), 151-165.

Macdonald, I. (2001). The teaching community: recreating university teaching. Teaching in Higher Education, 6(2), 153-167.

MacDonald, R., \& Bernado, M. (2005). Reconceptualizing diversity in higher education: Borderlands Research Program. Journal of Developmental Education, 29(1), 2-43.

MacIntosh, L. (2007). Does anyone have a band-aid? Anti-homophobia discourses and pedagogical impossibilities. Educational Studies: Journal of the American Educational Studies Association, 41(1), 33-43.

MacKeracher, D. (2004). Making sense of adult learning (2nd ed.). Toronto: University of Toronto Press.

Maher, F., \& Tetreault, M. K. (2001). The feminist classroom: Dynamics of gender, race, and privilege (Expanded ed.). Lanham, Maryland: Rowman \& Littlefield Publishers.

Mankowski, E., \& Rappaport, J. (2000). Narrative concepts and analysis in spirituallybased communities. Journal of Community Psychology, 28(5), 479-493.

Manning, K. (2009). Philosophical underpinnings of student affairs work on difference. About Campus, 14(2), 11-17.

Marsh, M. M. (2002). Examining the discourses that shape our teacher identities. Curriculum Inquiry, 32(4), 393-416.

Martin, L., Gutman, H., \& Hutton, P. (Eds.). (1988). Technologies of the self: A seminar with Michel Foucault. London: Tavistock.

Massey University (2010). Teaching and learning update, December 2010, Issue 3. Retrieved 29 March, 2011, from http://www.massey.ac.nz/fms/AVC\%20Academic/documents/newsletters/Decembe r\%202010\%20News\%20Update.pdf

Matthews, N. (2009). Teaching the 'invisible' disabled students in the classroom: Disclosure, inclusion and the social model of disability. Teaching in Higher Education, 14(3), 229-239. 
May, H., \& Bridger, K. (2010). Developing and embedding inclusive policy and practice in higher education. Heslington, UK: The Higher Education Academy.

Mayuzumi, K., Motobayashi, K., Nagayama, C., \& Takeuchi, M. (2007). Transforming diversity in Canadian higher education: A dialogue of Japanese women graduate students. Teaching in Higher Education, 12(5-6), 581-592.

McKenzie, K., \& Schweitzer, R. (2001). Who succeeds at university? Factors predicting academic performance in first year Australian university students. Higher Education Research \& Development, 20(1), 21-33.

McNair, S. (2001). Social, economic and political contexts. In P. Jarvis (Ed.), The age of learning: Education and the knowledge society (pp. 16-26). London: Kogan Page.

Meachem, J. (1999). Connecting life-course challenges of caring with the college curriculum. Journal of Adult Development, 6(3), 153-161.

Merriam, S., Cafferella, R., \& Baumgarten, L. (2007). Learning in adulthood: A comprehensive guide (3rd ed.). San Francisco: John Wiley \& Sons.

Middleton, S. (2001). Educating researchers: New Zealand Education PhDs 1948-1998. Wellington, NZ: New Zealand Association for Research in Education.

Ministry of Education (2007). Tertiary Education Strategy 2007-2012. Wellington, New Zealand: Ministry of Education.

Ministry of Education (2010). Tertiary Education Strategy 2010-15. Wellington: Ministry of Education.

Mirza, H. (2006). Transcendence over Diversity: Black women in the academy. Policy Futures in Education, 4(2), 101-113.

Molesworth, M., Nixon, E., \& Scullion, R. (2009). Having, being and higher education: The marketisation of the university and the transformation of the student into consumer. Teaching in Higher Education, 14(3), 277-287.

Moore, M. (2006). Nourishing relationships that nourish life. In G. Allan \& M. Evans (Eds.), A different three Rs for education: Reason, relationality, rhythm (pp. 103120). New York: Rodopi.

Morrow, R., \& Torres, C. (2006). The state, globalization, and educational policy. In N. Burbules \& C. Torres (Eds.), Globalization and education: Critical perspectives (pp. 27-56). New York: Routledge.

Murray, S. (2007). Care and the self: Biotechnology, reproduction, and the good life. Philosophy, Ethics and Humanities in Medicine, 2(6). 
Nakhid, C. (2006). Ethics and the obstruction of social justice for Māori and Pasifika (Pacific Islands) students in tertiary institutions in Aotearoa (New Zealand). Race Ethnicity and Education, 9(3), 295-305.

Narayan, U. (1995). Colonialism and its others: Considerations on rights and care discourses. Hypatia, 10(2), 133-140.

New Zealand History Online (n.d.). The Treaty of Waitangi Retrieved 21 February, 2011, from http://www.nzhistory.net.nz/category/tid/133

Neyland, J. (2010). Rediscovering the spirit of education after scientific management. Rotterdam, The Netherlands: Sense Publishers.

Nieli, R. (2008). Diversity's discontents: The "Contact Hypothesis" exploded. Academic Questions, 21, 409-430.

Noblit, G. (1993). Power and caring. American Educational Research Journal, 30(1), 2338.

Noddings, N. (2003). Caring: A feminine approach to ethics and moral education (2nd ed.). Berkeley: University of California Press.

Northedge, A. (2003). Rethinking teaching in the context of diversity. Teaching in Higher Education, 8(1), 17-32.

Nunan, T., Rigmor, G., \& McCausland, H. (2000). Inclusive education in universities: Why it is important and how it might be achieved. International Journal of Inclusive Education, 4(1), 63-88.

O'Brien, L. (2010). Caring in the ivory tower. Teaching in Higher Education, 15(1), 109115.

O'Connor, K. (2006). "You choose to care": Teachers, emotions and professional identity. Teaching and Teacher Education, 24, 117-126.

Olson, M., \& Craig, C. (2005). Uncovering cover stories: Tensions and entailments in the development of teacher knowledge. Curriculum Inquiry, 35(2), 161-182.

Olssen, M., Codd, J., \& O'Neill, A.-M. (2004). Education policy: Globalization, citizenship \& democracy. London: Sage Publications.

O'Neill, J., Bourke, R., \& Kearney, A. (2009). Discourses of inclusion in initial teacher education: Unravelling a New Zealand 'number eight wire' knot. Teaching and Teacher Education, 25, 588-593.

Orner, M. (1992). Interrupting the calls for student voice in "liberatory" education: A feminist poststructural perspective. In C. Luke \& J. Gore (Eds.), Feminisms and critical pedagogy (pp. 74-89). New York: Routledge. 
O'Sullivan, E. (1999). Transformative learning: Educational vision for the 21 st century. London: Zed Books.

Parker, I. (1992). Discourse dynamics: Critical analysis for social and individual psychology. New York: Routledge.

Parker, J. (2007). Diversity and the academy. Teaching in Higher Education, 12(5-6), 787792.

Parsons, E. (2001). Using power and caring to mediate white male privilege, equality, and equity in an urban elementary classroom: Implications for teacher preparation. The Urban Review, 33(4), 321-338.

Pearson, C. (1991). Awakening the heroes within: Twelve archetypes to help us find ourselves and transform the world. San Francisco: HarperCollins.

Perry, W. G. (1970). Forms of intellectual and ethical development in the college years. New York: Holt, Rinehart \& Winston.

Peters, M. (2002). Neoliberalism, postmodernity and the reform of education in Aotearoa/New Zealand. Access: Critical Perspectives on Cultural and Policy Studies in Education, 21(1), 3-17.

Peters, M., \& Roberts, P. (1999). University futures and the politics of reform in New Zealand. Palmerston North, New Zealand: Dunmore Press.

Peterson, E., \& Langellier, K. (2006). The performance turn in narrative studies. Narrative Inquiry, 16(1), 173-180.

Phillips, S. (1994). Introduction. In S. Phillips \& P. Benner (Eds.), The crisis of care: Affirming and restoring caring practices in the helping professions (pp. 1-16). Washington, DC: Georgetown University Press.

Phillips, S., \& Benner, P. (1994). Preface. In S. Phillips \& P. Benner (Eds.), The crisis of care: Affirming and restoring caring practices in the helping professions (pp. viixi). Washington, DC: Georgetown University Press.

Polkinghorne, D. (1995). Narrative configuration in qualitative analysis. In J. A. Hatch \& R. Wisniewski (Eds.), Life history and narrative (pp. 5-23). London: The Falmer Press.

Polkinghorne, D. (1996). Narrative knowing and the study of lives. In J. Birren, G. Kenyon, J.-E. Ruth, J. Schroots \& T. Svensson (Eds.), Aging and biography: Explorations in adult development (pp. 77-99). New York: Springer Publishing. 
Porter, E. (1996). Women and friendships: Pedagogies of care and relationality. In C. Luke (Ed.), Feminisms and pedagogies of everyday life (pp. 56-79). New York: State University of New York.

Prebble, T., Hargraves, H., Leach, L., Naidoo, K., Suddaby, G., \& Zepke, N. (2004). Impact of student support services and academic development programmes on student outcomes in undergraduate tertiary study: A synthesis of the research. Wellington, New Zealand: Ministry of Education.

Preece, J., Modise, O. M., \& Mosweunyane, D. (2008). 'Context matters': Whose concept of growth and development are we talking about? Compare, 38, 267-280.

Raivoka, M. (2009). Creating opportunities: The village at the university. In K. Sanga \& C. Chu (Eds.), Living and leaving a legacy of hope: Stories by new generation Pacific leaders (pp. 69-74). Wellington: He Parekereke, Victoria University of Wellington. Ramazanoglu, C., \& Holland, J. (2002). Feminist methodology: Challenges and choices. London: Sage Publications.

Rata, E., \& Openshaw, R. (2006). Public policy and ethnicity: The politics of ethnic boundary marking. Hampshire, UK: Palgrave Macmillan.

Reynolds, M., \& Trehan, K. (2001). Classroom as real world: Propositions for a pedagogy of difference. Gender and Education, 13(4), 357-372.

Richardson, L. (2000). Writing: A method of inquiry. In N. Denzin \& Y. Lincoln (Eds.), Handbook of qualitative research (pp. 923-948). Thousand Oaks, CA: Sage Publications.

Ricoeur, Paul (1981). Hermeneutics and the human sciences. (J Thompson, Ed. \& Trans.) Cambridge: Cambridge University Press.

Riessman, C. (1993). Narrative analysis. Newbury Park, CA: Sage.

Riessman, C. (2008). Narrative methods for the human sciences. Thousand Oaks, CA: Sage.

Ritter, L. (2007). Unfulfilled promises: How inventories, instruments and institutions subvert discourses of diversity and promote commonality. Teaching in Higher Education, 12(5-6), 569-579.

Roach, M. (1987). The human act of caring: A blueprint for the health professions. Ottawa: Canadian Hospital Association.

Roberts, P. (2008). Beyond the rhetoric of "Quality" and "Relevance": Evaluating the Tertiary Education Strategy 2007-12. New Zealand Annual Review of Education, $17,41-57$. 
Roberts, P. (2009). A new patriotism? Neoliberalism, citizenship and tertiary education in New Zealand. Educational Philosophy and Theory, 41(4), 410-423.

Robson, S., \& Turner, Y. (2007). 'Teaching is a co-learning experience': Academics reflecting on learning and teaching in an 'internationalized' faculty. Teaching in Higher Education, 12(1), 41-54.

Rogers, D., \& Webb, J. (1991). The ethic of caring in teacher education. Journal of Teacher Education, 42(3), 173-181.

Ross, C. (2009). Student diversity in Aotearoa New Zealand: A discourse of deficit. Journal of Adult Learning Aotearoa New Zealand, 37(2), 47-51.

Ross, H. (2002). The space between us: The relevance of relational theories to comparative and international education. Comparative Education Review, 46(4), 407-432.

Rossiter, M. (1999a). Caring and the graduate student: A phenomenological study. Journal of Adult Development, 6(4), 205-216.

Rossiter, M. (1999b). A narrative approach to development: Implications for adult education. Adult Education Quarterly, 50(1), 56-71.

Ryan, J., \& Viete, R. (2009). Respectful interactions: Learning with international students in the English-speaking academy. Teaching in Higher Education, 14(3), 303-314.

Saavedra, D., \& Saavedra, M. (2007). Women of colour teaching students of colour: Creating an effective classroom climate through caring, challenging, and consulting. New Directions for Teaching and Learning, 110, 75-83.

Sarup, M. (1996). Identity, culture and the postmodern world. Edinburgh: Edinburgh University Press.

Sawicki, J. (1994). Foucault and feminism: A critical reappraisal. In M. Kelly (Ed.), Critique and power: Recasting the Foucault / Habermas debate (pp. 347-364). Cambridge, MA: Massachusetts Institute of Technology.

Sawir, E., Marginson, S., Nyland, C., Ramia, G., \& Rawlings-Sanaei, F. (2009). The pastoral care of international students in New Zealand: Is it more than a consumer protection regime? Asia Pacific Journal of Education, 29(1), 45-59.

Schirato, T., \& Webb, J. (2003). Understanding globalization. London: Sage Publications.

Schuck, S., Gordon, S., \& Buchanan, J. (2008). What are we missing here? Problematising wisdoms on teaching quality and professionalism in higher education. Teaching in Higher Education, 13(5), 537-547.

Schultz, K. (2009). Rethinking classroom participation: Listening to silent voices. New York: Teachers College Press. 
Scott, D., \& Usher, R. (1999). Researching education: Data, methods and theory in educational enquiry. London: Continuum.

Scott, J. (2001). Power. Cambridge, UK: Polity Press.

Scott, J. W. (1992). Experience. In J. Butler \& J. W. Scott (Eds.), Feminists theorize the political (pp. 22-40). London: Routledge.

Sernak, K. (2004). Slaves no more: The caring power of African American female leaders. Scholar-Practitioner Quarterly, 2(3), 71-97.

Sevenhuijsen, S. (1998). Citizenship and the ethics of care: Feminist considerations on justice, morality and politics. London: Routledge.

Sevenhuijsen, S. (2000). Caring in the Third Way: The relation between obligation, responsibility and care in Third Way discourse. Critical Social Policy, 20(1), 5-37.

Sharkey, J. (2004). Lives stories don't tell: Exploring the untold in autobiographies. Curriculum Inquiry, 34(4), 465-512.

Sherrard, I. (2004). People who have an impairment and tertiary education. New Zealand Journal of Adult Learning, 32(1), 66-74.

Sidorkin, A. (2002). Learning relations: Impure education, deschooled schools, \& dialogue with evil. New York: Peter Lang.

Sikes, P., Measor, L., \& Woods, P. (1985). Teacher careers: Crises and continuities. Lewes: Falmer Press.

Sinclair, A. (2000). Women within diversity: Risks and possibilities. Women in Management Review, 15(5/6), 237-245.

Skelton, A. (2002). Towards inclusive learning environments in higher education? Reflections on a professional development course for university lecturers. Teaching in Higher Education, 7(2), 193-214.

Small, N. (1993). Self-care in institutional settings. Generations, 17(3), 19-24.

Smith, B., \& Sparkes, A. (2008). Contrasting perspectives on narrating selves and identities: an invitation to dialogue. Qualitative Research, 8(1), 5-35.

Somers, M. (1994). The narrative constitution of identity: A relational and network approach. Theory and Society, 23(5), 605-649.

Somerville, M. (2007). Postmodern emergence. International Journal of Qualitative Studies in Education, 20(2), 225-243.

Sonn, C. (2008). Educating for anti-racism: Producing and reproducing race and power in a university classroom. Race Ethnicity and Education, 11(2), 155-166. 
Squire, C. (2008). Experience-centred and culturally-oriented approaches to narrative. In M. Andrews, C. Squire \& M. Tamboukou (Eds.), Doing narrative research (pp. 4163). London: Sage.

Squire, C., Andrews, M., \& Tamboukou, M. (2008). What is narrative research? In M. Andrews, C. Squire \& M. Tamboukou (Eds.), Doing narrative research (pp. 1-21). London: Sage.

Srivastava, A. (1997). Anti-racism inside and outside the classroom. In L. G. Roman \& L. Eyre (Eds.), Dangerous territorial struggles for difference and equality in education (pp. 113-126). New York: Routledge.

St. Pierre, E. \& Pillow, W. (2000). Introduction: Inquiry among the ruins. In E. St. Pierre $\&$ W. Pillow (Eds.), Working the ruins: Feminist poststructural theory and methods in education (pp. 1-24). New York: Routledge.

Stengel, B. (2004). Knowing is response-able relation. In C. Bingham \& A. Sidorkin (Eds.), No education without relation (pp. 139-152). New York: Peter Lang.

Stephens, M., \& Higgins, T. R. (2003). Older Māori as students - 'I'm finally moving from being a spectator to being a participant in my own culture'. In J. Davey, J. Neale \& K. Morris Matthews (Eds.), Living and learning: Experiences of university after age 40 (pp. 61-75). Wellington: Victoria University of Wellington.

Stetsenko, A. (2008). From relational ontology to transformative activist stance on development and learning: Expanding Vygotsky's (CHAT) project. Cultural Studies of Science Education, 3, 471-491.

Strathdee, R., \& Hughes, D. (2006). Socio-economic status and tertiary attendance in New Zealand. New Zealand Journal of Educational Studies, 41(2), 293-305.

Suárez, S. C. (2008). Sharing the wealth: Guiding all students into the professional discourse. In L. Bartolomé (Ed.), Ideologies in education: Unmasking the trap of teacher neutrality (pp. 135-158). New York: Peter Lang.

Summers, M., \& Volet, S. (2008). Students' attitudes towards culturally mixed groups on international campuses: Impact of participation in diverse and non-diverse groups. Studies in Higher Education, 33(4), 357-370.

Swan, D., \& Linehan, C. (2000). Positioning as a means of understanding the narrative construction of self: A story of lesbian escorting. Narrative Inquiry, 10(2), 403427.

Te Tari Matauranga Māori (2007). Lifelong learning: Beyond the rhetoric of retention. Higher Education Research \& Development, 26(4), 363-376. 
Thayer-Bacon, B. (2003). Relational “(e)pistemologies”. New York: Peter Lang.

Thayer-Bacon, B. (2004). Personal and social relations in education. In C. Bingham \& A. Sidorkin (Eds.), No education without relation (pp. 165-177). New York: Peter Lang.

Thomas, C. (1999). Female forms: Experiencing and understanding disability. Buckingham, UK: Open University Press.

Thompson, A. (1998). Not the color purple: Black feminist lessons for educational caring. Harvard Educational Review, 68(4), 522-554.

Thornton, M. (2008). The evisceration of equal employment opportunity in higher education. Australian Universities Review, 50(2), 59-70.

Tierney, W. (2003). Cultural disintegration and the decline of the engaged intellectual: The transformation of academic work. Discourse: Studies in the Cultural Politics of Education, 24(3), 371-383.

Tisdall, E. (1998). Poststructural feminist pedagogies: The possibilities and limitations of feminist emancipatory adult learning theory and practice. Adult Education Quarterly, 48(3), 139-156.

Tobias, R. (2005). Education and older adults: Discourse, ideologies and policies from the 1980s to 2001. New Zealand Journal of Adult Learning, 33(2), 5-25.

Tolich, M., \& Davidson, C. (1999). Starting fieldwork: An introduction to qualitative research in New Zealand. Auckland: Oxford University Press.

Tomalin, E. (2007). Supporting cultural and religious diversity in higher education: Pedagogy and beyond. Teaching in Higher Education, 12(5-6), 621-634.

Tronto, J. (1994). Moral boundaries: A political argument for an ethic of care. New York: Routledge.

Turp, M. (2004). The capacity for self-care. Infant Observation, 7(1), 108-125.

Uitto, M., \& Syrjälä, L. (2008). Body, caring and power in teacher-pupil relationships: Encounters in former pupils' memories. Scandinavian Journal of Educational Research, 52(4), 355-371.

Ukpokodu, N. (2002). Breaking through preservice teachers' defensive dispositions in a multicultural education course: A reflective practice. Multicultural Education, 9(3), 25-33.

Usher, R., Bryant, I., \& Johnston, R. (1997). Adult education and the postmodern challenge: Learning beyond the limits. London: RoutledgeFalmer. 
Vacarr, B. (2001). Moving beyond polite correctness: Practicing mindfulness in the diverse classroom. Harvard Educational Review, 71(2), 285-195.

Victoria University of Wellington (2009). Treaty of Waitangi Statute Retrieved 21 February, 2011, from

http://policy.vuw.ac.nz/amphora! policy.vuw.ac.nz Policy 000000000746.pdf

Viskovic, A. (2006). Becoming a tertiary teacher: Learning in communities of practice. Higher Education Research \& Development, 25(4), 323-339.

Walker, C., Gleaves, A., \& Grey, J. (2006). A study of the difficulties of care and support in new university teachers' work. Teachers and Teaching: Theory and Practice, 12(3), 347-363.

Walshaw, M. (2007). Working with Foucault in education. Rotterdam: Sense Publishers.

Ward, C. (2006). International students: Interpersonal, institutional and community impacts. Wellington: Ministry of Education.

Warhurst, R. (2008). 'Cigars on the flight-deck': New lecturers' participatory learning within workplace communities of practice. Studies in Higher Education, 33(4), 453-467.

Watson, C. (2006). Unreliable narrators? 'Inconsistency' (and some inconstancy) in interviews. Qualitative Research, 6(3), 367-384.

Webster, L., \& Mertova, P. (2007). Using narrative inquiry as a research method: An introduction to using critical event narrative analysis in research on learning and teaching. London \& New York: Routledge.

Weedon, C. (1997). Feminist practice and poststructuralist theory (2nd ed.). Oxford: Blackwell Publishers.

Weimer, M. E. (2002). Learner-centered teaching: Five key changes to practice. San Francisco: Jossey-Bass.

Wenger, E. (1998). Communities of practice: Learning, meaning, and identity. New York: Cambridge University Press.

Wilkie, M. (2006). Kaupapa Māori intervention in post-graduate education: Ko te pae tawhiti arumia kia tata: Seek to bring the distant horizons closer. New Zealand Annual Review of Education, 15, 45-63.

Willig, C. (2001). Introducing qualitative research in psychology: Adventures in theory and method. Buckingham: Open University Press.

Windschuttle, K. (1997). The ethnic myths of cultural relativism. Australian Journal of Education, 41(1), 90-100. 
Winslade, J. (2005). Utilising discursive positioning in counselling. British Journal of Guidance \& Counselling, 33(3), 351-364.

Woods, P. (1993). Critical events in education. British Journal of Sociology of Education, 14(4), 355-371.

Wright, L., Ratliff, M., \& Neal, A. (2006). The politically correct and culturally one-sided campus: Causes, consequences, remedies. Academic Questions, 19(4), 55-77.

Young, I. M. (1990). Justice and the politics of difference. Princeton, NJ: Princeton University Press.

Zepke, N. (2003). Reflecting-learning-teaching. In N. Zepke, D. Nugent \& L. Leach (Eds.), Reflection to transformation: A self-help book for teachers (pp. 17-33). Palmerston North: Dunmore Press.

Zepke, N. (2008). Some reflections on critiques of diversity in adult education. New Zealand Journal of Adult Learning, 36(2), 5-19.

Zepke, N., \& Leach, L. (2002). Appropriate pedagogy and technology in a cross-cultural distance education context. Teaching in Higher Education, 7(3), 309-321.

Zepke, N., \& Leach, L. (2007). Improving student outcomes in higher education: New Zealand teachers' views on teaching students from diverse backgrounds. Teaching in Higher Education, 12(5-6), 655-668.

Zepke, N., Leach, L., \& Prebble, T. (2006). Being learner centred: one way to improve student retention? Studies in Higher Education, 31(5), 587-600.

Zhou, Y., Knoke, D., \& Sakamoto, I. (2005). Rethinking silence in the classroom: Chinese students' experiences of sharing indigenous knowledge. International Journal of Inclusive Education, 9(3), 287-311. 


\section{Appendix A \\ Study participants}

In this study, I do not provide information about individual participants due to the need to maintain confidentiality within what is a small and well-connected academic community in New Zealand. Instead, I pool the data from the two universities and provide a summary of participant characteristics. I chose not to give participants a questionnaire, and instead I asked them prior to the interview to provide me with information about themselves that they thought relevant to this study. I did this because I wanted to see how participants described themselves. Because one of my key questions in the interview involved asking about what 'diversity' meant to participants rather than asking them about specific characteristics of students such as ethnicity, gender, or age, I did not want to influence participants' ideas about what diversity might mean by having them fill out a questionnaire that specified categories of their own 'diversity'. The following summary therefore, reflects only what participants chose to tell me, and shows by what is included, as well as excluded, the personal characteristics that these participants considered salient for this study.

Of the twenty-two academic teaching staff who participated in this study, sixteen are female and six are male. At the time of the interviews, three were aged in their late twenties, eight were in their thirties, and the remainder were aged in their forties, fifties or sixties. There were a variety of ethnicities, with thirteen participants identifying as New Zealand European or Pakeha. Four participants are British or European immigrants, one is from North America, and one comes from an Asian country. One participant is a New Zealander with Asian ancestry, one has Pasifika ancestry and one participant has Pakeha and Māori heritage.

Study participants taught in several faculties in a variety of positions and departments. Eight taught in Business faculties, eight in Humanities, five in Social Sciences, and three in Education. This list includes two teachers who currently teach papers in two faculties. Three participants had previously taught in faculties different from where they currently work. Three teachers were also professional practitioners, and two mentioned previous professional work. Three participants said they were school teachers prior to teaching at 
university, and two had taught in adult or community education. A few mentioned life and/or previous work experiences that influence their academic career or their approach to teaching. Several participants talked about their academic or research interests.

My advertisement for participants asked for those who had face-to-face small group teaching experience. I did not specify whether this should be as a lecturer, tutor, teaching assistant or other role. Some study participants identified as lecturers and some described themselves as tutors. Some did not have a $\mathrm{PhD}$, some said they were completing a $\mathrm{PhD}$, and some referred indirectly to their $\mathrm{PhD}$. Some participants had many years of experience teaching, in one case over forty years, while others were early career academics. Most were in-between these points.

Four participants said that they have a partner, three said they have children, and two said they have no children. Only one teacher mentioned sexual identity. No participants described themselves as having an impairment or disability. Four mentioned something about their family of origin background. One teacher was the first in the family to get a degree, while another had a family member who was an academic which had supported his/her own development as an academic. Only three participants mentioned financial background or socio-economic status. Seven teachers spoke about travel for work or leisure. 


\section{Appendix B \\ Transcribing conventions}

Audiotapes were used to record the interviews and mostly provided good sound quality and clear diction. Because this study did not require a finely detailed analysis of every aspect of speech (including nonverbal), the transcribing focused on what was said, as well as some of the more obvious non-verbal cues. The conventions used for transcribing are:

- $\quad$ Underline for emphasis

- $\quad$ Pauses are represented by commas, using one comma per second up to three seconds and [pause] for anything longer

- $\quad(\ldots)$ used for words or phrases that are indistinct

- Anything that the transcriber added was placed within square brackets [ ] for example [laugh] or [coughs] 


\section{Appendix C \\ Participant information and consent forms}

June 2008

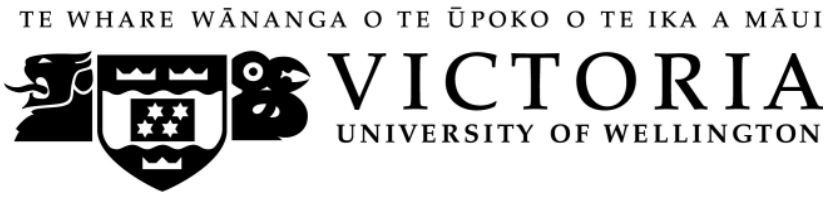

\section{TERTIARY TEACHERS' EXPERIENCE OF STUDENT DIVERSITY}

A PhD research project conducted by Clare Mariskind School of Education Studies, Victoria University of Wellington

\section{INFORMATION SHEET}

This research project explores how tertiary teachers experience student diversity in their teaching practice. It aims to offer teachers an opportunity to express their views and talk about their experiences. The researcher will analyse the data from interviews and integrate this with theoretical analyses to provide new knowledge that could assist in creating learning environments that respect diverse students and teachers and enhance educational experiences.

I invite university teachers whose teaching includes working with small groups (less than 30 students) to participate in this study. You will be interviewed by me and asked to discuss issues of diversity in your teaching practice that are pertinent. The interviews will take place at your institution at a mutually suitable time and place. They will last approximately one hour, up to a maximum of two hours, and will be audio-taped. One interview should be sufficient, however, if a follow-up would be helpful, this will be negotiated with you.

Should you feel the need to withdraw from the project, you may do so without question at any time before the data analysis begins, approximately November 2008. You will have the opportunity to check the transcript of your interview to ensure it is accurate and appropriate, and to amend it if required. Your name and any identifying details will remain confidential and will not appear in the thesis or any publications relating to the project. All material collected will be kept confidential and secure. No other person besides myself and my supervisors, Dr Lise Claiborne and Dr Sue Cornforth, and a professional transcriber who has signed a confidentially agreement, will see the transcripts which will have names removed. The thesis will be submitted for marking to the School of Education Studies and deposited in the University Library. It is intended that one or more articles will be submitted for publication in scholarly journals, and excerpts from the thesis may also be used for teaching purposes. Audio-tapes will be returned or destroyed at the end of the project. 
This research has ethical approval from the Victoria University of Wellington College of Education Ethics Committee. If you have any questions or would like to receive further information about this project, please contact me at clare.mariskind@vuw.ac.nz.

You can also contact my supervisors at Victoria University School of Education Studies:

Associate Professor Lise Claiborne

Dr Sue Cornforth Phone 4635177

Phone 4635164 lise.claiborne@ vuw.ac.nz

sue.cornforth@vuw.ac.nz

Thank you for your interest in this project.

Clare Mariskind 


\section{A STUDY OF TERTIARY TEACHERS' EXPERIENCE OF STUDENT DIVERSITY}

\section{CONSENT TO PARTiCiPATION IN RESEARCH}

I have read the information sheet and I have had an opportunity to ask questions and have them answered to my satisfaction.

I understand that I may withdraw myself or any information I have provided from this project before data analysis begins without having to give reasons. If I withdraw from the project, any data I have provided will be returned to me or destroyed.

I understand that any information I provide will be kept confidential to the researcher, her supervisors and a professional transcriber (if used). The published results will not use my name or any identifying details, and no opinions will be attributed to me in any way that will identify me.

I understand that I will have the opportunity to check the transcript of the interview before data analysis and may add to, delete or amend the transcript.

I understand that the data I provide will not be used for any other purpose than this research project and the thesis and other publications relating to the project, and that excerpts from the thesis may be used for teaching purposes.

I would like the audiotape recordings of my interview returned to me at the conclusion of the project.

I would like to receive a summary of the results of this research when it is completed.

I agree to take part in this research.

Name of participant:

Signed:

Date: 